ORNL/TM-2014/154

\title{
Preliminary Evaluation of Alternate Designs for HFIR Low-Enriched Uranium Fuel
}

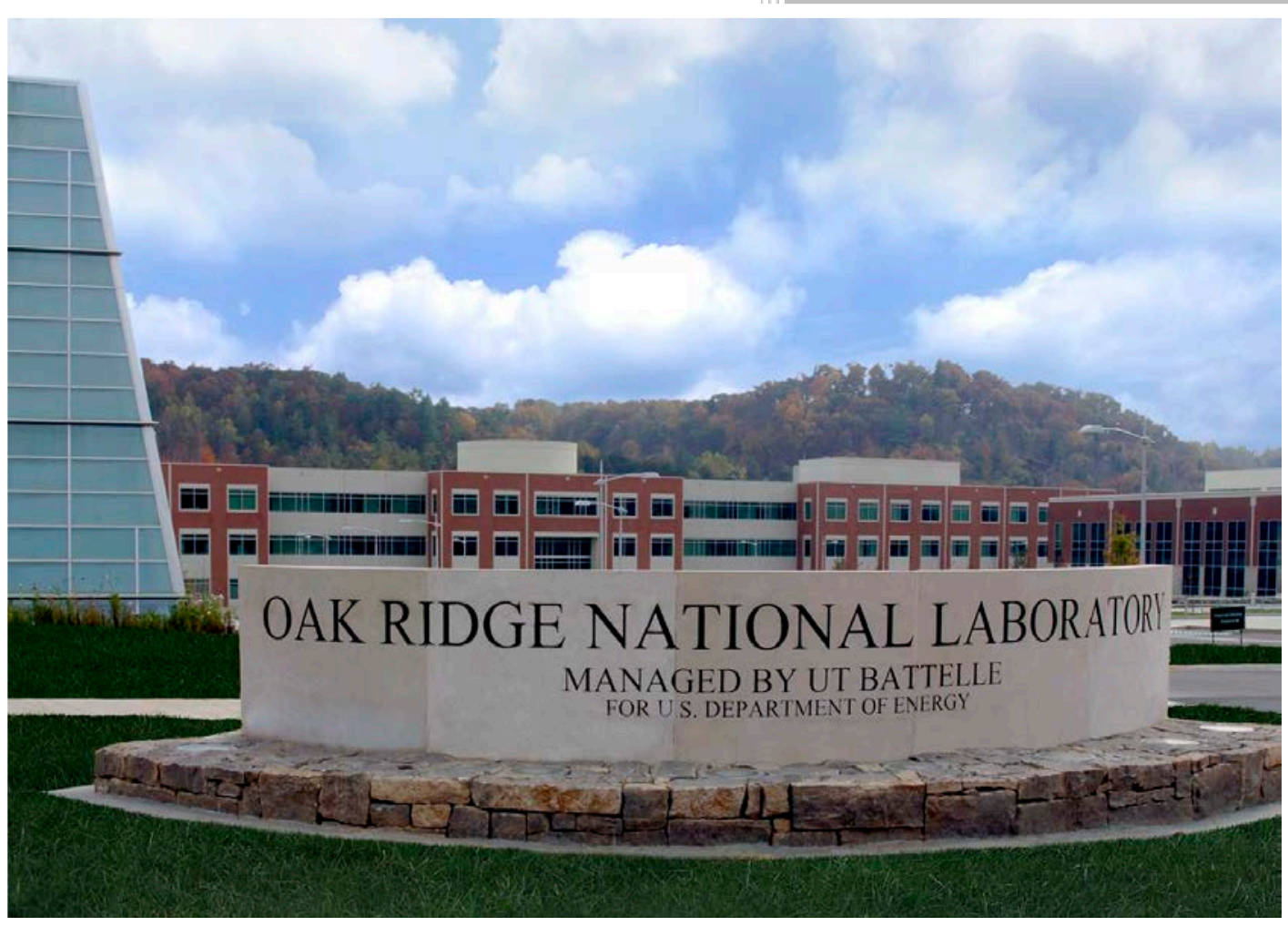

Approved for public release; distribution is unlimited.
David Renfro

David Chandler

David Cook

Germina Ilas

Prashant Jain

Jennifer Valentine

October 30, 2014 


\section{DOCUMENT AVAILABILITY}

Reports produced after January 1, 1996, are generally available free via US Department of Energy (DOE) SciTech Connect.

Website http://www.osti.gov/scitech/

Reports produced before January 1, 1996, may be purchased by members of the public from the following source:

National Technical Information Service

5285 Port Royal Road

Springfield, VA 22161

Telephone 703-605-6000 (1-800-553-6847)

TDD 703-487-4639

Fax 703-605-6900

E-mail info@ntis.gov

Website http://www.ntis.gov/help/ordermethods.aspx

Reports are available to DOE employees, DOE contractors, Energy Technology Data Exchange representatives, and International Nuclear Information System representatives from the following source:

Office of Scientific and Technical Information

PO Box 62

Oak Ridge, TN 37831

Telephone 865-576-8401

Fax 865-576-5728

E-mail reports@osti.gov

Website http://www.osti.gov/contact.html

This report was prepared as an account of work sponsored by an agency of the United States Government. Neither the United States Government nor any agency thereof, nor any of their employees, makes any warranty, express or implied, or assumes any legal liability or responsibility for the accuracy, completeness, or usefulness of any information, apparatus, product, or process disclosed, or represents that its use would not infringe privately owned rights. Reference herein to any specific commercial product, process, or service by trade name, trademark, manufacturer, or otherwise, does not necessarily constitute or imply its endorsement, recommendation, or favoring by the United States Government or any agency thereof. The views and opinions of authors expressed herein do not necessarily state or reflect those of the United States Government or any agency thereof. 


\title{
PRELIMINARY EVALUATION OF ALTERNATE DESIGNS FOR HFIR LOW-ENRICHED URANIUM FUEL
}

\author{
David Renfro \\ David Chandler \\ David Cook \\ Germina Ilas \\ Prashant Jain \\ Jennifer Valentine
}

October 30, 2014

Prepared by

OAK RIDGE NATIONAL LABORATORY

Oak Ridge, Tennessee 37831-6283

managed by

UT-BATTELLE, LLC

for the

US DEPARTMENT OF ENERGY

under contract DE-AC05-00OR22725 
This page intentionally blank 


\section{CONTENTS}

LIST OF TABLES ... V

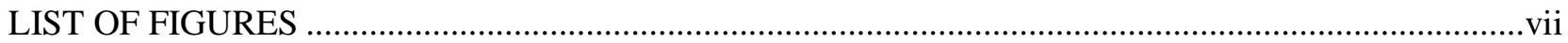

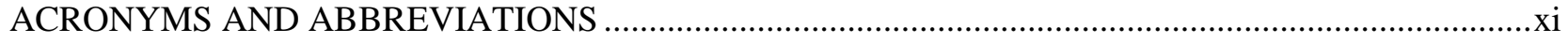

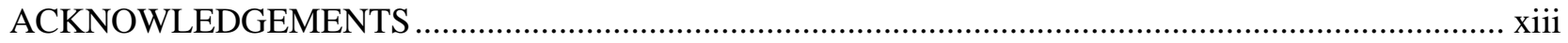

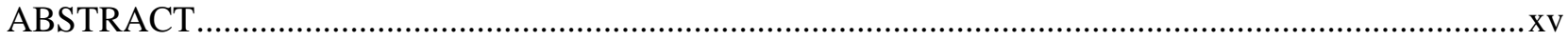

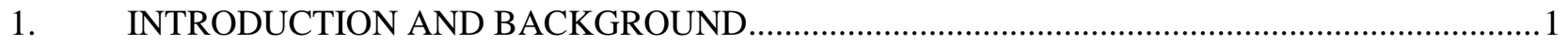

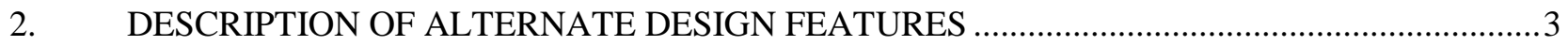

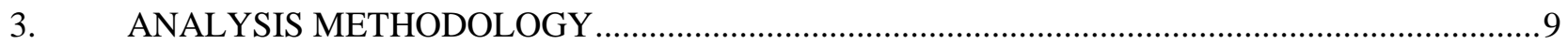

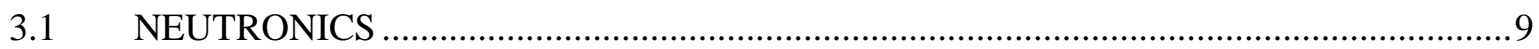

3.1.1 MCNP — Monte Carlo Transport Code ..........................................................

3.1.2 VESTA — Monte Carlo-Based Depletion Tool ....................................................... 11

3.1.3 Post-Shutdown Heat Power Generation.................................................................. 12

3.1.3.1 Delayed neutron induced fission heat...................................................12

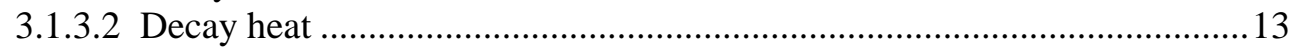

3.1.3.3 Distribution of shutdown heat power....................................................16

3.2 STEADY-STATE THERMAL HYDRAULICS [TH] (using HSSHTC) ..........................18

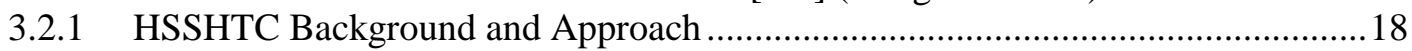

3.2.2 Uncertainties Considered in HFIR Steady-State Thermal Analysis .......................19

3.2.3 Use of HSSHTC to Produce Input Parameters for HFIR System

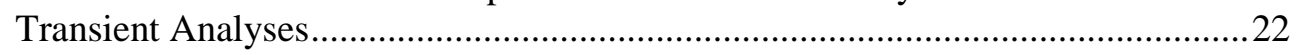

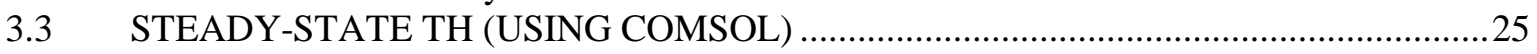

3.4 TRANSIENT TH WITH SAFETY CASE ASSUMPTIONS (using RELAP)....................28

4. EVALUATION OF REFERENCE LEU FUEL DESIGN (ORNL/TM-2010/318) .......................31

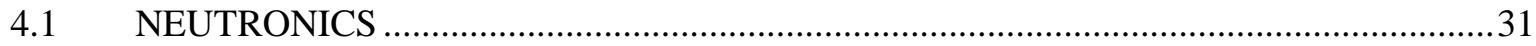

4.2 STEADY-STATE TH WITH SAFETY CASE ASSUMPTIONS (using HSSHTC)...........36

4.3 TRANSIENT TH WITH SAFETY CASE ASSUMPTIONS (using RELAP)....................38

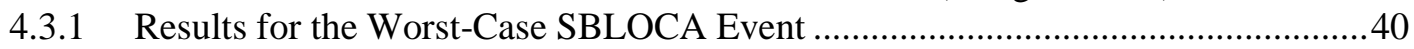

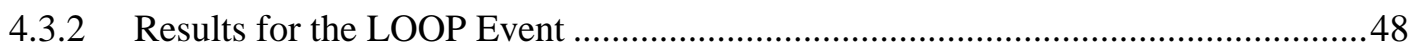

4.4 STEADY-STATE TH WITH NOMINAL ASSUMPTIONS (using COMSOL)................56

4.5 STEADY-STATE TH WITH NOMINAL ASSUMPTIONS (using HSSHTC) .................60

5. EVALUATION OF FUEL WITH NO RADIAL OR AXIAL CONTOURING ............................69

6. EVALUATION OF ALTERNATE 1 (no axial contouring) …....................................................73

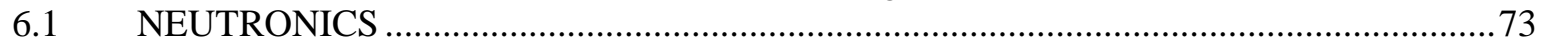

6.2 STEADY-STATE TH WITH SAFETY CASE ASSUMPTIONS (using HSSHTC)..........78

6.3 STEADY-STATE EVALUATIONS OF ALTERNATIVE 1A-REFERENCE FUEL WITH NO AXIAL CONTOURING AND CENTERED, SYMMETRIC FUEL ................79

7. EVALUATION OF ALTERNATE 2 (permanent Hf absorber instead of axial contouring)...........81

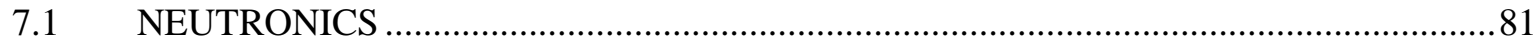

7.2 STEADY-STATE TH WITH SAFETY CASE ASSUMPTIONS (using SSHTC).............86

8. EVALUATION OF ALTERNATE 3 (burnable B absorber in side plates instead of fuel plates) ...89

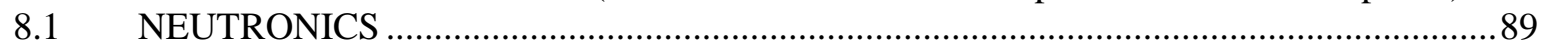

8.2 STEADY-STATE TH WITH SAFETY CASE ASSUMPTIONS (using SSHTC)...............97 


\section{CONTENTS}

9. $\quad$ EVALUATION OF ALTERNATE 4 (Zr clad instead of Al) …..................................................99

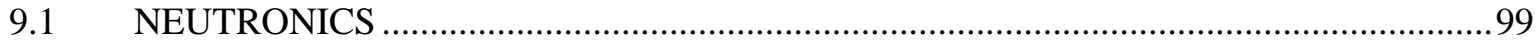

9.2 STEADY-STATE TH WITH SAFETY CASE ASSUMPTIONS (using SSHTC)...........104

10. EVALUATION OF ALTERNATE 5 (additional Hf absorber) …..............................................107

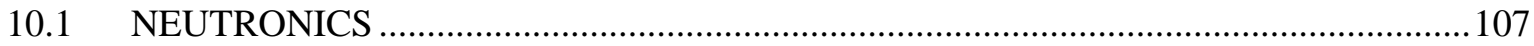

10.2 STEADY-STATE TH WITH SAFETY CASE ASSUMPTIONS (using SSHTC)...........112

11. EVALUATION OF ALTERNATE 6 (combination of ALTERNATES 3 and 5)........................115

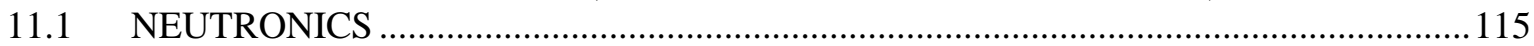

11.2 STEADY-STATE TH WITH SAFETY CASE ASSUMPTIONS (using SSHTC)...........127

12. EVALUATION OF ALTERNATE 7 (no axial contouring, Hf absorber, B absorber in side plates, Al clad, centered and symmetric fuel zone) …...........................................................133

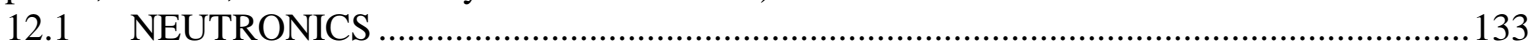

12.2 STEADY-STATE TH WITH SAFETY CASE ASSUMPTIONS (using SSHTC)...........134

12.3 TRANSIENT TH WITH SAFETY CASE ASSUMPTIONS (using RELAP)..................136

12.3.1 Results for the Worst-Case SBLOCA Event ......................................................138

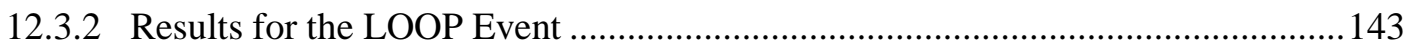

12.4 STEADY-STATE TH WITH NOMINAL ASSUMPTIONS (using COMSOL)..............147

12.5 STEADY-STATE TH WITH NOMINAL ASSUMPTIONS (using SSHTC) ...................152

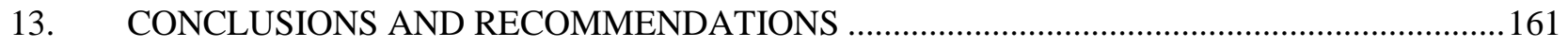

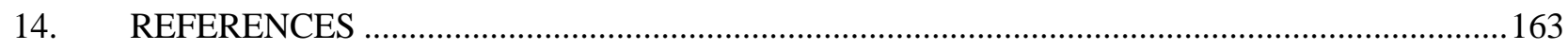




\section{LIST OF TABLES}

2.1 Summary of evaluated alternate LEU design ........................................................................... 3

2.2 Boron in IFE side plates for alternate LEU designs.................................................................. 6

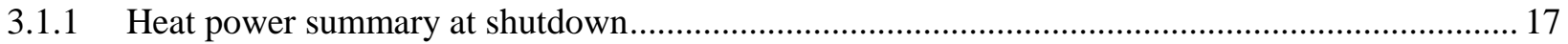

3.2.2.1 Uncertainty factors considered in steady state thermal analysis ................................................. 20

4.1.1 Relative fission densities for LEU Reference design at BOC................................................... 33

4.1.2 Relative fission densities for LEU Reference design at EOC (26d). .......................................... 34

4.3.1 Normalized HFIR fuel axial power peaking factors for LEU Reference fuel design .................... 38

4.3.2 Hot fuel regions and local power peaking factors for LEU Reference fuel design ....................... 39

4.3.3 Internal source multipliers for LEU Reference fuel design ......................................................... 39

4.5.1 Comparison of COMSOL and HSSHTC peak clad surface temperatures and

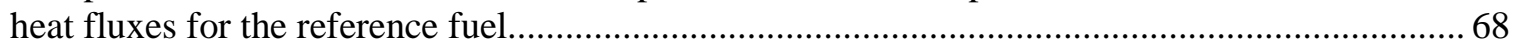

6.1.1 Relative fission densities for LEU Alternate Design 1 at BOC............................................... 75

6.1.2 Relative fission densities for LEU Alternate Design 1 at EOC (28d)......................................... 76

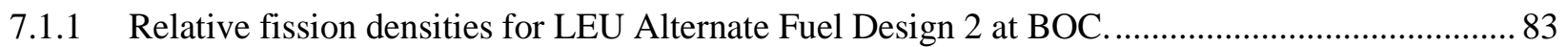

7.1.2 Relative fission densities for LEU Alternate Fuel Design 2 at EOC (26d).................................84

8.1.1 Relative fission densities for LEU Alternate Design $3\left(3.4 \mathrm{~g}{ }^{10} \mathrm{~B}\right)$ at BOC.............................. 91

8.1.2 Relative fission densities for LEU Alternate Design $3\left(3.4 \mathrm{~g}{ }^{10} \mathrm{~B}\right)$ at EOC (28d)....................... 92

8.1.3 Relative fission densities for LEU Alternate Design $3\left(4.6 \mathrm{~g}{ }^{10} \mathrm{~B}\right)$ at BOC. ................................ 93

8.1.4 Relative fission densities for LEU Alternate Design $3\left(4.6 \mathrm{~g}^{10} \mathrm{~B}\right)$ at EOC $(28 \mathrm{~d})$......................... 94

9.1.1 Relative fission densities for LEU Alternate Design 4 at BOC............................................... 101

9.1.2 Relative fission densities for LEU Alternate Design 4 at EOC (27d)....................................... 102

10.1.1 Relative fission densities for LEU Alternate Fuel Design 5 at BOC...................................... 109

10.1.2 Relative fission densities for LEU Alternate Fuel Design 5 at EOC. ........................................ 110

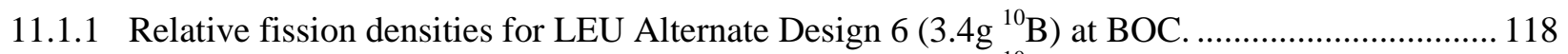

11.1.2 Relative fission densities for LEU Alternate Design $6\left(3.4 \mathrm{~g}{ }^{10} \mathrm{~B}\right)$ at EOC $(28 \mathrm{~d}) \ldots \ldots \ldots \ldots \ldots \ldots \ldots . . . . . . . . . .119$

11.1.3 Relative fission densities for LEU Alternate Design $6\left(3.6 \mathrm{~g}{ }^{10} \mathrm{~B}\right)$ at BOC.............................. 120

11.1.4 Relative fission densities for LEU Alternate Design $6\left(3.6 \mathrm{~g}{ }^{10} \mathrm{~B}\right)$ at EOC $(28 \mathrm{~d}) \ldots \ldots \ldots \ldots \ldots \ldots \ldots . . . . . . . . . . .121$

11.1.5 Relative fission densities for LEU Alternate Design $6\left(4.6 \mathrm{~g}{ }^{10} \mathrm{~B}\right)$ at BOC. ............................. 122

11.1.6 Relative fission densities for LEU Alternate Design $6\left(4.6 \mathrm{~g}{ }^{10} \mathrm{~B}\right)$ at EOC $(28 \mathrm{~d})$...................... 123

11.2 Burnout power versus day in cycle and location of node at burnout conditions for ALT6A,

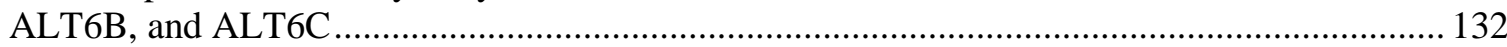

12.2 Burnout power versus day in cycle and location of node at burnout conditions for ALT7A,

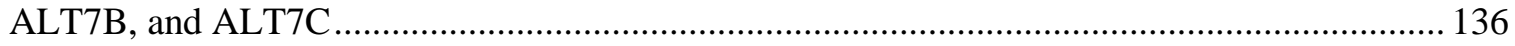

12.3.1 Normalized HFIR fuel axial power peaking factors for LEU Alternate-7 fuel design ................ 137

12.3.2 Hot fuel regions and local power peaking factors for LEU Alternate-7 fuel design ................... 137

12.3.3 Internal source multipliers for LEU Alternate-7 fuel design .................................................. 138 


\section{LIST OF TABLES}

12.4.1 Comparison of the peak values for important thermal safety variables for the reference LEU fuel design (Alt.0) and the Alternate 7 LEU fuel design (Alt. 7) at the beginning and end of reactor cycle...

12.5 Comparison of COMSOL and HSHTC peak clad surface temperatures and heat fluxes for the ALT7C fuel . 


\section{LIST OF FIGURES}

2.1 Illustration of the radial fuel contouring applied in Alternate \#7.............................................. 4-5

3.1.1 As-modeled geometry of HFIR LEU MCNP model. ............................................................. 10

3.1.2 Delayed neutron-induced fission heat power fraction following four plate scram ....................... 13

3.1.3 Comparison of ANSI/ANS standard to VESTA/ORIGEN decay heats ...................................... 15

3.1.4 Decay heat, delayed fission heat, and total heat power after shutdown...................................17-18

3.2 Comparison of RELAP 5-note axial average power density sets for EOC HEU fuel using SAR Chapter 4 power density distribution ................................................................................. 24

3.2.2 Comparison of RELAP 9-node axial hot streak power density sets for EOC HEU fuel

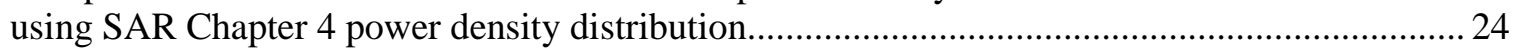

3.3.1 Typical COMSOL model geometry and mapped mesh with boundary layers for HFIR

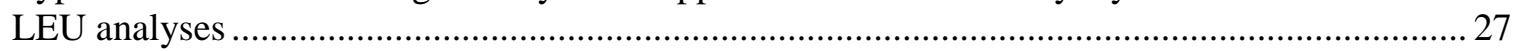

3.3.2 COMSOL model for the HFIR inner and outer elements ....................................................... 28

3.4.1 RELAP5 noding diagram of HFIR core region (taken from INT-154) ........................................ 30

4.1.1 Relative fission density for LEU reference design at BOC (left) and EOC (right). ..................... 32

4.1.2 Radial distribution of fission rate densities for LEU reference design. ........................................ 35

4.1.3 Axial distribution of fission rate densities for LEU reference design.......................................... 35

4.2.1 Hot spot burnout power versus day in the cycle for the reference fuel....................................... 37

4.3.1 Fraction of incipient boiling heat flux data for worst-case 2.0-in-diameter break in the HFIR primary coolant system pressure boundary for LEU reference fuel design at $100 \mathrm{MW} . . . . .41$

4.3.2 Fraction of incipient boiling heat flux data for worst case 2.0-in-diameter break in the HFIR primary coolant system pressure boundary for current HEU fuel design at $85 \mathrm{MW}$........... 43

4.3.3 Fraction of incipient boiling heat flux data for the loss of off-site AC power (LOOP) event for LEU reference fuel design at $100 \mathrm{MW}$......................................................................... 45

4.3.4 Fraction of incipient boiling heat flux data for the loss of off-site AC power (LOOP) event for current HEU fuel design at $85 \mathrm{MW}$

4.3.5 Fraction of incipient boiling heat flux data for the loss of off-site AC power (LOOP) event for LEU Reference fuel design at $100 \mathrm{MW}$................................................................................ 49

4.3.6 Fraction of incipient boiling heat flux data for the loss of off-site AC power (LOOP) event for current HEU fuel design at $85 \mathrm{MW}$.....

4.3.7 Fuel temperatures for loss of off-site ac power (LOOP) for LEU Reference fuel design at $100 \mathrm{MW}$

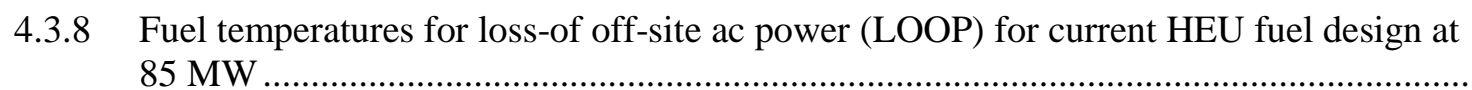

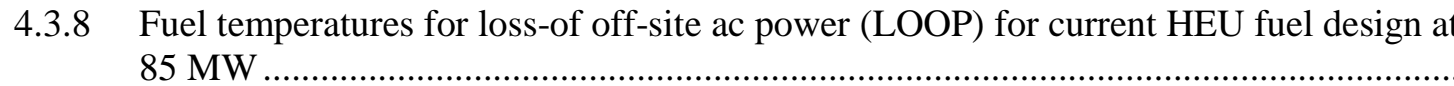

4.4.1 Volumetric power density (in $\mathrm{kW} / \mathrm{cm}^{3}$ ) of the reference LEU fuel design for $100 \mathrm{MW}$

nominal HFIR operation conditions.

4.4.2 "Hot-side" clad surface temperature (in ${ }^{\circ} \mathrm{C}$ ) of the reference LEU fuel design for 100 MW nominal HFIR operating conditions .....

4.4.3 "Hot-side" surface heat flux (in W/ $\mathrm{cm}^{2}$ ) of the reference LEU fuel design for $100 \mathrm{MW}$ nominal HFIR operating conditions....

4.4.4 Fuel plate thermal deflection (in mil, 1 mil $=0.001$ inch) of the reference LEU fuel design for 100 MW nominal HFIR operating conditions.

4.5.1 LEU reference fuel BOC inner and outer element relative power densities................................. 62

4.5.2 LEU reference fuel BOC inner and outer element hot plate surface temperature ...........................63

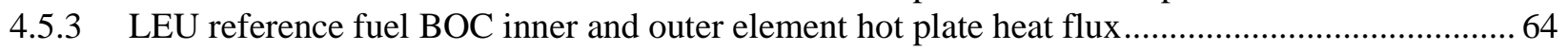

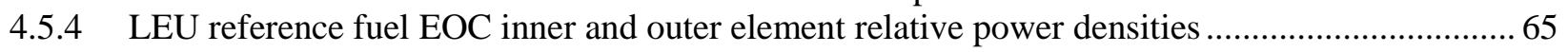

4.5.5 LEU reference fuel EOC inner and outer element hot plate surface temperature..............................6

4.5.6 LEU reference fuel EOC inner and outer element hot plate heat flux ........................................6 67 


\section{LIST OF FIGURES}

5.1 Flat fuel zone geometry for IFE (left) and OFE (right).

5.2 Comparison of reference and flat fuel zone designs relative fission densities (3D profile) at BOC 70

5.3 Comparison of reference and flat fuel zone designs relative fission densiti72 (core midplane) at BOC. 70

5.4 BOC radial distribution of fission rate densities for flat fuel zone design................................... 71

5.5 BOC axial distribution of fission rate densities for flat fuel zone design .................................... 72

6.1.1 Effective multiplication factor for LEU reference and Alternate Design 1.............................. 73

6.1.2 Relative fission density for LEU alternate 1 at BOC (left) and EOC (right)............................... 74

6.1.3 Radial distribution of fission rate densities for LEU Alternate Design 1................................... 77

6.1.4 Axial distribution of fission rate densities for LEU Alternate Design 1.................................... 77

6.2 Hot spot burnout power versus day in the cycle for the reference fuel and Alternative 1-

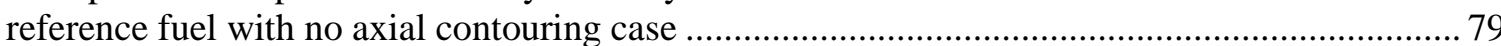

6.3 Hot spot burnout power versus day in the cycle for the reference fuel, Alternative 1, and Alternative 1A-reference fuel with no axial contouring and symmetric, centered fuel. 80

7.1.1 Effective multiplication factor for reference design and Alternate Fuel Design 2 .81

7.1.2 Relative fission density for LEU Alternate Fuel Design 2 at BOC (left) and EOC (right) ...........82

7.1.3 Radial distribution of fission rate densities for LEU Alternate Fuel Design 2 ........................... 85

7.1.4 Axial distribution of fission rate densities for LEU Alternate Fuel Design 2.............................. 86

7.2 Hot spot burnout power versus day in the cycle for the reference fuel and Alternative 2 no axial contouring plus $\mathrm{Hf}$ in the lower unfueled region of the plate

8.1.1 Effective multiplication factor for LEU reference and Alternate Design 3.

8.1.2 Relative fission density for LEU alternate $3\left(3.4 \mathrm{~g}{ }^{10} \mathrm{~B}\right)$ at BOC (left) and EOC (right) ................. 90

8.1.3 Relative fission density for LEU alternate $3\left(4.6 \mathrm{~g}{ }^{10} \mathrm{~B}\right)$ at BOC (left) and EOC (right) ............... 90

8.1.4 Radial distribution of fission rate densities for LEU Alternate Design $3\left(3.4 \mathrm{~g}{ }^{10} \mathrm{~B}\right)$.................. 95

8.1.5 Axial distribution of fission rate densities for LEU Alternate Design $3\left(3.4 \mathrm{~g}{ }^{10} \mathrm{~B}\right)$................... 95

8.1.6 Radial distribution of fission rate densities for LEU Alternate Design $3\left(4.6 \mathrm{~g}^{10} \mathrm{~B}\right)$.................. 96

8.1.7 Axial distribution of fission rate densities for LEU Alternate Design $3\left(4.6 \mathrm{~g}{ }^{10} \mathrm{~B}\right)$.................... 96

8.2.1 Hot spot burnout power versus day in the cycle for the reference fuel plus inner element

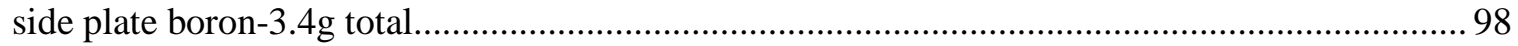

8.2.2 Hot spot burnout power versus day in the cycle for the reference fuel plus inner element

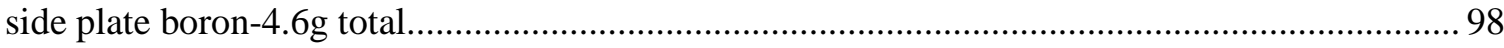

9.1.1 Effective multiplication factor for LEU reference and Alternate Design 4............................... 99

9.1.2 Relative fission density for LEU alternate 4 at BOC (left) and EOC (right) ............................. 100

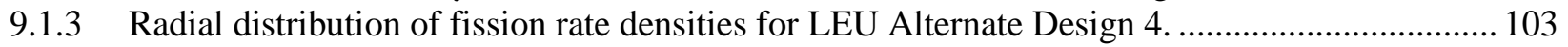

9.1.4 Axial distribution of fission rate densities for LEU Alternate Design 4................................... 103

9.2 Hot spot burnout power versus day in the cycle for the reference fuel with Zr cladding ............ 105

10.1.1 Effective multiplication factor for reference design and Alternate Fuel Design 5.................... 107

10.1.2 Relative fission density for LEU Alternate Fuel Design 5 at BOC (left) and EOC (right). ........ 108

10.1.3 Radial distribution of fission rate densities for LEU Alternate Fuel Design 5 .......................... 111

10.1.4 Axial distribution of fission rate densities for LEU Alternate Fuel Design 5........................... 112

10.2 Hot spot burnout power versus day in the cycle for Alternative 5-the reference fuel with no axial contouring plus additional Hf. 


\section{LIST OF FIGURES}

11.1.1 Effective multiplication factor for LEU reference and Alternate Design 6.............................. 115

11.1.2 Relative fission density for LEU alternate $6\left(3.4 \mathrm{~g}{ }^{10} \mathrm{~B}\right)$ at BOC (left) and EOC (right) ............... 116

11.1.3 Relative fission density for LEU alternate $6\left(3.6 \mathrm{~g}{ }^{10} \mathrm{~B}\right)$ at BOC (left) and EOC (right) .............. 117

11.1.4 Relative fission density for LEU alternate $6\left(4.6 \mathrm{~g}{ }^{10} \mathrm{~B}\right)$ at BOC (left) and EOC (right) .............. 117

11.1.5 Radial distribution of fission rate densities for LEU Alternate Design $3\left(3.4 \mathrm{~g}{ }^{10} \mathrm{~B}\right)$................ 124

11.1.6 Axial distribution of fission rate densities for LEU Alternate Design $3\left(3.4 \mathrm{~g}{ }^{10} \mathrm{~B}\right) \ldots \ldots \ldots \ldots \ldots \ldots . . . . . . . .124$

11.1.7 Radial distribution of fission rate densities for LEU Alternate Design $3\left(3.6 \mathrm{~g}{ }^{10} \mathrm{~B}\right)$................. 125

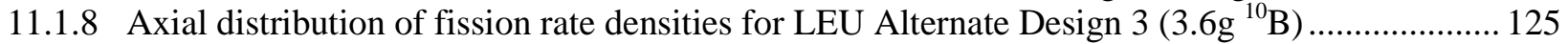

11.1.9 Radial distribution of fission rate densities for LEU Alternate Design $3\left(4.6 \mathrm{~g}^{10} \mathrm{~B}\right)$................ 126

11.1.10 Axial distribution of fission rate densities for LEU Alternate Design $3\left(4.6 \mathrm{~g}{ }^{10} \mathrm{~B}\right)$................... 126

11.2.1 Comparison of original and updated reference LEU fuel cycle cases ...................................... 128

11.2.2 Hot spot burnout power versus day in the cycle for Alternative 6A — reference fuel with $3.4 \mathrm{~g}$ B in side plates and Hf in lower unfueled region of plates ............................................. 129

11.2.3 Hot spot burnout power versus day in the cycle for Alternative 6B-reference fuel with $3.6 \mathrm{~g} \mathrm{~B}$ in side plates and $\mathrm{Hf}$ in lower unfueled region of plates .............................................. 130

11.2.4 Hot spot burnout power versus day in the cycle for Alternative 6C-reference fuel with $4.6 \mathrm{~g} \mathrm{~B}$ in side plates and $\mathrm{Hf}$ in lower unfueled region of plates ............................................. 131

12.1.1 Sketch of fuel zones for Alternate 7 centered, symmetric fuel ................................................ 133

12.2.1 Hot spot burnout power versus day in the cycle for reference fuel and alternative

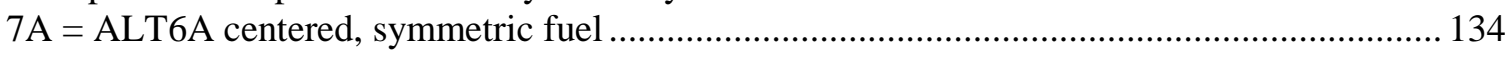

12.2.2 Hot spot burnout power versus day in the cycle for Alternatives 7A, 7B, and 7C .................... 135

12.3.1 Fraction of incipient boiling heat flux data for worst case 2.0-in. diameter break in the HFIR primary coolant system pressure boundary for LEU “Alt-7” fuel design at $100 \mathrm{MW}$.................. 140

12.3.2 Fraction of incipient boiling heat flux data for the loss of off-site AC power (LOOP) event for LEU “Alt-7” fuel design at $100 \mathrm{MW}$................................................................................. 142

12.3.3 Fraction of incipient boiling heat flux data for the loss of off-site ac power (LOOP) event for LEU “Alt-7” fuel design at $100 \mathrm{MW}$.................................................................................. 144

12.3.4 Fuel temperatures for the loss of off-site ac power (LOOP) event for LEU “Alt 7” fuel design at $100 \mathrm{MW}$.....

12.4.1 Centered and symmetric fuel zone as modeled in COMSOL .................................................. 147

12.4.2 Volumetric power density (in $\mathrm{kW} / \mathrm{cm}^{3}$ ) of the alternate $7 \mathrm{LEU}$ fuel design for $100 \mathrm{MW}$ nominal HFIR operating conditions.

12.4.3 "Hot-side" clad surface temperature (in ${ }^{\circ} \mathrm{C}$ ) of the alternate $7 \mathrm{LEU}$ fuel design for $100 \mathrm{MW}$ nominal HFIR operating conditions.

12.4.4 "Hot-side" surface heat flux (in W/ $/ \mathrm{cm}^{2}$ ) of the alternate $7 \mathrm{LEU}$ fuel design for $100 \mathrm{MW}$ nominal HFIR operating conditions. 150

12.4.5 Fuel plate thermal deflection (in mil, 1 mil $=0.001$ inch) of the alternate 7 LEU fuel design

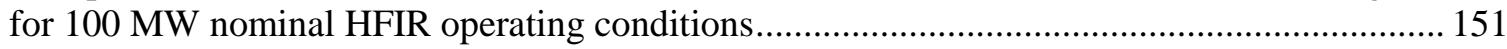

12.5.1 LEU ALT7C fuel BOC inner and outer element relative power densities ................................. 153

12.5.2 LEU ALT7C fuel BOC inner and outer element Hot Plate Surface Temperature....................... 154

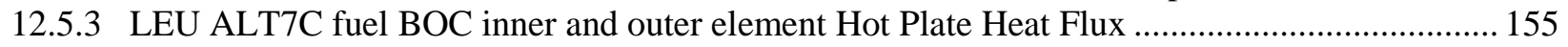

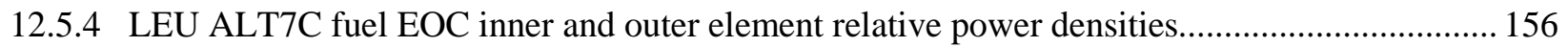

12.5.5 LEU ALT7C fuel EOC inner and outer element Hot Plate Surface Temperature........................ 157

12.5.6 LEU ALT7C fuel EOC inner and outer element Hot Plate Heat Flux........................................ 158 
This page intentionally blank 


\section{ACRONYMS AND ABBREVIATIONS}

2-D two-dimensional

3-D three-dimensional

AC alternating current

ANL Argonne National Laboratory

ATR Advanced Test Reactor

$\mathrm{B}$

Boron

BOC beginning of cycle

DC direct current

DOE U.S. Department of Energy

EOC end of cycle

FD Fuel Development pillar

FFC Fuel Fabrication Capability pillar

GTRI Global Threat Reduction Initiative

HEU high-enriched uranium

Hf hafnium

HFIR High Flux Isotope Reactor

HSSHTC HFIR Steady State Heat Transfer Code

IFE inner fuel element

$\mathrm{k}_{\mathrm{eff}} \quad$ effective multiplication constant

LCS limiting control setting

LEU low-enriched uranium

LOOP loss-of-off-site (AC) power

MCNP Monte Carlo N-Particle code

MFIBHF maximum fraction of incipient boiling heat flux

MW megawatt

NA not applicable

NNSA National Nuclear Security Administration

ORNL Oak Ridge National Laboratory

OFE outer fuel element

RERTR Reduced Enrichment for Research and Test Reactors Program

RNSD Reactor and Nuclear Systems Division

RRD Research Reactors Division

SAR Safety Analysis Report

SBLOCA small-break loss-of-coolant accident

SL safety limit

TH thermal hydraulics

TOAF top of active fuel

TSR Technical Safety Requirement 
This page intentionally blank 


\section{ACKNOWLEDGEMENTS}

The authors would like to acknowledge that the support of this project was provided by the Global Threat Reduction Initiative, Reduced Enrichment for Research and Test Reactors Program, a program of the Nuclear National Security Administration, U. S. Department of Energy. Review of the manuscript by J. D. Freels, Research Reactors Division (RRD), Oak Ridge National Laboratory, and the formatting of the document by M. L. Wells, RRD, are very much appreciated. The authors would also like to acknowledge the improvements from the technical review performed by E. Wilson, et al of Argonne National Laboratory. 
This page intentionally blank 


\begin{abstract}
Engineering design studies of the feasibility of conversion of the High Flux Isotope Reactor (HFIR) from high-enriched uranium (HEU) to low-enriched uranium (LEU) fuel are ongoing at Oak Ridge National Laboratory (ORNL) as part of an effort sponsored by the U.S. Department of Energy's Global Threat Reduction Initiative (GTRI)/Reduced Enrichment for Research and Test Reactors (RERTR) program. The fuel type selected by the program for the conversion of the five high-power research reactors in the U.S. that still use HEU fuel is a new U-Mo monolithic fuel. Studies by ORNL have previously indicated that HFIR can be successfully converted using the new fuel provided (1) the reactor power can be increased from $85 \mathrm{MW}$ to $100 \mathrm{MW}$ and (2) the fuel can be fabricated to a specific reference design. Fabrication techniques for the new fuel are under development by the program but are still immature, especially for the "complex" aspects of the HFIR fuel design. In FY 2012, the program underwent a major shift in focus to emphasize developing and qualifying processes for the fabrication of reliable and affordable LEU fuel. In support of this new focus and in an effort to ensure that the HFIR fuel design is as suitable for reliable fabrication as possible, ORNL undertook the present study to propose and evaluate several alternative design features. These features include (1) eliminating the fuel zone axial contouring in the previous reference design by substituting a permanent neutron absorber in the lower unfueled region of all of the fuel plates, (2) relocating the burnable neutron absorber from the fuel plates of the inner fuel element to the side plates of the inner fuel element (the fuel plates of the outer fuel element do not contain a burnable absorber), (3) relocating the fuel zone inside the fuel plate to be centered on the centerline of the depth of the plate, and (4) reshaping the radial contour of the relocated fuel zone to be symmetric about this centerline. The present studies used current analytical tools to evaluate the various alternate designs for cycle length, scientific performance (e.g., neutron scattering), and steady-state and transient thermal performance using both safety limit and nominal parameter assumptions. The studies concluded that a new reference design combining a permanent absorber in the lower unfueled region of all of the fuel plates, a burnable absorber in the inner element side plates, and a relocated and reshaped (but still radially contoured) fuel zone will allow successful conversion of HFIR. Future collaboration with the program will reveal whether the new reference design can be fabricated reliably and affordably. Following this feedback, additional studies using state-of-the-art developmental analytical tools are proposed to optimize the design of the fuel zone radial contour and the amount and location of both types of neutron absorbers to further flatten thermal peaks while maximizing the performance of the reactor.
\end{abstract}


This page intentionally blank 


\section{INTRODUCTION AND BACKGROUND}

Engineering design studies of the feasibility of conversion of the High Flux Isotope Reactor (HFIR) from high-enriched uranium (HEU) to low-enriched uranium (LEU) fuel are ongoing at Oak Ridge National Laboratory (ORNL) as part of an effort sponsored by the U.S. Department of Energy's (DOE's) Global Threat Reduction Initiative (GTRI)/Reduced Enrichment for Research and Test Reactors (RERTR) program. For the conversion of the remaining five U.S. high-power research reactors, DOE GTRI committed to achieve several performance goals including designing, developing, and qualifying an LEU fuel and manufacturing process and facility that, to the extent possible,

- maintains current fuel safety margins and reliability for use in the reactors,

- maintains the scientific performance of the reactors,

- is affordable,

- preserves the current physical dimensions of the fuel and core geometry,

- minimizes the impacts to reactor safety systems or other infrastructure, and

- does not increase the annual fuel consumption.

The fuel type selected by the program for the conversion of the five U.S. high-power research reactors is a new U-Mo monolithic fuel with $10 \%$ molybdenum by weight and $19.75 \mathrm{wt} \%{ }^{235} \mathrm{U}$ enriched uranium. As described in Irradiation Performance of U-Mo Alloy Based 'Monolithic' Plate-Type-Design Selection Update, INL/EXT-09-16807, Revision 1, July 2013[1], the fuel plate will consist of a U-10Mo monolithic foil with a $\mathrm{Zr}$ foil barrier applied to the faces of the fuel foil by co-rolling and then encapsulated within $\mathrm{Al}$ cladding by a hot isostatic press (HIP) process.

The High Flux Isotope Reactor (HFIR) at ORNL is a very high flux, pressurized light-water-cooled and moderated, flux-trap type research reactor whose current missions are to support neutron scattering experiments, isotope production, and materials irradiation, including neutron activation analysis. Details of the reactor configuration including core geometry can be found in Low Enriched Uranium Fuel Design with Two-Dimensional Grading for the High Flux Isotope Reactor, ORNL/TM-2010/318, April 2011.[2].

Reference 2 reports on preliminary neutronic and thermal analyses which demonstrated that conversion of HFIR to LEU fuel was theoretically achievable provided (1) the reactor power can be increased from 85 MW to $100 \mathrm{MW}$ and (2) the fuel can be fabricated to a specific reference design. That reference design includes a radially contoured fuel zone (similar in principle to the radial contour of the current HEU fuel zone), an axially contoured fuel zone (a new requirement), and a burnable neutron absorber (boron) in a non-fueled zone of the fuel plates in the inner fuel element that is inversely contoured to the fuel zone (similar in principle to the "filler" region of the current HEU inner element fuel plates.) This conceptual reference design was developed primarily to achieve analytical performance and safety goals. The state of development of the monolithic LEU fuel and its manufacturing process was fairly immature at that time. As a result, the reference design has features that would be challenging to manufacture at the required throughput while achieving cost objectives.

HEU fuel for HFIR and other U.S. high-power research reactors has been manufactured using essentially the same process for almost fifty years, involving creating a U-Al powder compact captured in an $\mathrm{Al}$ "picture frame" cladding and rolled into a plate for further sizing and forming. The LEU fuel selected by the program for conversion of the five U.S. reactors, as described above, is produced by casting a monolithic U-Mo coupon which is co-rolled into a thin foil with an even thinner Zr barrier. This coated fuel foil is then clad with $\mathrm{Al}$ using a HIP process. It is apparent that very different manufacturing techniques will be required to produce the LEU fuel (casting, co-rolling, and HIPing) than those that have been proven for HEU fuel production (blending, pressing, and rolling). 
Although the GTRI program has been working on LEU manufacturing techniques for several years, the emphasis was recently increased in order to meet the reliability and affordability objectives listed above by ensuring that the LEU fuel manufacturing process will be stable and repeatable. The program has decided to prioritize the development of "base" LEU fuel for use by the Massachusetts Institute of Technology Reactor, Missouri University Research Reactor, and National Institute of Standards and Technology (National Bureau of Standards) Reactor. The development of “complex" LEU fuel (includes a burnable absorber in the fuel plate and, in the case of HFIR, a contoured fuel zone within the plate) for use by the Advanced Test Reactor (ATR) and HFIR has largely been deferred. In recognition of the practical difficulties that have been encountered in the development of the base fuel manufacturing processes, it is apparent that the additional features of the complex fuel will be even more challenging to manufacture in a stable, repeatable manner. It is with this recognition that both ATR and HFIR staffs are attempting to create new reference designs that are simpler and easier to manufacture.

In particular, the complex features of the HFIR reference fuel[2] that appear to be problematic to manufacture include (1) the axial contouring of the bottom of the fuel zone (when the fuel is inserted vertically in the reactor), (2) the radial contouring of a zone containing the burnable absorber within the fuel plates in the inner fuel element, and (3) the radial contouring of the fuel zone itself. The present evaluation of alternate HFIR fuel designs examines altering or eliminating these complex features. In addition, to further optimize the new reference fuel in order to flatten thermal peaks while maximizing the performance of the reactor, a relocated and reshaped fuel zone within the plate was evaluated.

The evaluation consisted of:

- neutronics analyses with MCNP[3] and VESTA[4] that predicted the flux and cycle length to ensure that reactor performance was maintained and calculated power distributions for subsequent use in thermal analyses,

- $\quad$ steady-state thermal analyses with the HFIR Steady State Heat Transfer Code (HSSHTC)[5] , which was modified for LEU fuel and conservatively predicted temperatures and heat fluxes for comparison with safety limits,

- transient thermal analyses with RELAP[6] (with modified input for LEU fuel) that conservatively predicted temperatures and other parameters for comparison with safety limits, and

- $\quad$ steady-state thermal analyses with both HSSHTC (modified for LEU fuel) and COMSOL[7] that predicted nominal temperatures and other parameters.

These analyses were not checked or documented as formal calculations because they were intended as scoping studies to evaluate a range of alternate fuel design features. These studies did not cover the full extent of steady state bounding calculations required for Chapter 4 of the HFIR Safety Analysis Report (SAR) [19] —only full power and full flow safety limit cases were examined. Additionally, all of the transient cases required by Chapter 15 of the SAR were not examined-a small break loss of coolant accident and a loss of offsite power accident were evaluated as two representative transient cases to evaluate the reference fuel design and one of the more promising alternatives. 


\section{DESCRIPTION OF ALTERNATE DESIGN FEATURES}

This section provides a brief description of the alternate LEU designs evaluated in this report. The analysis methodology used in the evaluation is summarized in Section 3. The primary basis used for comparison in this evaluation consists of the initially proposed reference LEU design, discussed in detail in [2]. Results obtained for this design that are relevant to the comparisons discussed in the current report are presented in Section 4. For each of the studied alternate designs, the main results of the evaluation are presented in separate sections (6 to 12), one for each alternate design considered.

The alternate HFIR LEU designs and their main features are listed in Table 2.1 and their schematics (conceptual - not to scale) are provided in Fig. 2.1. A more detailed sketch illustrating Alternate 7 is provided in Fig. 12.1.1. The reference and all of the alternate designs have a radial contouring of the fuel, different though in shape and distribution from the radial contouring of the current HEU fuel. The reference and two (\#3 and \#4) of the seven alternate designs have axial contouring applied to the bottom $3 \mathrm{~cm}$ of the fuel zone in all plates, shaped as a "toe". See [2] for more details regarding the geometry of the "toe" region. Five alternate designs (\#1, \#2, \#5, \#6, and \#7) have no axial fuel contouring ("no toe") the fuel contour is uniform axially, as for the current HEU fuel. The core load of ${ }^{235} \mathrm{U}$ increases to $26.04 \mathrm{~kg}$ for the alternate designs with no axial fuel contouring compared to the $25.27 \mathrm{~kg}$ value for the reference and the alternate designs with axial fuel contouring applied.

Table 2.1. Summary of evaluated alternate LEU design

\begin{tabular}{|c|c|c|c|c|c|c|c|c|}
\hline \multirow{2}{*}{ \# } & \multirow{2}{*}{ Description } & \multirow{2}{*}{$\begin{array}{l}\text { Total }{ }^{235} \mathbf{U} \\
\text { load (kg) }\end{array}$} & \multicolumn{2}{|c|}{$\begin{array}{c}\text { Fuel } \\
\text { contouring }\end{array}$} & \multicolumn{2}{|c|}{$\begin{array}{c}\text { Burnable } \\
\text { absorber(boron) }\end{array}$} & \multicolumn{2}{|c|}{$\begin{array}{c}\text { Permanent absorber } \\
\text { (Hafnium) }\end{array}$} \\
\hline & & & Radial & Axial & $\begin{array}{c}\text { Mass } \\
{ }^{10} \mathrm{~B}\end{array}$ & Location & Mass & Location \\
\hline 0 & Reference & 25.27 & Yes & Yes & $5.40 \mathrm{~g}$ & $\begin{array}{l}\text { IFE fuel } \\
\text { plates }\end{array}$ & NA & NA \\
\hline 1 & $\begin{array}{l}\# 0+\text { no axial } \\
\text { contouring }\end{array}$ & 26.04 & Yes & No & $5.29 \mathrm{~g}$ & $\begin{array}{l}\text { IFE fuel } \\
\text { plates }\end{array}$ & NA & NA \\
\hline 2 & $\# 1$ + hafnium & 26.04 & Yes & No & $5.29 \mathrm{~g}$ & $\begin{array}{l}\text { IFE fuel } \\
\text { plates }\end{array}$ & $\begin{array}{l}362.25 g \\
124.43 g(34 \mathrm{wt} \%) \\
\text { IFE } \\
237.82 \mathrm{~g}(66 \mathrm{wt} \%) \\
\text { OFE }\end{array}$ & $\begin{array}{l}\text { lower unfueled } \\
\text { regions of IFE } \\
\text { and } \\
\text { OFE fuel } \\
\text { plates } \\
\end{array}$ \\
\hline 3 & $\begin{array}{l}\# 0 \text { +boron } \\
\text { relocation }\end{array}$ & 25.27 & Yes & Yes & $\begin{array}{l}\text { a) } 3.4 \mathrm{~g} \\
\text { b) } 4.6 \mathrm{~g}\end{array}$ & $\begin{array}{l}\text { IFE side } \\
\text { plates } \\
\text { 25wt\% inner } \\
\text { 75wt\% outer }\end{array}$ & NA & NA \\
\hline 4 & $\begin{array}{l}\# 0+\text { Zircaloy } \\
4 \text { cladding }\end{array}$ & 25.27 & Yes & Yes & $5.40 \mathrm{~g}$ & $\begin{array}{l}\text { IFE fuel } \\
\text { plates }\end{array}$ & NA & NA \\
\hline 5 & $\begin{array}{l}\# 2+ \\
\text { additional } \\
\text { hafnium }\end{array}$ & 26.04 & Yes & No & $5.29 \mathrm{~g}$ & $\begin{array}{l}\text { IFE fuel } \\
\text { plates }\end{array}$ & $\begin{array}{l}364.46 \mathrm{~g} \\
174.20 \mathrm{~g}(48 \mathrm{wt} \%) \\
\text { IFE } \\
190.26 \mathrm{~g}(52 \mathrm{wt} \%) \\
\text { OFE }\end{array}$ & $\begin{array}{l}\text { lower unfueled } \\
\text { regions of IFE } \\
\text { and } \\
\text { OFE fuel } \\
\text { plates }\end{array}$ \\
\hline 6 & $\begin{array}{l}\text { Combination } \\
\text { of \#3 and \#5 }\end{array}$ & 26.04 & Yes & No & $\begin{array}{l}\text { a) } 3.4 g \\
\text { b) } 3.6 g \\
\text { c) } 4.6 g\end{array}$ & $\begin{array}{l}\text { IFE side } \\
\text { plates } \\
25 w t \% \text { inner } \\
75 w t \% \text { outer }\end{array}$ & $\begin{array}{l}364.46 g \\
174.20 \mathrm{~g}(48 \mathrm{wt} \%) \\
\text { IFE } \\
190.26 \mathrm{~g}(52 \mathrm{wt} \%) \\
\text { OFE }\end{array}$ & $\begin{array}{l}\text { lower unfueled } \\
\text { regions of IFE } \\
\text { and } \\
\text { OFE fuel } \\
\text { plates }\end{array}$ \\
\hline 7 & $\begin{array}{l}\# 6+\text { relocated } \\
\text { and reshaped } \\
\text { fuel zone }\end{array}$ & 26.04 & Yes & No & $\begin{array}{l}\text { a) } 3.4 g \\
\text { b) } 3.6 g \\
\text { c) } 4.6 g\end{array}$ & $\begin{array}{l}\text { IFE side } \\
\text { plates } \\
25 w t \% \text { inner } \\
75 w t \% \text { outer }\end{array}$ & $\begin{array}{l}364.46 \mathrm{~g} \\
174.20 \mathrm{~g}(48 \mathrm{wt} \%) \\
\text { IFE } \\
190.26 \mathrm{~g}(52 \mathrm{wt} \%) \\
\text { OFE }\end{array}$ & $\begin{array}{l}\text { lower unfueled } \\
\text { regions of IFE } \\
\text { and } \\
\text { OFE fuel } \\
\text { plates }\end{array}$ \\
\hline
\end{tabular}


Reference 0

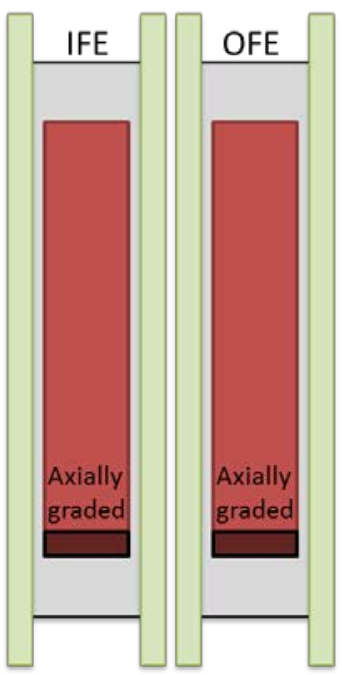

Alternate 1

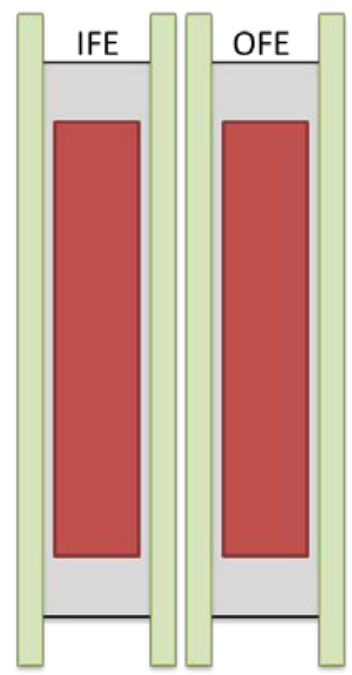

Alternate 2
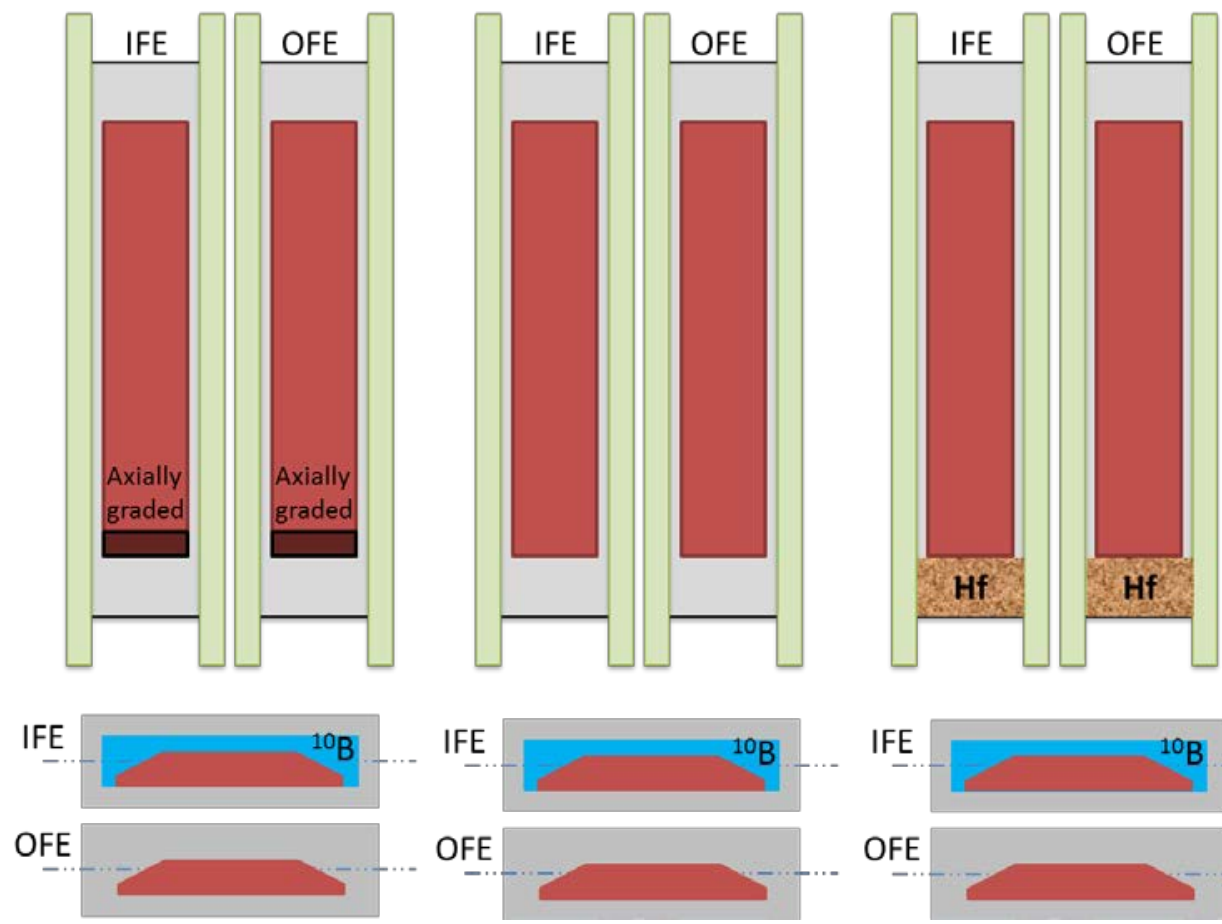

Alternate 3
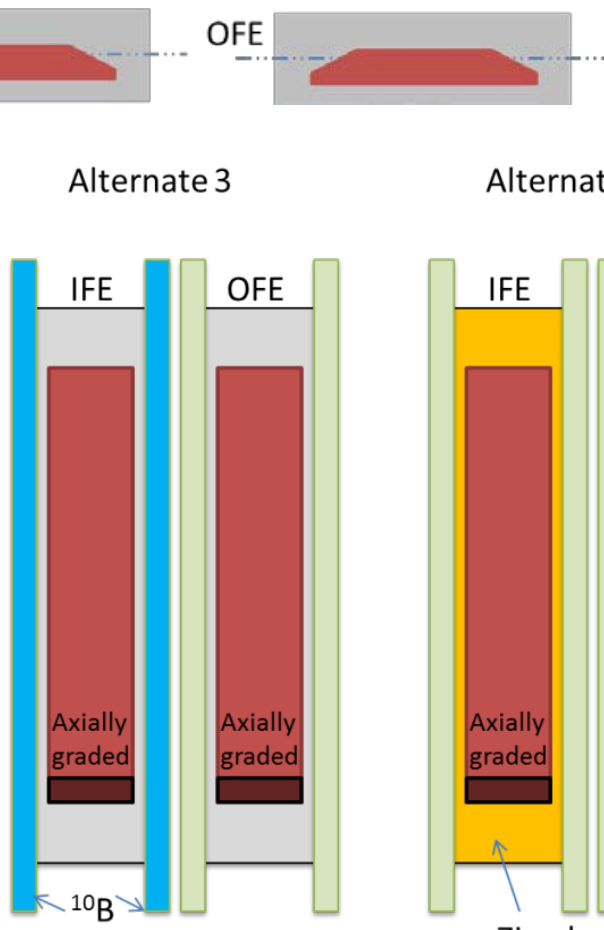

OFE
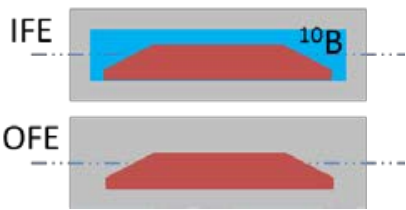

Alternate 4

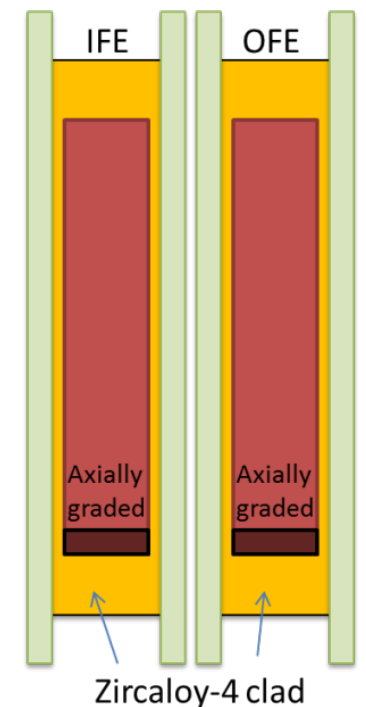

Alternate 5

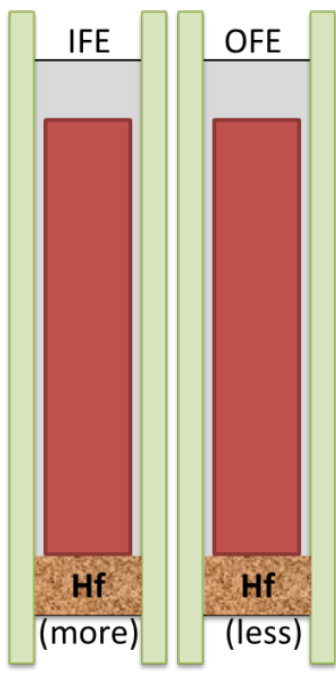

IFE

IFE

Zircaloy-4 clad

OFE
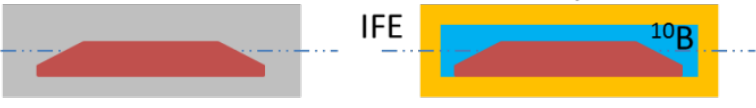

IFE

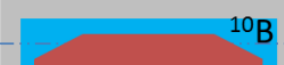

OFE

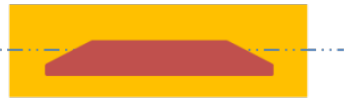

OFE

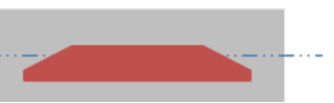


Alternate 6
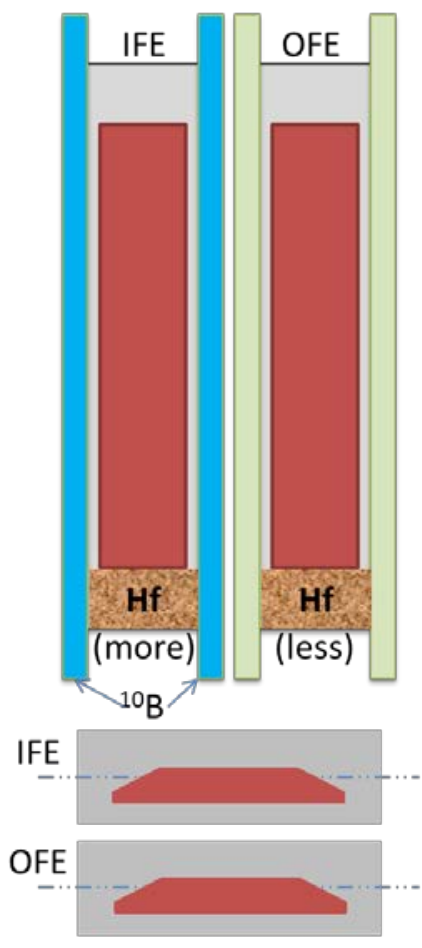

Alternate 7
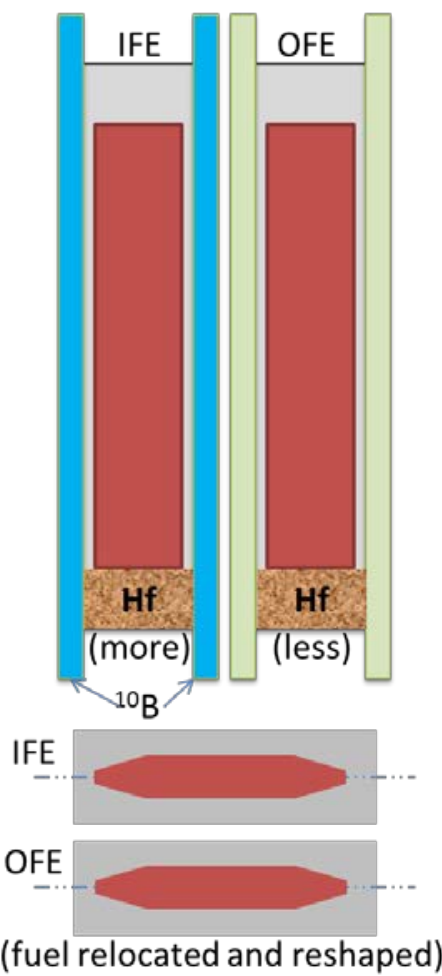

Fig. 2.1. Conceptual (not-to-scale) schematics of evaluated alternate LEU designs.

Four of the alternate designs with no axial fuel contouring (\#2, \#5, \#6, and \#7) have hafnium (Hf), a semipermanent absorber, included in the lower unfueled regions of the inner fuel element (IFE) and outer fuel element (OFE) fuel plates to compensate for the presence of additional fuel at the bottom compared to the reference design, with the purpose of decreasing the power peaking at the bottom of the fuel plates. Whereas roughly the same amount of Hf is used in all of these four designs, the distribution of the Hf content between the IFE and OFE regions differs. Alternate \#2 has $34 \mathrm{wt} \%$ and $66 \mathrm{wt} \%$ of $362.25 \mathrm{~g} \mathrm{Hf}$ distributed in the IFE and OFE unfueled regions, respectively. The distribution for Alternates \#5, \#6, and \#7 of $364.46 \mathrm{~g}$ Hf is $48 \mathrm{wt} \%$ in the IFE and $52 \mathrm{wt} \%$ in the OFE, respectively. Each HFIR fuel plate is 24 inches long and the center 20 inches of the plate contains fuel meat. The bottom two inches of the fuel plate is Al cladding (i.e., no fuel) and because the fuel plate is not explicitly modeled in the MCNP geometry used in these studies, the two-inch region below the active fuel is modeled by homogenizing the $\mathrm{Al}$ clad, Hf absorber, and water coolant. One material is defined for the two-inch region below the IFE and one material is defined for the two-inch region below the OFE; thus, the Hf is evenly distributed (i.e., not axially or radially contoured) in each of these regions. The Hf isotopic composition is assumed to be that of natural $\mathrm{Hf}\left(0.16,5.13,18.45,27.21,13.66\right.$, and $35.39 \mathrm{wt} \%{ }^{174} \mathrm{Hf},{ }^{176} \mathrm{Hf},{ }^{177} \mathrm{Hf},{ }^{178} \mathrm{Hf},{ }^{179} \mathrm{Hf}$, and ${ }^{180} \mathrm{Hf}$, respectively) and the form considered is pure $\mathrm{Hf}$ metal (i.e., not $\mathrm{HfO}_{2}, \mathrm{Hf} / \mathrm{Zr}$, etc.).

All alternate designs, similar to the reference one, contain boron (B) as a burnable absorber in the form of $\mathrm{B}_{4} \mathrm{C}$ in the IFE. However, the quantity and location of $\mathrm{B}$ varies among the considered designs. The reference LEU design includes a total of $5.4 \mathrm{~g}$ of ${ }^{10} \mathrm{~B}$ in the IFE fuel plates. The same location and amount of $\mathrm{B}$ is also present in Alternate \#4, whose difference from the reference design is only the replacement of aluminum (Al) cladding with Zircaloy 4. The same location of $\mathrm{B}$, in the IFE fuel plates, also applies to Alternates \#1, \#2, and \#5; however, the total amount of ${ }^{10} \mathrm{~B}$ is $5.29 \mathrm{~g}$, decreased from the reference case 
due to the presence of additional fuel at the bottom of the fuel plates, which replaces part of the B-bearing aluminum.

Three of the seven alternate designs (\#3, \#6, and \#7) have the boron included in the inner and outer side plates of the IFE rather than in the IFE fuel plates as in the reference design. In all of these three latter cases, irrespective of the total amount of B used (range 3.4-4.6 $\mathrm{g}{ }^{10} \mathrm{~B}$ ), $25 \mathrm{wt} \%$ of the boron is included in the inner (\#1) side plate, and the remaining $75 \mathrm{wt} \%$ is present in the outer (\#2) side plate of the IFE. The side plates are the cylindrical tubes between which the fuel plates are located. The B is evenly distributed in both of the entire radial regions representing the inner and outer side plates of the inner fuel element, which are 24 inches in length. No boron is modeled in the end adaptors that are welded to the ends of the side plates. A summary of the quantities of boron modeled in the IFE inner and outer side plates for the 3.4, 3.6, and 4.6 gram cases is provided in Table 2.2.

Table 2.2. Boron in IFE side plates for alternate LEU designs

\begin{tabular}{c|c|c|r|r|r}
\hline $\begin{array}{c}\text { Side } \\
\text { plate }\end{array}$ & Absorber & Units & $\begin{array}{c}\text { 3.4g } \\
\text { case }\end{array}$ & $\begin{array}{c}\text { 3.6g } \\
\text { case }\end{array}$ & \multicolumn{1}{c}{$\begin{array}{c}\mathbf{4 . 6 g} \\
\text { case }\end{array}$} \\
\hline \multirow{4}{*}{ Inner } & \multirow{2}{*}{$\mathrm{B}-10$} & grams & 0.85 & 0.90 & 1.15 \\
\cline { 3 - 6 } & & $\mathrm{ppm}^{\mathrm{a}}$ & 273 & 289 & 370 \\
\cline { 2 - 6 } & \multirow{2}{*}{$\mathrm{B}$} & grams & 4.59 & 4.86 & 6.21 \\
\cline { 3 - 6 } & & $\mathrm{ppm}$ & 1476 & 1563 & 1997 \\
\hline \multirow{4}{*}{ Outer } & \multirow{2}{*}{$\mathrm{B}-10$} & grams & 2.55 & 2.70 & 3.45 \\
\cline { 3 - 6 } & & $\mathrm{ppm}$ & 302 & 319 & 408 \\
\cline { 2 - 6 } & \multirow{2}{*}{$\mathrm{B}$} & grams & 13.77 & 14.58 & 18.63 \\
\cline { 3 - 6 } & & ppm & 1628 & 1724 & 2203 \\
\hline
\end{tabular}

${ }^{\mathrm{a}} \mathrm{ppm}$ by weight in aluminum assuming the side plates have no notches or grooves cut into them; thus, actual ppm boron required will be greater than amounts listed.

Alternate Designs \#6 and \#7 are similar with respect to the presence of burnable and permanent absorbers, the presence of radial fuel contouring, the absence of axial fuel contouring, and the total mass of fuel in each of the fuel plates. However, they have a different profile of the radial fuel contouring and location of the fuel region within the fuel plate. In Alternate \#7, the fuel zone inside the fuel plate has been relocated to be centered on the centerline of the (50 mil) depth of the plate and has been reshaped to be symmetric about this centerline (see Fig. 2.1). The volume of the fuel within the fuel plate and the distribution of the fuel along the width of the plate as a function of the radial distance with respect to the core axial centerline were conserved for these studies. The effectiveness of the changes in fuel zone radial contouring and location in improving the LEU design will be discussed in detail in Section 12 of this report, based on thermal-hydraulics considerations under nominal conditions. Alternate \#6 makes use of the same fuel shape and location as that used in the reference design[2].

All the neutronics studies documented in this report consistently used the reactor model presented in Section 3, with a simplified approach (no explicit involute representation) used for the fuel plate modeling. This model was considered adequate for these scoping studies, given its significantly better computational speed compared to an explicit fuel modeling; in addition, this ensures better consistency among the investigations that spanned a period of time of a few years, given that only a simplified fuel model was available when these studies were initiated. 
A concerted effort over the past couple of years has focused on further improving the accuracy of the HFIR neutronics (MCNP and VESTA) models for HEU and LEU cores, with these models being extensively reviewed and revised to improve geometry and material modeling based on HFIR primary drawings and documents and also by including an explicit representation of the involute fuel plates based on the methodology developed by Argonne National Laboratory (ANL)[8]. Due to the ongoing updates of the data in the HFIR neutronics models, some of the alternate studies are based on a reference model slightly different from that documented in [2]. However, these changes are not so significant, as discussed where applicable in the following sections of the report, to affect the relative comparison used in assessing the performance of the alternate designs.

The reference model (\#0 in Table 2.1) and the Alternate Designs \#1, \#2, \#3, and \#5 are completely consistent except for the changes summarized in Table 2.1 and discussed in more detail in the corresponding sections of the report. In Alternate \#4, there are small differences in geometry compared to reference \#0, although not affecting the fuel element regions and not impacting the relative comparison of alternate and reference designs (see Section 9). For the most recent studies of Alternate designs \#6 and \#7, the basis (reference) model has more changes implemented during FY 2013, which included the use of a new spatial mesh in the fuel zones of the core. The effect of these changes is discussed in detail in Section 11 of the report.

Note that the neutronic models for Alternate Designs \#6 and \#7 are identical since the simplified fuel modeling approach used does not explicitly represent the involute geometry of the fuel plate and the different material regions in the plate.

Although deemed unsatisfactory for operation in HFIR, a fuel with no radial or axial fuel zone contouring applied was also studied briefly, to quantify the effect of the use of such a fuel on the fission density profile and power peaking. The results obtained for this design, not included as a potential alternate design, are presented in Section 5. 
This page intentionally blank 


\section{ANALYSIS METHODOLOGY}

\subsection{NEUTRONICS}

The computational tools used for the neutronics analyses of the HFIR LEU fuel alternate designs include the Monte Carlo N-Particle 5 (MCNP5) version 1.5.1 code[3], the VESTA 2.0.2 Monte Carlo-based depletion tool[4], and the SCALE 6.1[9] nuclear safety analysis and design code package. This set of tools was also employed for the neutronics studies performed on the reference LEU core design documented in [2]. Cross section data based on the ENDF/B-VII.0 nuclear data evaluation was utilized for the MCNP and VESTA calculations. A brief description of the codes used in these studies is provided in this section.

\subsubsection{MCNP - Monte Carlo Transport Code}

The MCNP5 code, which is a Monte Carlo-based neutron-photon-electron transport code developed and maintained at the Los Alamos National Laboratory, is used in this study to perform neutron transport calculations. MCNP can be used to simulate neutron, photon, electron, or coupled neutron/photon/electron transport and includes the capability to calculate eigenvalues for critical systems in three-dimensional (3-D) arbitrary geometry configurations. Its capabilities to model complex geometries and to use pointwise cross-section data for the neutron transport treatment make the code a desirable tool for analysis of highly heterogeneous systems such as HFIR.

An MCNP model of the HFIR HEU core, which includes a detailed representation of the reactor components and experiment facilities based on HFIR Cycle 400, was previously developed[10] and has served as a reference model to perform analyses in support of HFIR operation. Based on this existing model for the HEU core, an MCNP model for the reference LEU fuel core was developed in [2]. The MCNP inputs used to study the alternate designs discussed in this report are based on this reference LEU MCNP input.

The MCNP as-modeled geometry includes the flux trap target region that is located inside of the inner and outer fuel elements. This region contains 30 curium targets, a hydraulic tube, and six peripheral target tubes filled with water. On the outside of the fuel elements is the control element region, which consists of two concentric poison-bearing control elements and water coolant channels. A large beryllium reflector is located outside of the control element region and contains 42 vertical penetrating experimental sites, four horizontal beam tubes that enter the reflector on the core midplane, and two slant engineering facilities. The as-modeled MCNP geometry is illustrated in Fig. 3.1.1. 


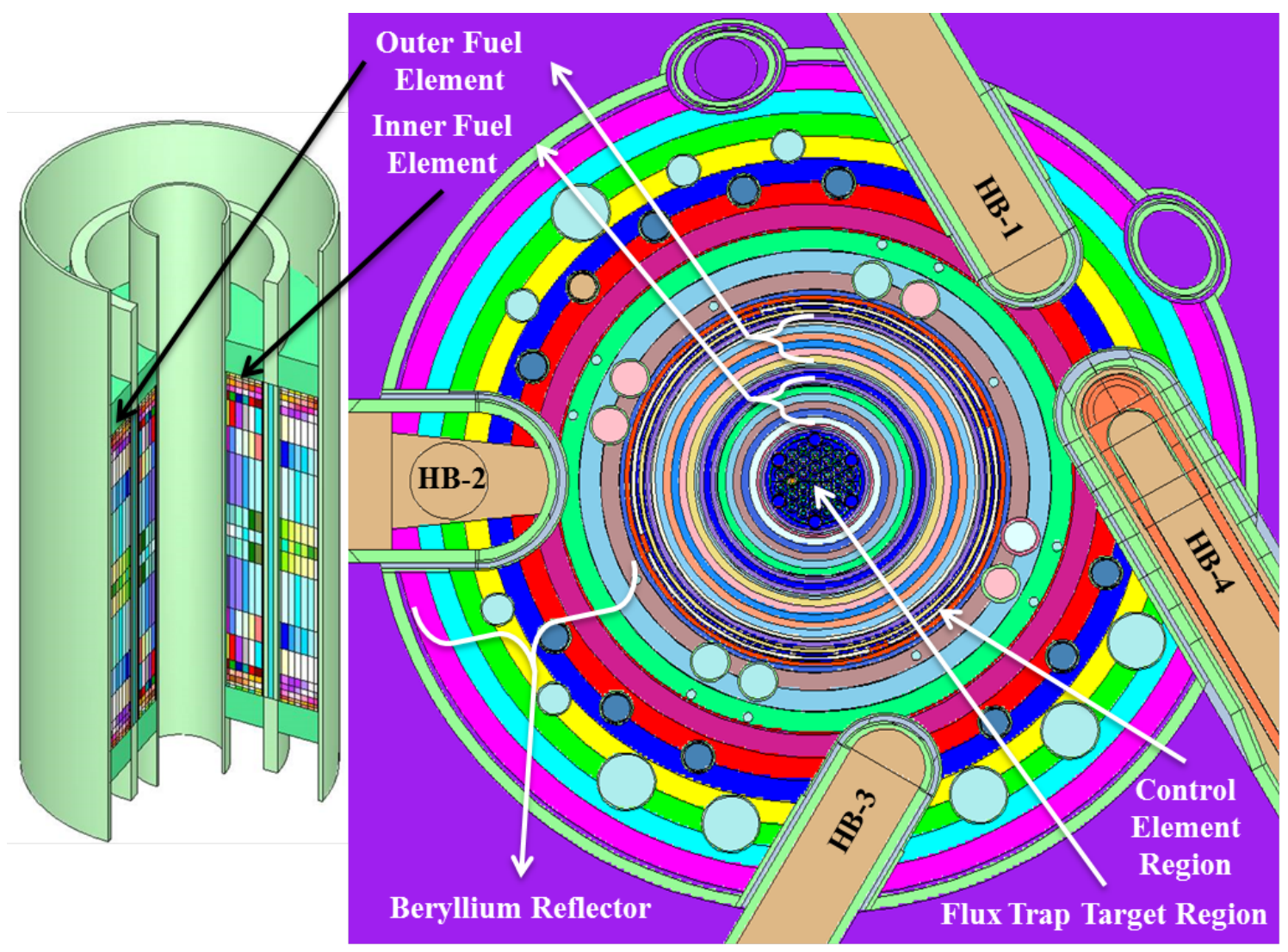

Fig. 3.1.1. As-modeled geometry of HFIR LEU MCNP model.

The fuel elements are modeled by volumetrically homogenizing the fuel meat (U-10Mo), filler (Al), clad $(\mathrm{Al})$, diffusion barrier layer $(\mathrm{Zr})$, and water in between the fuel plates. The inner fuel element is divided into 8 radial regions and 19 axial regions and the outer fuel element is divided into 9 radial regions and 19 axial regions. The fuel elements are divided radially to approximate the variation of the fuel in the radial direction of the fuel plate (i.e., radial fuel contouring) and they are divided axially in order to model the time- and spatially-dependent neutron flux and fuel composition. For more information regarding the detailed modeling of the HFIR core in MCNP refer to [2].

Fission rate densities and relative fission densities are the primary physics metrics that are calculated and documented in the neutronics sections of this report. The fission rate densities per source fission neutron were calculated with the MCNP code for each of the homogenized fuel-bearing regions through the use of flux and reaction rate tallies for each fueled region. The fission rate density, $F_{i}$, in a spatial mesh $i$ located in the homogenized fuel region is calculated as:

$$
F_{i}\left(\frac{\text { fissions }}{c m^{3} \text { fuel }-s}\right)=\left(\frac{1}{V_{\text {fuel }}^{i}}\right) \int_{V_{i}} \int_{0}^{\infty} \Sigma_{f}(\vec{r}, E) \Phi(\vec{r}, E) d E d V
$$

In the above equation, $V_{\text {fuel }}^{i}$ is the volume of the fuel meat (U-10Mo) in the fuel-bearing homogenized cell $i, V_{i}$ is the homogenized cell volume, $\mathrm{E}$ is energy, $\Sigma_{f}(r, E)$ is the energy dependent macroscopic fission cross section, and $\Phi(r, E)$ is the energy dependent neutron flux. The relative fission density, $f_{i}$, in a spatial mesh $i(\mathrm{i}=1, \mathrm{~N})$ located in the fuel region is calculated as: 


$$
f_{i}=\frac{\left(1 / V_{i}\right) \int_{V_{i}} \int_{0}^{\infty} \Sigma_{f}(\vec{r}, E) \Phi(\vec{r}, E) d E d V}{\left(1 / \sum_{i=1}^{N} V_{i}\right) \sum_{i=1}^{N} \int_{V_{i}} \int_{0}^{\infty} \Sigma_{f}(\vec{r}, E) \Phi(\vec{r}, E) d E d V}
$$

\subsubsection{VESTA - Monte Carlo-Based Depletion Tool}

VESTA, a "generic" Monte Carlo-based depletion tool developed and maintained at Institut de Radioprotection et de Sûreté Nucléaire in France, was utilized for the HFIR fuel cycle depletion analyses documented in this report. VESTA has been validated against HFIR HEU post-irradiation, spatiallydependent, uranium isotopic measurements[11]. Version 2.0.2 was utilized in these studies to couple the MCNP5 code to the point depletion and decay code ORIGEN 2.2[12]. VESTA has been selected as the primary depletion tool for HFIR core analysis because of its ability to simulate the vertical control element movement necessary to maintain critical conditions during the fuel cycle and because extensive resources have been devoted to benchmarking MCNP models of HFIR[13-16].

VESTA uses MCNP to determine the neutron flux in each of the depletion materials in an ultra-fine 43,000-group energy structure. Then, outside of the MCNP calculation, VESTA calculates the reaction rates with pre-generated pointwise microscopic cross sections that are consistent with the cross section data used in the MCNP transport calculations (ENDF/B-VII.0 used here). The one-group data required for the ORIGEN 2.2 depletion calculations are thus determined using the ultra-fine calculated spectrum. This unique approach is called the multi-group binning approach. The updated material compositions, including the initial set of isotopics plus all those that contribute to a user-defined percentage (99.99\% used here) of the total number of absorptions, are passed to the subsequent MCNP input. This process iterates until the simulation of the desired irradiation history is complete.

During the LEU depletion simulations, the reactor fuel (238 unique materials; material symmetry was used across the core horizontal midplane except for the upper and lower four regions ), control elements' poison-bearing regions ( 4 unique materials), and the curium targets ( 1 unique material) in the flux trap target region are depleted based on a total reactor power of $100 \mathrm{MW}$. A total of 243 materials are depleted and tracked during the depletion simulations less the neutron absorber materials used in the alternate design studies. Two additional materials are depleted when Hf is utilized in the fuel plate lower unfueled regions: one material in the IFE fuel plate lower unfueled region and one in the OFE fuel plate lower unfueled region. A total of 22 borated aluminum materials are depleted (11 in the IFE inner side plate and 11 in the IFE outer side plate) for the alternate design calculations utilizing ${ }^{10} \mathrm{~B}$ in the side plates to compensate for the removal of the burnable poison in the fuel plate filler regions associated with the reference LEU fuel design. The same axial mesh used to define the 19 axial fuel regions was used to define the borated aluminum side plate regions. An additional borated aluminum region is located above the active fuel and one region is located below the active fuel; thus, 22 borated aluminum regions are modeled in each side plate. Because material symmetry is used across the core horizontal midplane, a total of 22 unique depletion materials are assigned to the 44 borated aluminum regions. Also, one day time steps, control element withdrawal, 300 Kelvin temperature cross section data, and the predictor-only approach are utilized with VESTA.

Some of the alternate design analyses made use of a criticality search algorithm[8] to find the symmetrical critical control element positions during the cycle; whereas others made use of the control element withdrawal curve generated for the reference LEU design[2]. During the fuel cycle, the fuel is being consumed and fission product poisons are being produced. In order to compensate for the negative reactivity introduced due to fissions and transmutations in the fuel, the two control elements are withdrawn during the cycle. Once the control elements are fully withdrawn, the fuel cycle is finished 
because criticality can no longer be maintained. The criticality search algorithm calculates an approximate average control element differential worth based on effective multiplication constants calculated with the control elements fully inserted and fully withdrawn, and the axial distance between these two positions. Then, at the end of each steady-state calculation, if criticality ( \pm a statistical tolerance) is not achieved, the symmetrical control element position is changed based on the calculated worth. This process is repeated until the tolerance is met.

\subsubsection{Post-Shutdown Heat Power Generation}

The heat power generated from delayed neutron induced fissions and radioactive decay must be accounted for after reactor shutdown and during a transient because it must be removed to ensure all safety requirements are met. This section describes the methods used to estimate the amount of heat that is generated during reactor shutdown and after shutdown.

\subsubsection{Delayed neutron induced fission heat}

The prompt power decay associated with the insertion of the safety plates and the subsequent termination of fission reactions, referred to as delayed neutron induced fission heat power, was characterized with point kinetics calculations and the MATLAB code[17]. The point kinetics calculations performed in these studies utilized six-groups of delayed neutron precursors (LEU data from [18]), no reactivity feedback effects, and the safety plate insertion rates and reactivity worth curves. The four outer safety plates were assumed to be fully withdrawn, which is the position corresponding to end of cycle (EOC) where their differential reactivity worth is the smallest. The inner control cylinder position remained constant during the simulation.

Three independent safety channels are connected to a magnet coil on each of the four safety plates, and the magnets hold the scram latches in position. If at least two of the three channels detect any nuclear or process parameters exceeding their prescribed limits, the safety plates will be released following a delay time that exists between the rate trip signal and the release of the safety plates. The safety plates are spring loaded and are inserted with an initial acceleration of four times gravity. The acceleration decreases linearly from $4 \mathrm{~g}$ to $1 \mathrm{~g}$ over the first $15.24 \mathrm{~cm}$ and then remains $1 \mathrm{~g}$ until the safety plates are fully inserted. The downward hydrodynamic forces caused by downward coolant flow are ignored, and thus, the calculated movement of the safety plates is slightly conservative; meaning the modeled rate of change of position is slower than reality. For this set of calculations, it was assumed that all four safety plates were released during the scram.

More effort in this area, including generating and implementing reactivity feedback data (e.g., fuel temperature, moderator temperature, void) and including their effects, will be required for final design studies. However, for the purpose of these calculations, assuming no reactivity feedback is reasonable because no power pulses take place and the large negative reactivity introduced during the rapid insertion of the safety plates would overshadow any reactivity feedback such as that from fuel and moderator temperature changes.

The point kinetics equations describing the power and delayed neutron precursor concentrations are:

$$
\begin{gathered}
\frac{d P(t)}{d t}=P(t)\left[\frac{\rho(t)-\beta_{e f f}}{\Lambda}\right]+\sum_{i=1}^{6} \lambda_{i} C_{i}(t) \\
\frac{d C_{i}(t)}{d t}=P(t)\left(\frac{\beta_{i}}{\Lambda}\right)-\lambda_{i} C_{i}(t), \mathrm{i}=1: 1: 6
\end{gathered}
$$


where $P$ is the power, $\rho$ is reactivity, $\beta_{\text {eff }}$ is the effective delayed neutron fraction, $\beta_{\mathrm{i}}$ is the delayed neutron fraction for delayed neutron Group $i, \Lambda$ is the mean generation time between birth of a fission neutron and the subsequent absorption leading to another fission, $\lambda_{\mathrm{i}}$ is the decay constant for Group $i$, and $\mathrm{C}_{\mathrm{i}}$ is the concentration of Group $i$. MATLAB's “ode15s" solver was utilized to solve these equations since this solver is able to efficiently solve stiff problems such as reactor kinetics problems. The delayed neutron induced fission heat power fraction is shown as a function of time after shutdown in Fig. 3.1.2.

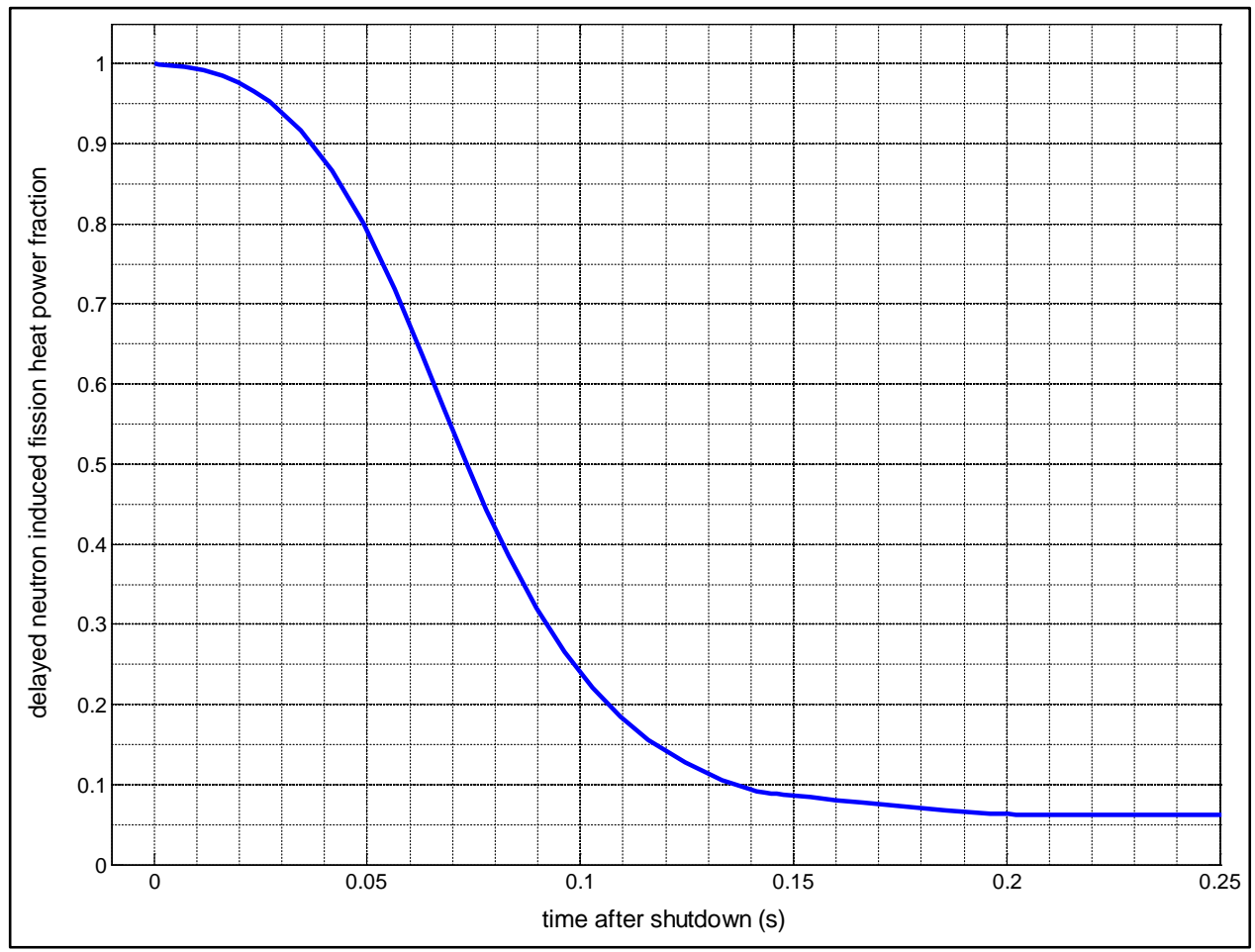

Fig. 3.1.2. Delayed neutron-induced fission heat power fraction following four plate scram.

\subsubsection{Decay heat}

Decay heat is the energy released as the result of the radioactive decay of fission products and actinides. During the radioactive decay process, radiation is emitted and the energy released is deposited throughout the reactor. Decay heat can be calculated by either tracking the isotopic content of the fuel during the irradiation cycle and the subsequent decay or by using published standards like the ANSI/ANS-5.1-2005 decay heat power in light water reactors standard[22]. The isotopic composition of the fuel is tracked during the VESTA computations previously described, but this method relies on the nuclear decay and fission yield data while the standards are based on experimental data.

During the irradiation cycle, which is simulated with the VESTA code, a large number of isotopes are generated and depleted in the reactor core by neutron transmutation, fission, and radioactive decay. The EOC VESTA-calculated isotopic compositions for the reference LEU fuel design[2] fueled regions were fed into standalone ORIGEN inputs for source term characterization. For these studies, the ORIGEN point depletion and decay code was utilized to calculate the total decay heat and the delayed gamma decay heat source terms as a function of time after scram. The difference of the total decay heat and the gamma only decay heat is the beta decay heat. The total mass of the used fuel including both the inner and outer fuel elements was considered. The ORIGEN code is one of the 89 computational modules in the "plug-and-play" framework of the SCALE 6.1 code package[9], which is a comprehensive modeling 
and simulation suite used for nuclear safety analysis and design that is developed and maintained by ORNL.

The decay heat for the fuel from reactor shutdown until 21 hours after shutdown was calculated in nonuniform time steps between 0.01 seconds and 1 hour for consistency with the RELAP input deck based on [6] and modified for the LEU fuel design. The total decay heat due to beta and gamma radiation at shutdown was calculated to be $9.61 \mathrm{MW}$, which is in good agreement with the $9.58 \mathrm{MW}$ reported in [2]. Following 1 minute, 1 hour, and 20 hours of decay time, the core decay heat is reduced to 3.16, 1.11, and $0.35 \mathrm{MW}$, respectively. The decay heat source terms were not calculated for each alternate design because the normalized decay curves should be similar for all designs.

The initial (time=0) decay heat power of 9.61 MW is a conservative overestimation, especially since decay heat power reduces much slower than the delayed neutron induced fission heat discussed previously. Of the 9.61 MW, the gamma decay heat was calculated to be $3.36 \mathrm{MW}$ (35\%) and the beta decay heat was calculated to be $6.24 \mathrm{MW}(65 \%)$. The 3.36 MW of gamma decay heat seems reasonable, but the $6.24 \mathrm{MW}$ of beta decay heat is much greater than expected.

To better understand the greater than expected decay heat, a simple single pin cell problem was analyzed. The NEA-OECD BUC IV-B benchmark single pin cell VESTA example problem provided in the VESTA user's manual[4] was used with ENDF/B-VII data (consistent with the HFIR VESTA calculations). The isotopic composition of the fuel after 30 days of irradiation (after the first depletion step) was fed into ORIGEN to characterize the post-irradiation decay heat. A similar calculation was performed using the CSAS, COUPLE, and ORIGEN sequence in the SCALE code for comparison purposes. The CSAS code was used to calculate the self-shielded cross sections of the fuel pin and the COUPLE code, along with the 238-group flux spectrum collapsed from the 43,000-group spectrum calculated with the MCNP code (in the VESTA simulation), was used to appropriately calculate the effective one-group cross sections for use in the ORIGEN irradiation simulation.

Both methods utilized ORIGEN to decay the material and convert the isotopic compositions to decay heats, but the methods used to generate the day 30 isotopic compositions differed. The total decay heats calculated with both methods were then compared to calculations performed with the ANSI/ANS standards data previously discussed. For this pin cell problem, the gamma only decay heat calculated with the VESTA-generated isotopics was about 15\% greater than that calculated with the SCALEgenerated isotopics at shutdown ( $\mathrm{t}=0$ seconds), but the results were found to agree well after about 10 seconds of decay. The beta decay heat calculated with the VESTA-generated isotopics was almost twice that of the beta decay heat calculated with the SCALE-generated isotopics at $t=0$ seconds. However, the beta only and the total decay heats come into excellent agreement after about 20-30 seconds of decay.

The total decay heat calculated for the pin cell problem with the SCALE-generated isotopics was in excellent agreement with the calculations performed with the ANSI/ANS standard data from $t=0$ seconds onwards while the decay heat calculated with the VESTA-generated isotopics was observed to be much greater than the ANSI/ANS standard at $\mathrm{t}=0$ seconds and reach good agreement with the standard following about 20 seconds of decay. The primary radionuclides being over-predicted in the VESTA simulation in comparison to the SCALE calculation leading to differences in the decay heat were determined to be ${ }^{96} \mathrm{Sr}\left(\mathrm{t}_{1 / 2}=1.07\right.$ seconds), ${ }^{96} \mathrm{Y}$ ( $\mathrm{t}_{1 / 2}=5.34$ seconds), ${ }^{102} \mathrm{Zr}\left(\mathrm{t}_{1 / 2}=2.9\right.$ seconds $),{ }^{103} \mathrm{Nb}\left(\mathrm{t}_{1 / 2}=\right.$ 1.5 seconds), ${ }^{105} \mathrm{Mo}\left(\mathrm{t}_{1 / 2}=35.6\right.$ seconds), ${ }^{109} \mathrm{Tc}\left(\mathrm{t}_{1 / 2}=0.86\right.$ seconds), ${ }^{110} \mathrm{Rh}\left(\mathrm{t}_{1 / 2}=28.5\right.$ seconds), and ${ }^{134} \mathrm{Sb}$ $\left(\mathrm{t}_{1 / 2}=0.78\right.$ seconds).

To provide more accurate decay heat results to the RELAP thermal hydraulics analysts, the ANSI/ANS5.1-2005 standard was applied to the HFIR LEU fuel. This standard contains decay heat information related to thermal fission of ${ }^{235} \mathrm{U},{ }^{239} \mathrm{Pu}$, and ${ }^{241} \mathrm{Pu}$ and fast fission of ${ }^{238} \mathrm{U}$. The VESTA output files 
contain the time-dependent isotopic concentrations of each material, the time-dependent effective onegroup fission cross sections of each material, and the time-dependent total neutron flux in each material. These data were utilized to determine the time-dependent fission rates of each of the four nuclides. At BOC, ${ }^{235} \mathrm{U}$ and ${ }^{238} \mathrm{U}$, respectively, contribute to about 97.4 and $2.6 \%$ of the total fission rate $\left(\sim 3.08 \times 10^{18}\right.$ fissions/second). At EOC, ${ }^{235} \mathrm{U},{ }^{239} \mathrm{Pu},{ }^{238} \mathrm{U}$, and ${ }^{241} \mathrm{Pu}$ contribute to about 92.2, 5.0, 2.6, and 0.2\%, respectively, of the total fission rate.

The time- and nuclide-dependent fission rates were used along with the nuclide-dependent parameters listed in the ANSI/ANS standard to solve the exponential fits to the $F(t, \mathrm{~T})$ equation for each of the four nuclides:

$$
F(t, T)=\sum_{i=1}^{23} \frac{\alpha_{i}}{\lambda_{i}} e^{\left(-\lambda_{i} t\right)}\left[1-e^{\left(-\lambda_{i} T\right)}\right]
$$

where $F(t, \mathrm{~T})$ is the decay heat power $t$ seconds after an operating period of $\mathrm{T}$ seconds in the absence of neutron capture in fission products, $\alpha_{\mathrm{i}}$ is the decay power fraction of the $\mathrm{i}^{\text {th }}$ group, and $\lambda_{\mathrm{i}}$ is the decay constant of the $\mathrm{i}^{\text {th }}$ group. The effect of neutron capture in fission products was estimated using the $\mathrm{G}(t)$ equation (Eq. 11 in [22]) for shutdown times less than $10^{4}$ seconds and the maximum values of $\mathrm{G}(t)$ listed in Table 13 of [22] were utilized for shutdown times greater than $10^{4}$ seconds. The decay heat power calculated by ORIGEN with the VESTA-generated isotopics is compared to the ANSI/ANS standard results in Fig. 3.1.3. As shown, the method using the ANSI/ANS standard calculated a decay heat of about 6.59 MW at shutdown.

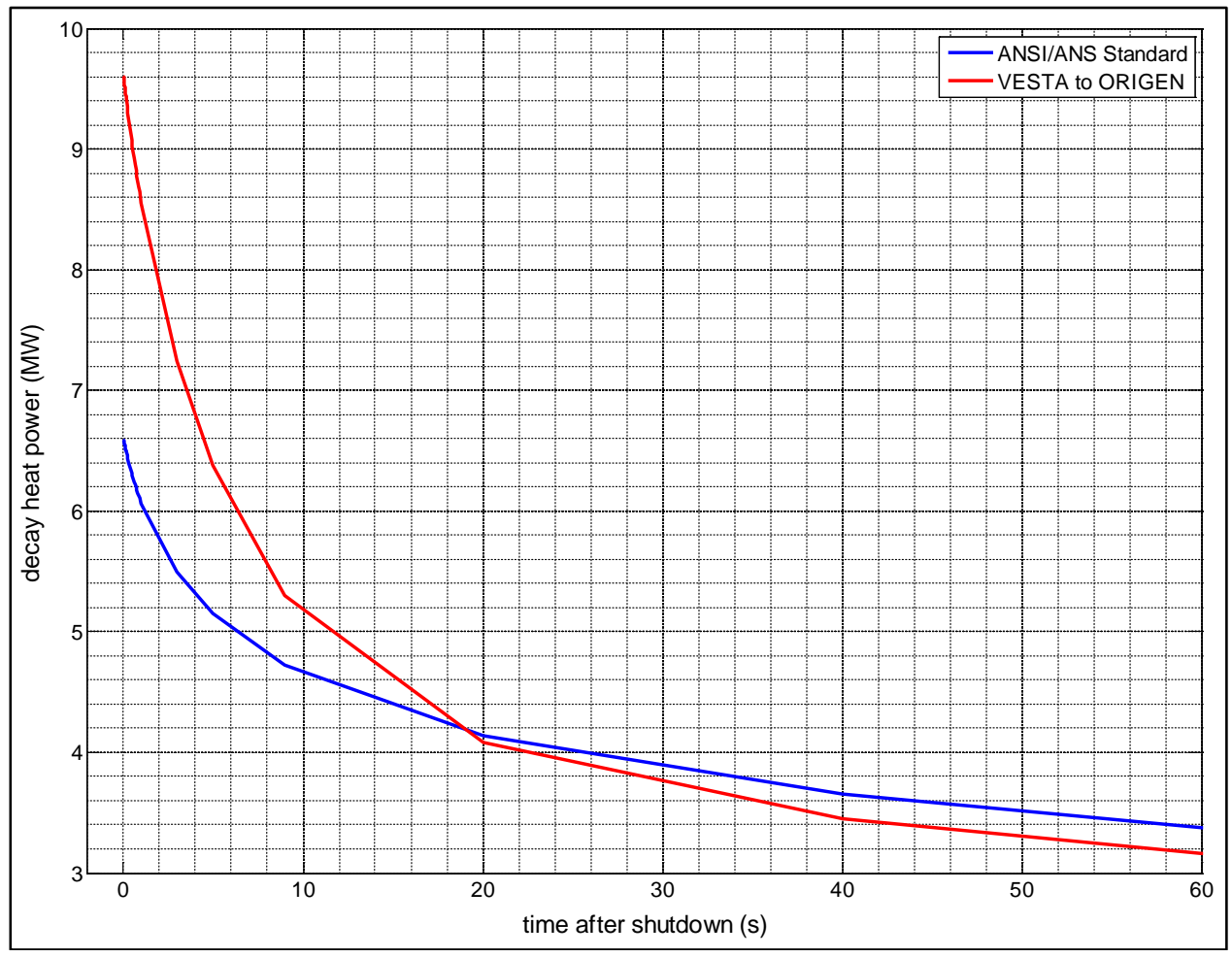

Fig. 3.1.3. Comparison of ANSI/ANS standard to VESTA/ORIGEN decay heats. 


\subsubsection{Distribution of shutdown heat power}

The ANSI/ANS standard is very useful to determine the total decay heat, but follow-on transport calculations are required to determine where in the reactor (e.g., fuel meat, clad, coolant, control elements, beryllium reflector) the decay heat is deposited and how much of the decay heat is due to beta and gamma radiation. In order to determine the spatially dependent decay heat deposition, two MCNP neutron-photon simulations were performed with the most recent and unpublished "explicit" LEU input that explicitly represents the fuel meat, Zr layer, clad, and coolant channels in the core rather than homogenizing these regions together as discussed in the Section 3.1.1. The explicit geometry was initially developed in [8] and has since been slightly modified. This input was utilized instead of the homogenized input because it allows for the heat deposition to be calculated in the fuel meat, clad, and coolant separately.

The first MCNP calculation tallied the neutron plus fission product kinetic energy deposition (F6:N) and the prompt plus capture gamma energy deposition (F6:P) in every MCNP cell described in the input as well as the delayed beta energy deposition (F7: $\left.\mathrm{N} \mathrm{x}_{\beta} / \mathrm{Q}_{\mathrm{F} 7}\right)$ in all of the fuel cells. A second MCNP calculation utilizing the "pikmt" card to bias prompt, fission-induced gammas was utilized to calculate the prompt gamma energy deposition (F6:P) in every MCNP cell. Assuming the delayed gamma and prompt gamma energy spectrums are similar, the delayed gamma energy deposition was approximated by

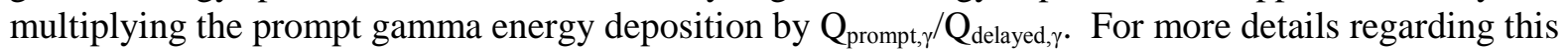
extensive energy deposition method, refer to [23].

From these calculations, it was estimated that about 93.84 of the total $100 \mathrm{MW}$ comes from prompt reactions (i.e., prompt neutrons, prompt gammas, capture gammas, and fission product kinetic energy). Of this 93.84 MW, it was determined that about 90.42 MW (96.36\%) is deposited in the core (i.e., all fuel element regions, coolant in between plates, and side plates - considered in the RELAP input as "fuel" regions) and the remaining $3.64 \%$ (3.42 MW) is deposited in the flux trap, control element region, beryllium reflector, and pool water (considered in the RELAP input as "non-fuel” regions).

The remaining 6.16 MW comes from delayed betas that are assumed to be locally deposited in the fuel meat and delayed gammas that are distributed throughout the reactor. Given the differences between methods, the 6.16 MW of decay heat calculated with MCNP is in good agreement with the $6.59 \mathrm{MW}$ calculated with the ANSI/ANS standard.

The initial delayed neutron induced fission heat is assumed to be the difference between the total power (100 MW) and the initial decay heat (6.59 MW); thus equal to 93.41 MW. The heat is further split into "fuel" and "non-fuel" regions as previously discussed using the proportions calculated with the MCNP results. A summary of the "at shutdown" ( $\mathrm{t}=0$ seconds after scram) heat power provided for use in the follow-on RELAP thermal hydraulics calculations is provided in Table 3.1.1 and the shutdown heat generation curves for the fuel and non-fuel regions are shown in Fig. 3.1.4. 
Table 3.1.1. Heat power summary at shutdown

\begin{tabular}{l|l|r}
\hline Region & Heating Type & P (MW) at t=0 \\
\hline fuel & delayed fission & 90.01 \\
\hline fuel & decay heat & 6.09 \\
\hline fuel & delayed fission + decay heat & 96.10 \\
\hline non-fuel & delayed fission & 3.40 \\
\hline non-fuel & decay heat & 0.50 \\
\hline non-fuel & delayed fission + decay heat & 3.90 \\
\hline fuel + non-fuel & delayed fission & 93.41 \\
\hline fuel + non-fuel & decay heat & 6.59 \\
\hline fuel + non-fuel & delayed fission + decay heat & 100.00 \\
\hline
\end{tabular}
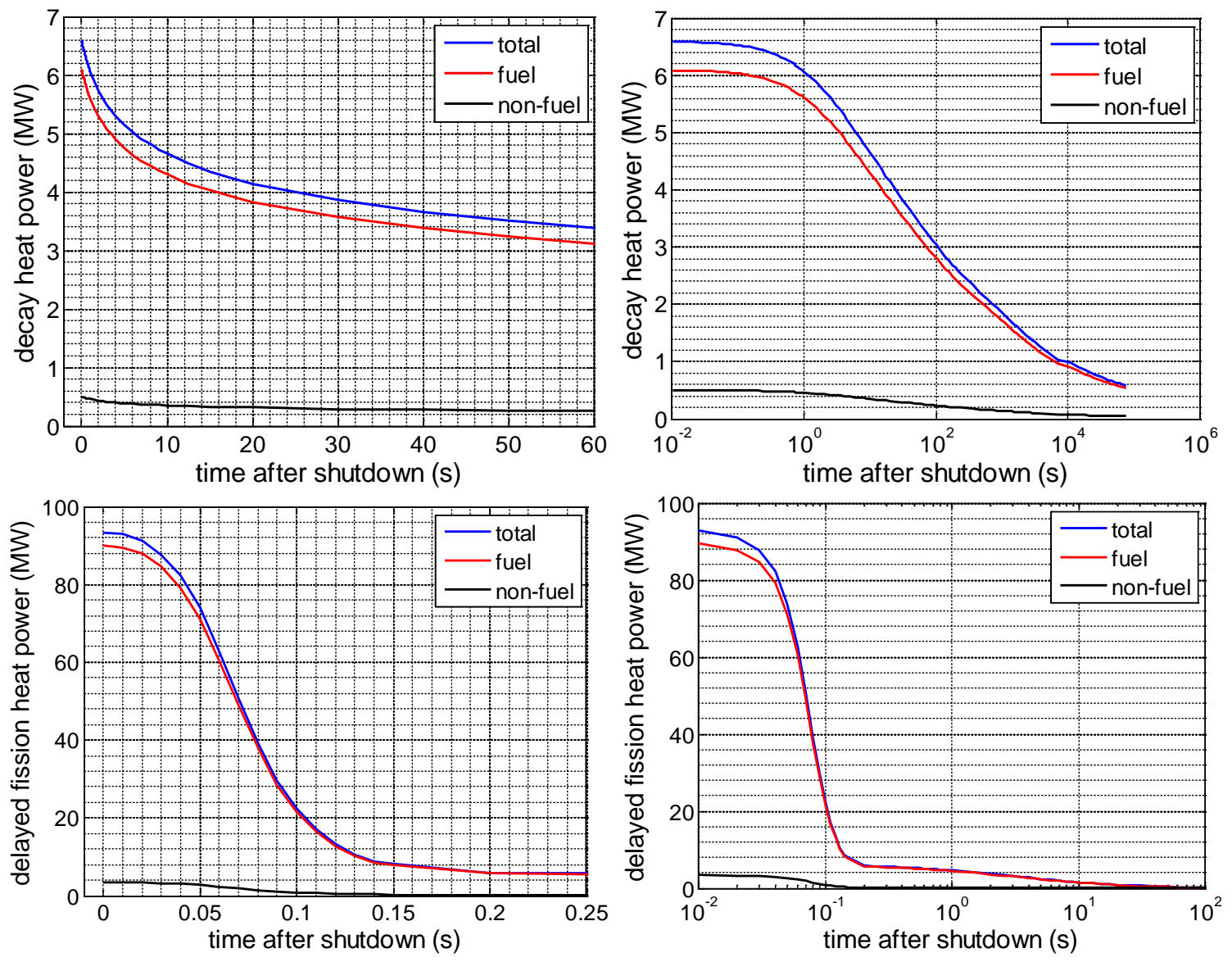

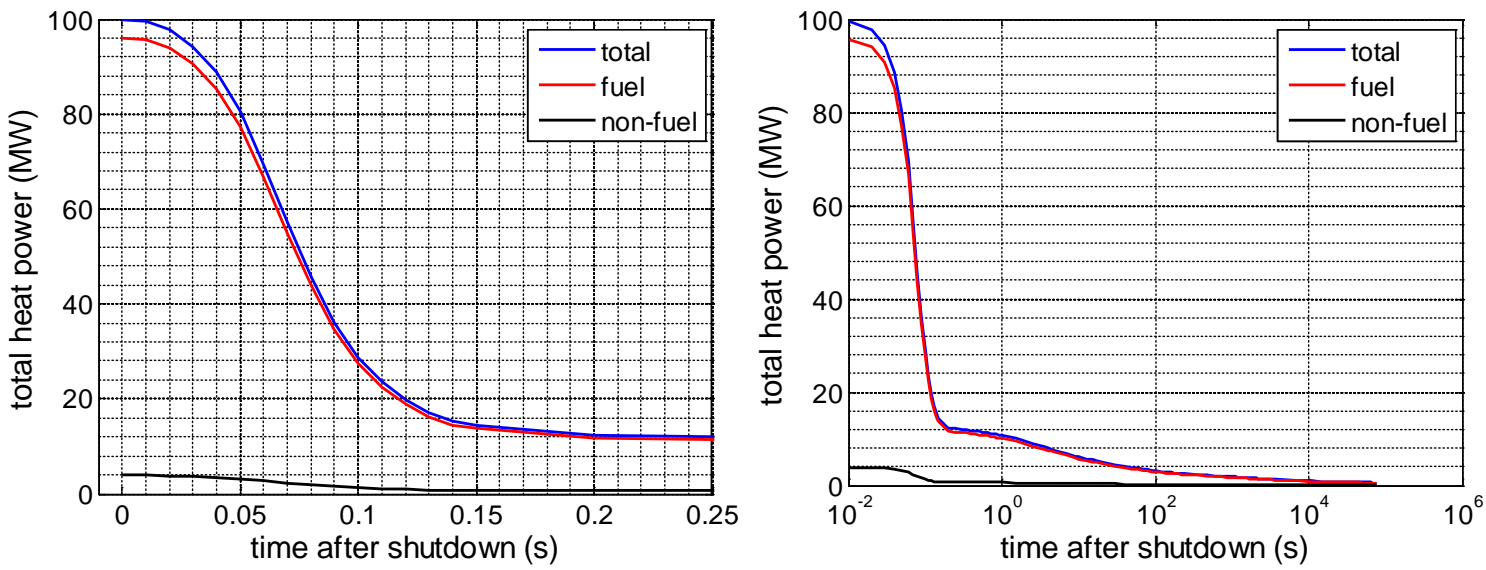

Fig. 3.1.4. Decay heat, delayed fission heat, and total heat power after shutdown.

\subsection{STEADY-STATE THERMAL HYDRAULICS (TH) (USING HSSHTC)}

\subsubsection{HSSHTC Background and Approach}

The HSSHTC[5] is a steady-state channel code with 2D R-Z geometry nodes that correspond to the MCNP neutronic modeling nodes. The analysis solves integral mass, momentum, and energy equations on each axial coolant channel. The code searches the entire core for the worst hot streak and worst hot spot in that hot streak over the course of a fuel cycle, considering best-estimate modeling of the physical processes that affect the heat transfer and fluid flow. The code also models a multiplicative combination of process, manufacturing, modeling, and parameter uncertainties that are provided as inputs. The fuel internal conduction and energy generation is not explicitly modeled in the HSSHTC, only the local heat flux to reject the local power produced in the plates is considered. As a result, the HSSHTC only produces 2D distributions of plate surface temperatures.

The HSSHTC is tailored and focused on thermal analysis necessary to produce reactor limiting control settings (LCSs) and safety limits (SLs), which are equivalent to limiting safety system settings and SLs, respectively, for NRC-regulated reactors. A typical HSSHTC calculation includes a first time step that corresponds to the beginning of cycle (BOC) and at least one last step that corresponds to the end of the fuel element irradiation under consideration, which could be the EOC conditions. At each time step, the HSSHTC determines the average fuel temperatures and heat fluxes at the given power, then calculates the effects of manufacturing tolerances on the temperature and heat flux distributions, e.g., combined effects of wide and narrow coolant channels are considered. The HSSHTC always ends the last part of the core time step with a calculation of the power increase required to cause either hot spot incipient boiling or hot spot burnout (depending on the input choice) taken from the steady-state power and conditions at the end of the last step. Thus, the course of a fuel cycle is modeled by a series of quasistatic time steps that move the fuel through the cycle and allow the user to model the effects of changing power density distributions and oxide layer growth based on the calculated fuel conditions as the cycle evolves. If only the BOC conditions are desired, the code user inputs a timestep of 0.0 hours and the code outputs the BOC average, hot channel, and hot plate results.

The core thermal-hydraulic model includes numerous physical models that are connected and iteratively solved together with the mass, momentum, and energy balance to consider the effects on local coolant channel width caused by oxide layer growth, plate thermal expansion, plate radiation swelling, plate deflections due to axial thermal expansion differences between the hot plate center and cool plate edges, 
plate deflection due to axial temperature gradients between an adjacent hot plate (overloaded with fuel) and cold plate (underloaded with fuel), and azimuthal pressure gradients caused by velocity difference between adjacent wide and narrow coolant channels. These models were not changed for this study (they include characteristics of HEU dispersion fuel) and were applied to the extent possible for the LEU fuel calculations. In some cases the models are conservative (e.g., because the HEU plate deflections and effects on coolant channels are expected to be greater than the corresponding LEU deflections). In some cases the models are nonconservative (e.g., the current model has the radiation swelling calculation turned off because this has been shown to not be a significant effect for HFIR HEU dispersion fuel). However, radiation swelling could be an important parameter to model for any final LEU calculations performed with the HSSHTC.

\subsubsection{Uncertainties Considered in HFIR Steady State Thermal Analysis}

The steady state heat transfer analysis for the HFIR fuel design considers numerous uncertainty factors to capture the uncertainty in reactor process conditions, fuel manufacturing uncertainties, fuel element fabrication tolerances, and analysis/correlation uncertainties. Table 3.2.2.1 is a list of these uncertainties, together with the values that are used for HEU fuel (provided in Chapter 4 of the SAR[19]) and a preliminary value used to represent the LEU fuel and its manufacturing process uncertainties. 
Table 3.2.2.1. Uncertainty factors considered in steady state thermal analysis

\begin{tabular}{|c|c|c|c|}
\hline \multirow[b]{2}{*}{$\begin{array}{c}\text { Symbol/ } \\
\text { parameter }\end{array}$} & \\
\hline & Uncertainty variable description & Current HEU value & Current LEU value \\
\hline $\mathrm{U}_{1}$ & Uncertainty in the reactor power level & 1.00 & 1.00 \\
\hline $\mathrm{U}_{2}$ & Uncertainty in fissile loading & 1.01 & 1.01 \\
\hline $\mathrm{U}_{3}$ & Uncertainty in power distribution & 1.199 & 1.199 \\
\hline $\mathrm{U}_{4}$ & $\begin{array}{l}\text { Uncertainty in the "average" fuel } \\
\text { concentration in the hot plate }\end{array}$ & $\begin{array}{l}0.90 \text {-upper half } \\
1.12 \text {-lower half }\end{array}$ & $\begin{array}{l}\text { 1.04-upper half } \\
\text { 1.06-lower half }\end{array}$ \\
\hline $\mathrm{U}_{5}$ & $\begin{array}{l}\text { Uncertainty in the "average" fuel } \\
\text { concentration in the cold plate }\end{array}$ & $\begin{array}{l}\text { 1.10-upper half } \\
0.88 \text {-lower half }\end{array}$ & $\begin{array}{l}\text { 0.96-upper half } \\
\text { 0.94-lower half }\end{array}$ \\
\hline $\mathrm{U}_{6}$ & $\begin{array}{l}\text { Uncertainty in the inlet coolant } \\
\text { temperature }\end{array}$ & 1.00 & 1.00 \\
\hline $\mathrm{U}_{7}$ & Uncertainty in the friction factor & 1.05 & 1.05 \\
\hline $\mathrm{U}_{8}$ & $\begin{array}{l}\text { Uncertainty in the local heat transfer } \\
\text { correlation }\end{array}$ & 0.90 & 0.90 \\
\hline $\mathrm{U}_{9}$ & Uncertainty in the oxide film correlation & 1.25 & 1.25 \\
\hline $\mathrm{U}_{10}$ & $\begin{array}{l}\text { Uncertainty in the relationship for } \\
\text { deflection as a result of the differential } \\
\text { pressure across the plate }\end{array}$ & 1.10 & 1.10 \\
\hline $\mathrm{U}_{11}$ & $\begin{array}{l}\text { Uncertainty in the relationship for } \\
\text { deflection of plate being considered in } \\
\text { reference to an average plate as a result } \\
\text { of temperature differences }\end{array}$ & 1.10 & 1.10 \\
\hline $\mathrm{U}_{12}$ & $\begin{array}{l}\text { Uncertainty in the increase in the fuel } \\
\text { plate thickness as a result of thermal } \\
\text { expansion }\end{array}$ & 2.00 & 2.00 \\
\hline $\mathrm{U}_{13}$ & $\begin{array}{l}\text { Uncertainty in the increase in the fuel } \\
\text { plate thickness as a result of radiation } \\
\text { damage }\end{array}$ & 1.00 & 1.00 \\
\hline $\mathrm{U}_{14}$ & $\begin{array}{l}\text { Uncertainty in the longitudinal buckling } \\
\text { of the fuel plate as a result of the } \\
\text { temperature differences between the fuel } \\
\text { plate and the side plates }\end{array}$ & 1.00 & 1.00 \\
\hline $\mathrm{U}_{15}$ & $\begin{array}{l}\text { Uncertainty in the longitudinal buckling } \\
\text { of the fuel plate as a result of the } \\
\text { radiation damage }\end{array}$ & 1.00 & 1.00 \\
\hline $\mathrm{U}_{16}$ & $\begin{array}{l}\text { Uncertainty in the side plate heat } \\
\text { generation rate at } 100 \mathrm{MW}\end{array}$ & 1.00 & 1.00 \\
\hline $\mathrm{U}_{17}$ & $\begin{array}{l}\text { Uncertainty in the coolant heat } \\
\text { generation rate } 100 \mathrm{MW}\end{array}$ & 1.00 & 1.00 \\
\hline $\mathrm{U}_{18}$ & $\begin{array}{l}\text { Fuel segregation flux peaking on the hot } \\
\text { side of the fuel plate }\end{array}$ & 1.27 & 1.27 \\
\hline $\mathrm{U}_{19}$ & $\begin{array}{l}\text { Fuel segregation flux peaking on the } \\
\text { cold side of the fuel plate }\end{array}$ & 1.27 & 1.27 \\
\hline $\mathrm{U}_{22}$ & $\begin{array}{l}\text { Uncertainty in the Gambill burnout } \\
\text { correlation }\end{array}$ & 0.8 & 0.8 \\
\hline $\mathrm{U}_{23}$ & Uncertainty in the IB correlation & 1.00 & 1.00 \\
\hline $\mathrm{U}_{24}$ & Hot streak factor & 1.12 & 1.06 \\
\hline $\mathrm{U}_{25}$ & $\begin{array}{l}\text { Flux peaking for fuel plate extending } \\
\text { beyond normal boundaries-factor } \\
\text { applied to lower end nodes }\end{array}$ & $\begin{array}{l}\text { Ranges1.00-1.44 across } \\
\text { inner plate } \\
\text { Ranges 1.00-1.35 } \\
\text { across outer plate }\end{array}$ & $\begin{array}{l}\text { Ranges1.00-1.23 across } \\
\text { inner plate } \\
\text { Ranges } 1.00-1.25 \\
\text { across outer plate }\end{array}$ \\
\hline
\end{tabular}


Reactor process variable uncertainties $\mathrm{U}_{1}$ and $\mathrm{U}_{6}$ are set to 1.00 in the HEU and LEU analyses because the process setpoints at HFIR are controlled via formal uncertainty calculations such that the actual setpoint plus all uncertainties is less than the value used in the safety analysis.

Uncertainty in the fissile loading, $\mathrm{U}_{2}$, is based on the value used in the HEU fuel manufacturing process and calculations. This study uses the same value as a starting point for the LEU analysis. This uncertainty may be adjusted based on input from the FFC and FD pillars.

Uncertainty in the power distribution, $\mathrm{U}_{3}$, is based on a factor of 1.10 to represent uncertainty in the neutron transport (MCNP) calculations and 1.09 to represent variations in the local power density due to experiment-related flux tilts.

Uncertainty factors $U_{4}$ and $U_{5}$ are parameters used to represent fuel distribution variations along the length of the plate as measured by the fuel homogeneity scanner axial scans. The HEU fuel is made to a $\pm 12 \%$ integral accuracy along the length of each track of the fuel scans. In the thermal hydraulics model, this information is used to represent HEU fuel axial concentration variations within the overall loading tolerance for a hot plate (overloaded, with an assumed high concentration in the lower half of the plate) and an adjacent cold plate (underloaded, with an assumed low concentration in the lower half of the plate). These assumptions produce a calculated fuel deflection that creates the greatest channel narrowing around the hot plate at the core exit, where the limiting hot spot is known to occur in the hot channel. These same assumptions are currently used in the LEU analysis with a tighter integral accuracy of $\pm 6 \%$, to represent axial variations in the LEU foil thickness. Input from the GTRI FFC and FD pillars is expected to refine this first approach to axial fuel distribution uncertainties.

Uncertainty factors $\mathrm{U}_{7}$ through $\mathrm{U}_{17}$ are uncertainties related to modeling and experiment-based correlations that represent key physics effects on the fuel plate thermal hydraulics results. Currently, the $\mathrm{U}_{7}-\mathrm{U}_{17}$ values used for HEU analyses, as documented in the SAR, are used for the LEU analyses.

Uncertainty factors $U_{18}$ and $U_{19}$ represent the local heat flux effects of a fuel particle agglomeration for the $\mathrm{U}_{3} \mathrm{O}_{8} \mathrm{HEU}$ fuel, for the inner and outer fuel plates, respectively. For LEU, this uncertainty parameter is considered to represent two effects: (1) the effect of a locally high alloy concentration that may lead to an increased fission rate density (an uncertainty effect that is expected to be around 1.10), and (2) the effect of a nonbond on the LEU local heat flux. Because of the high degree of uncertainty in the LEU nonbond performance, the existing $\mathrm{U}_{18}$ value of 1.27 from the HEU analysis is used for the LEU analysis. Input from the GTRI FFC and FD pillars is expected to refine this first approach to the local combined fuel homogeneity and nonbond effects.

Uncertainty factors $\mathrm{U}_{20}$ and $\mathrm{U}_{21}$ are not included in table 3.2.2.1 because they are not input variables; these factors are hard-wired into the HSSHTC as described in Ref. 5, p. 48. . Uncertainties $U_{20}$ and $U_{21}$ are given by the third order polynomials shown below that represent the hot side $\left(\mathrm{U}_{20}\right)$ and cold side $\left(\mathrm{U}_{21}\right)$ peaking factors for a nominal involute plate in each element as a function of distance across the involute.

$$
\begin{aligned}
& \mathrm{U}_{20}=1.33687-0.35423 \mathrm{~s}+0.14503 \mathrm{~s}^{2}-0.01669 \mathrm{~s}^{3} \text { for the inner fuel element, } \\
& \mathrm{U}_{20}=1.180171-0.278079 \mathrm{~s}+0.151756 \mathrm{~s}^{2}-0.014261 \mathrm{~s}^{3} \text { for the outer fuel element, } \\
& \mathrm{U}_{21}=0.863686-0.016507 \mathrm{~s}-0.010950 \mathrm{~s}^{2}+0.0047976 \mathrm{~s}^{3} \text { for the inner fuel element, } \\
& \mathrm{U}_{21}=0.881393-0.249204 \mathrm{~s}+0.181639 \mathrm{~s}^{2}-0.033932 \mathrm{~s}^{3} \text { for the outer fuel element. }
\end{aligned}
$$


For each fuel node radial center position, the involute coordinate $S$ is calculated, and the local peaking factors are calculated. Uncertainties $U_{20}$ and $U_{21}$ are based on original calculations with an offline conduction model that considered the complex fuel plate dimensions and included the effects of offset fuel, variable fuel thickness, internal heat generation in the fuel meat, and an assumed nonbond consistent with the manufacturing specifications.

Uncertainty factors $\mathrm{U}_{22}$ and $\mathrm{U}_{23}$ represent uncertainty in the burnout and incipient boiling correlations, respectively. When the HSSHTC is run, one of these correlations is used as an iterative search criterion to find the reactor power to cause either burnout or incipient boiling (depending on the input choice) at the hot spot in the worst hot streak of the core. Currently, the $U_{22}$ and $U_{23}$ values used for HEU analyses are also used for LEU analyses.

Uncertainty factor $U_{24}$ represents the hot channel integral effect on the local heat flux of an axial track that may be overloaded, within the fuel manufacturing tolerance. For HEU fuel, the specification requires $\pm 12 \%$ as the allowable integral allowance. For LEU foils, this value is expected to be more tightly controlled than the axial distribution of $\mathrm{U}_{3} \mathrm{O}_{8}$ particles after the hot rolling process. Consequently, a value of 1.06, or $\pm 6 \%$, was used for this parameter in the LEU analysis as a first choice for this parameter. Future analysis may use a revised value based on input from the GTRI FFC pillar, and will be consistent with the LEU fuel specification.

Uncertainty factor $U_{25}$ is used to capture the uncertainty associated with the fuel element fabrication process wherein the plates are welded into the side plates at an axial location to ensure the lower end of the fuel meat is at the nominal end of the core as modeled in the analysis. The current HEU drawings and specifications allow a $\pm 1 / 4$-inch variation in the end location of the fuel meat on either end of the nominally 20 -inch long active fuel region. If a single plate were axially misaligned, its fuel could extend into the axial water-reflector flux peak region and result in a local hot spot at the end of the core. To model this effect, a $\mathrm{U}_{25}$ uncertainty distribution across the involute plate is applied to the last row of nodes in the HSSHTC model to provide additional power peaking to the lower end of the fuel. The $U_{25}$ local heat flux peaking is above that associated with the calculated local power density and its uncertainty. The $\mathrm{U}_{25}$ uncertainty distributions are not applied to the upper end of the fuel because the lower end is always the limiting location for HEU fuel. The $\mathrm{HEU} \mathrm{U}_{25}$ uncertainty distributions were based on the original nuclear analysis, which was benchmarked to flux wire measurements of axial fuel peaking beyond the nominal end of an experimental core. The basis for the original HEU $\mathrm{U}_{25}$ values was an assumed extension of the misaligned plate into the axial flux peak by $1.34 \mathrm{~cm}$, which is larger than the manufacturing tolerance for axial alignment of the plates $( \pm 0.635 \mathrm{~cm}[ \pm 0.25 \mathrm{in}])$.

For the LEU calculations, the MCNP analysis was benchmarked to the original HEU flux wire measurements [24], and then applied to the MCNP-LEU model to produce the $\mathrm{U}_{25}$ uncertainty distributions used in the LEU thermal analysis. The primary cause of the reduction in the $\mathrm{U}_{25}$ values used in the current calculations is use of the current manufacturing tolerance rather than the original analysis assumption.

\subsubsection{Use of HSSHTC to Produce Input Parameters for HFIR System Transient Analyses}

The RELAP transient analysis uses a different axial mesh for average cell and hot streak noding in the IFE and OFE than is used in the MCNP and HSSHTC modeling. Normalized power density distributions represent the power deposition in the fuel region and peaking factors are used to represent heat flux peaking due to: uncertainties in the power distribution, hot streak fuel distribution, fuel plate heated length, fuel non-bond/distribution heat flux peaking, fuel segregation uncertainty, and fuel element assembly error uncertainty. RELAP also uses a different approach for hot streak noding and hot spot noding. The existing HFIR RELAP modeling also uses a constant width hot channel, with defined hot 
spots at the entrance and exit region of the hot channels to represent channel width and hot spot location uncertainties.

The approach to establish the LEU RELAP model normalized peaking factor distributions was developed and verified using the 1965-vintage HEU $100 \mathrm{MW}$ power density distributions, which are described in Chapter 4 of the HFIR SAR[19], to replicate the existing HEU RELAP input parameters from normalized power distributions. After verification of the method to recreate the RELAP model axial peaking factors was performed, the approach was then applied to the current LEU $100 \mathrm{MW}$ power distribution to produce RELAP input for the two fuel designs considered in the transient analysis, which were the reference fuel design and the Alternate $7 \mathrm{C}$ fuel design.

The HFIR RELAP nodalization was chosen in the early 1990's based on modeling and development capabilities at that time and balanced the level of detail used to model the core region with that needed for the rest of the primary and secondary system components, control and safety systems, and transient modeling features (e.g., pipe break models). The axial discretization chosen was 2 streaks of 5 large nodes to represent the average behavior for each fuel element and 1 streak of 9 powered nodes to represent a hot streak for each element. The power densities for each of the RELAP nodes were normalized over the full 24-inch length of the plates and included an estimate of the gamma heating in the 2-inch unfueled zones at the top and bottom of the fuel. The detailed 2D, r-z energy distribution used to produce the 1-D axial RELAP power density distribution was based on discrete ordinates neutron and gamma transport analysis performed at that time. These codes and the models used to produce the results are no longer available.

The current neutron and gamma transport analysis for LEU fuel is based on MCNP 2D, Monte Carlo modeling. In order to use the existing RELAP model with the current nuclear heating models, it was necessary to create a process to average the 2D MCNP distributions over the radial dimension and then collapse the axial noding (42 axial nodes, with 38 of the nodes representing heated fuel for the HSSHTC LEU models) into the 5-node heated-length sets for the average behavior of each element and the 9-node sets for the element hot streaks. Since the nuclear heating information used in the early 90's was unavailable, we used the HFIR HEU power density profiles described in Chapter 4 of the SAR [19] from the original nuclear analysis report[25], to benchmark the process for producing the RELAP input. Figure 3.2.1 below shows a comparison of the inner element EOC relative power density versus axial position together with a comparison of the 1990-era RELAP 5-node average set and the 5-node average set based on the radial averaging followed by axial collapsing of the EOC power density set in Table 4.4-8 of the SAR. Figure 3.2.2 below shows a similar comparison of the inner element EOC 9-node hot streak sets. The normalized RELAP power density input is reproduced very well by the averaging/collapsing process, considering the fact that the nuclear heating information was generated by two different analysis methods (3-group diffusion theory in 1965 versus multigroup discrete ordinates theory in 1992). Based on evaluating both elements for BOC and EOC power density profiles, the collapsing approach was verified to produce a good replica of the RELAP input for HEU and was considered valid for preparing the LEU RELAP input power density sets from the current MCNP nuclear information. 


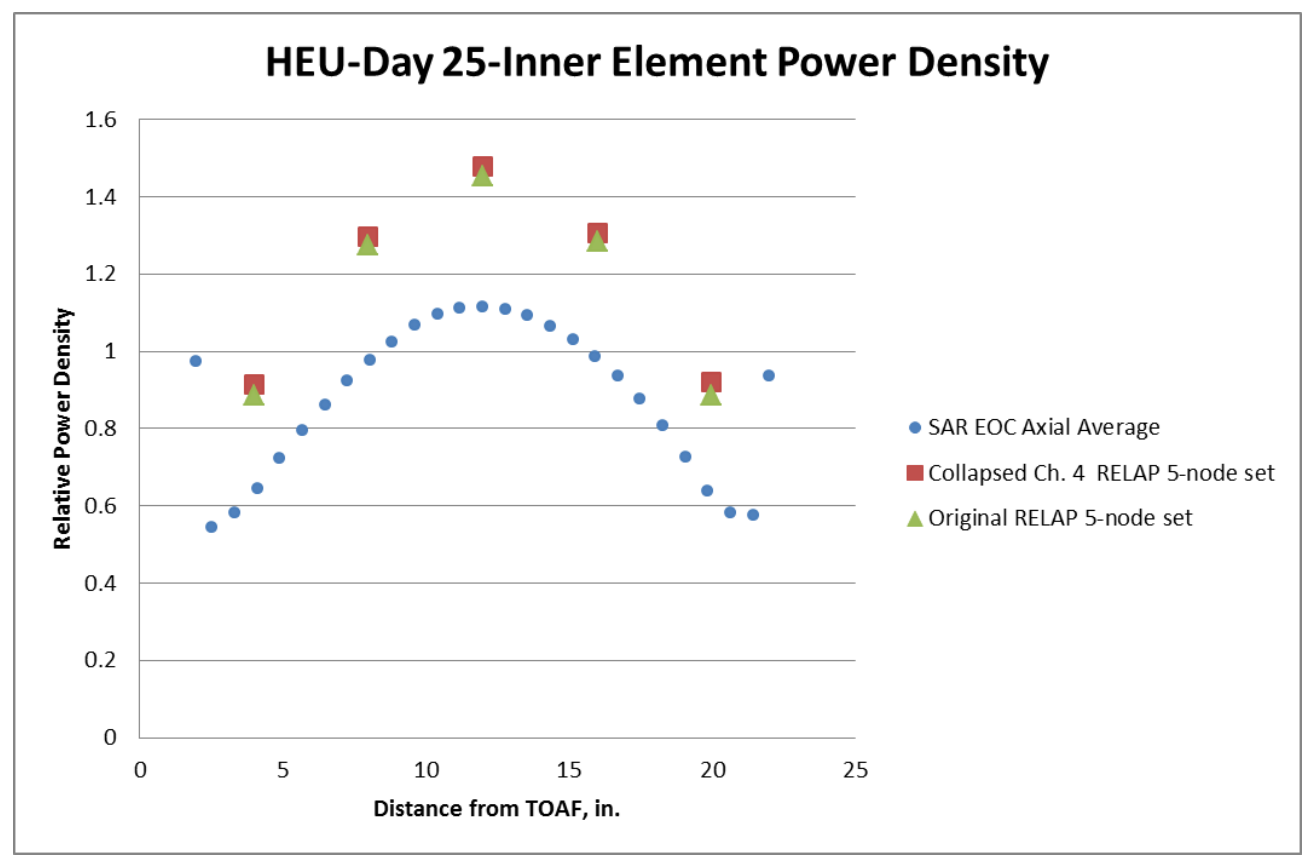

Fig. 3.2. Comparison of RELAP 5-node axial average power density sets for EOC HEU fuel using SAR Chapter 4 power density distribution.

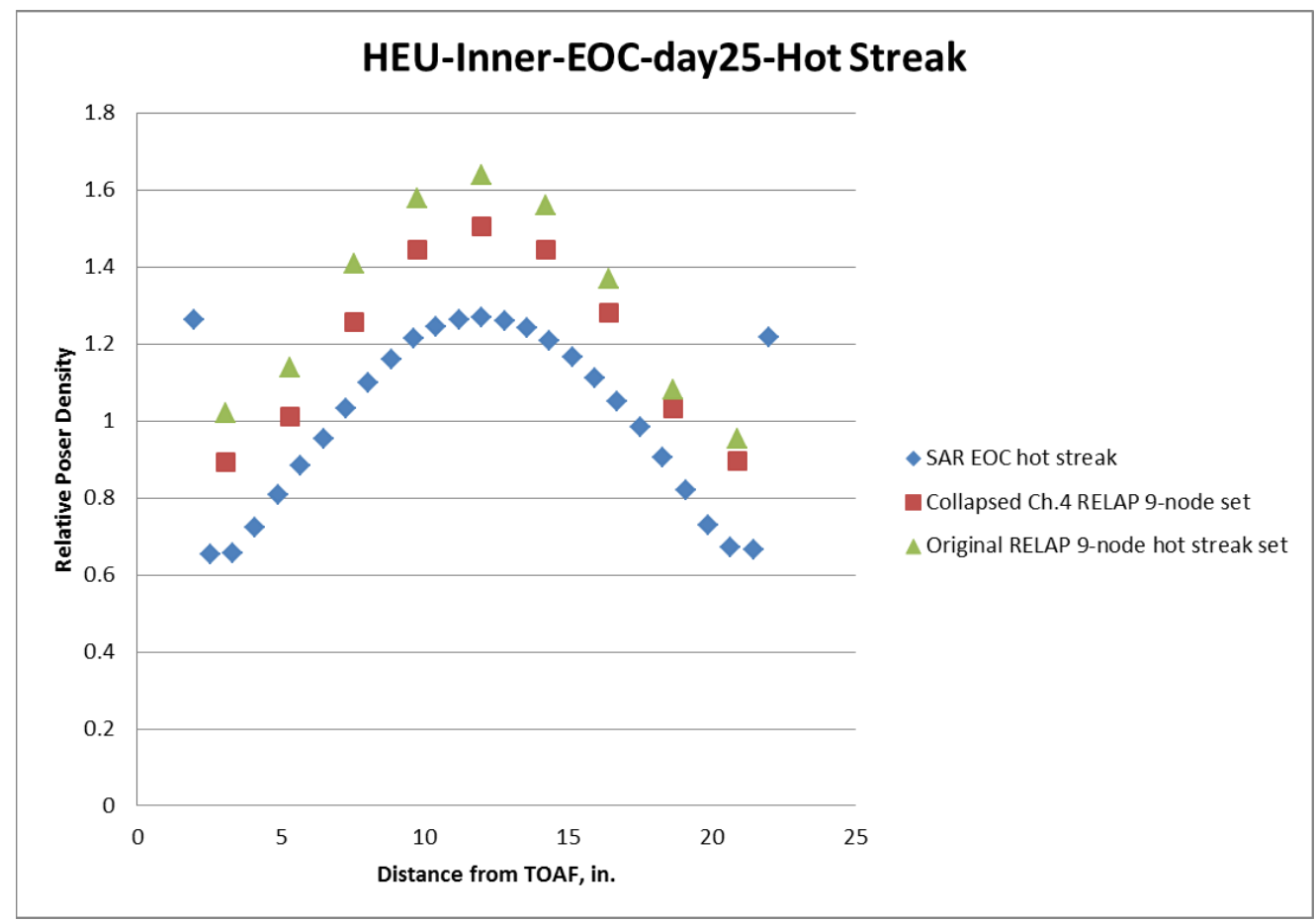

Fig. 3.2.2. Comparison of RELAP 9-node axial hot streak power density sets for EOC HEU fuel using SAR Chapter 4 power density distribution.

The hot streak for each element was determined by choosing the largest integrated MCNP power density distribution along each axial track for each LEU fuel. Once the radial hot streak was established for each element, the average hot channel width for the hot streak was found by integrating the HSSHTC- 
determined channel width vs. axial height over the appropriate axial track. The HSSHTC output at the EOC time step, at the nominal $100 \mathrm{MW}$ power, was used for the averaging so that appropriate oxide layer thickness, plate thermal expansion, and deflection effects were included in the determination of the average hot channel width.

\subsection{STEADY-STATE TH (USING COMSOL)}

Three-dimensional models of HFIR inner and outer fuel elements are developed in COMSOL Multiphysics software[7], as shown in Figs. 3.3.1 and 3.3.2. These models consider a single fuel plate and an adjacent single coolant channel, both periodically connected in the azimuthal direction to represent the full HFIR fuel element. The modeled geometry of the radially contoured fuel zone is accurate to the drawing specifications.

A unique mapped-mesh scheme with coolant boundary layers was developed to subdivide the model geometry in linear-basis finite elements. Inside the coolant channel, ten boundary layers are used with a stretching factor of 1.2 and first layer thickness of $0.005 \mathrm{~mm}$ to capture the steep gradients near the wall surface. In the longitudinal z-direction of the model, both the top and bottom two in., corresponding to the unfueled region of the fuel plate, have eight elements each and the central $20 \mathrm{in}$. of the fueled region has 40 elements, all distributed in a geometric sequence with an element ratio of four. In the radial involute direction, the model is subdivided into 60 elements with a geometric distribution and an element ratio of four. In the thickness direction, the model is discretized with ten elements of uniform distribution for the coolant channel (in addition to the boundary layers), six and three elements for the cladding on the convex and concave sides of the fuel plate, and four elements for the fuel meat. This mesh density is optimum enough to provide a solution that does not vary much by further mesh refinements (i.e., the solutions are mesh-converged).

Heat generated in the fuel zone (volumetric heat source in units of $\mathrm{kW} / \mathrm{cm}^{3}$ ) is obtained from the MCNPgenerated relative fission density distribution and is scaled appropriately for the 100-MW total power nominal operation. Steps below provide further details on the procedure to transfer power from MCNP neutronics to COMSOL thermal-hydraulics models:

i) Relative fission density distribution $f_{i}$ is defined as the number of fissions per unit volume of each homogenized fuel-bearing MCNP cell divided by the total number of fissions per unit volume of total inner and outer element cells. MCNP provides these values in a 8 x 19 (for IFE) and 9 x 19 (for OFE) matrix form, each value corresponding to an annular, homogenized fuel region of HFIR core in its radial and axial directions.

ii) Power produced in each homogenized MCNP cell $P_{i}$ is calculated from

where $V_{i}$ is the volume of $i^{\text {th }}$ MCNP cell,

$$
P_{i}[\text { in } W]=f_{i} *\left(V_{i} / V_{t}\right) * Q
$$

$V_{t}$ is the total volume of MCNP cells in both the inner and outer elements, and $Q$ is the total reactor power in Watts (i.e., $100 \mathrm{MW}$ ).

iii) For each homogenized MCNP cell, the power density (or volumetric heat source) $q^{\prime \prime \prime}$ in its fuel zone is calculated from

$$
q^{\prime \prime \prime}\left[\text { in } W / m^{3}\right]=P_{i} / V_{\text {fuel }}^{i}
$$

where $V_{f u e l}^{i}$ is the volume of the fuel zone (U-10Mo) in the fuel-bearing homogenized cell $i$. 
iv) Power density $q^{\prime \prime \prime}$ from MCNP is imported to COMSOL Multiphysics as a lookup table of radial and axial distance, i.e., as $q^{\prime \prime \prime}(r, z)$ where $r^{2}=x^{2}+y^{2}$. These discrete values are then interpolated within COMSOL using linear piecewise functions and extrapolated as constants to the corners and boundary regions. A scaling factor, $S_{f}$ is then calculated and multiplied to the power density profile, i.e., $S_{f} * q^{\prime \prime \prime}(r, z)$ to ensure that each HFIR fuel plate produces the correct total power which is known from the MCNP-produced power split between the IFE and OFE.

$$
\begin{gathered}
Q=Q_{I F E}+Q_{O F E} \\
q_{I F P}=Q_{I F E} / N p_{I F E} \\
q_{O F P}=Q_{O F E} / N p_{O F E} \\
S_{f, I F P}=\frac{q_{I F P}}{\int_{V, I F P} q^{\prime \prime \prime}(r, z) d V} \\
S_{f, O F P}=\frac{q_{O F P}}{\int_{V, O F P} q^{\prime \prime \prime}(r, z) d V}
\end{gathered}
$$

where $Q_{I F E}$ and $Q_{O F E}$ represent the power split between the inner and outer fuel elements and are obtained in step (ii) above;

$q_{I F P}$ and $q_{\text {OFP }}$ represent the total power produced in each plate of the inner and outer fuel elements and are obtained by uniformly dividing inner and outer element power in the total number of plates ( $N p_{I F E}$ in IFE and $N p_{O F E}$ in OFE); $S_{f, I F P}$ and $S_{f, O F P}$ are power scaling factor for each individual plate in the IFE and OFE and are obtained by dividing the total power produced in each plate by the volume integral of the MCNP-provided power density profile.

A power factor of $1.0628(=0.975 \times 1.09)$ is applied to the $100 \mathrm{MW}$-scaled volumetric heat source to account for the assumed 97.5\% local heat deposition inside the fuel zone ([19] in SAR Table 4.4-7) and an additional 9\% increase to consider any experimental flux tilts ([19] in SAR Sec. 4.4.3.2).

Models are solved for the steady-state nominal operating conditions of HFIR at the beginning and end of the reactor cycle; the following multiple physics were included in the analyses:

- heat conduction within the fuel plate,

- conjugate heat transfer from the fuel plate to the coolant channel,

- Reynolds averaged Navier-Stokes (k-epsilon) turbulence model for flow in the coolant channel, and

- thermal-expansion physics for the fuel plate.

The following boundary conditions are used for both the inner and outer element COMSOL models to simulate the nominal operating conditions of HFIR:

- $\quad$ inlet flow velocity in the coolant channel $=15.798 \mathrm{~m} / \mathrm{s}$ (based on combined inner and outer fuel element flow rate of $13440 \mathrm{gpm})$,

- $\quad$ outlet pressure of the coolant $=(468 \mathrm{psig}+14.7 \mathrm{psi})-108 \mathrm{psi}=374.7 \mathrm{psi}$ (saturation temperature corresponding to this outlet pressure is $225.7^{\circ} \mathrm{C}$ ),

- inlet temperature of the coolant $=120^{\circ} \mathrm{F}$,

- periodic heat condition (i.e., heat flux and temperature continuity) in the azimuthal direction applied over the domain boundaries of the single fuel plate and channel,

- thermal insulation over both the longitudinal edges of the fuel plate and channel connecting them to the element side plates, and a 
- fixed constraint structural boundary condition over both the longitudinal edges of the fuel plate connecting it to the element side plates.

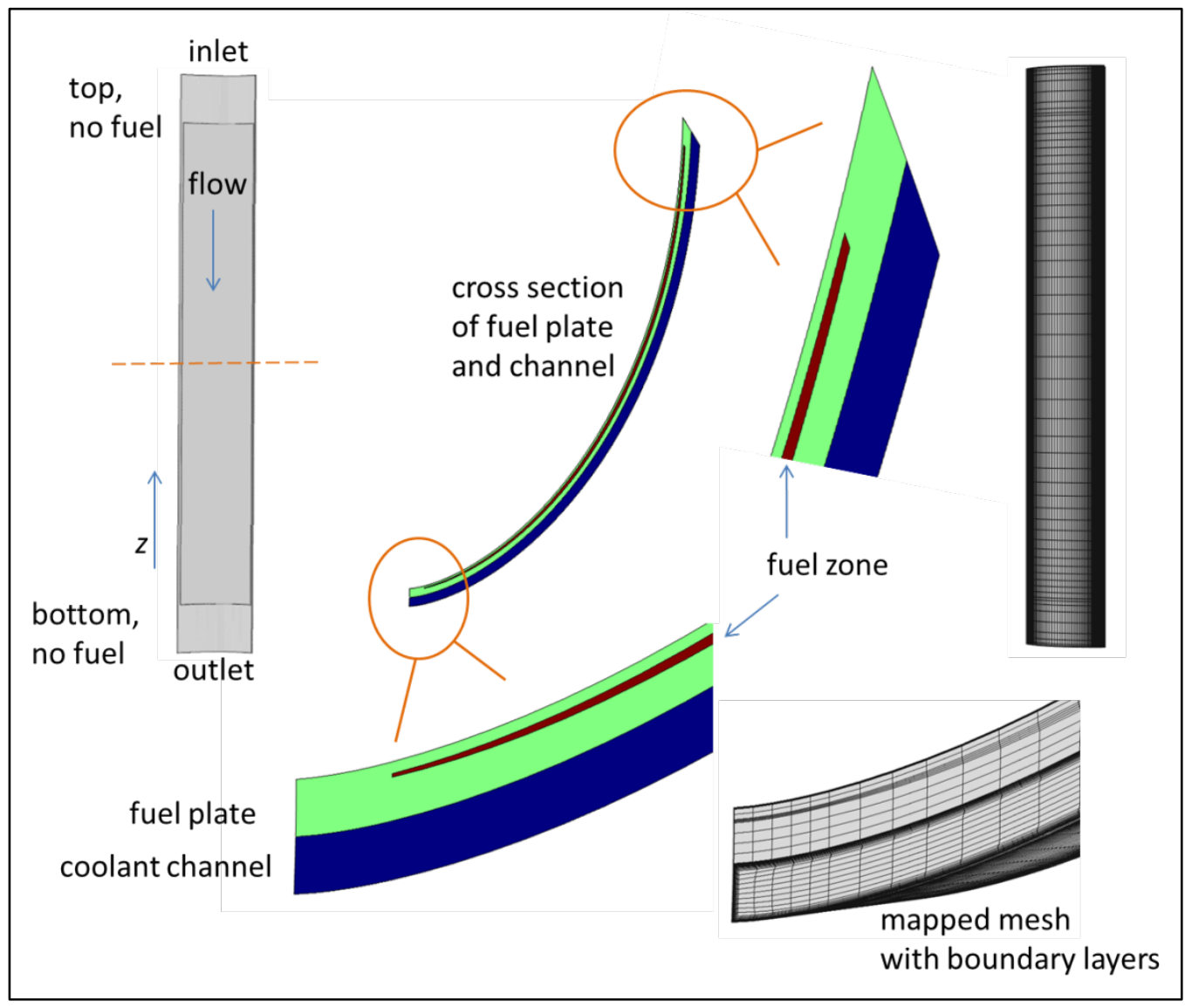

Fig. 3.3.1. Typical COMSOL model geometry and mapped mesh with boundary layers for HFIR LEU analyses. 
In the COMSOL model, all the field variables, including velocity $(u, v, w)$, pressure $(p)$, turbulent kinetic energy $(k)$, turbulent dissipation rate $(e)$, and temperature $(T)$ are input and described by first-order, linear finite elements. Note that the thermal effects of oxide growth on the plate surface are not yet included in these models.

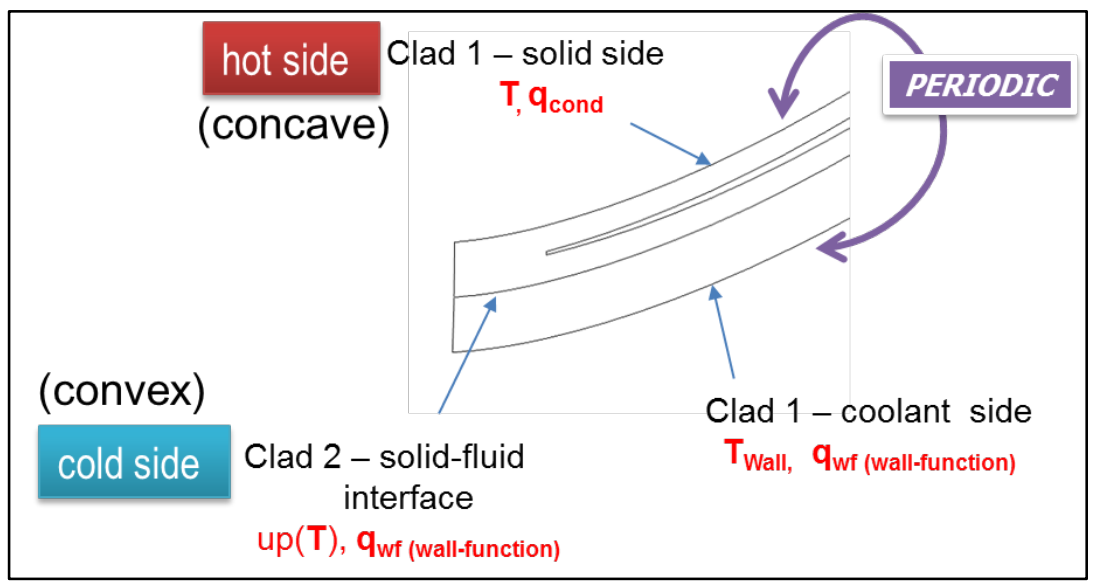

(a) Inner fuel plate and channel

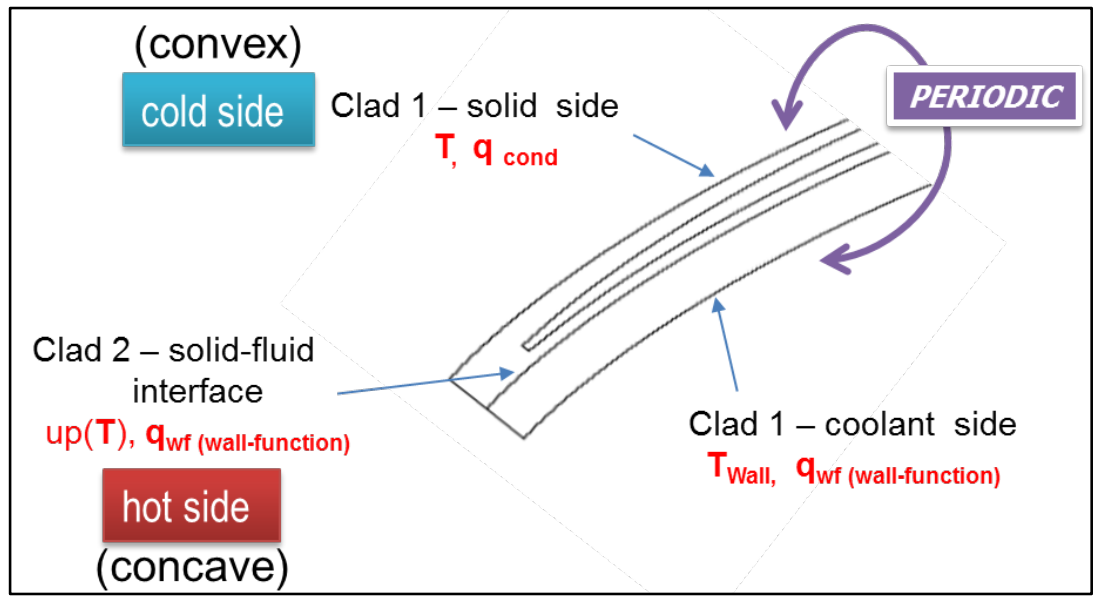

(b) Outer fuel plate and channel

Fig. 3.3.2. COMSOL model for the HFIR inner and outer elements. [COMSOL variables of interest are domain temperature ( $T)$, conductive heat flux (dfluxMag), wall temperature (Twall) and thermal wall function heat flux (qwf).]

\subsection{TRANSIENT TH WITH SAFETY CASE ASSUMPTIONS (USING RELAP)}

The RELAP transient analyses in this document were performed with the HFIR-specific version of RELAP5/MOD2.5 Version 3t which includes HFIR-specific point kinetics modifications. The RELAP5 code has been used at HFIR for the past 20+ years and is ideally suited for performing transient thermal/hydraulic analyses of reactor systems such as HFIR. The steady-state RELAP5 Consolidated HFIR Model documented in ORNL/RRD/INT-154[6] was revised to model LEU fuel with a reactor power level of $100 \mathrm{MW}$. Specific changes include (1) updating the reactor power level from $85 \mathrm{MW}$ to 100 MW and rescaling the flux-to-flow reactor scram setpoint, (2) updating the normalized decay heat curve corresponding to that calculated for the LEU fuel with the ANSI/ANS-5.1-2005 standard and the MCNP code as discussed in Section 3.1.3, (3) updating the fuel composition with revised material 
properties and adding a 1-mil layer of zirconium between the fuel and cladding, (4) changing the hot channel gap widths of the inner and outer fuel elements for each LEU fuel design evaluated with data obtained from HSSHTC, and (5) changing the internal source multipliers for each LEU fuel design evaluated with data obtained from both MCNP and HSSHTC.

Several different types of transients are evaluated in Chapter 15 of the HFIR Safety Analysis Report (SAR)[19]. These include transients that present a challenge to the reactor vessel in regard to brittle fracture of the nozzle regions or over-pressurization of the primary coolant system or present a challenge to the thermal limits of the fuel. Still others are concerned with radiological releases from various postulated spills. The specific design of the fuel is a major consideration only for those transients that challenge the thermal limits of the fuel. Thus, only this type of transient will be examined in this report.

Within the group of transients that challenge the thermal limits of the fuel, two events have been chosen for evaluation of the acceptability of two LEU fuel designs: (1) small-break loss-of-coolant accident (SBLOCA) and (2) loss of offsite AC power (LOOP). Although several additional transients are evaluated in the SAR where thermal margin is a concern, these two transients present the most severe challenge to the thermal limits of the fuel. In addition, the LOOP transient represents the bounding moderate-frequency event for the HEU fuel, while the SBLOCA transient represents the bounding infrequent event for the HEU fuel. If the SBLOCA and LOOP transients for the LEU fuel designs meet the appropriate acceptance criteria, then it can be concluded that (1) the acceptance criteria for all other transients evaluated in the SAR that challenge the thermal limits of the fuel most likely will be met and (2) the robustness of the proposed LEU fuel design is most likely acceptable with respect to the thermal limits. While it is possible that other transients could be bounding for the LEU fuel, these two events have been chosen as screening tools until more complete transient analyses are performed for the candidate LEU fuel design.

The SBLOCA transient is for the worst location (cold leg near the pressurization line connection) discussed in SAR Section 15.3.6.2[19] and also documented in RRD calculation C-HFIR-2007057/R1[20]. This transient is the bounding infrequent event for the "Decrease in Primary Inventory" category of events and must meet the following acceptance criteria outlined in SAR Section 15.3.0.1.5.

Acceptance Criteria for Infrequent Events That Challenge the Core Thermal Margin:

The accident results are acceptable if core damage is limited to damage at the hot channel only, provided that the radiological consequences are well below 10 CFR 100 guidelines conservatively interpreted as off-site total effective dose equivalents (i.e., $\leq 2.5 \mathrm{rem}$ ).

The LOOP transient is discussed in SAR Section 15.3.3.1 and is also based on analyses documented in CHFIR-2007-057/R1. This transient is the bounding moderate frequency event for the "Decrease in Primary System Flow Rate" category of events and must meet the following acceptance criteria outlined in SAR Section 15.3.0.1.5.

Acceptance Criteria for Moderate Frequency Events That Challenge the Core Thermal Margin: During normal primary flow rate conditions, i.e., the primary coolant pump ac motors are operating, the accident results are acceptable if the hot spot heat flux remains below both the Costa flow excursion heat flux and the Gambill critical heat flux (see Section 15.3.0.1.4.5) for the thermal-hydraulic conditions associated with the accident. During low primary flow rate conditions, i.e., the pony motors are operating, the accident results are acceptable if the maximum fraction of incipient boiling heat flux (MFIBHF) for both the Bergles-Rohsenow/Dittus-Boelter and Bergles-Rohsenow/Hausen correlations remains below 1.0 . 
For the acceptance criteria stated above, the most limiting location (hot spot) in the hot channel of both the inner and outer elements must be determined and then the appropriate acceptance criteria applied to this location. Fig. 3.4.1 below is taken from the HFIR Consolidated Model documentation, INT-154[6]. Both the inner fuel element hot channel (Component 10) and the outer fuel element hot channel (Component 16) are circled below and are divided into eleven nodes, with Node-01 at the very top of the fuel and Node-11 at the very bottom of the fuel. For the current HEU fuel design, the hot spot for both elements is located at the very bottom of the fuel in Node-11. The hot spot locations for the LEU fuel designs will be determined and discussed in later sections of this report.

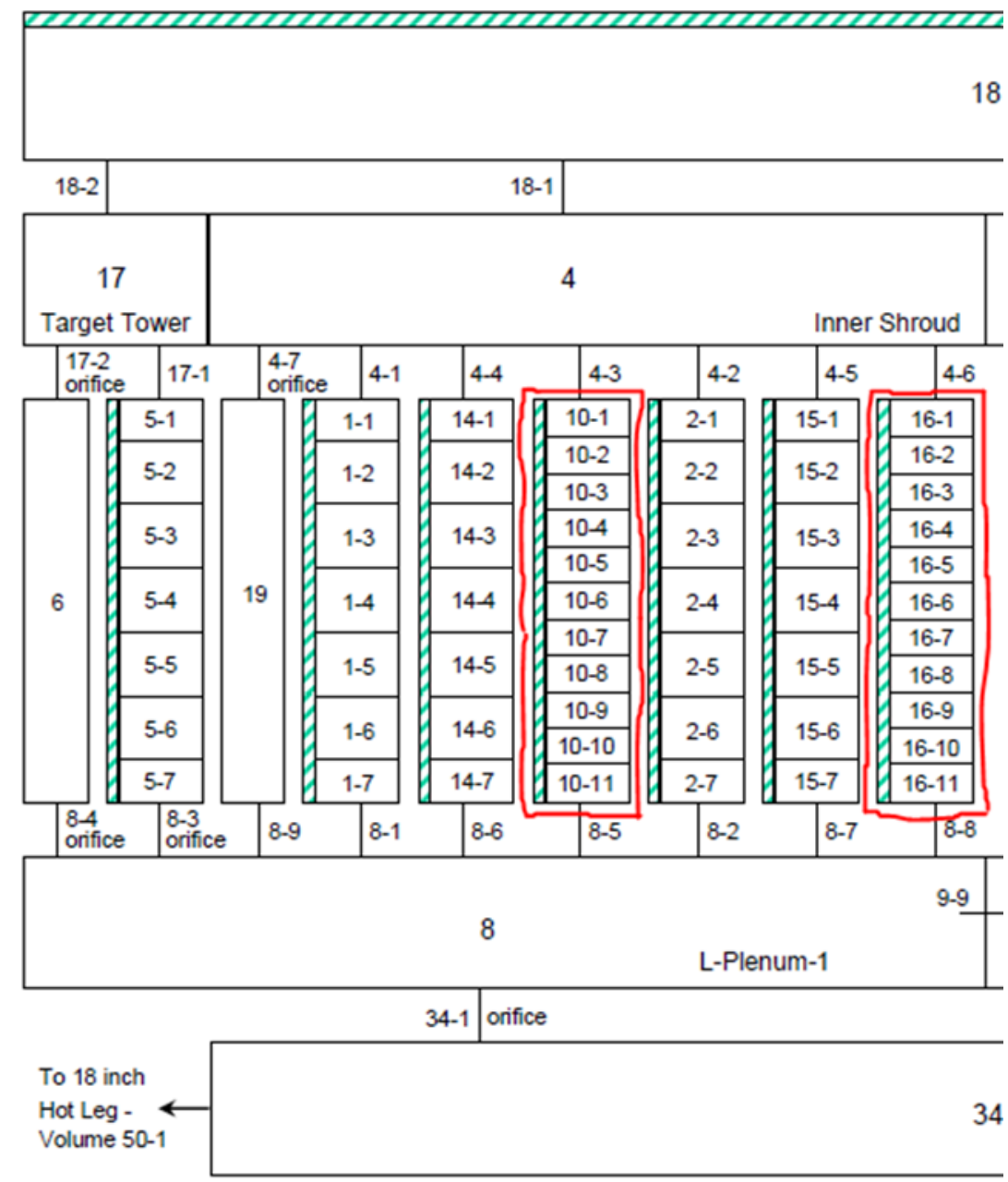

Fig. 3.4.1. RELAP5 noding diagram of HFIR core region (taken from INT-154).

Both of the transients evaluated herein are based upon worst-case initial operating conditions for that specific transient. The initial operating conditions and assumptions used for the SBLOCA and the LOOP transients can be found in C-HFIR-2007-057/R1[20]. It is noted that the analyses documented in CHFIR-2007-057/R1 assumed a reactor power of 85 MW, (87.6 MW, including instrument uncertainty), while the analyses documented in this report assume a reactor power of $100 \mathrm{MW}$, (103 MW, including instrument uncertainty). All other assumptions remain unchanged from C-HFIR-2007-057/R1. 
ORNL/TM-2014/154

\section{EVALUATION OF REFERENCE LEU FUEL DESIGN (ORNL/TM-2010/318)}

\subsection{NEUTRONICS}

Although the LEU reference model has been discussed in detail in [2] and other reports and presentations since 2011, relevant data are also shown here for completeness, for those metrics that are presented for the alternate designs, and to facilitate a relative comparison among the designs studied.

The BOC and EOC (at 26d) relative fission density data are illustrated, as surface plots, in Fig. 4.1.1 and listed in Tables 4.1.1 and 4.1.2. The maximum value for the relative fission density at BOC and EOC is 1.560 and 1.502, respectively. Both of these "hot spots" are located in the uppermost axial region (i.e., at the coolant inlet) of the IFE.

Fission rate density profiles, at BOC and EOC, for select axial regions (core horizontal midplane, upper edge of the active fuel region, lower edge of the active fuel region, and average over active fuel height) are shown in Fig. 4.1.2 as a function of the radial distance from the longitudinal centerline of the core. A similar plot, illustrating the fission rate density profiles for select radial regions (innermost, outermost, and central radial meshes) in the IFE and OFE is provided in Fig. 4.1.3 as a function of the axial distance from the core horizontal midplane.

Maximum local fission rate densities of $2.26 \times 10^{15}$ and $1.40 \times 10^{15}$ fissions/ ( $\mathrm{cm}^{3} \mathrm{U}-10 \mathrm{Mo} \bullet \mathrm{s}$ ) were calculated for the BOC and EOC cores, respectively; both of these maxima are located at the inner radial edge of the IFE on the core horizontal midplane. Assuming conservatively that $100 \%$ of the total reactor power (100 MW) is deposited in the fuel meat, these maximum fission rate densities would correspond to power densities of $\sim 72.40$ and $45.30 \mathrm{~kW} /\left(\mathrm{cm}^{3} \mathrm{UMo}\right)$, respectively.

There are $5.40 \mathrm{~g}{ }^{10} \mathrm{~B}$ in the IFE fuel plates at BOC. Approximately $70 \%$ of this burnable absorber is consumed during the $26 \mathrm{~d}$ reactor cycle.

The minimum and maximum calculated local burnups, in terms of percent ${ }^{235} \mathrm{U}$ removed during the irradiation cycle, compared to the content at BOC, are $4.9 \%$ and $58.5 \%$, respectively. The maximum burnup occurs at the innermost edge of the IFE, at the core midline. Approximately $12.7 \%$ of the initial ${ }^{235} \mathrm{U}$ is consumed during the cycle, with $22.05 \mathrm{~kg}$ remaining in the core at EOC. 

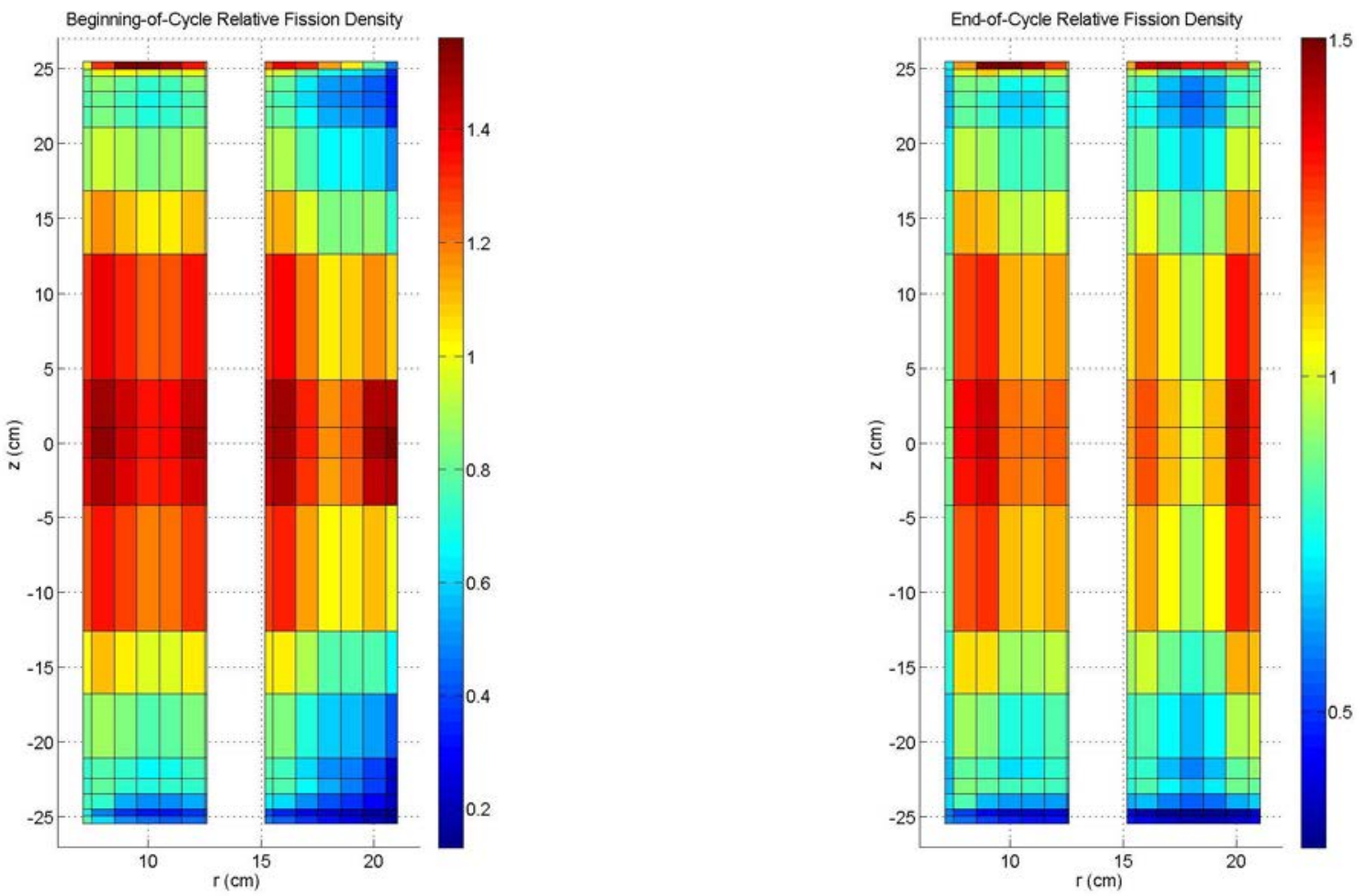

Fig. 4.1.1. Relative fission density for LEU reference design at BOC (left) and EOC (right). 
Table 4.1.1 Relative fission densities for LEU reference design at BOC.

\begin{tabular}{|c|c|c|c|c|c|c|c|c|c|c|c|c|c|c|c|c|c|}
\hline & \multicolumn{8}{|c|}{ IFE } & \multicolumn{9}{|c|}{ OFE } \\
\hline & $\mathbf{r}=\mathbf{1}^{a}$ & $r=2$ & $r=3$ & $r=4$ & $r=5$ & $r=6$ & $r=7$ & $r=8$ & $r=1$ & $r=2$ & $r=3$ & $r=4$ & $r=5$ & $r=6$ & $r=7$ & $r=8$ & $r=9$ \\
\hline 1 & 0.998 & ) & ) & 9 & 3 & 1 & 8 & 1.144 & 5 & 33 & 89 & 328 & 155 & 38 & 791 & 469 & 350 \\
\hline 2 & & 3 & & 8 & & 0 & 2 & & & & 52 & 97 & 76 & 31 & 35 & & 297 \\
\hline 3 & & 46 & 98 & 3 & 39 & 25 & 36 & 353 & 384 & 857 & 795 & 634 & 529 & & & & \\
\hline 4 & 59 & 0. & 0.743 & 0.681 & 0.693 & 0.777 & 0.777 & 0.791 & 0.815 & 797 & 755 & 611 & 509 & 87 & 432 & 16 & .259 \\
\hline 5 & & & 771 & 1 & & & & & & & & & & & & & \\
\hline 6 & 0.890 & 0.954 & 0.901 & 0.839 & 0.852 & 0.911 & 0.866 & 0.877 & 0.904 & 05 & 11 & 77 & 61 & 99 & 9 & 1 & 11 \\
\hline 7 & & 62 & 101 & 1.029 & 1.045 & 1.11 & 1.051 & 1.065 & 092 & 00 & 120 & & 34 & 0 & & & 0.6 \\
\hline 8 & 1.299 & 1.395 & 1.324 & 1.239 & 1.261 & 1.344 & 1.272 & 1.288 & 1.321 & 1.331 & 1.366 & 1.192 & 1.043 & 1.076 & 67 & 73 & 0.9 \\
\hline 9 & & & 434 & $1.3^{3}$ & 1.371 & 1.463 & & 9 & & & 96 & & 69 & & & & \\
\hline 10 & 3 & 8 & 1.440 & 1.351 & 1.378 & 1.471 & 1.3 & 1.410 & 1.458 & 77 & 1.504 & 6 & 179 & 6 & & & 396 \\
\hline 11 & & & & 1.331 & 1.356 & 1.447 & 1.369 & 1.386 & 1.430 & 1.441 & 1.480 & 1.303 & 1.157 & 239 & .470 & & 1.354 \\
\hline 1 & 57 & 1.349 & 1.281 & 1.200 & 1.220 & 1.298 & 1.229 & 1.244 & 1.278 & 1.286 & 1.318 & 148 & 1.002 & .030 & 101 & 98 & .870 \\
\hline 1 & & & 1.035 & 0.962 & 0.977 & 1.040 & 0.985 & 0.998 & 1.021 & 1.026 & 1.044 & 0.901 & 0.775 & 0.772 & & & 0.554 \\
\hline 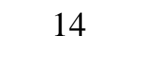 & 0.829 & 0.882 & 0.826 & 0.766 & 0.779 & 0.838 & 0.802 & 0.814 & 0.836 & 34 & 833 & 3 & 594 & 575 & 528 & 0 & 37 \\
\hline 15 & 0.725 & 0.770 & 0.715 & 0.666 & 0.681 & 0.753 & 0.741 & 0.756 & 0.782 & 0.769 & 0.743 & 0.609 & 0.505 & 469 & 82 & & .185 \\
\hline 10 & 0.713 & 0.780 & 0.714 & 0.702 & 0.716 & 0.732 & 0.690 & 0.697 & 0.724 & 0.751 & 0.765 & 0.646 & 0.539 & 0.488 & 0.381 & 229 & 163 \\
\hline 17 & & 0.718 & 0.537 & 0.508 & 0.506 & 0.553 & 0.549 & 0.531 & 0.546 & 0.639 & 0.604 & 0.496 & 0.419 & 0.365 & 0.296 & 13 & 0.137 \\
\hline & & 0.481 & 0.370 & 0.328 & 0.320 & 0.361 & 0.433 & 0.449 & 0.451 & 0.414 & 0.338 & 0.276 & 0.236 & 0.201 & 0.166 & 0.140 & 0.131 \\
\hline 19 & 0.774 & 0.607 & 0.498 & 0.448 & 0.431 & 0.450 & 0.501 & 0.511 & 0.516 & 0.485 & 0.422 & 0.361 & 0.313 & 0.265 & 0.212 & 0.168 & 0.153 \\
\hline
\end{tabular}

${ }^{a} \mathrm{r}=\mathrm{n}$ denotes the radial region number; $\mathrm{n}$ varies from 1 to 8 for the IFE and from 1 to 9 for the OFE. 
ORNL/TM-2014/154

Table 4.1.2. Relative fission densities for LEU reference design at EOC (26d)

\begin{tabular}{|c|c|c|c|c|c|c|c|c|c|c|c|c|c|c|c|c|c|}
\hline & \multicolumn{8}{|c|}{ IFE } & \multicolumn{9}{|c|}{ OFE } \\
\hline & $\mathrm{r}=1^{a}$ & $\mathrm{r}=2$ & $r=3$ & $r=4$ & $r=5$ & $r=6$ & $\mathrm{r}=7$ & $r=8$ & $\mathrm{r}=1$ & $r=2$ & $r=3$ & $\mathrm{r}=4$ & $\mathrm{r}=5$ & $\mathrm{r}=6$ & $\mathrm{r}=7$ & $\mathrm{r}=8$ & $\mathrm{r}=9$ \\
\hline 1 & 0 . & 1. & 1.502 & 1.502 & 1.441 & 1.276 & .024 & 1.032 & 1.098 & 1.136 & 1.394 & 1.416 & 1.316 & 1.325 & 1.247 & .949 & 0.792 \\
\hline 2 & 0.698 & 1.004 & 1.090 & 0.991 & 0.968 & 0.989 & 0.892 & 0.916 & 0.962 & 0.949 & 0.979 & 0.858 & 0.771 & 0.809 & 0.902 & 0.843 & 0.755 \\
\hline 3 & 0.668 & 0.888 & 0.868 & 0.753 & 0.752 & 0.832 & 0.794 & 0.820 & 0.852 & 0.826 & 0.803 & 0.665 & 0.589 & 0.639 & 0.793 & 0.818 & 0.752 \\
\hline 4 & 0.657 & 0.847 & 0.794 & 0.682 & 0.689 & 0.771 & 0.737 & 0.767 & 0.793 & 0.764 & 0.752 & 0.629 & 0.560 & 0.618 & 0.793 & 0.844 & 0.782 \\
\hline 5 & 0.671 & 0.862 & 0.812 & 0.704 & 0.707 & 0.773 & 0.727 & 0.755 & 0.780 & 0.753 & 0.767 & 0.659 & 0.590 & 0.652 & .844 & 97 & 0.831 \\
\hline 6 & 0.726 & 0.964 & 0.930 & 0.812 & 0.812 & 0.861 & 0.793 & 0.829 & 0.854 & 0.825 & 0.867 & 0.766 & 0.689 & 0.764 & 0.979 & 1.011 & 0.930 \\
\hline 7 & 0.808 & 1.126 & 1.116 & 0.970 & 0.964 & 1.008 & 0.916 & 0.96 & 0.993 & 0.956 & 1.022 & 0.909 & 0 . & 0.910 & 1.156 & 37 & 1.024 \\
\hline 8 & 0.866 & 1.275 & 1.303 & 1.131 & 1.120 & 1.160 & 1.041 & 1.106 & 1.137 & 1.087 & 1.177 & 1.051 & 0.947 & 1.054 & 1.330 & 1.251 & 1.107 \\
\hline 9 & 0.882 & 1.334 & 1.390 & 1.207 & 1.193 & 1.233 & 1.101 & 1.170 & 1.202 & 1.146 & 1.250 & 1.115 & 1.006 & 1.122 & 1.408 & 1.301 & 1. \\
\hline 10 & 0.884 & 1.342 & 1.401 & 1.214 & 1.201 & 1.237 & 1.101 & 1.171 & 1.203 & 1.151 & 1.256 & 1.121 & 1.011 & 1.124 & 1.414 & 1.302 & 1.147 \\
\hline 1 & 0.879 & 1.328 & 1.385 & 1.203 & 1.188 & 1.224 & 1.095 & 1.164 & 1.196 & 1.142 & 1.244 & 1.112 & 1.002 & 1.116 & 1.402 & 1.295 & 1.141 \\
\hline 12 & 0.851 & 1.252 & 1.280 & 1.113 & 1.101 & 1.140 & 1.023 & 1.086 & 1.117 & 1.067 & 1.156 & 1.034 & 0.931 & 1.037 & 1.309 & 1.234 & 1.093 \\
\hline 1 & 0.783 & 1.087 & 1.077 & 0.937 & 0.933 & 0.974 & 0.886 & 0.934 & 0.961 & 0.923 & 0.986 & 0.877 & 0.792 & 0.881 & 1.126 & 1.113 & 1.003 \\
\hline 14 & 0.707 & 0.931 & 0.891 & 0.775 & 0.776 & 0.829 & 0.769 & 0.807 & 0.832 & 0.803 & 0.835 & 0.732 & 0.658 & 0.733 & 0.952 & 0.993 & 0.914 \\
\hline 15 & 0.664 & 0.854 & 0.811 & 0.708 & 0.716 & 0.793 & 0.759 & 0.789 & 0.814 & 0.785 & 0.790 & 0.669 & 0.598 & 0.661 & 0.858 & 0.912 & 0.846 \\
\hline 16 & 0.668 & 0.896 & 0.855 & 0.809 & 0.816 & 0.812 & 0.721 & 0.734 & 0.756 & 0.776 & 0.841 & 0.746 & 0.671 & 0.723 & 0.864 & 0.849 & 0.728 \\
\hline 17 & 0.695 & 0.827 & 0.670 & 0.632 & 0.619 & 0.634 & 0.580 & 0.562 & 0.557 & 0.653 & 0.665 & 0.592 & 0.548 & 0.563 & 0.637 & 0.690 & 0.530 \\
\hline 18 & 0.584 & 0.513 & 0.434 & 0.392 & 0.379 & 0.402 & 0.442 & 0.458 & 0.435 & 0.403 & 0.351 & 0.314 & 0.298 & 0.298 & 0.326 & 0.386 & 0.432 \\
\hline 19 & 0.609 & 0.563 & 0.506 & 0.473 & 0.455 & 0.462 & 0.484 & 0.492 & 0.474 & 0.450 & 0.415 & 0.388 & 0.372 & 0.368 & 0.381 & 0.414 & 0.441 \\
\hline
\end{tabular}

${ }^{a} \mathrm{r}=\mathrm{n}$ denotes the radial region number; $\mathrm{n}$ varies from 1 to 8 for the IFE and from 1 to 9 for the OFE. 

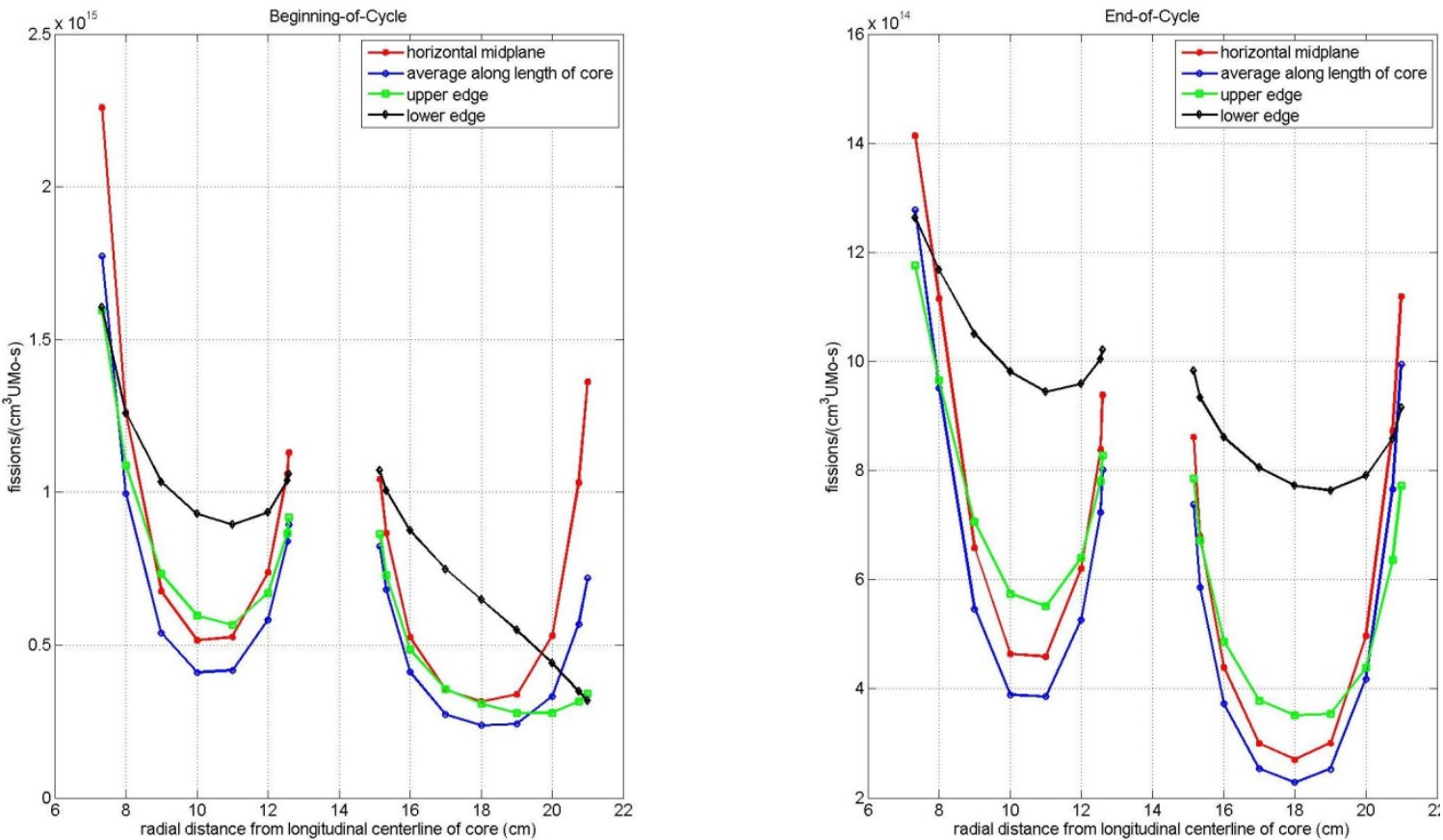

Fig. 4.1.2. Radial distribution of fission rate densities for LEU reference design.
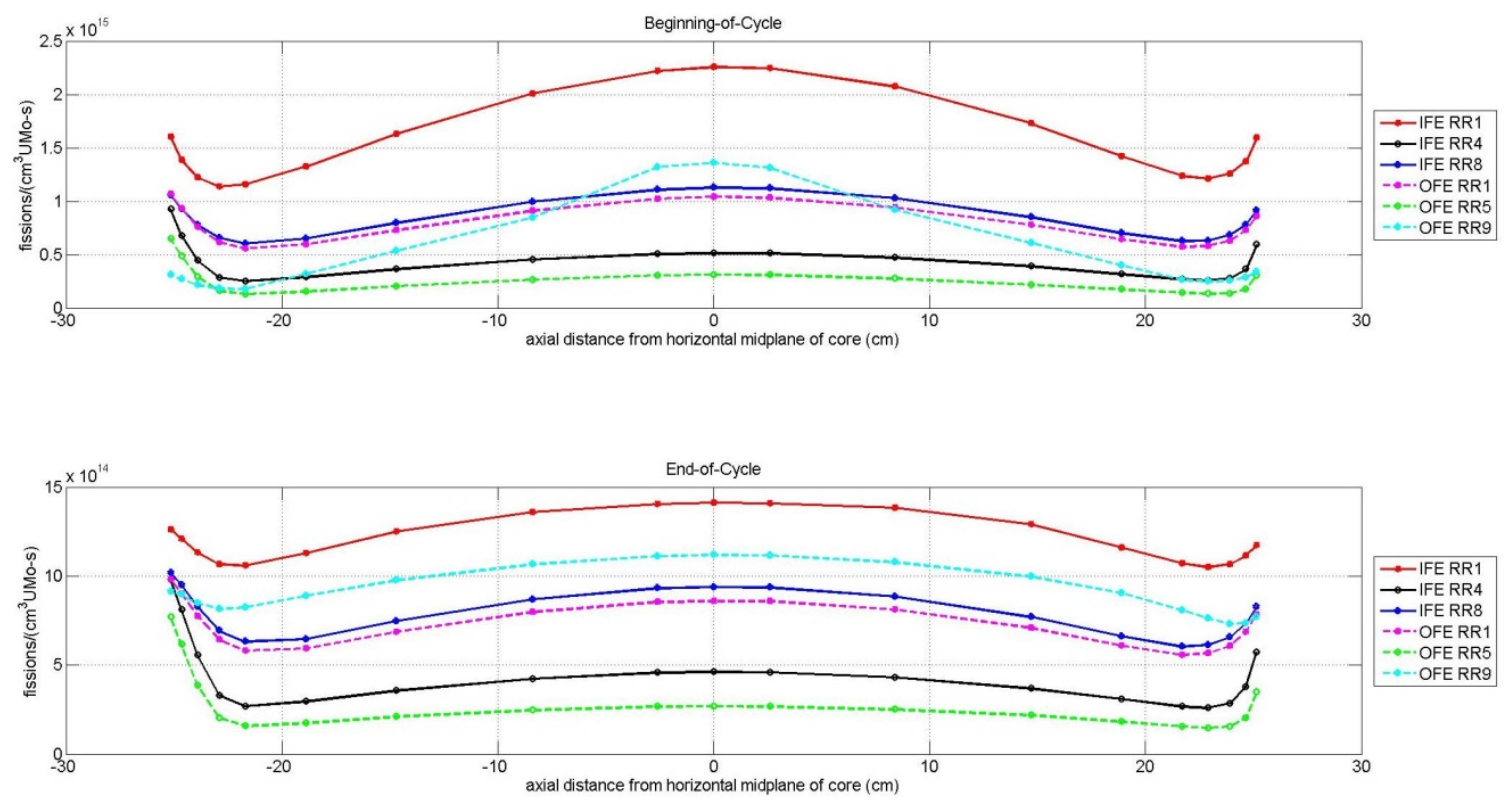

Fig. 4.1.3. Axial distribution of fission rate densities for LEU reference design. 


\subsection{STEADY-STATE TH WITH SAFETY CASE ASSUMPTIONS (USING HSSHTC)}

The safety design criteria provided in the HFIR SAR Section 4.4, "Thermal and Hydraulic Design," establish a bounding approach for calculating the reactor safety system settings, SLs, and LCSs for the key process variables of reactor power, primary coolant flow, core inlet coolant pressure, and core inlet coolant temperature. For the HFIR, the reactor safety system limits on core thermal power and primary coolant flow are coupled into the flux-to-flow ratio, which is the ratio of percent of full power divided by the percent of full primary coolant flow.

In Section 4.4 of the HFIR SAR, a very conservative steady-state design point is established so that the fuel can survive in terms of no hot spot burnout when operated at a combination of any process variable at its SL, all the other process variables at their LCSs, and all known uncertainties in manufacturing tolerances, technical knowledge of the fuel performance, and technical knowledge of applicable thermal hydraulics processes resolved unfavorably. In this manner, all nominal steady state operations are bounded with a wide safety margin so that the consequences of transients that must be considered in the accident analysis are likely to be acceptable when they are mitigated with credited safety system actions based on these LCSs and SLs.

In order to perform a scoping study for the reference LEU fuel design and the various alternatives, the existing HEU safety design criteria and thermal hydraulics analysis approach were used as a method to evaluate the alternatives. Success of a fuel alternative was measured by requiring a minimum margin of safety equivalent to the current HEU fuel. Performance of one alternative versus another was judged by comparing the safety margin versus time in the fuel cycle of the alternatives against each other and against the HEU existing SL for the flux-to-flow ratio. The basis for the existing set of SLs and LCSs is provided in Ref. 26.

To perform the analysis, the HSSHTC was run with best-estimate uncertainty factors as described in Table 3.2.2.1 of Section 3.2.2, with key process variable inputs that would allow choice of a flux-to-flow ratio SL for LEU fuel similar to the analysis used in Chapter 4 of the SAR to determine the core SLs for HEU fuel. For this study, only the full power, full flow combination of power and flow is evaluated to limit the number of calculations that must be done and to focus this report on fuel alternatives rather than on SAR analyses for a particular fuel design. For all the fuel designs, the core inlet temperature was set at the current LCS value of $135 \mathrm{~F}$ and core inlet pressure was set at the current LCS value of 350 psia. With this input, the code searches for the power that produces hot-spot + hot-streak burnout conditions based on the Gambill additive burnout correlation and then outputs the results.

The LEU fuel full power is $100 \mathrm{MW}$, so the HSSHTC safety case output power divided by 100 would be an upper limit on the allowable SL for the flux-to-flow ratio parameter governed by the HFIR TSRs. The existing full power flux-to-flow ratio SL for HEU fuel is 1.36, so any LEU case that results in a burnout power over $136 \mathrm{MW}$ gives more margin than the current HFIR safety basis for the flux-to-flow ratio SL and is deemed an acceptable LEU fuel design case. Future studies with the final fuel design will evaluate low flow safety case studies to cover the full flux-to-flow ratio range and, for the high end of the flow range, will examine success criteria that pertain to parallel channel flow instability as a surrogate for fuel damage rather than hot spot burnout.

Figure 4.2.1 shows the LEU reference fuel cycle in terms of hot spot burnout power versus time in the cycle. For the reference fuel, which is axially contoured, the core is driven by the power profiles as given in the reference fuel design report. As shown in Fig. 4.2.1, this case is well above the SL for the entire cycle, with the BOC burnout power being about $153 \mathrm{MW}$. The minimum calculated burnout power of 146.5 MW occurs in the outer element at day 3 at radial node $18(\mathrm{r}=20.74 \mathrm{~cm})$ and axial node $26(\mathrm{z}=$ $33.90 \mathrm{~cm})$. The data points in the plot are HSSHTC-calculated hot spot burnout values for the hot plate in 
the core assumed to be suddenly increased in power at the given time in the cycle, with the fuel oxide layer calculated based on nominal reactor power operation up to that point in the cycle.

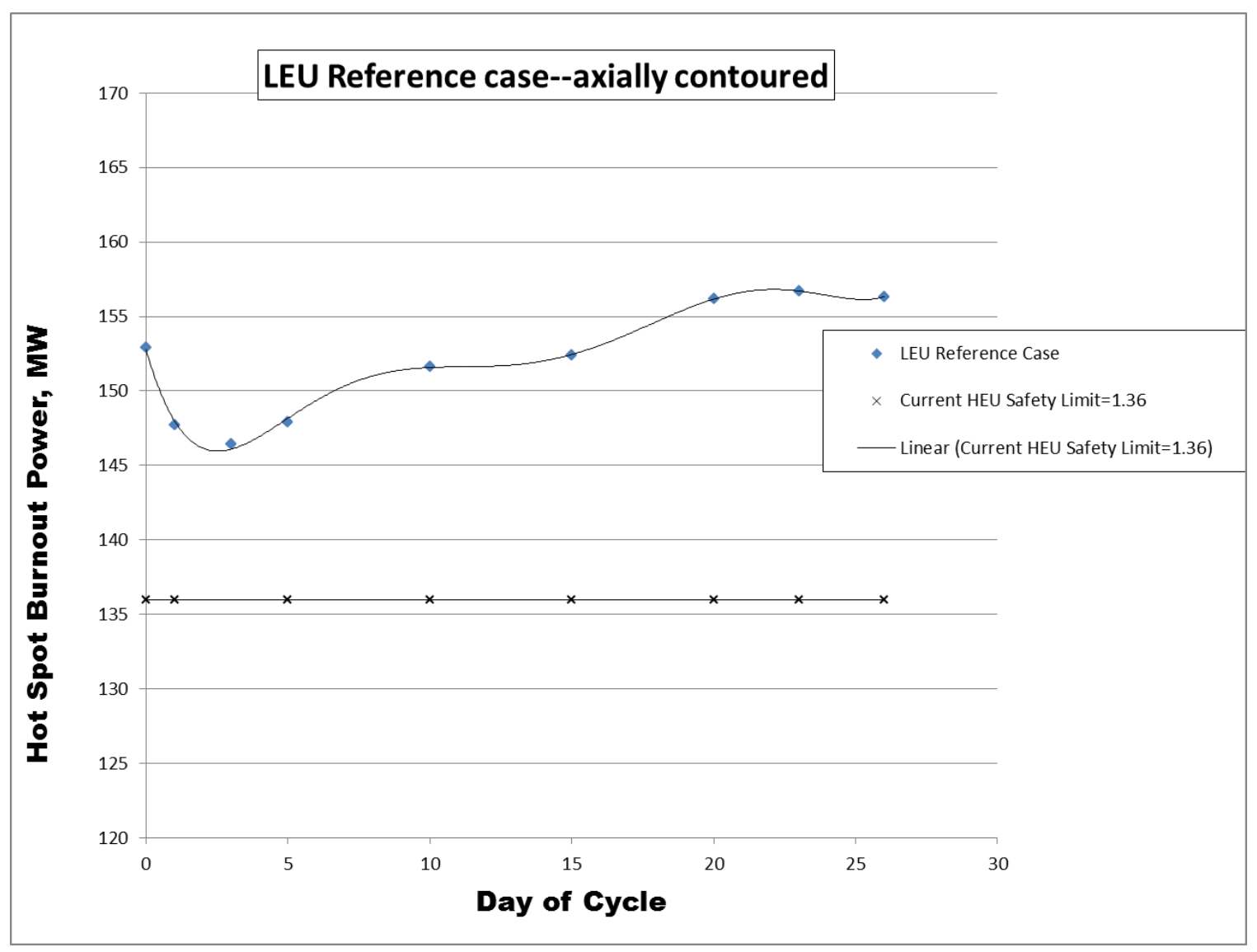

Fig. 4.2.1. Hot spot burnout power versus day in the cycle for the reference fuel. 


\subsection{TRANSIENT TH WITH SAFETY CASE ASSUMPTIONS (USING RELAP)}

The worst case small break loss of coolant accident (SBLOCA) and the loss of off-site ac power (LOOP) events were executed with RELAP while modeling the Reference LEU fuel design. In addition to the assumptions already discussed in Section 3.4, assumptions specific to the LEU reference fuel design are below:

1. The hot channel gap widths of the inner and outer fuel elements are 38.8 mils and 38.5 mils, respectively.

Justification: These values were generated based on results from the HSSHTC discussed in Section 4.2 and are different from 38.7 mils and 38.7 mils for the inner and outer elements, respectively, used for the current HEU fuel design.

2. The axial power peaking factors, local power peaking factors, and internal source multipliers for the average fuel channels, hot channels, and hot spot locations for the inner and outer fuel elements were revised to be consistent with the LEU Reference fuel design. Tables 4.3.1, 4.3.2, and 4.3.3 correspond to Tables 9, 10, and 11 found in INT-154[6] for the current HEU fuel design

Table 4.3.1. Normalized HFIR fuel axial power peaking factors for LEU Reference fuel design

\begin{tabular}{|c|c|c|c|c|}
\hline \multirow[b]{3}{*}{$\begin{array}{l}\text { Axial Location } \\
\text { (Top to Bottom) }\end{array}$} & \multicolumn{4}{|c|}{ Peaking Factors } \\
\hline & \multicolumn{2}{|c|}{ Inner Element } & \multicolumn{2}{|c|}{ Outer Element } \\
\hline & $\begin{array}{l}\text { Average } \\
\text { Fuel }\end{array}$ & Hot Fuel & $\begin{array}{l}\text { Average } \\
\text { Fuel }\end{array}$ & Hot Fuel \\
\hline$N$ & $\left(P F_{\text {Avg }}{ }^{\text {Inner }}\right)_{N}$ & $\left(P F_{\text {Hot }}{ }^{\text {Inner }}\right)_{N}$ & $\left(P F_{\text {Avg }}{ }^{\text {Outer }}\right)_{N}$ & $\left(P F_{\text {Hot }}{ }^{\text {Outer }}\right)_{N}$ \\
\hline 1 & 0.0809 & 0.0163 & 0.0643 & 0.0144 \\
\hline 2 & 1.021300841 & 0.98871505 & 1.010604439 & 0.92713915 \\
\hline 3 & 1.298052866 & 1.10321655 & 1.310805734 & 1.1056449 \\
\hline 4 & 1.419908689 & 1.29002488 & 1.428617431 & 1.30885281 \\
\hline 5 & 1.268793962 & \begin{tabular}{|l|}
1.39306317 \\
\end{tabular} & 1.28237053 & 1.42704516 \\
\hline 6 & 0.911040832 & 1.42137811 & 0.904250218 & 1.4575175 \\
\hline 7 & 0.0809 & \begin{tabular}{|l|}
1.37757681 \\
\end{tabular} & 0.0624 & 1.40928847 \\
\hline 8 & & 1.25716763 & & 1.27987119 \\
\hline 9 & & \begin{tabular}{|l|}
1.06457892 \\
\end{tabular} & & 1.07551275 \\
\hline 10 & & 0.87630127 & & 0.78430558 \\
\hline 11 & & 0.0149 & & 0.0133 \\
\hline Entrance (local) & & 1.175 & & 1.249 \\
\hline Exit (local) & & 0.564 & & 0.389 \\
\hline
\end{tabular}


Table 4.3.2. Hot fuel regions and local power peaking factors for LEU Reference fuel design

\begin{tabular}{|c|c|c|c|c|}
\hline \multicolumn{5}{|l|}{ Peaking Factors } \\
\hline & Hot Fuel & & & \\
\hline Power Distribution Uncertainty & 1.199 & & & \\
\hline Hot Streak ("U24" in C-HFIR-2007-005) & 1.06 & & & \\
\hline Fuel plate heated length uncertainty & 1.025 & & & \\
\hline & & & & \\
\hline \multirow{2}{*}{ Total (Multiplicative) } & $P F_{\text {Hot }}^{\text {Total }}$ & & & \\
\hline & 1.3027 & & & \\
\hline & & & & \\
\hline & \multicolumn{2}{|c|}{ Local - Active } & \multicolumn{2}{|c|}{ Entrance and Exit } \\
\hline & Inner & Outer & Inner & Outer \\
\hline Power Distribution Uncertainty & 1.199 & 1.199 & 1.199 & 1.199 \\
\hline Nonbond & 1.08 & 1.16 & 1.08 & 1.16 \\
\hline Fuel Segregation ("U18/U19" in C-HFIR-2007-005) & 1.27 & 1.27 & 1 & 1 \\
\hline Fuel Beyond Axial Boundary & & & 1.227 & 1.255 \\
\hline \multirow{3}{*}{ Total (Multiplicative) } & & & & \\
\hline & $P F_{\text {Local II }}^{\text {Iner }}$ & $P F_{\text {Local }}$ Outer & $P F_{\text {Loc-Entr/Exit }}{ }^{\text {Inner }}$ & $\mathrm{PF}_{\text {Loc-Ent//Exit }}$ outer \\
\hline & 1.64 & 1.77 & 1.59 & 1.75 \\
\hline
\end{tabular}

Table 4.3.3. Internal source multipliers for LEU Reference fuel design Table 11. Internal Source Multipliers = Pf $($ area ratio $) *$ P1\% (1.01 or 0.99) * Paxial (Table 9) * Ppower (Table 10)

\begin{tabular}{|c|c|}
\hline Average Fuel & \\
\hline $\begin{array}{c}\text { Axial Location } \\
\text { (Top to Bottom) }\end{array}$ & Node (in) \\
\hline
\end{tabular}

\begin{tabular}{|c|c|c|c|c|c|} 
(Top to Bottom) & Node (in) & Inner $+1 \%$ & Inner-1\% & Outer+1\% & Outer-1\% \\
\hline 1 & 2 & $1.15 \mathrm{E}-03$ & $1.13 \mathrm{E}-03$ & $1.78 \mathrm{E}-03$ & $1.75 \mathrm{E}-03$ \\
\hline 2 & 4 & $2.91 \mathrm{E}-02$ & $2.85 \mathrm{E}-02$ & $5.60 \mathrm{E}-02$ & $5.49 \mathrm{E}-02$ \\
\hline 3 & 4 & $3.70 \mathrm{E}-02$ & $3.62 \mathrm{E}-02$ & $7.26 \mathrm{E}-02$ & $7.12 \mathrm{E}-02$ \\
\hline 4 & 4 & $4.04 \mathrm{E}-02$ & $3.96 \mathrm{E}-02$ & $7.91 \mathrm{E}-02$ & $7.75 \mathrm{E}-02$ \\
\hline 5 & 4 & $3.61 \mathrm{E}-02$ & $3.54 \mathrm{E}-02$ & $7.10 \mathrm{E}-02$ & $6.96 \mathrm{E}-02$ \\
\hline 6 & 4 & $2.59 \mathrm{E}-02$ & $2.54 \mathrm{E}-02$ & $5.01 \mathrm{E}-02$ & $4.91 \mathrm{E}-02$ \\
\hline 7 & 2 & $1.15 \mathrm{E}-03$ & $1.13 \mathrm{E}-03$ & $1.73 \mathrm{E}-03$ & $1.69 \mathrm{E}-03$ \\
\hline
\end{tabular}

\begin{tabular}{|c|c|c|c|c|c|}
\hline \multirow[b]{2}{*}{ Axial Location } & \multirow[b]{2}{*}{ Length (in.) } & \multicolumn{2}{|c|}{ Hot Fuel } & \multicolumn{2}{|c|}{ Hot Spots } \\
\hline & & Inner & Outer & Inner Local & Outer Local \\
\hline $\mathrm{N}$ & $L_{N}$ & ISM $_{\text {Hot }}{ }^{\text {Inner }}$ & ISM $_{\text {Hot }}$ Outer & ISM $_{\text {Local }}$ Inner & ISM Local $_{\text {Luter }}$ \\
\hline 1 & 2.00 & $3.52 \mathrm{E}-06$ & $2.79 \mathrm{E}-06$ & $3.71 \mathrm{E}-06$ & $3.90 \mathrm{E}-06$ \\
\hline 2 & 2.22 & 2.37E-04 & $2.00 \mathrm{E}-04$ & $3.00 E-06$ & 2.71E-06 \\
\hline 3 & 2.22 & $2.65 \mathrm{E}-04$ & $2.38 \mathrm{E}-04$ & $3.34 \mathrm{E}-06$ & $3.23 \mathrm{E}-06$ \\
\hline 4 & 2.22 & $3.10 \mathrm{E}-04$ & $2.82 \mathrm{E}-04$ & $3.91 E-06$ & $3.83 \mathrm{E}-06$ \\
\hline 5 & 2.22 & $3.34 \mathrm{E}-04$ & $3.08 \mathrm{E}-04$ & $4.22 \mathrm{E}-06$ & 4.17E-06 \\
\hline 6 & 2.22 & $3.41 \mathrm{E}-04$ & $3.14 \mathrm{E}-04$ & 4.31E-06 & $4.26 \mathrm{E}-06$ \\
\hline 7 & 2.22 & 3.31E-04 & $3.04 \mathrm{E}-04$ & 4.17E-06 & $4.12 \mathrm{E}-06$ \\
\hline 8 & 2.22 & $3.02 \mathrm{E}-04$ & $2.76 \mathrm{E}-04$ & $3.81 \mathrm{E}-06$ & $3.74 \mathrm{E}-06$ \\
\hline 9 & 2.22 & $2.56 \mathrm{E}-04$ & $2.32 \mathrm{E}-04$ & $3.23 E-06$ & $3.15 \mathrm{E}-06$ \\
\hline 10 & 2.22 & $2.10 \mathrm{E}-04$ & $1.69 \mathrm{E}-04$ & $2.66 \mathrm{E}-06$ & $2.29 \mathrm{E}-06$ \\
\hline 11 & 2.00 & $3.22 \mathrm{E}-06$ & $2.58 \mathrm{E}-06$ & $1.78 \mathrm{E}-06$ & $1.21 \mathrm{E}-06$ \\
\hline
\end{tabular}

Ltotal $=$

Justification: These values were generated based on results from the HSSHTC code discussed in Section 4.2. 


\subsubsection{Results for the Worst-Case SBLOCA Event}

The reactor will automatically shut down on a low primary pressure scram signal within $0.17 \mathrm{~s}$ of the initiation of a small break LOCA occurring at the cold leg inlet. Results show that the most limiting hot spot location for the Reference LEU fuel design for this event occurs in "Node-07" which is roughly 2/3 down from the top of the fuel. See the core noding diagram presented in Section 3.4 of this report. This location for the peak power density is consistent with the axially contoured nature of the reference fuel which suppresses the power peak at the core exit and compensates with a slightly higher mid-core and upper-core power density.

It is noted that the most limiting hot channel location for the current HEU fuel design for this event occurs in "Node-11" which is at the very bottom of the fuel. Although the SBLOCA event is categorized as an infrequent event, the consequences of this event have historically met the acceptance criteria for a moderate frequency event. As such, the maximum fraction of incipient boiling heat flux for the inner and outer elements using the Bergles-Rohsenow/Dittus-Boelter correlation and the Bergles-Rohsenow/Hausen correlation are shown below for Nodes 07 and 11 for the LEU Reference fuel design and the current HEU fuel design at $85 \mathrm{MW}$ for comparison.

Figure 4.3.1 shows the peak maximum fraction of incipient boiling heat flux (MFIBHF) for the LEU Reference fuel design using the Bergles-Rohsenow/Dittus-Boelter correlation is 0.51 and 0.57 for the inner and outer fuel worst Hot Spot - Node 07, respectively. The peak MFIBHF for this case as determined via the Bergles-Rohsenow/Hausen correlation is predicted to be larger at 0.55 and 0.62 for the inner and outer fuel worst Hot Spot - Node 07, respectively, than was predicted using the BerglesRohsenow/Dittus-Boelter correlation. It is expected that the actual fraction of incipient boiling heat flux that would occur in the hot inner and outer fuel channels is within the range predicted by these two correlations. As such, the peak MFIBHF remains under the limit of 1.0 indicating that boiling in the hot channel is not expected to occur and, thus, no fuel damage is predicted. For comparison to the worst hot spot location for HEU fuel, Hot Spot - Node 11, results are also provided. The peak MFIBHF in Node11 is predicted to be 0.34 and occurs for the inner element using the Bergles-Rohsenow/Hausen correlation. 


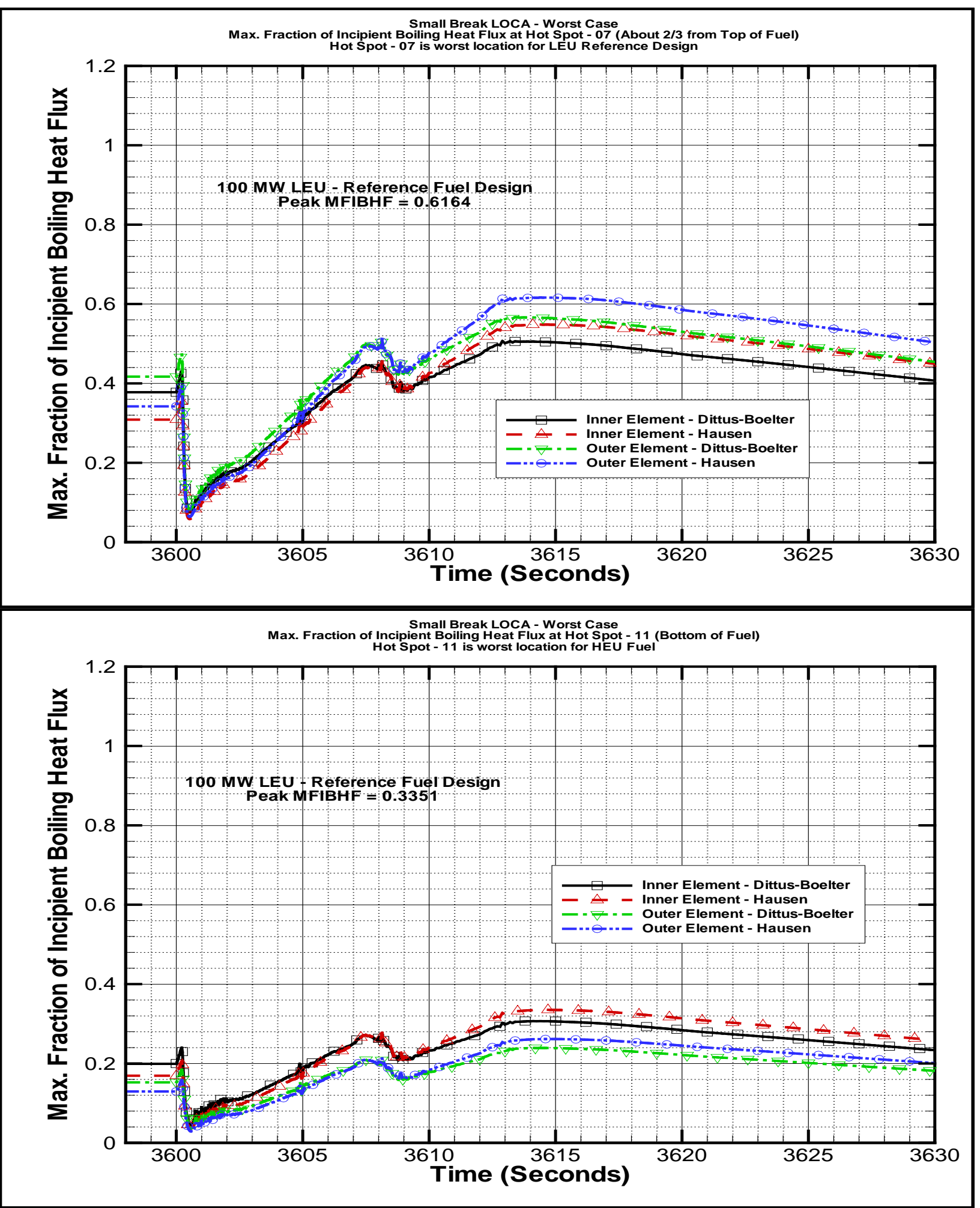

Fig. 4.3.1. Fraction of incipient boiling heat flux data for worst case 2.0-in. diameter break in the HFIR primary coolant system pressure boundary for LEU Reference fuel design at $100 \mathrm{MW}$. 
Figure 4.3.2 shows the MFIBHF for the current HEU fuel design at a reactor power of $85 \mathrm{MW}$. The peak MFIBHF values are 0.86 for both the inner and outer elements, respectively, using the BerglesRohsenow/Dittus-Boelter correlation and 0.93 and 0.94 for the inner and outer elements, respectively, using the Bergles-Rohsenow/Hausen correlation. As such, the peak MFIBHF remains under the limit of 1.0 indicating that boiling in the hot channel is not expected to occur and, thus, no fuel damage is predicted. Results for Node-07 show that the MFIBHF for both the inner and outer element using both correlations remains less than 1.0 at all times, with a peak value of 0.62 . 


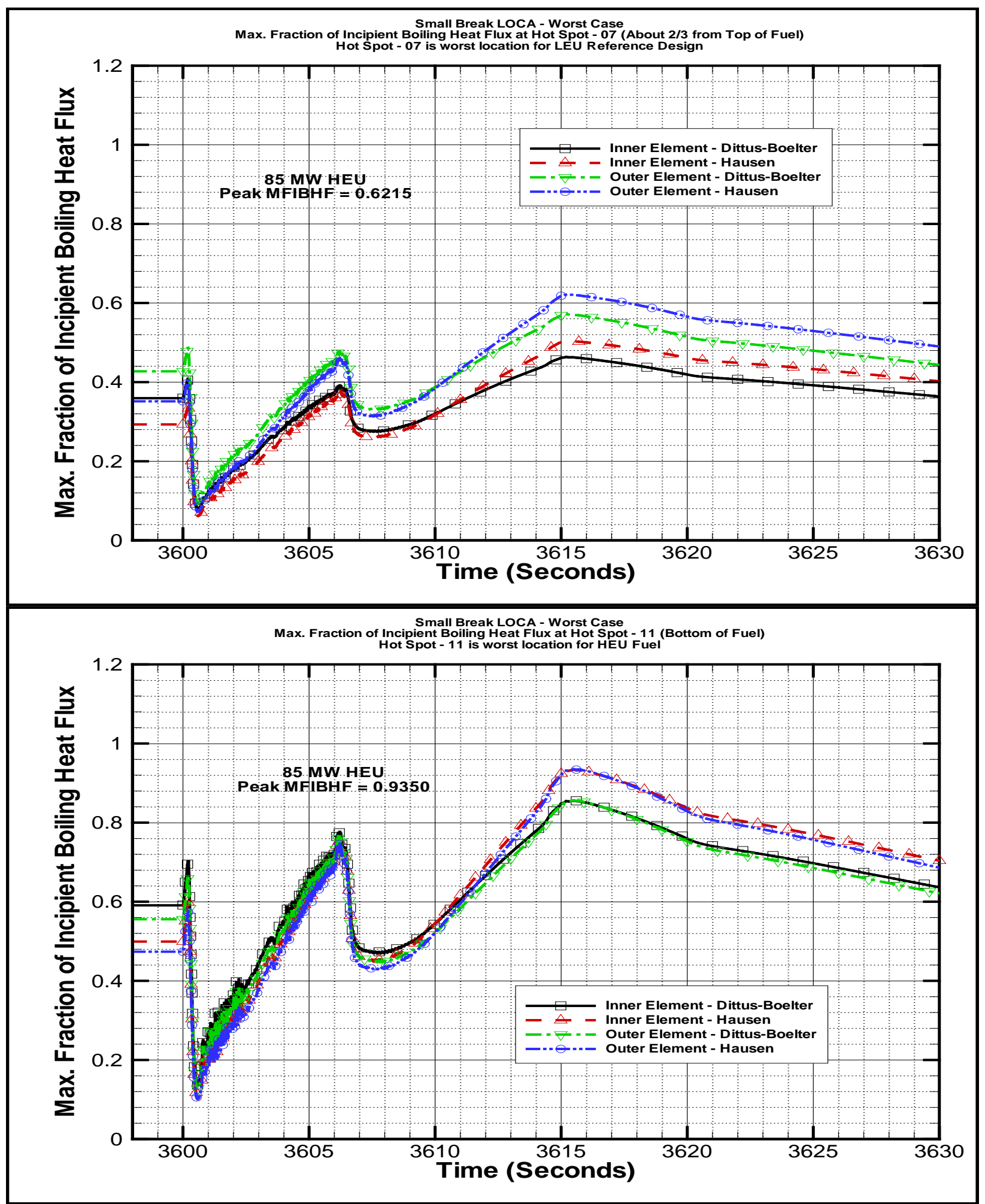

Fig. 4.3.2. Fraction of incipient boiling heat flux data for worst case 2.0-in. diameter break in the HFIR primary coolant system pressure boundary for current HEU fuel design at $85 \mathrm{MW}$. 
It is useful to compare the worst 100 MW LEU fuel hot spot in Fig. 4.3.1 (with MFIBHF of 0.62) to the worst 85 MW HEU fuel hot spot in Fig. 4.3.2 (MFIBHF of 0.94.) This comparison shows that for the bounding SBLOCA event, the reference LEU fuel has more transient margin to incipient boiling at 100 MW operation than the HEU fuel does at 85 MW.

Figure 4.3.3 shows the fuel centerline and cladding temperatures for the inner and outer fuel elements, respectively for the LEU Reference fuel design. For the most limiting Node-07, the peak cladding and peak centerline temperatures are 151.6 C and 281.7 C, respectively, in the outer element. For Node-11 at the bottom of the fuel, the peak cladding and peak centerline temperatures are less at $132.6 \mathrm{C}$ and 192.2 $\mathrm{C}$, respectively, in the inner element. These peak temperatures occur within the first 0.2 second of the onset of the event. This figure shows that significant margin exists to cladding damage and fuel melt for the LEU Reference fuel design. 


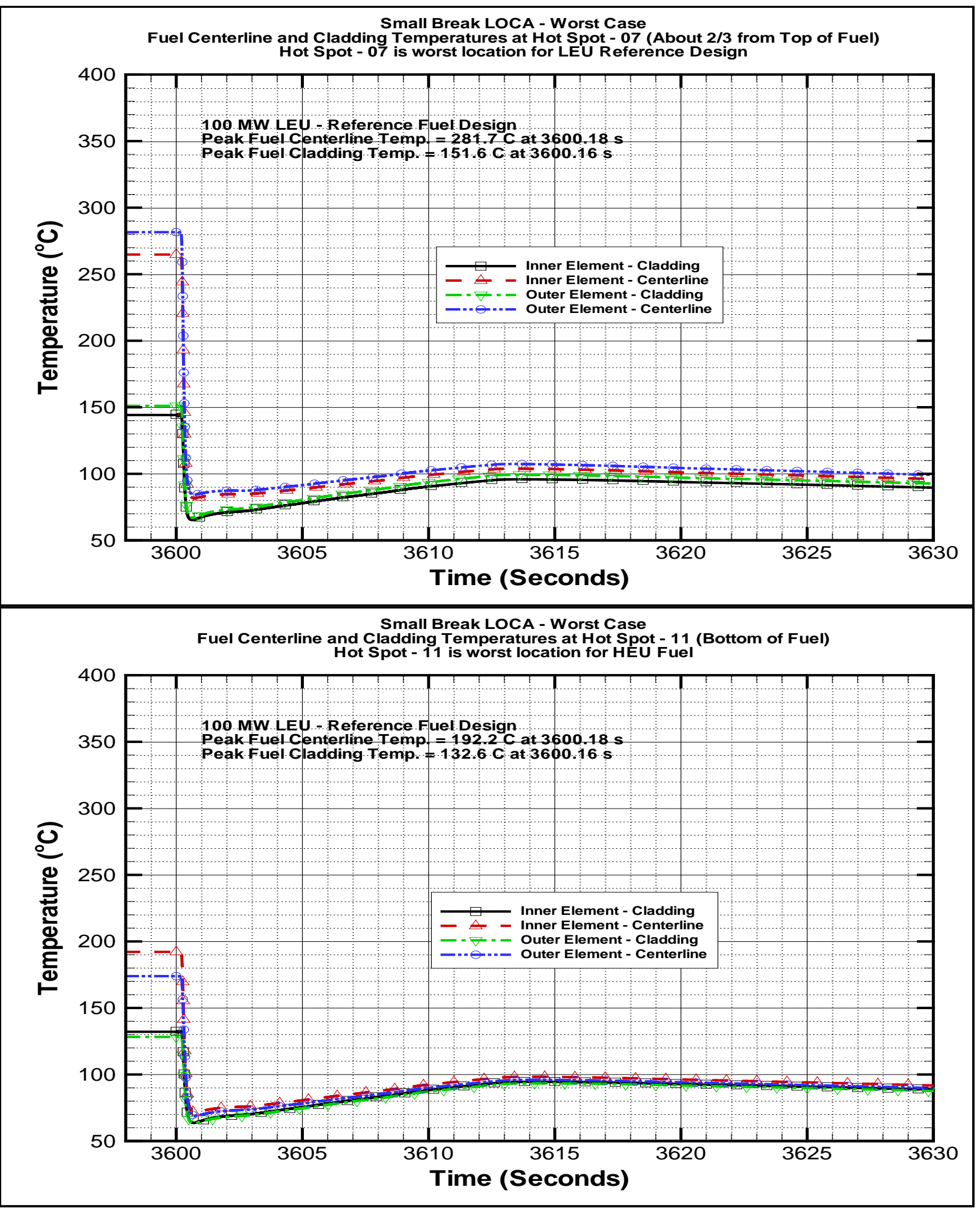

Fig. 4.3.3. Fuel temperatures for worst case 2.0-in. diameter break in the HFIR primary coolant system pressure boundary for LEU Reference fuel design at $100 \mathrm{MW}$. 
Figure 4.3.4 shows the fuel centerline and cladding temperatures for the inner and outer fuel elements, respectively for the current HEU fuel design at $85 \mathrm{MW}$. For Node-07, the peak cladding and peak centerline temperatures are $153.9 \mathrm{C}$ and $237.8 \mathrm{C}$, respectively, in the outer element. For the most limiting Node-11 at the bottom of the fuel, the peak cladding and peak centerline temperatures are greater at 177.2 $\mathrm{C}$ and $282.5 \mathrm{C}$, respectively, in the inner element. These peak temperatures occur within the first 0.2 second of the onset of the event. This figure shows that significant margin exists to cladding damage and fuel melt for the current HEU fuel design. 


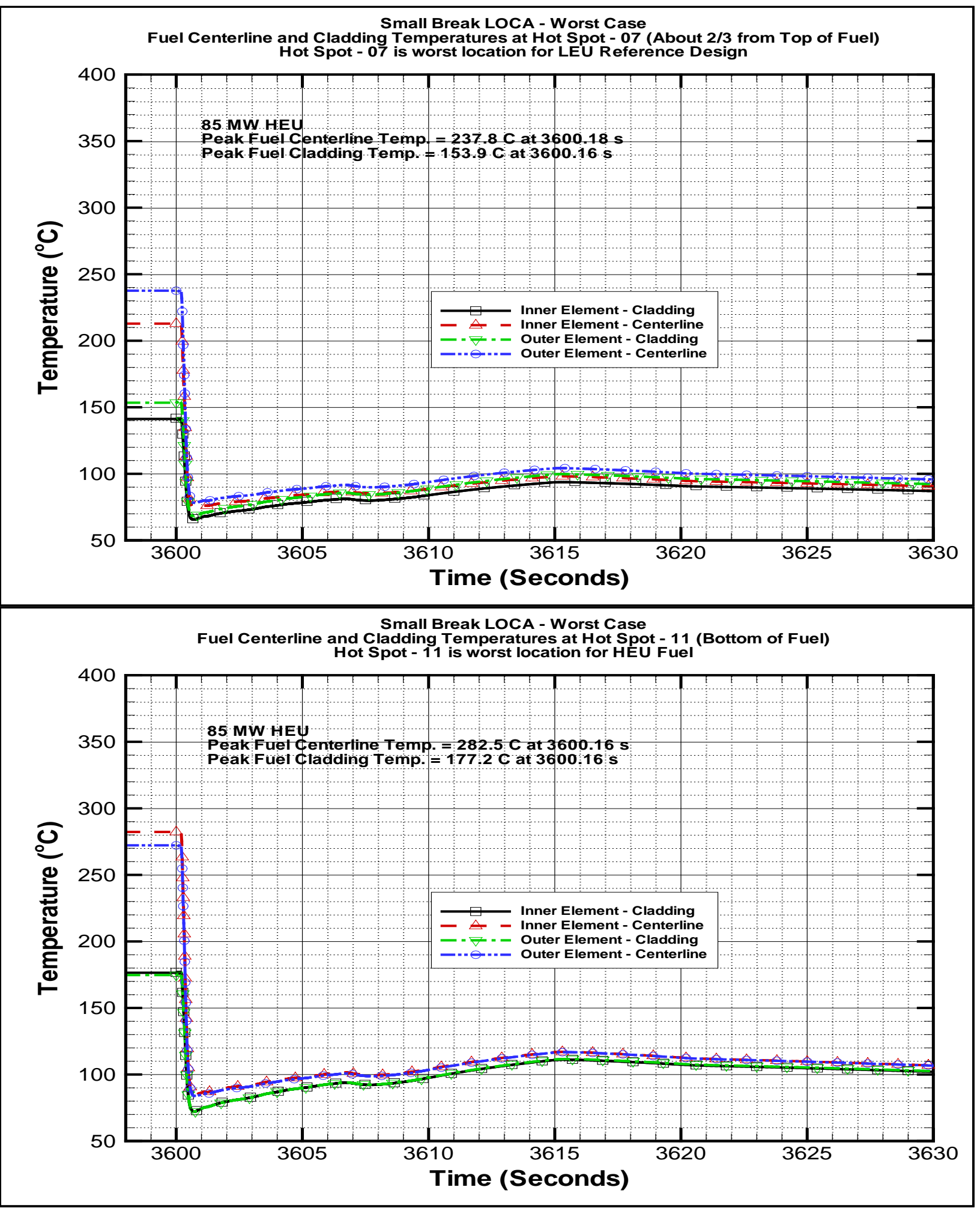

Fig. 4.3.4. Fuel temperatures for worst case 2.0-in. diameter break in the HFIR primary coolant system pressure boundary for current HEU fuel design at $85 \mathrm{MW}$. 
For both fuel designs, the temperatures decrease immediately after reactor scram. In comparing the LEU Reference fuel design at $100 \mathrm{MW}$ to the current HEU fuel design at $85 \mathrm{MW}$, the peak centerline temperatures at the hottest locations are comparable, i.e., 282 C. However, the peak cladding temperature for the LEU Reference fuel design is roughly $26 \mathrm{C}$ cooler than for the current HEU fuel design at the most limiting location in the fuel for each fuel design.

\subsubsection{Results for the LOOP Event}

The reactor will automatically shut down on a flux-to-flow scram signal within $1.28 \mathrm{~s}$ of the initiation of a loss of off-site AC power. Results show that the most limiting hot spot location for the Reference LEU fuel design for this event occurs in "Node-07" which is roughly $2 / 3$ down from the top of the fuel. See the core noding diagram presented in Section 3.4 of this report. This location for the peak power density is consistent with the axially contoured nature of the reference fuel which suppresses the power peak at the core exit and compensates with a slightly higher mid-core and upper-core power density.

It is noted that the most limiting hot channel location for the current HEU fuel design for this event occurs in "Node-11" which is at the very bottom of the fuel. The bottom of the HEU fuel has an axial water reflector peak that increases the local power density, as occurs at the top of the fuel. In addition, for LOOP, the bottom of the fuel has a lower pressure than the inlet (about 105 psi less at full flow and decreasing to a few psi as the LOOP event causes a primary coolant pump coastdown). The maximum fraction of incipient boiling heat flux for the inner and outer elements using the Bergles-Rohsenow/ Dittus-Boelter correlation and the Bergles-Rohsenow/Hausen correlation are shown below for Nodes 07 and 11 for the LEU Reference fuel design and the current HEU fuel design at $85 \mathrm{MW}$ for comparison. For this event, there are two MFIBHF peaks that must be examined. One occurs within $\sim 2 \mathrm{~s}$ of the onset of the LOOP, while the other peak occurs longer term around $50 \mathrm{~s}$ after the onset of the LOOP for the LEU reference fuel design and around $60 \mathrm{~s}$ after the onset of the LOOP for the HEU fuel design. As discussed in Section 3.4, these two correlations for MFIBHF are applicable for lower flow conditions such as for times after $\sim 3 \mathrm{~s}$ when the primary coolant flow rate is below $\sim 8,000 \mathrm{gpm}$. For times between 0 and $3 \mathrm{~s}$ when the primary coolant flow rate is above $\sim 8,000 \mathrm{gpm}$, it is acceptable to have a MFIBHF greater than 1.0 as long as the hot spot heat flux remains below both the Costa flow excursion heat flux and the Gambill critical heat flux. However, if the MFIBHF does not exceed 1.0 at any time, then it can be concluded that boiling does not occur in the hot channel.

Figure 4.3.5 shows the maximum fraction of incipient boiling heat flux in the worst hot channel location of Node-07 (about 2/3 from the top of the fuel) using the Bergles-Rohsenow/Dittus-Boelter correlation is predicted to be 0.61 and 0.68 for the inner and outer fuel hot spots, respectively. The maximum fraction of incipient boiling heat flux using the Bergles-Rohsenow/Hausen correlation is predicted to be 0.53 and 0.59 for the inner and outer fuel hot spots, respectively. These maximum values occur at 1.3 seconds into the event. Longer term, when primary flow is provided by two pony motors, the maximum fraction of incipient boiling heat flux occurs around 50 seconds and is 0.31 and 0.34 as predicted by the BerglesRohsenow/Dittus-Boelter correlation and 0.33 and 0.37 as predicted by the Bergles-Rohsenow/Hausen correlation, for the inner and outer fuel hot spots at Node 07, respectively. It is expected that the actual fraction of incipient boiling heat flux that would occur in the hot inner and outer fuel channels is within the range predicted by these two correlations. For Node-11 (very bottom of fuel) which is the worst hot channel location for the current HEU fuel design, the MFIBHF for both fuel elements and both correlations remains well below the limit of 1.0. At no time during the LOOP event is boiling expected to occur in the hot channel. As such, the acceptance criteria for this case are met. 


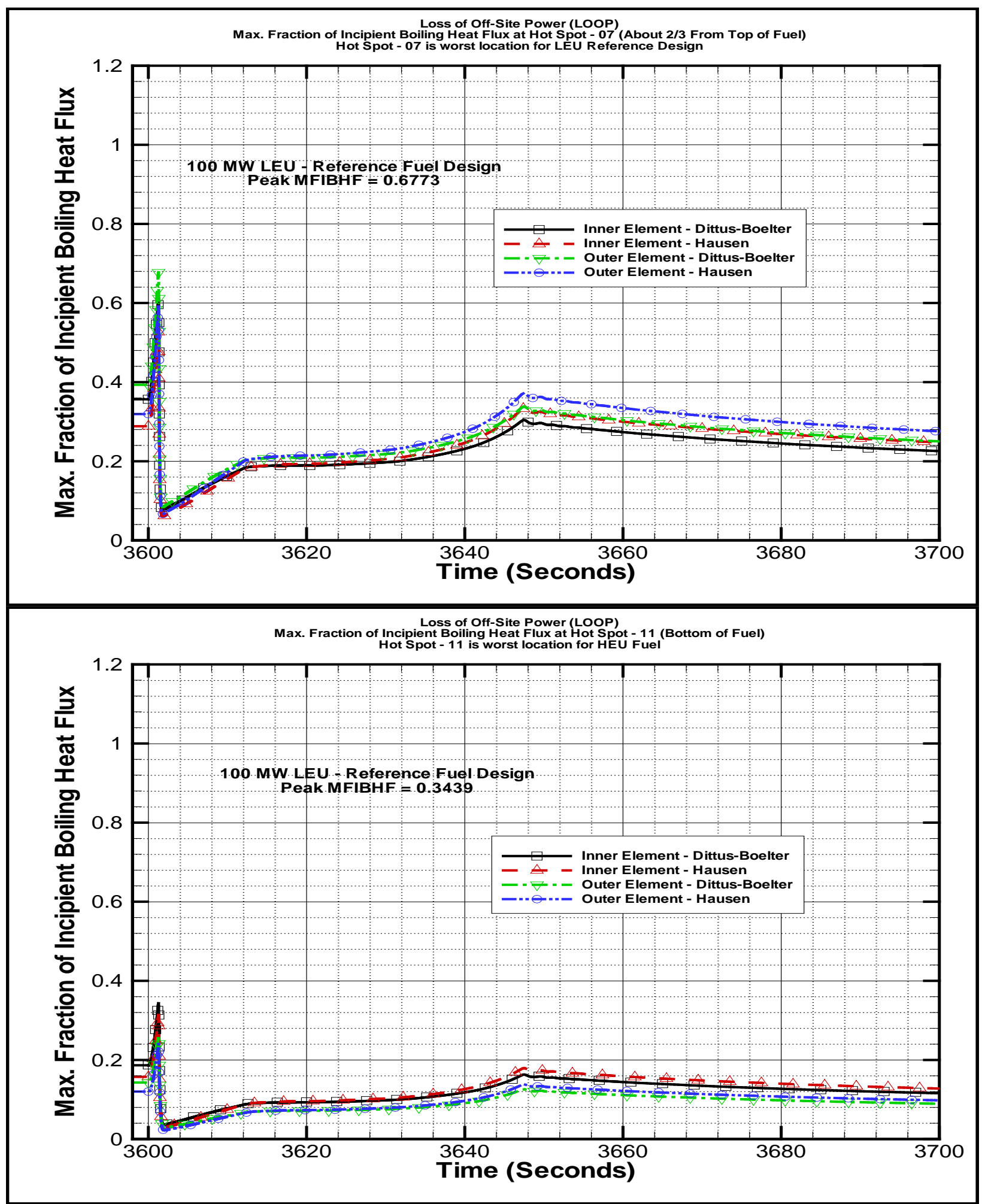

Fig. 4.3.5. Fraction of incipient boiling heat flux data for the loss of off-site ac power (LOOP) event for LEU Reference fuel design at $100 \mathrm{MW}$. 
Figure 4.3.6 shows the MFIBHF for the current HEU fuel design at a reactor power of $85 \mathrm{MW}$. As stated previously, the worst hot spot location occurs in Node-11 which is at the very bottom of the fuel.

Although the MFIBHF is greater than 1.0, this peak occurs around $1.3 \mathrm{~s}$ into the LOOP when primary coolant flow is greater than 8,000 gpm. As such, results are acceptable if the hot spot heat flux remains below both the Costa flow excursion heat flux and the Gambill critical heat flux. Although not shown here, this is the case for the LOOP event at 85 MW with HEU fuel. For the peak occurring longer term ( $\sim 00 \mathrm{~s}$ for the $85 \mathrm{MW}$ HEU case), the MFIBHF remains well below the limit of 1.0 for both fuel elements and both correlations. As such, the acceptance criteria for this case are met. 


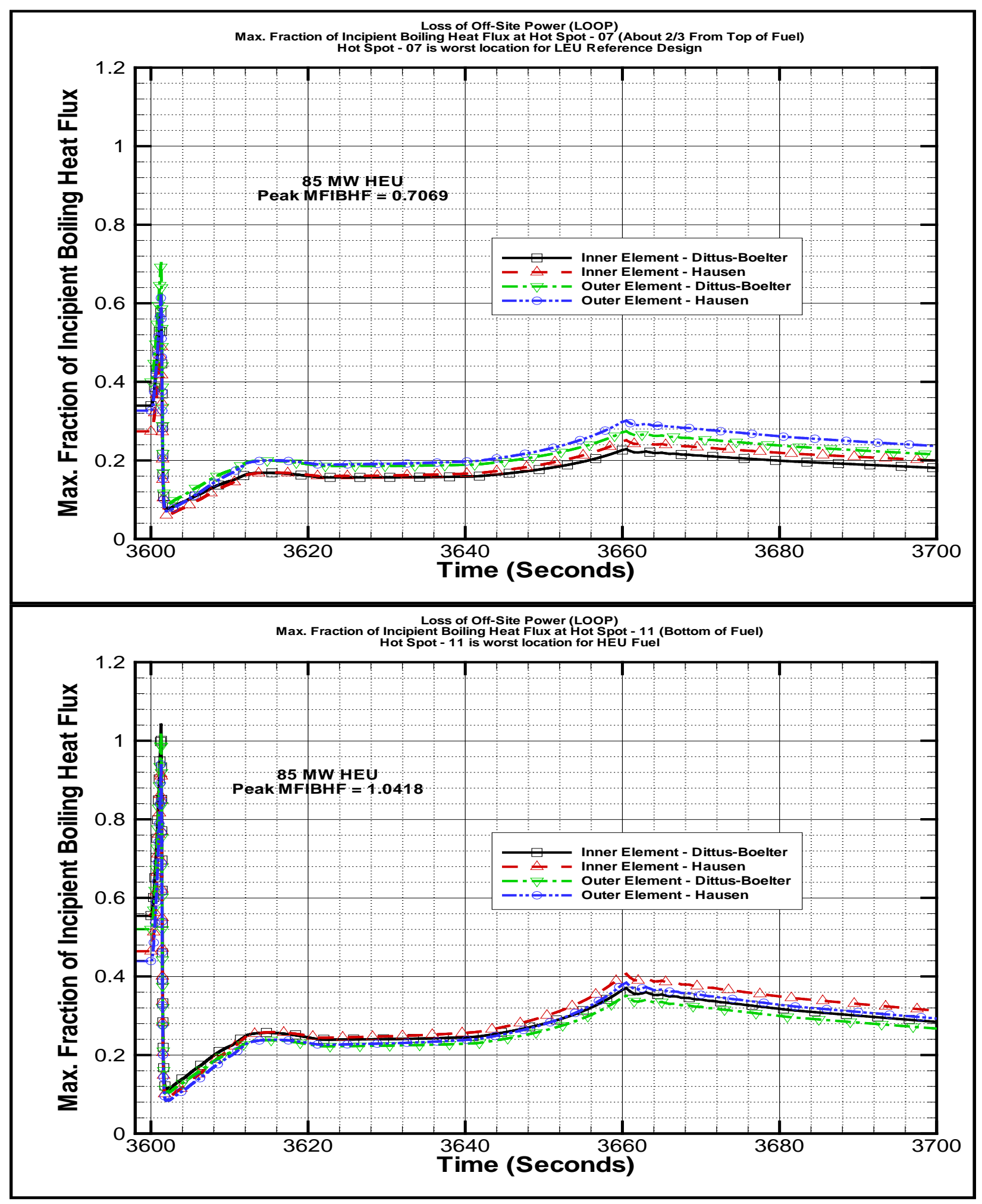

Fig. 4.3.6. Fraction of incipient boiling heat flux data for the loss of off-site AC power (LOOP) event for current HEU fuel design at $85 \mathrm{MW}$. 
A comparison of Figs. 4.3.5 and 4.3.6 shows that the 100 MW LEU fuel has a slightly better MFIBHF performance below the core midplane than the $85 \mathrm{MW}$ HEU fuel. At the outlet (normally the most limiting spot), the $100 \mathrm{MW}$ LEU reference fuel MFIBHF performance is much better than the $85 \mathrm{MW}$ HEU fuel (0.34 for LEU versus 1.05 for HEU).

Figure 4.3.7 shows the fuel centerline and cladding temperatures for the inner and outer fuel elements, respectively for the LEU Reference fuel design. For the most limiting Node-07, the peak cladding and peak centerline temperatures are 193.9 C and 319.2 C, respectively, in the outer element. For Node-11 at the bottom of the fuel, the peak cladding and peak centerline temperatures are less at 171.6 C and 227.4 $\mathrm{C}$, respectively, in the inner element. These peak temperatures occur within the first 1.3 seconds of the onset of the event. This figure shows that significant margin exists to cladding damage and fuel melt for the LEU Reference fuel design. Note that the RELAP5 results are for hot channel conditions and are, therefore, higher than the nominal fuel temperatures in the COMSOL results. 


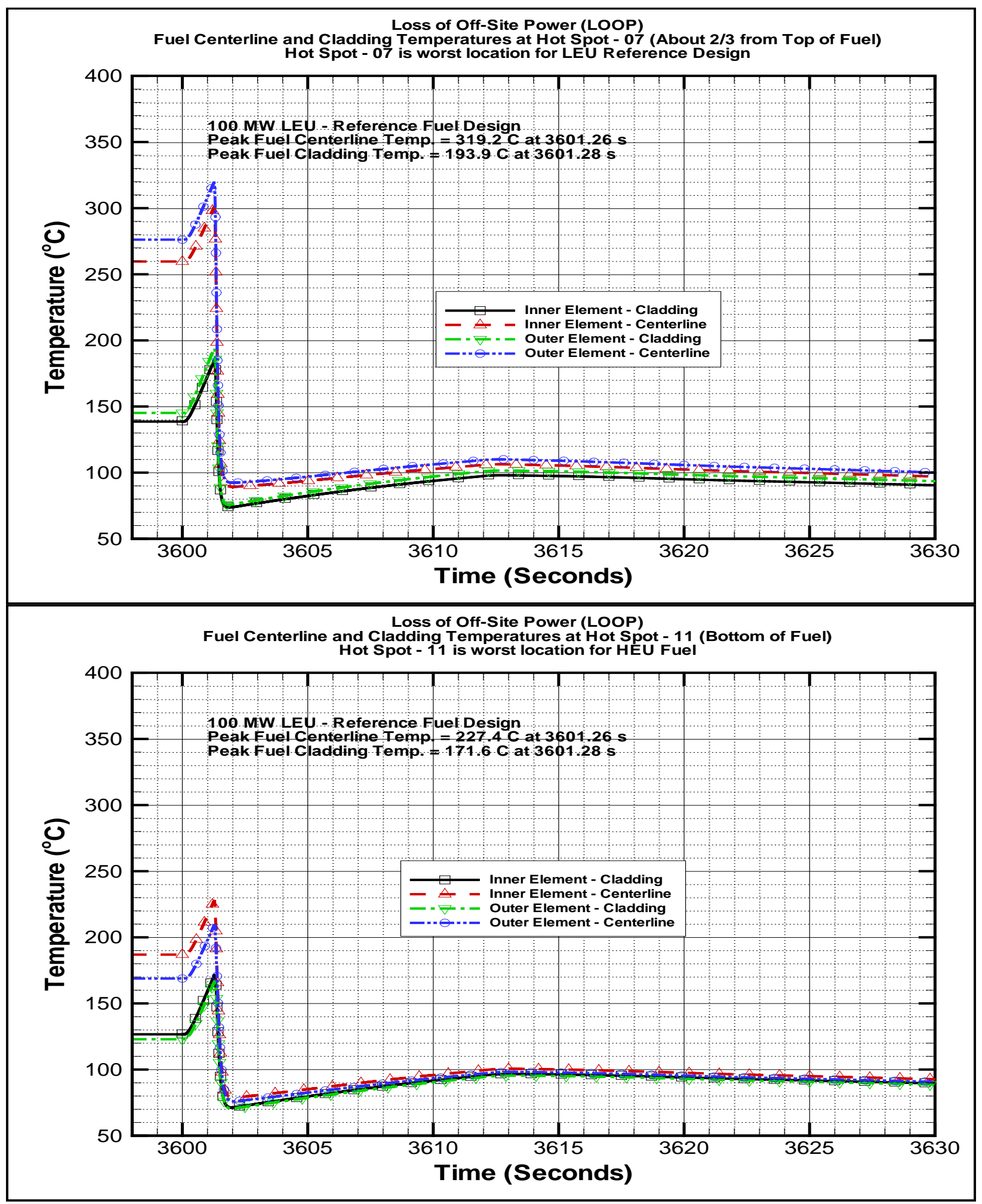

Fig. 4.3.7. Fuel temperatures for loss of off-site AC power (LOOP) for LEU Reference fuel design at $100 \mathrm{MW}$. 
Figure 4.3.8 shows the fuel centerline and cladding temperatures for the inner and outer fuel elements, respectively for the current HEU fuel design at $85 \mathrm{MW}$. For Node-07, the peak cladding and peak

centerline temperatures are 198.0 C and 280.8 C, respectively, in the outer element. For the most limiting Node-11 at the bottom of the fuel, the peak cladding and peak centerline temperatures are greater at 228.0 $\mathrm{C}$ and $332.7 \mathrm{C}$, respectively, in the inner element. These peak temperatures occur within the first 1.3 seconds of the onset of the event. This figure shows that significant margin exists to cladding damage and fuel melt for the current HEU fuel design. 


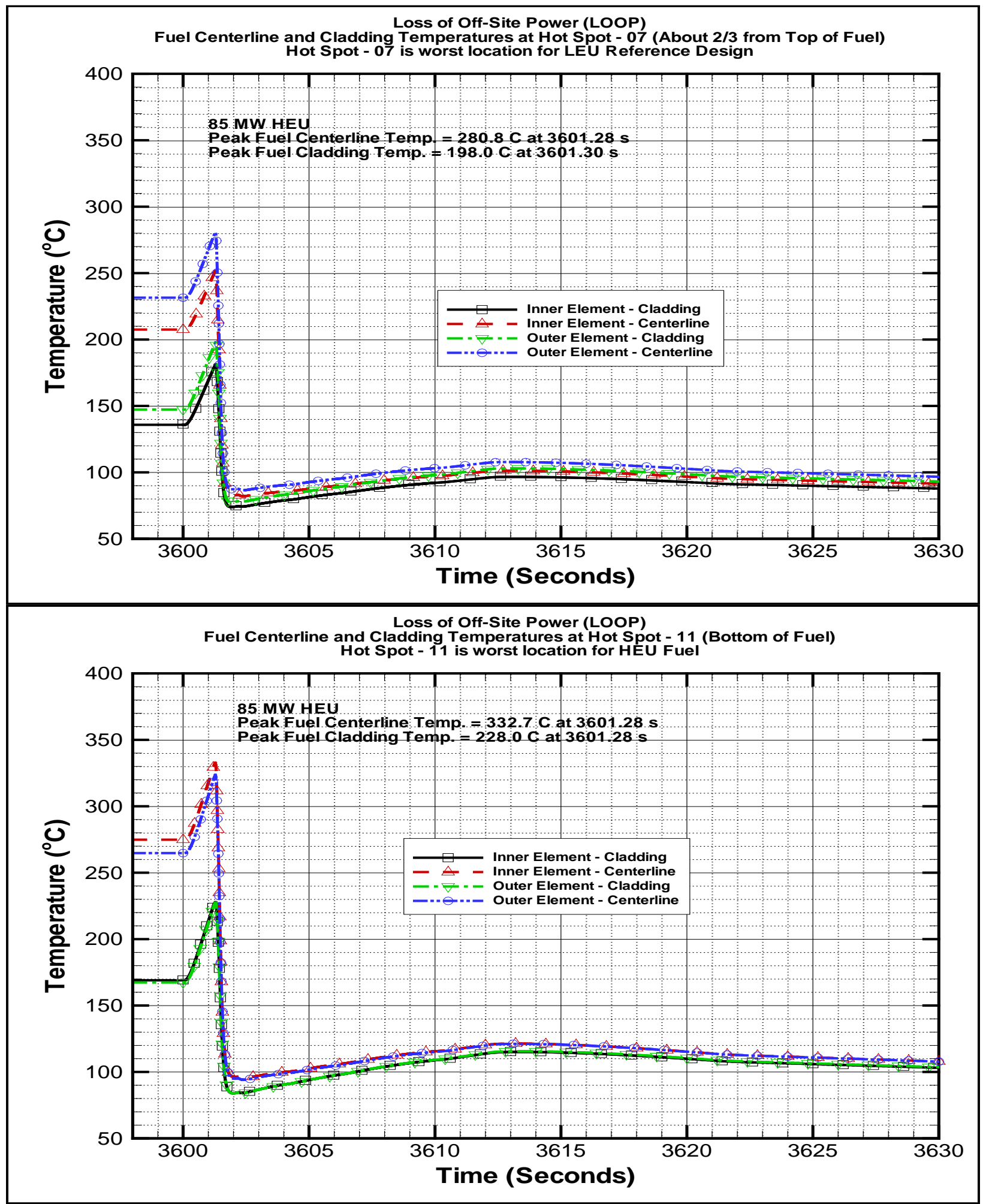

Fig. 4.3.8. Fuel temperatures for loss of off-site AC power (LOOP) for current HEU fuel design at $85 \mathrm{MW}$. 
For both fuel designs, the temperatures decrease immediately after reactor scram. In comparing the LEU Reference fuel design at $100 \mathrm{MW}$ to the current HEU fuel design at $85 \mathrm{MW}$, the peak centerline temperatures at the hottest locations are within roughly $14 \mathrm{C}$ of each other, with the HEU design resulting in the highest temperature of $332.7 \mathrm{C}$. The peak cladding temperature for the LEU Reference fuel design is roughly $34 \mathrm{C}$ cooler than for the current HEU fuel design at the most limiting location in the fuel for each fuel design.

\subsection{STEADY-STATE TH WITH NOMINAL ASSUMPTIONS (USING COMSOL)}

In the reference LEU fuel design, the radially contoured fuel zone is not located on the plate's centerline through its thickness leading to a design in which the fuel zone is closer to the so-called concave clad surface ("hot-side") than the convex clad surface ("cold-side"). The fuel zone is also axially contoured in a "toe" shape at its longitudinal bottom end in the direction of plate height.

Relative fission densities for this reference design were obtained from corresponding MCNP simulations at the beginning and end of reactor cycles. These fission densities were then converted and scaled for 100 MW nominal LEU operating conditions of HFIR. First-order smooth interpolated values for the volumetric heat source are provided to the fuel zone region in the COMSOL model in the units of $\mathrm{kW} / \mathrm{cm}^{3}$.

The heat source terms are plotted in Fig. 4.4.1 for both the IFE and OFE at BOC and EOC. The maximum heat source in each plate and its location are also shown in the figures by a 'max' • indicator. The top panels in Fig. 4.4.1 show "height expression plots" for the volumetric heat source in each plate. Plot views are chosen such that both the peaks at the inner and outer side edges are visible. These plots clearly show the difference in magnitude between both the heat source peaks at the side edges and their associated sharp gradients. The same data is plotted as "volumetric plots" in the bottom panels to show their respective locations inside the fuel plate. Notice that the effect of axial contouring on the volumetric heat source distribution significantly reduces the local peaking at the bottom of the fuel zone. 


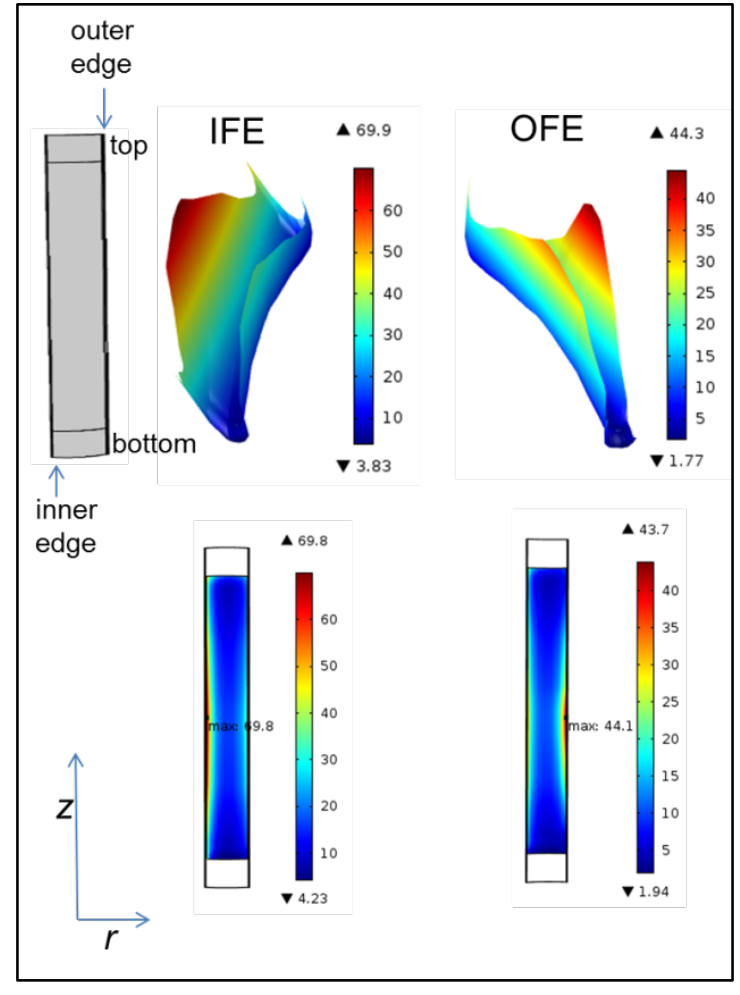

(a) beginning of cycle, BOC

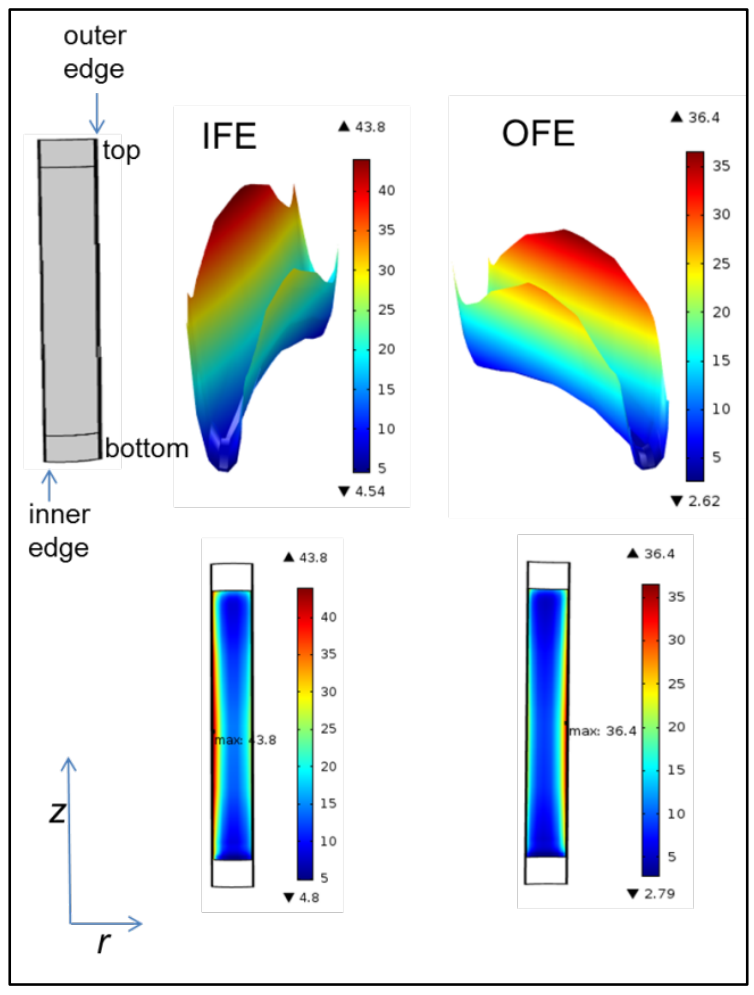

(b) end of cycle, EOC

Fig. 4.4.1. Volumetric power density (in $\mathrm{kW} / \mathrm{cm}^{3}$ ) of the reference $\mathrm{LEU}$ fuel design for 100 MW nominal HFIR operating conditions.

In both the inner and outer fuel plates, the volumetric heat source peaks at the core midplane ( $\mathrm{z}=12 \mathrm{in})$. For the IFE, the peaking occurs near its inner radial edge whereas for the OFE, peaking occurs at its outer radial edge for both the BOC and EOC. For the IFE, the ratio of its local peaks at the inner and outer radial edges is 1.99 at the $\mathrm{BOC}$ and 1.51 at the OC. For the OFE, the ratio of its local peaks at the outer and inner radial edges is 1.31 at the BOC and 1.30 at the EOC.

Three-dimensional surface plots for the concave ("hot-side") clad surface temperatures (in ${ }^{\circ} \mathrm{C}$ ) are shown in Fig. 4.4.2 for both the IFE and OFE at the BOC and the EOC. On the concave side of the fuel plate, the cladding is thinner due to the off-center location of the fuel zone and that results in less thermal resistance through the clad leading to a higher surface temperature and hence, it is called the "hot-side". 


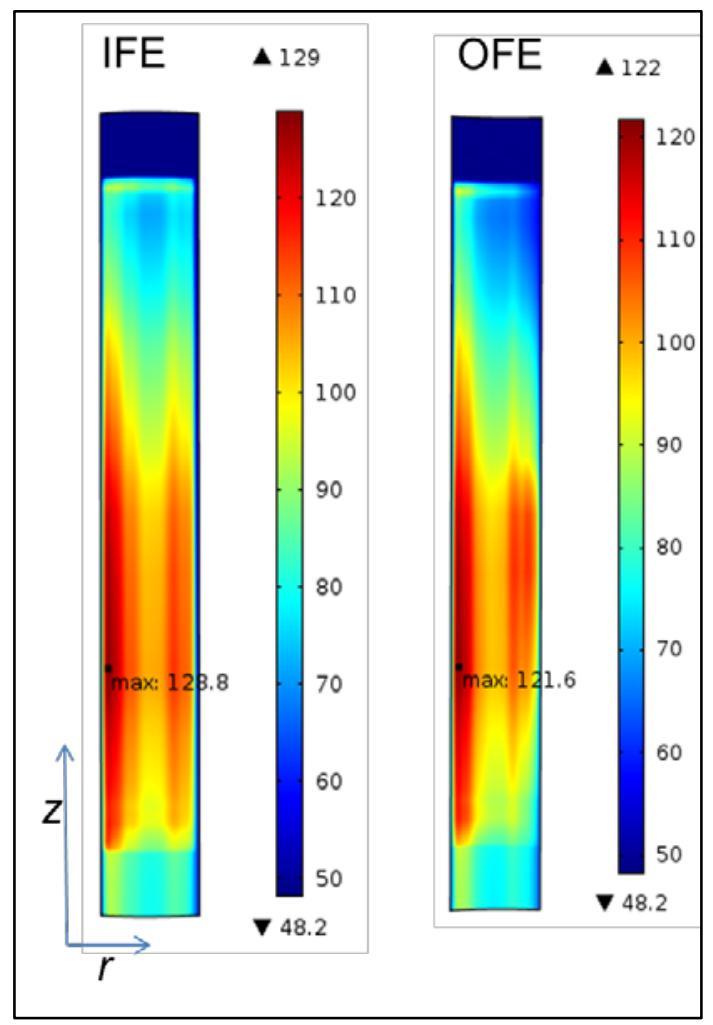

(a) beginning of cycle, BOC

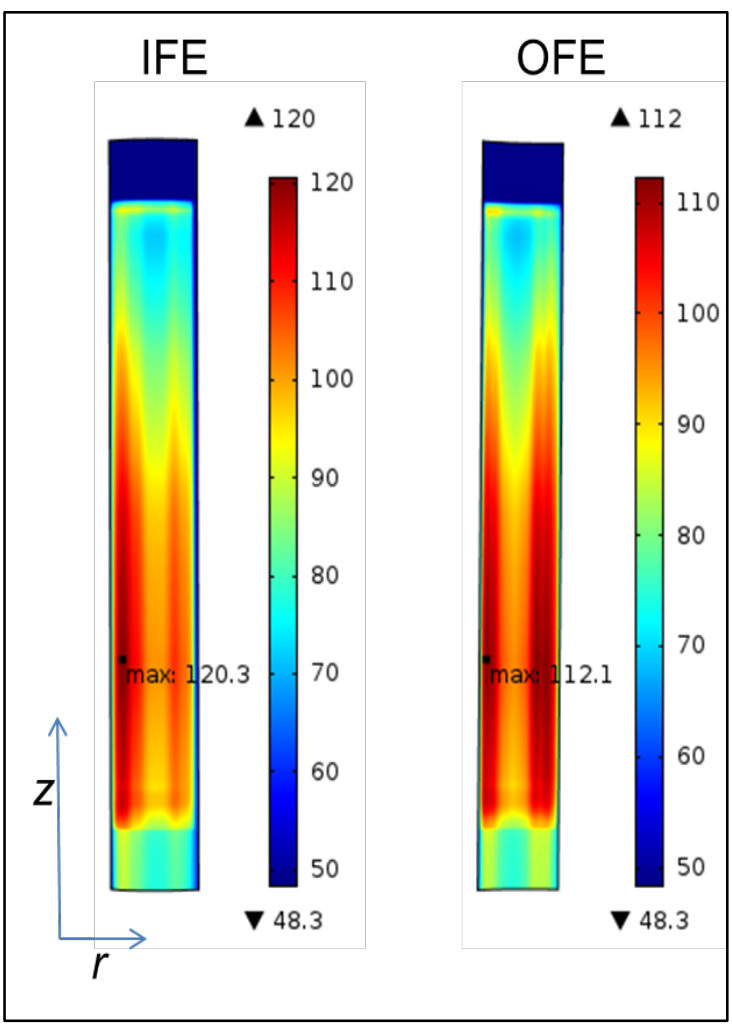

(b) end of cycle, EOC

Fig. 4.4.2. “Hot-side” clad surface temperature $\left(\right.$ in ${ }^{\circ} \mathrm{C}$ ) of the reference $\mathrm{LEU}$ fuel design for 100 MW nominal HFIR operating conditions.

At both the BOC and the EOC, peak surface temperature occurs at the inner radial edge of the IFE fuel plate. The peak location is about halfway between the core midplane and the bottom of the fuel zone. The peak surface temperature is higher in the IFE (by $\sim 8^{\circ} \mathrm{C}$ ) as compared to the OFE at both the BOC and EOC. Furthermore, the BOC peak temperatures are higher (by $\sim 8{ }^{\circ} \mathrm{C}$ ) than their corresponding EOC values.

Peak fuel meat temperatures for the IFE/OFE at the BOC are $153{ }^{\circ} \mathrm{C} / 164{ }^{\circ} \mathrm{C}$ and at the EOC are 147 ${ }^{\circ} \mathrm{C} / 151{ }^{\circ} \mathrm{C}$ which are considerably less than the aluminum melting temperature of $650{ }^{\circ} \mathrm{C}$ and the U-10Mo melting temperature of $1090^{\circ} \mathrm{C}$ for the steady-state nominal conditions.

Note that the saturation temperature corresponding to the channel outlet pressure of 374.7 psia is $225.7^{\circ} \mathrm{C}$ and the maximum clad surface temperature under nominal HFIR operating conditions at the BOC is 129 ${ }^{\circ} \mathrm{C}$ and at the EOC is $120^{\circ} \mathrm{C}$. The large difference between the saturation and peak temperatures indicates a good thermal margin during the nominal conditions of HFIR LEU operation.

Three-dimensional surface plots for the concave ("hot-side”) clad surface heat fluxes (in W/cm²) are shown in Fig. 4.4.3 for both the IFE and OFE at the BOC and EOC. At the BOC and EOC, peak surface heat fluxes are found at the core midplane and at the inner radial edge of the fuel plate for both the IFE and OFE. Additionally, the peak surface heat flux is higher in the IFE (by $\sim 50 \mathrm{~W} / \mathrm{cm}^{2}$ ) than in the OFE for both the BOC and EOC. Furthermore, the BOC peak heat fluxes are higher (by $\sim 90 \mathrm{~W} / \mathrm{cm}^{2}$ ) than their corresponding EOC values. 


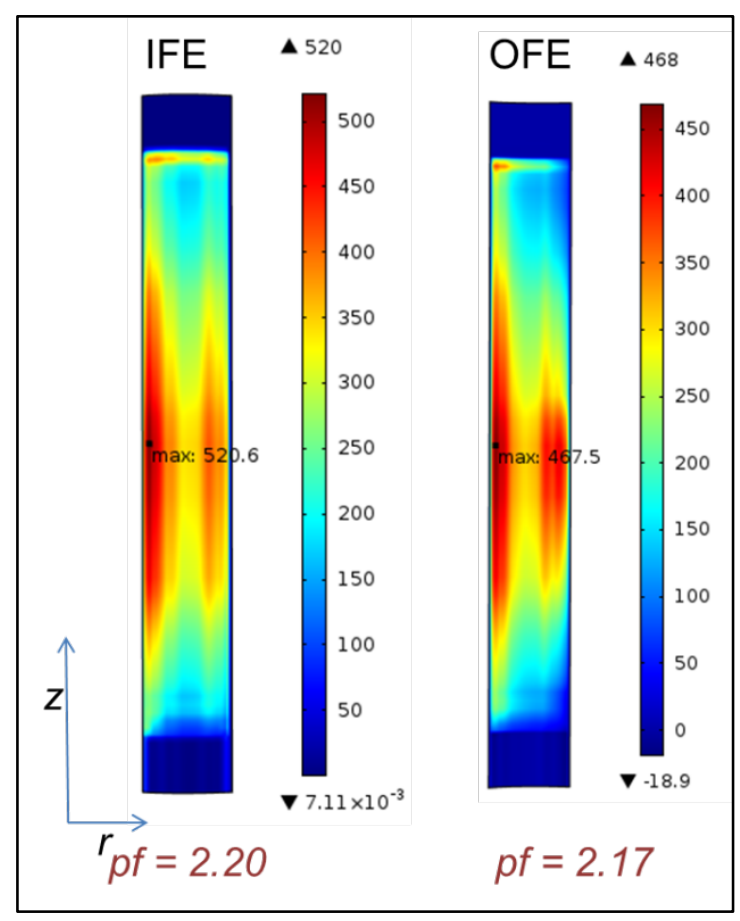

(a) beginning of cycle, BOC

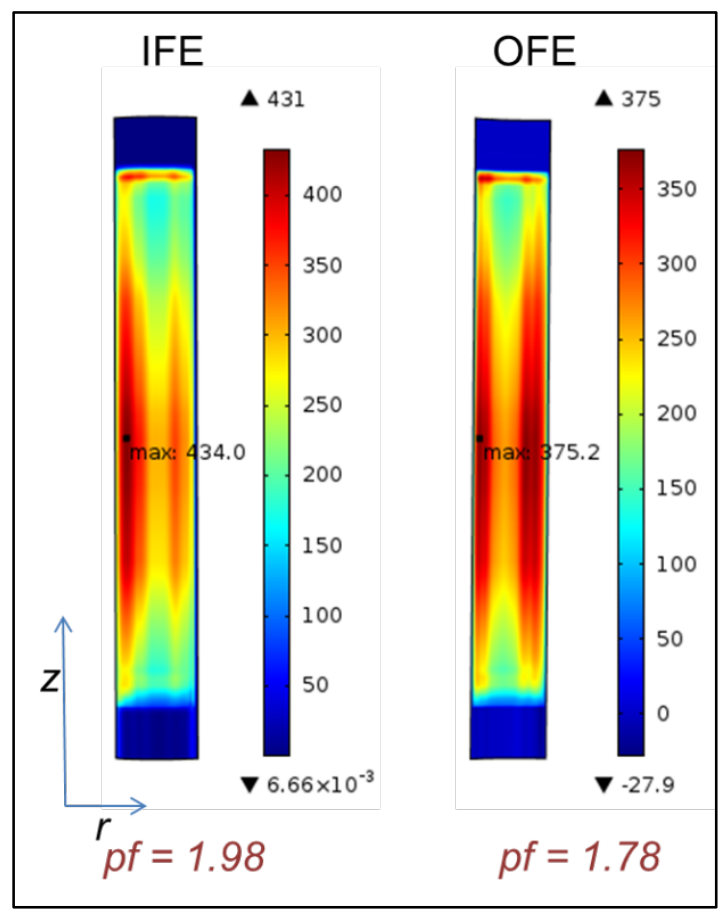

(b) end of cycle, EOC

Fig. 4.4.3. "Hot-side” surface heat flux (in W/cm²) of the reference LEU fuel design for $100 \mathrm{MW}$ nominal HFIR operating conditions.

[A peaking factor (pf) for each plate is obtained by dividing its maximum heat flux value by the surface-averaged heat flux.]

Flux peaking factors $(p f)$ are also shown in Fig. 4.4.3 for each plate. The peaking factor is calculated for each individual plate by dividing its maximum surface heat flux value by the surface-averaged value. Qualitatively, peaking factors represent the skewedness of heat generation inside the fuel plate; a lower value of which indicates a "flatter" and more optimal flux profile. A peaking factor of 1 would be ideal (although not achievable) and equivalent to a uniform heat source distribution. COMSOL results show a reduction in peaking factors as the cycle progressed from the BOC to the EOC for both the IFE and OFE.

Fuel plate thermal deflections are plotted for both the IFE and OFE in Fig. 4.4.4 at the BOC and EOC. As compared to the IFE, thermal deflections are higher in the OFE because of its thicker fuel zone (i.e., a thicker high temperature region produces a larger thermal expansion) and its flatter (i.e., less plate curvature) profile. Peak deflections are found at the plate's radial centerline slightly below the core midplane. Results also indicate slightly lower deflections at the EOC than at the BOC. 


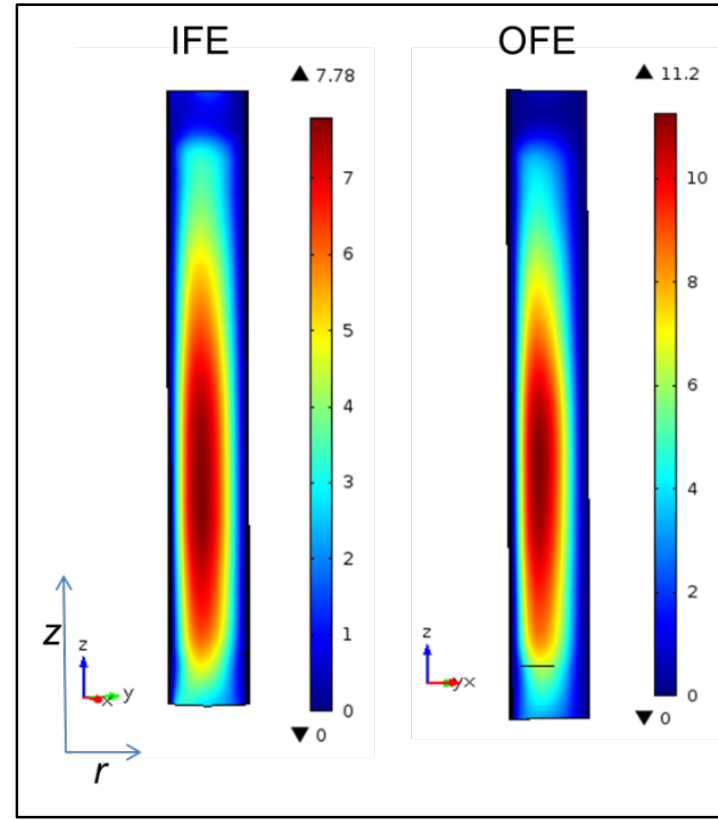

(a) beginning of cycle, BOC

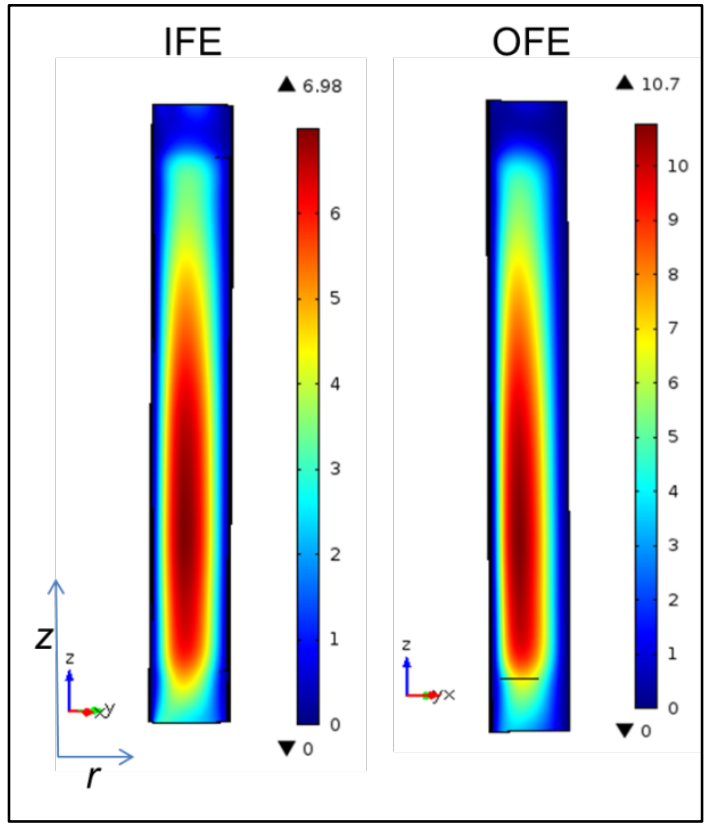

(b) end of cycle, EOC

Fig. 4.4.4. Fuel plate thermal deflection (in mil, $1 \mathrm{mil}=0.001 \mathrm{inch}$ ) of the reference $\mathrm{LEU}$ fuel design for $100 \mathrm{MW}$ nominal HFIR operating conditions.

Note that although the peak OFE deflection ( 10 mil) is significant (about $20 \%$ of the fuel plate thickness, $50 \mathrm{mil}$ ), it does not result in a similar amount of reduction in the overall channel thickness because of the azimuthal symmetry of the HFIR core. All the IFE and OFE plates deflect in the same direction and therefore, do not affect the coolant gaps significantly. However, there are other factors that may affect channel gaps including the plate fabrication uncertainties/tolerances, irradiation swelling, oxide layer deposition, pressure-induced deflections and fluid-structure interaction. These factors will be considered in the multi-plate, multi-channel safety basis models which are currently being developed.

\subsection{STEADY-STATE TH WITH NOMINAL ASSUMPTIONS (USING HSSHTC)}

The HSSHTC includes numerous uncertainty factors to consider process uncertainties, manufacturing uncertainties, uncertainties in correlations, and uncertainties in input parameters. To produce nominal temperature and heat flux information for comparison to COMSOL nominal fuel plate calculations, HSSHTC inputs, including the manufacturing uncertainties, model uncertainties, correlation uncertainties, and most input parameter modeling uncertainties, were set to "1.0." Key input adjustments and uncertainties that were retained with a non-unity value include a factor of 0.975 to model the assumption that $2.5 \%$ of the energy produced by the reactor could be deposited outside the fuel meat (i.e., in the coolant, target, reflector, and surrounding structures). The code does not track any of this lost energy-it only follows the power deposited in the fuel meat. The calculations were performed considering a factor of 1.09 on the normalized power density distribution to consider the local effects that occur due to flux tilts when strong-absorbing experiments are placed near the core.

To get EOC results for a nominal $100 \mathrm{MW}$ LEU cycle to support this report, the code input was used to cause burnout with an artificial uncertainty factor in an unfueled node located just below the core. This was done using a factor, U25, which normally models fabrication and assembly uncertainties that could cause an extension of a plate past the nominal end of the active core. For these calculations, all of the U25s were "1.0" except one, which was turned up to get convergence of the hot spot heat flux to burnout 
for a reactor power of 100MW. This allowed the code to run to completion properly and include consideration of important physical effects - such as the asymmetric heat flux over the thickness of the HFIR plates due to the location of the fuel meat closer to the concave side of the involute - without causing any significant perturbation on the resultant temperature and heat flux distributions.

To avoid code problems with the models that mimic the effects of adjacent narrow and wide channels in combination with hot and cold plates, the wide and narrow channels were modeled as a nominal channel (0.050 in. wide) plus or minus 0.001 inches deviation. The hot and cold channel uncertainty factors, plus axial fuel distribution uncertainty factors, were all set to 1.0.

The power density profile inputs to the HSSHTC for reference fuel BOC conditions are shown in Fig. 4.5.1 for both inner and outer elements. The lower end of the power density profiles show no axial water reflector peak like the upper end because of the effect of the contoured fuel, a.k.a. fuel toe. The effect of the control plate window is seen on the outer edge of the outer element power density in the lower part of Fig. 4.5.1. 


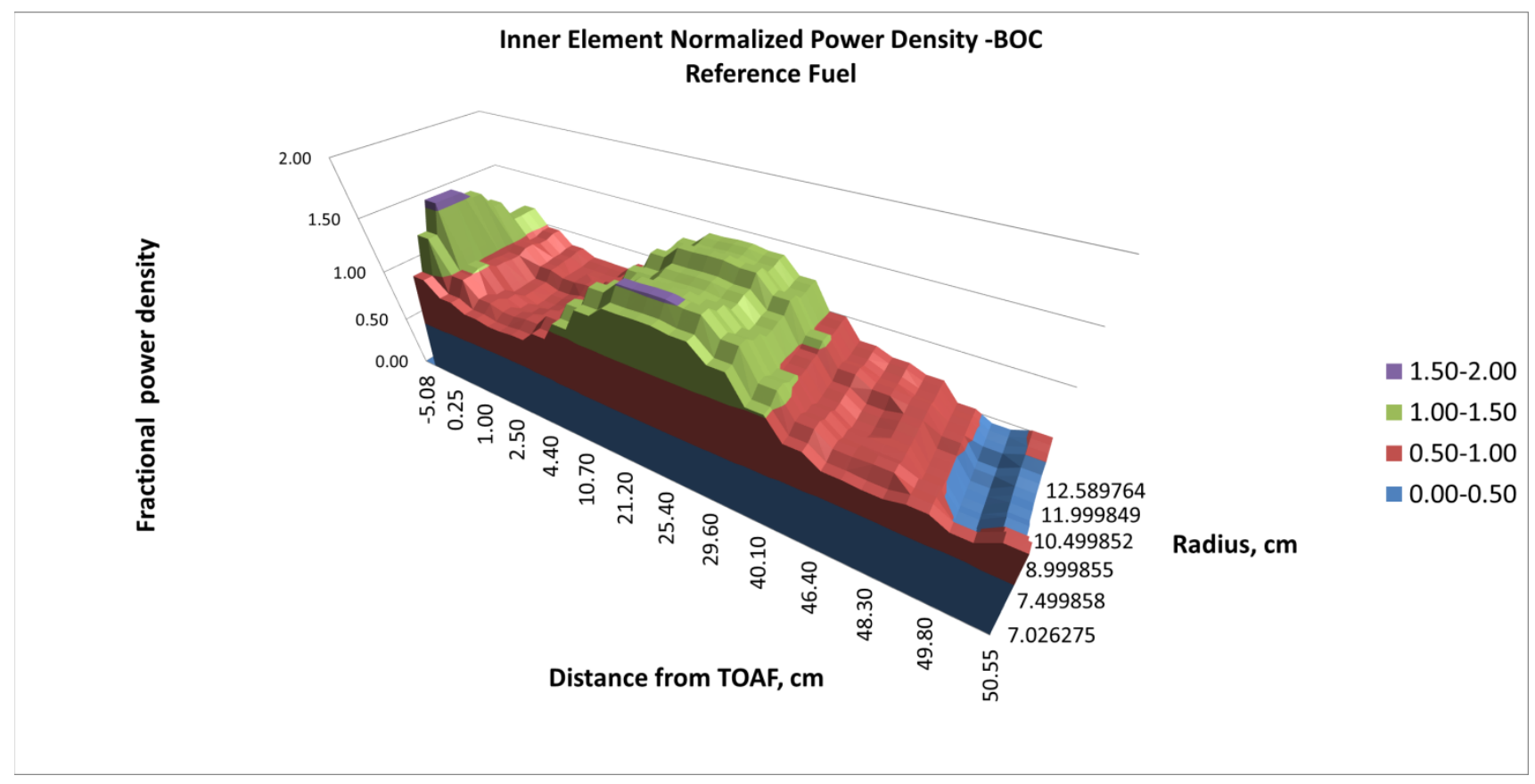
Reference Fuel

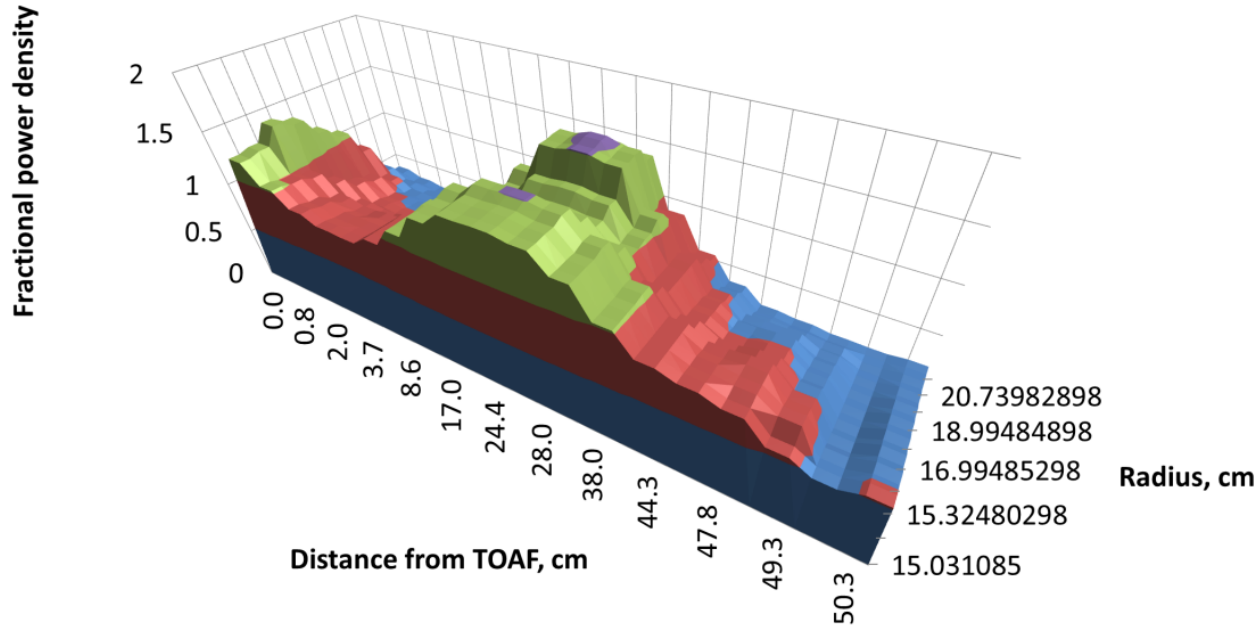

Fig. 4.5.1. LEU reference fuel BOC inner and outer element relative power densities.

Axial temperature profiles for the reference fuel BOC conditions are shown in Fig. 4.5.2 for both elements. The inner edge of the inner element has the highest temperatures as shown in the top half of Fig. 4.5.2. For the outer element, the peak temperatures alternate between the inner edge at the top and bottom of the plate and the outer edge in the middle of the plate as shown in the bottom half of Fig. 4.5.2. 


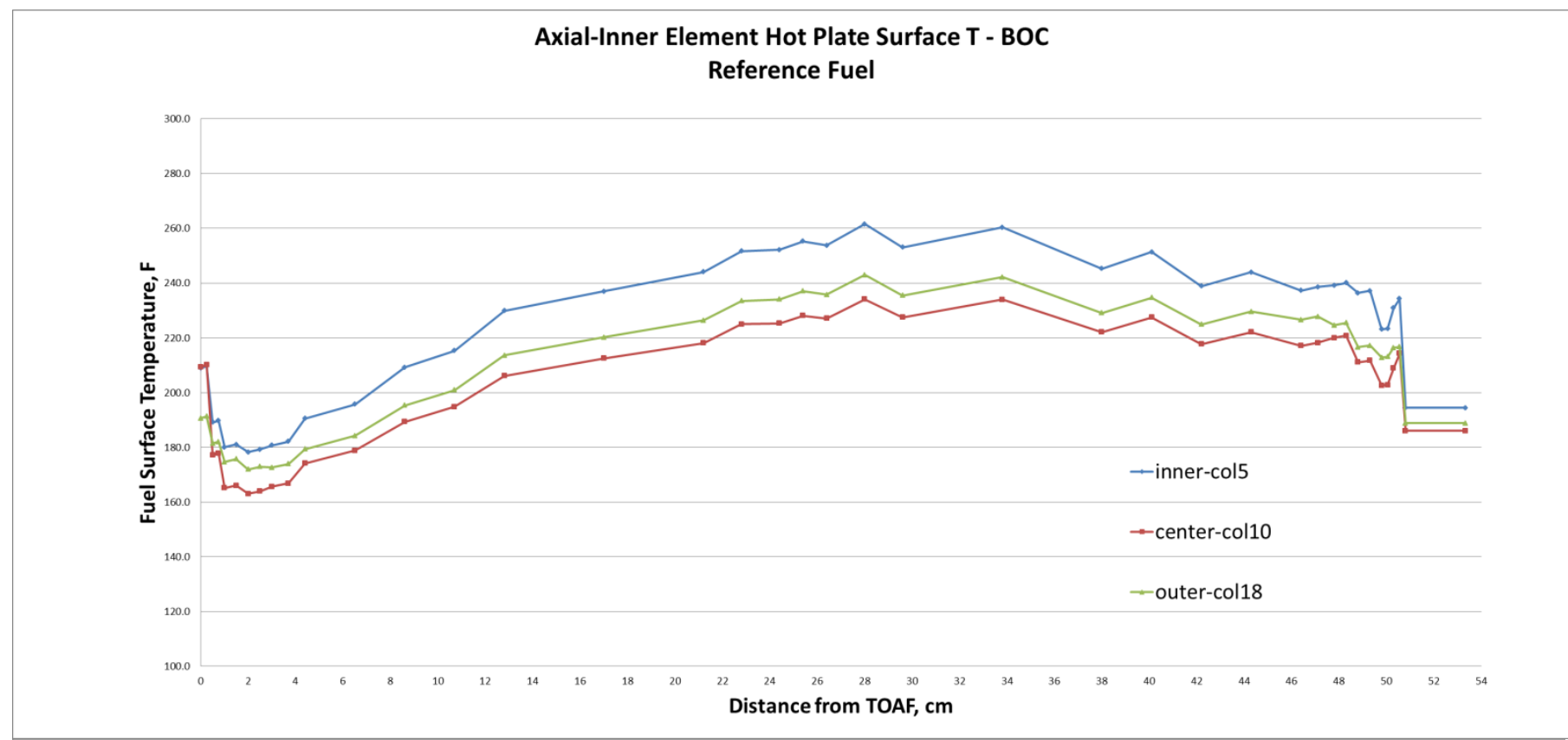

Axial-Outer Element Hot Plate Surface T - BOC

Reference Fuel

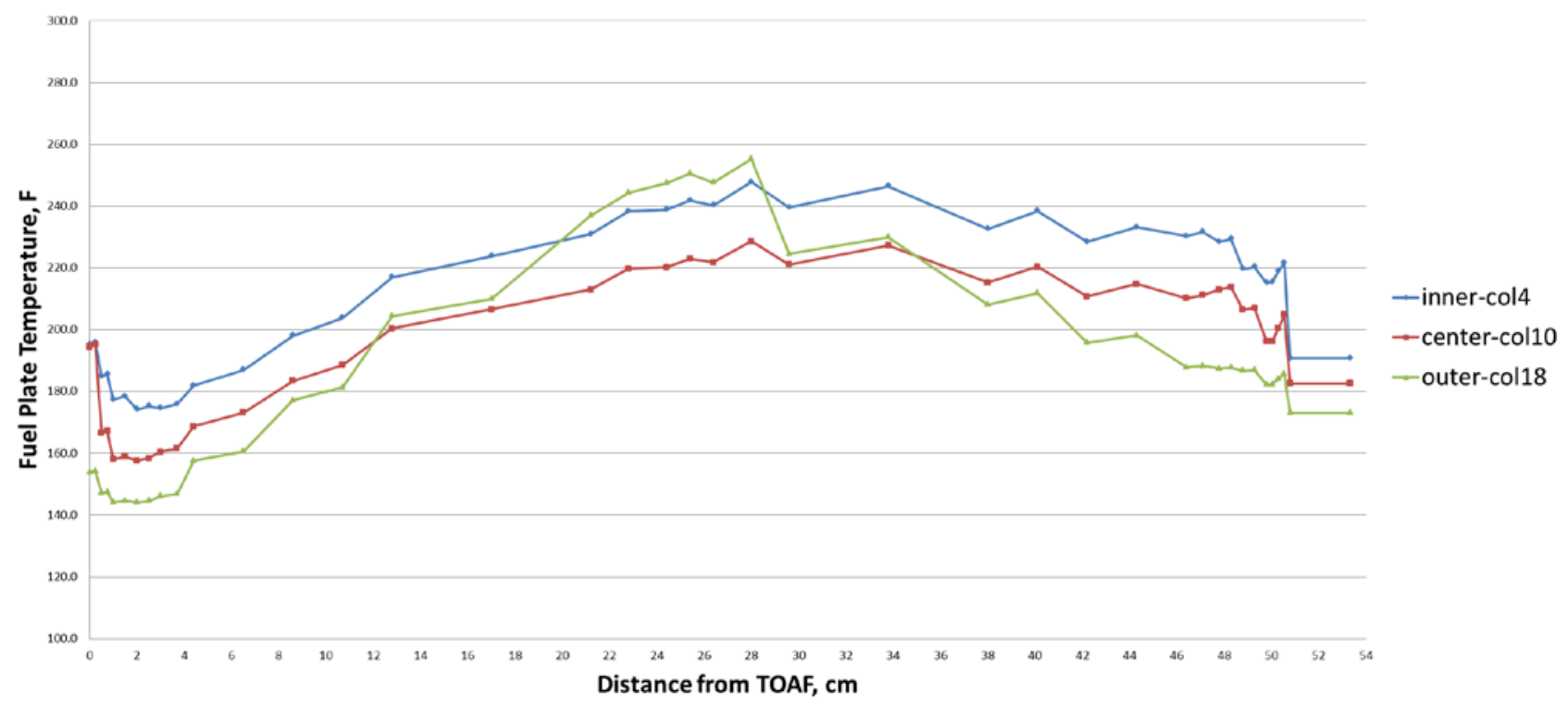

Fig. 4.5.2. LEU reference fuel BOC inner and outer element hot plate surface temperature.

Axial heat flux profiles for the reference fuel BOC conditions are shown in Fig. 4.5.3 for both elements. Similar to the temperature profiles, the inner edge of the inner element has the highest heat flux as shown in the top half of Fig. 4.5.3. For the outer element, the peak fluxes alternate between the inner edge at the top and bottom of the plate and the outer edge in the middle of the plate as shown in the bottom half of Fig. 4.5.3. 


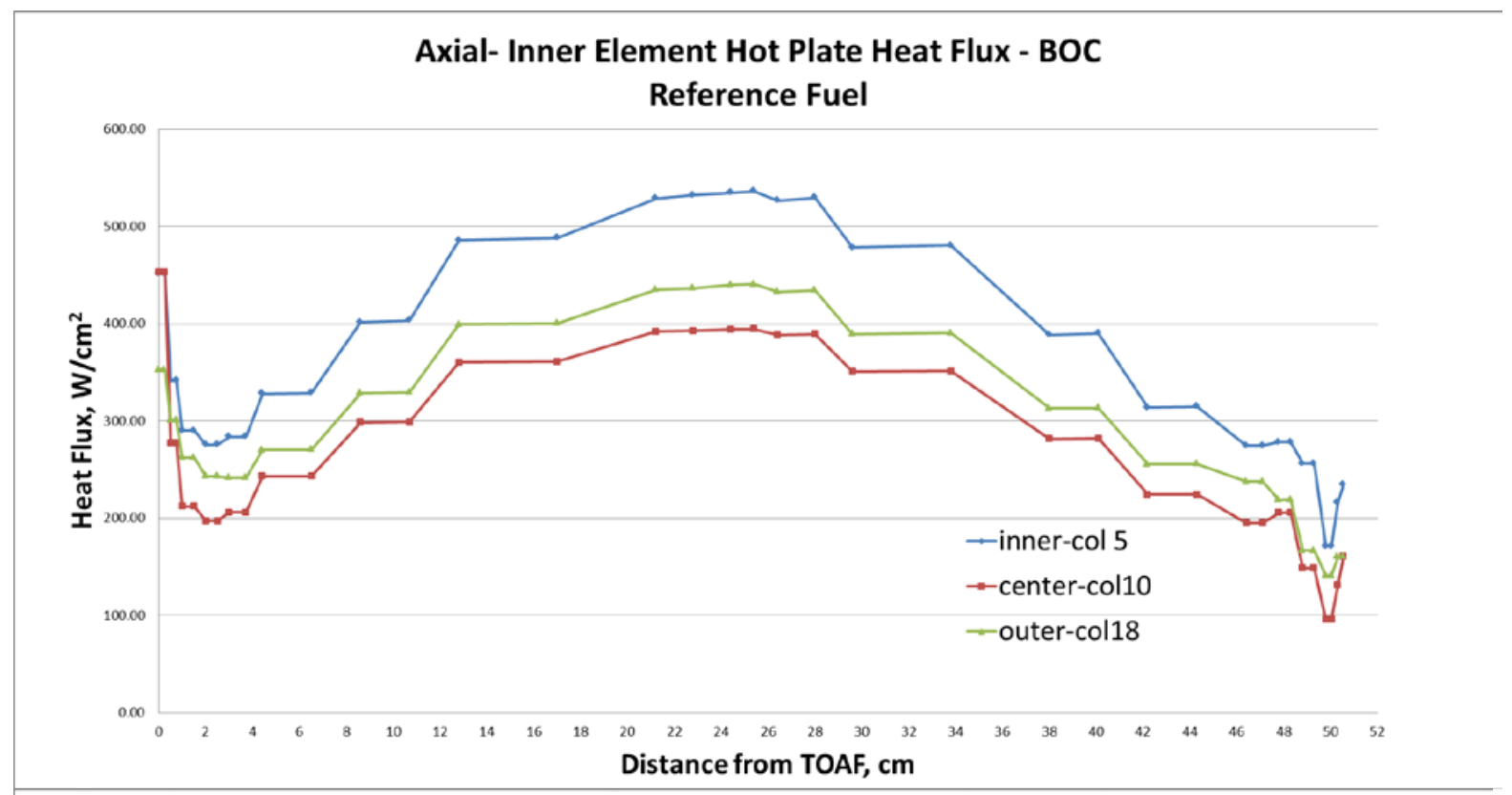

Axial - Outer Element Hot Plate Heat Flux - BOC Reference Fuel

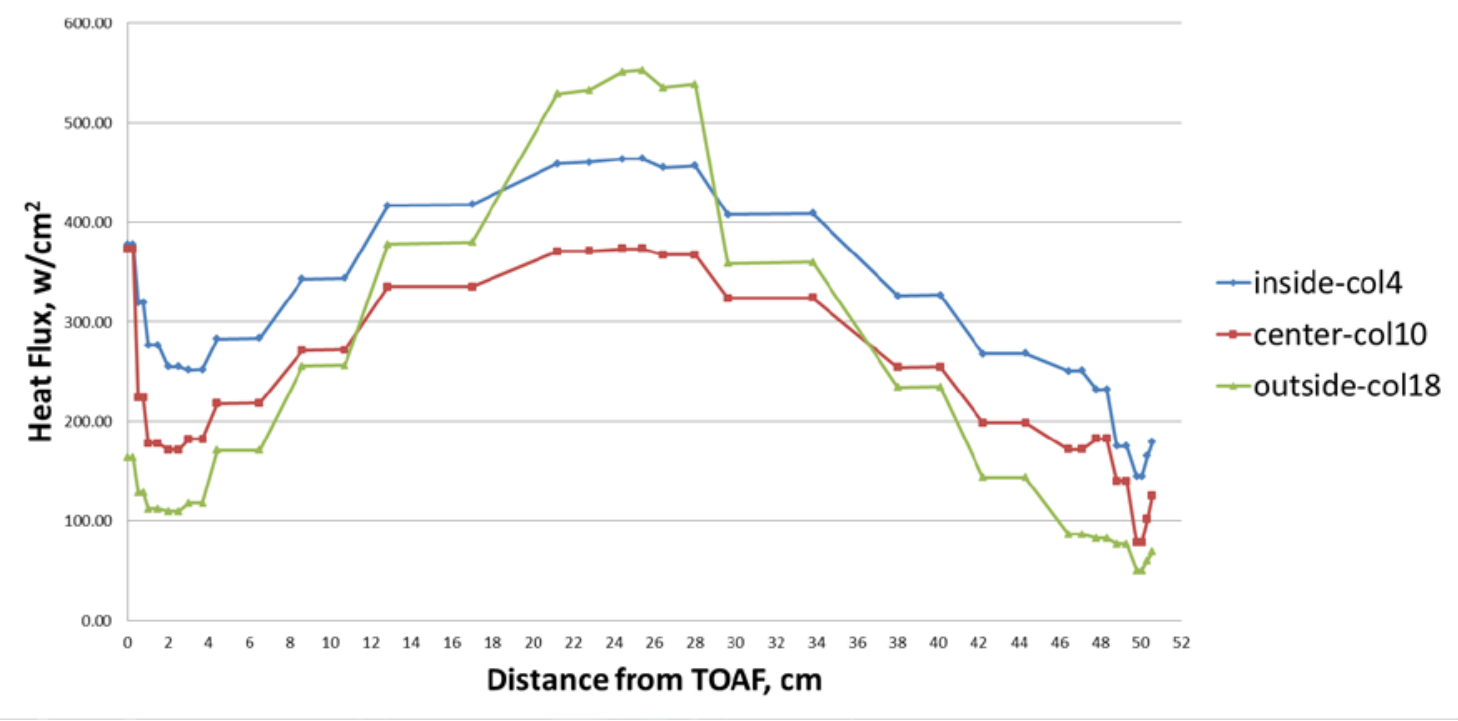

Fig. 4.5.3. LEU reference fuel BOC inner and outer element hot plate heat flux.

The power density profile inputs to the HSSHTC for reference fuel EOC conditions are shown in Fig. 4.5.4 for both inner and outer elements. In comparison to Fig. 4.5.1, the power density profiles in Fig. 4.5.4 are broader and flatter due to the fully withdrawn control elements. The effect of the control plate window on the outer element can still be seen on the outer edge of the power density in the lower part of Fig. 4.5.4. 


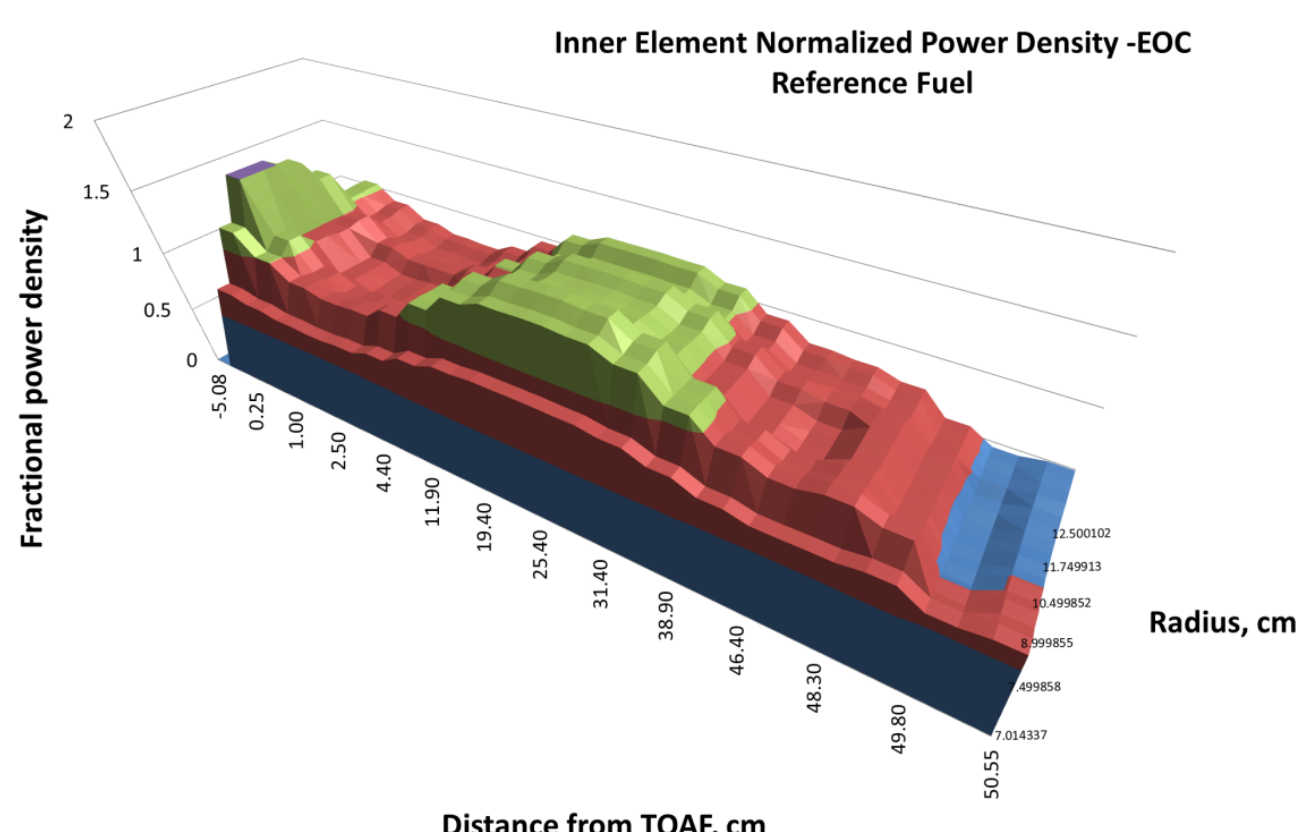

Distance from TOAF, cm

\section{Outer Element Normalized Power Density - EOC Reference Fuel}

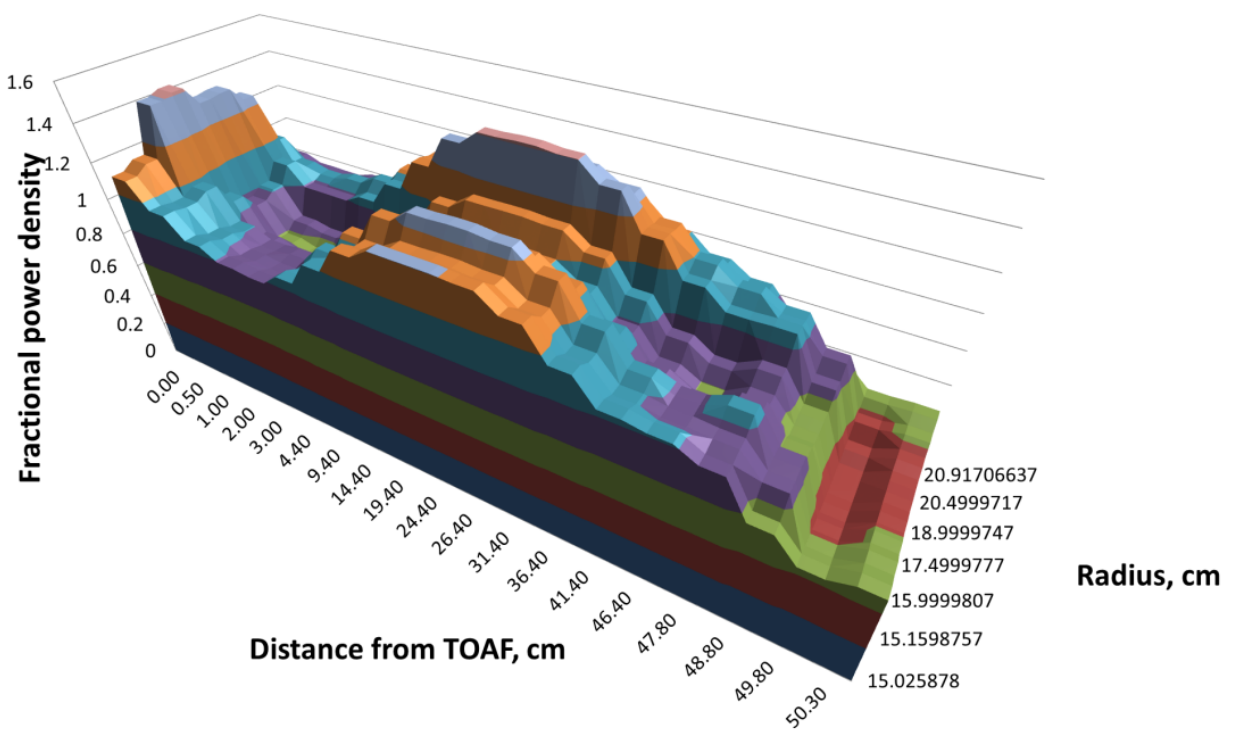

Fig. 4.5.4. LEU reference fuel EOC inner and outer element relative power densities.

Axial temperature profiles for the reference fuel EOC conditions are shown in Fig. 4.5.5 for both elements. The inner edge of the inner element has the highest EOC temperatures for the inner element plate as shown in the top half of Fig. 4.5.5. For the outer element plate, the peak temperatures occur all along the outer edge as shown in the bottom half of Fig. 4.5.5. 

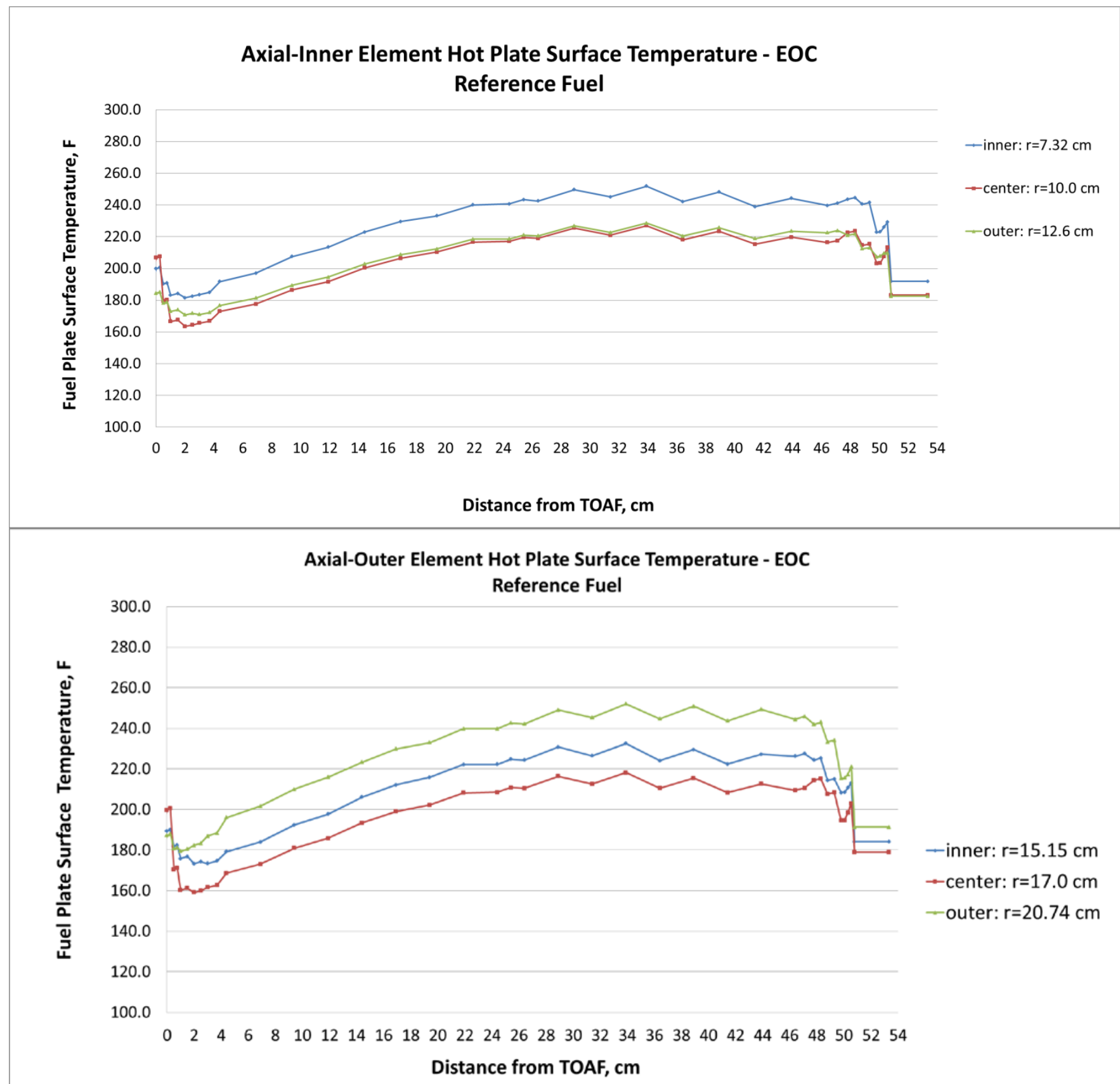

Fig. 4.5.5. LEU reference fuel EOC inner and outer element hot plate surface temperature.

Axial heat flux profiles for the reference fuel EOC conditions are shown in Fig. 4.5.6 for both elements. For the inner element plate, the center of the plate has the highest heat flux as shown in the top half of Fig. 4.5.6. For the outer element, the peak fluxes occur at the outer edge all along the plate as shown in the bottom half of Fig. 4.5.6. 


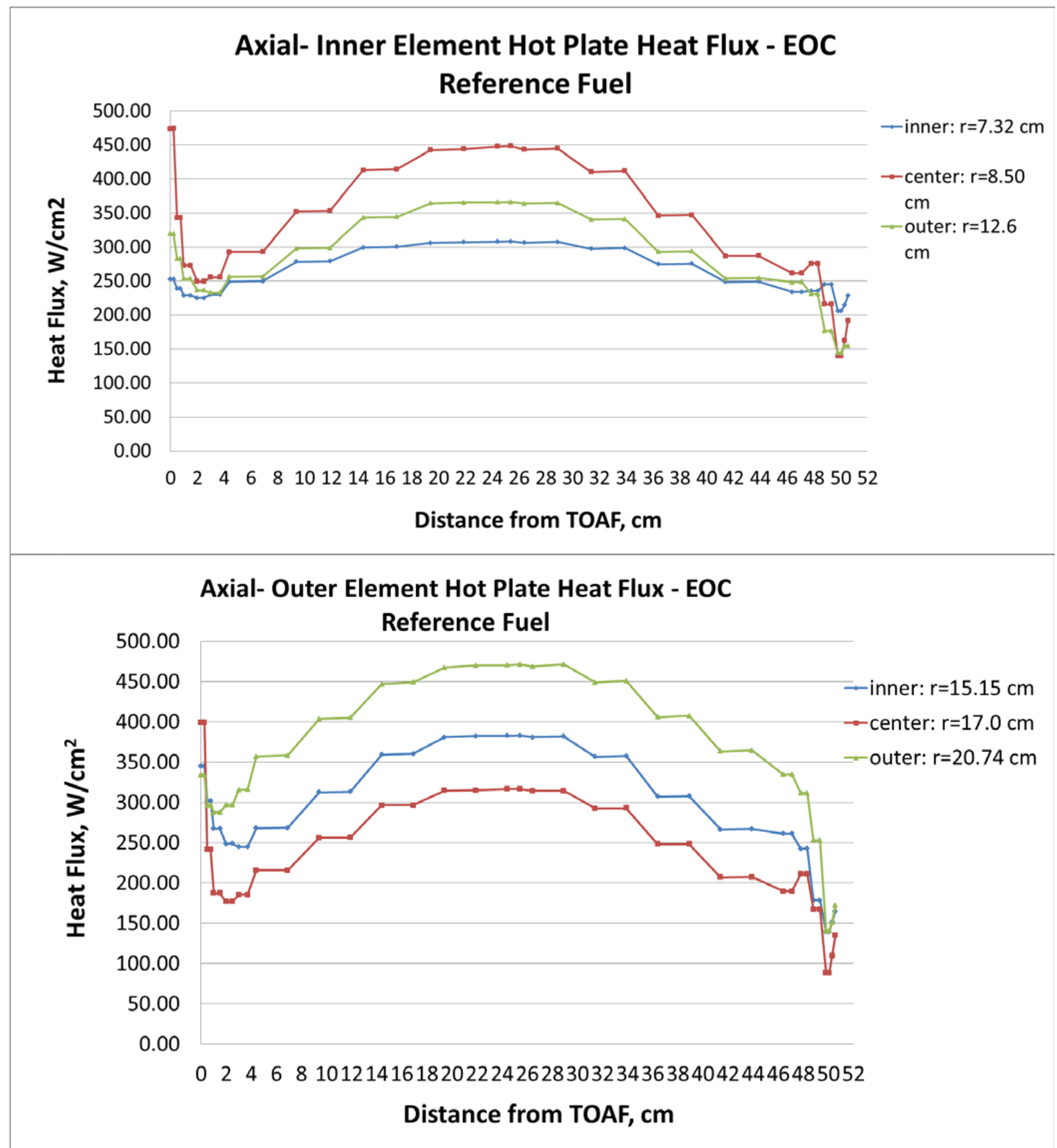

Fig. 4.5.6. LEU reference fuel EOC inner and outer element hot plate heat flux. 
A comparison between COMSOL and HSSHTC nominal results for peak surface temperatures and heat fluxes is provided in Table 4.5.1. In general, there is good agreement between the two codes for the inner element peak surface temperature and heat flux. For the outer element, the HSSHTC consistently predicts a higher surface temperature and heat flux than the COMSOL model.

Table 4.5.1. Comparison of COMSOL and HSSHTC peak clad surface temperatures and heat fluxes for the reference fuel

\begin{tabular}{|l|c|c|c|c|c|c|c|c|}
\hline & \multicolumn{4}{|c|}{ BOC } & \multicolumn{4}{c|}{ EOC } \\
\hline & $\begin{array}{c}\text { COMSOL } \\
\text { Results }\end{array}$ & $\begin{array}{c}\text { HSSHTC } \\
\text { Results }\end{array}$ & $\begin{array}{c}\text { COMSOL } \\
\text { Results }\end{array}$ & $\begin{array}{c}\text { HSSHTC } \\
\text { Results }\end{array}$ \\
\cline { 2 - 9 } & IFE & OFE & IFE & OFE & IFE & OFE & IFE & OFE \\
\hline Peak clad surface temperature $\left({ }^{\circ} \mathrm{C}\right)$ & 129 & 122 & 128 & 124 & 120 & 112 & 122 & 124 \\
\hline $\begin{array}{l}\text { Peak clad surface heat flux } \\
\left(\mathbf{W} / \mathrm{cm}^{2}\right)\end{array}$ & 521 & 468 & 536 & 552 & 434 & 375 & 474 & 490 \\
\hline
\end{tabular}




\section{EVALUATION OF FUEL WITH NO RADIAL OR AXIAL CONTOURING}

A complete fuel cycle analysis of a flat fuel zone design (i.e., no radial or axial contouring of the fuel) was not performed; however, a BOC study was conducted to assess the relative fission density profile of a flat fuel zone design and to compare it to that of the reference LEU fuel design[2] that utilizes both radial and axial contouring. The reference BOC LEU MCNP input was modified to incorporate fuel plates containing a flat fuel zone profile.

The thicknesses of the fuel zones in the IFE and OFE plates are 0.0302 and $0.0484 \mathrm{~cm}$, respectively, which are the average fuel thicknesses along the reference LEU design fuel plates. Thus, the total ${ }^{235} U$ mass loading is about $26.04 \mathrm{~kg}$, which is the same core loading used in Alternate Designs 1, 2, 5, 6, and 7. Since there is no radial contouring, it is assumed that there is no filler material, and thus, the burnable poison is distributed within the aluminum clad. The amount of $\mathrm{B}_{4} \mathrm{C}$ utilized in this model is the same as that used in the reference model, but the distribution is uniform across the plate. The flat fuel zone geometries are illustrated in Fig. 5.1.
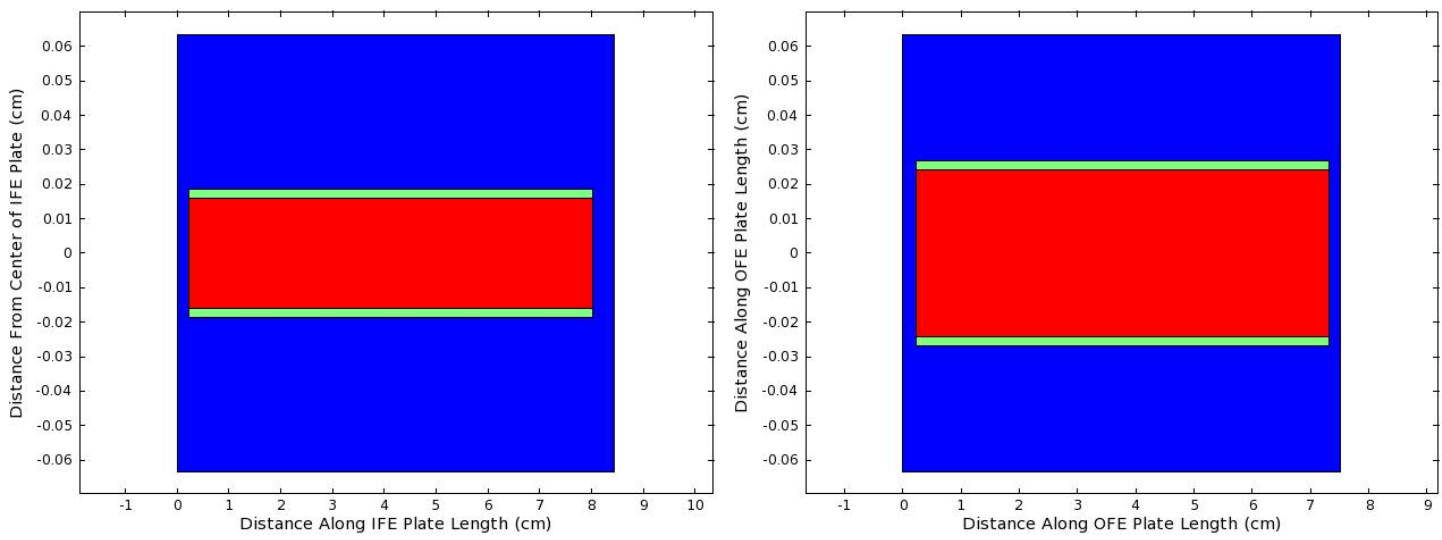

Fig. 5.1. Flat fuel zone geometry for IFE (left) and OFE (right) (red is fuel, green is $\mathrm{Zr}$, blue is clad).

All of the fuel-bearing radial regions as modeled in MCNP are volumetrically homogenized and contain the aluminum clad, the $\mathrm{Zr}$ diffusion layer, the U-10Mo fuel, the $\mathrm{B}_{4} \mathrm{C}$ burnable poison, and the water coolant in between fuel plates. The BOC relative fission densities for the flat fuel zone design are illustrated and compared to the reference design relative fission densities in Fig. 5.2. The relative fission density profiles across the horizontal midplane for both designs are illustrated in Fig. 5.3. As shown in Figs. 5.2 and 5.3, the relative fission density profile is much "flatter" for the reference design in comparison to the flat fuel zone design. A maximum BOC relative fission density of 3.45 at the inner edge of the inner fuel element (IFE) on the core horizontal midplane was calculated for the flat fuel zone design. This is signficantly greater than the maximum value of 1.56 (top center of IFE plate) calculated for the reference fuel design. 

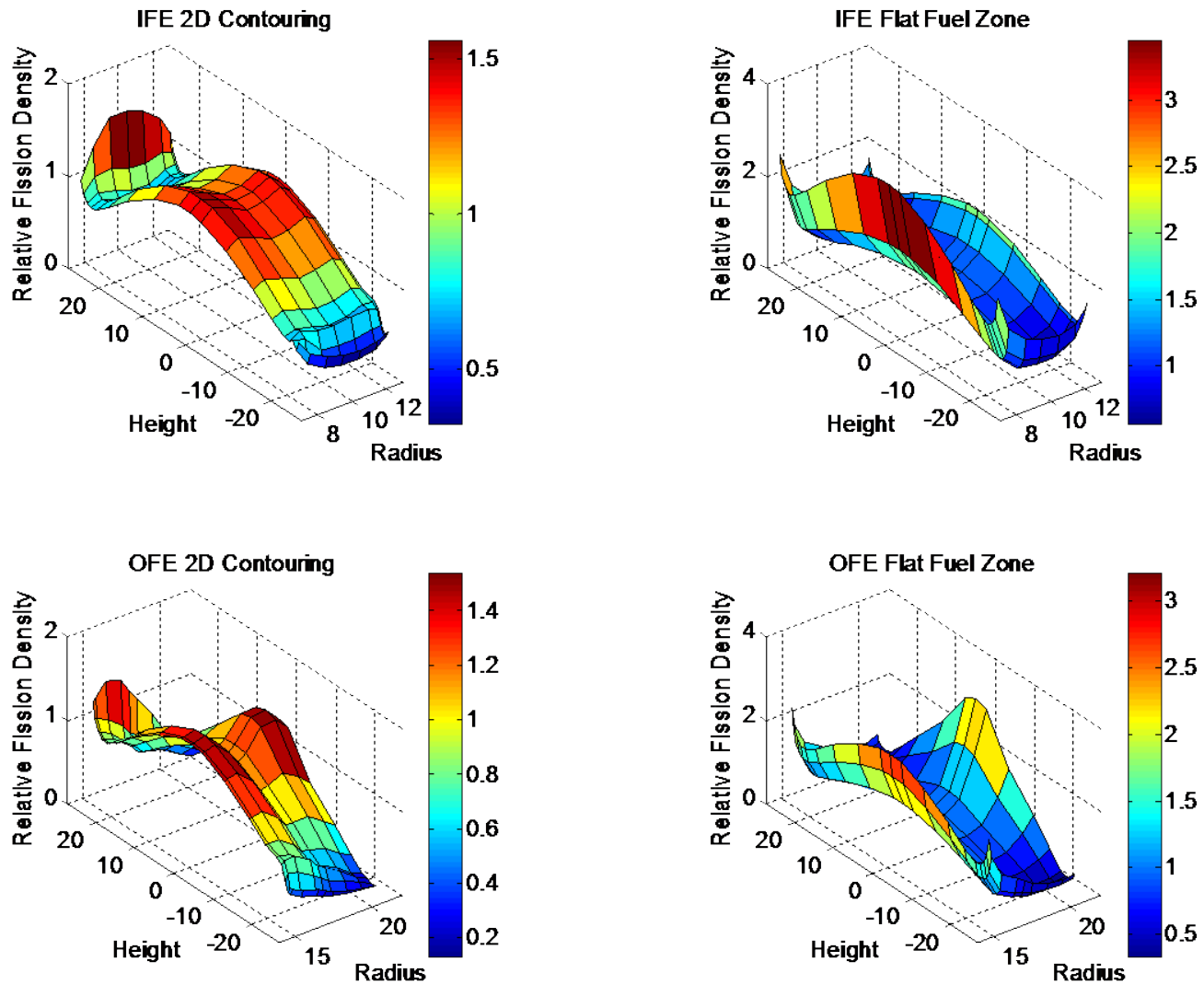

Fig. 5.2. Comparison of reference and flat fuel zone designs relative fission densities (3D profile) at BOC

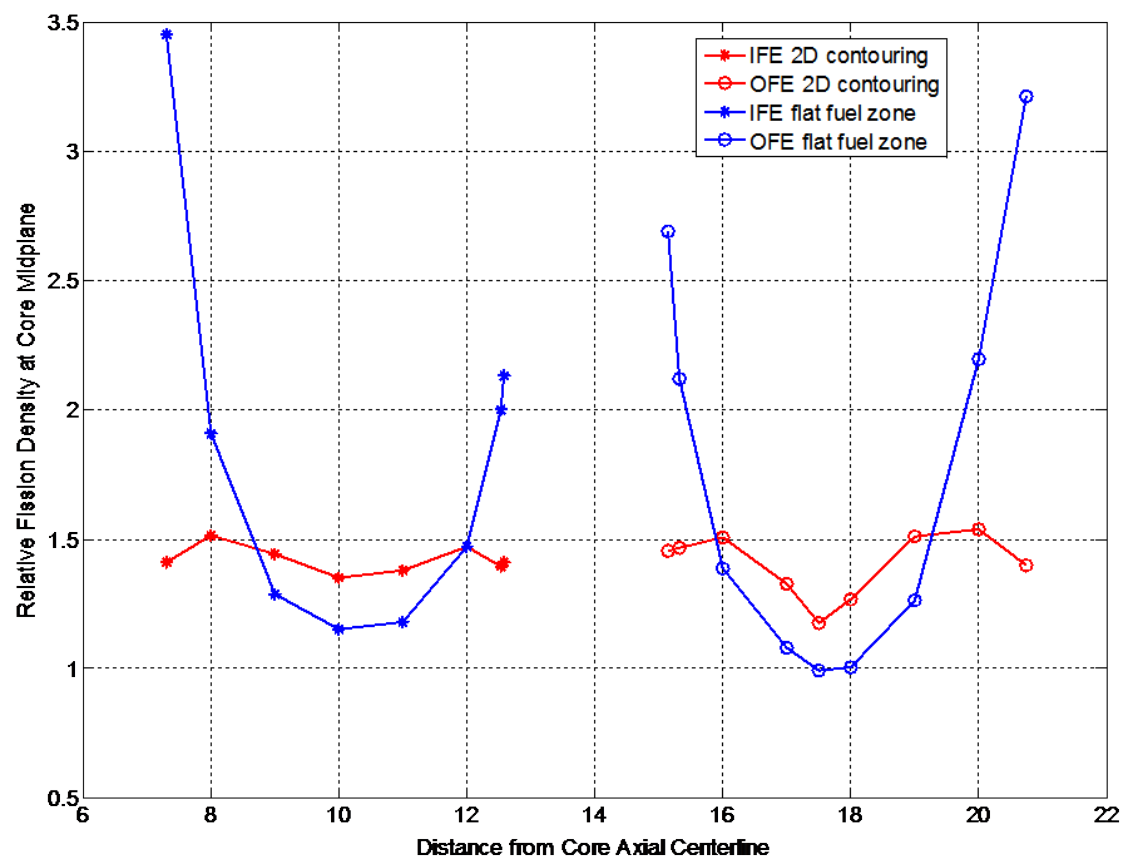

Fig. 5.3. Comparison of reference and flat fuel zone designs relative fission densities (core midplane) at BOC. 
Fission rate density profiles, at BOC, for select axial regions (core horizontal midplane, upper edge of the active fuel region, lower edge of the active fuel region, and average over active fuel height) are shown in Fig. 5.4 as a function of the radial distance from the longitudinal centerline of the core. A similar plot, illustrating the fission rate density profiles for select radial regions (innermost, outermost, and central radial meshes) in the IFE and OFE, is provided in Fig. 5.5 as a function of the axial distance from the core horizontal midplane.

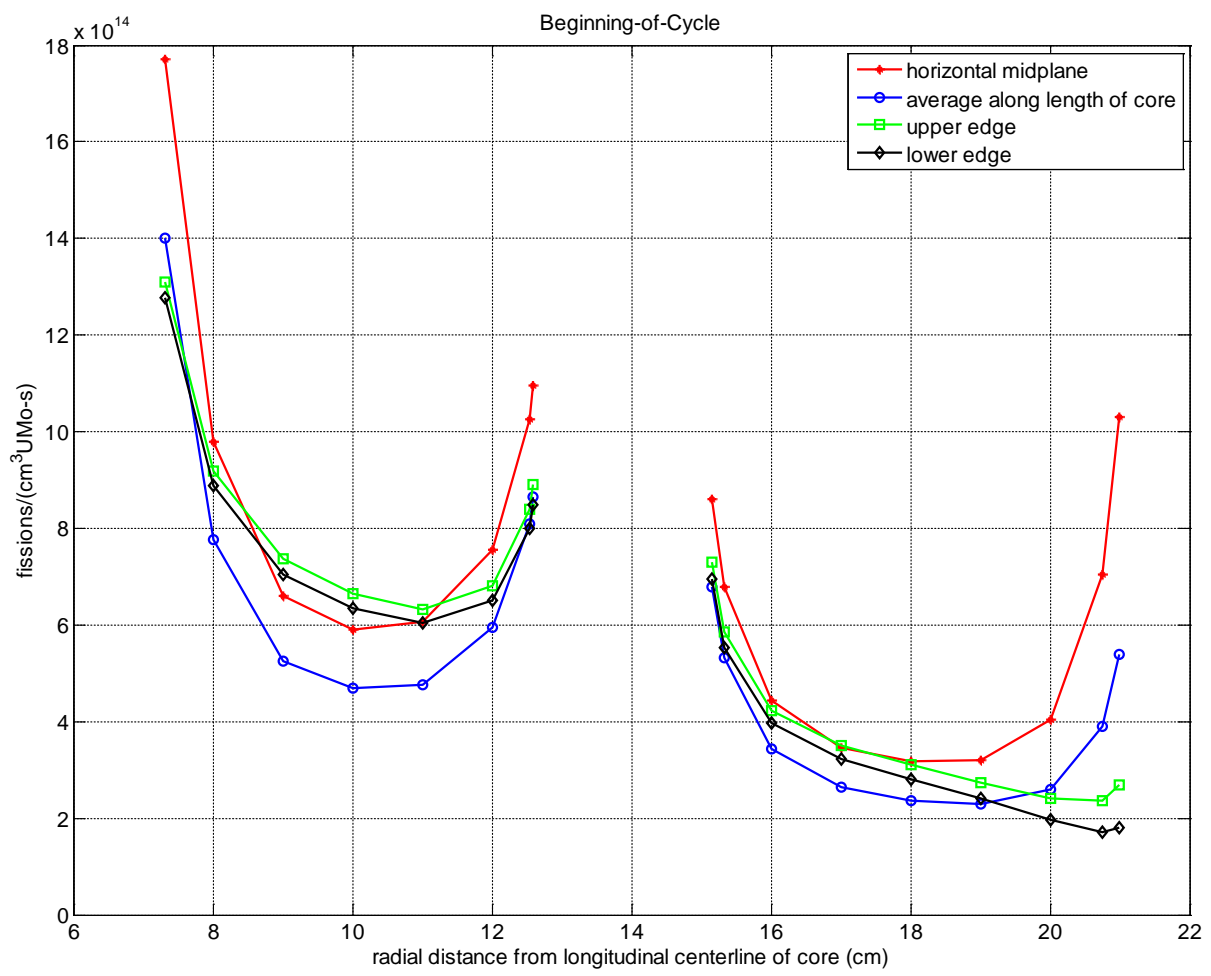

Fig. 5.4. BOC radial distribution of fission rate densities for flat fuel zone design. 


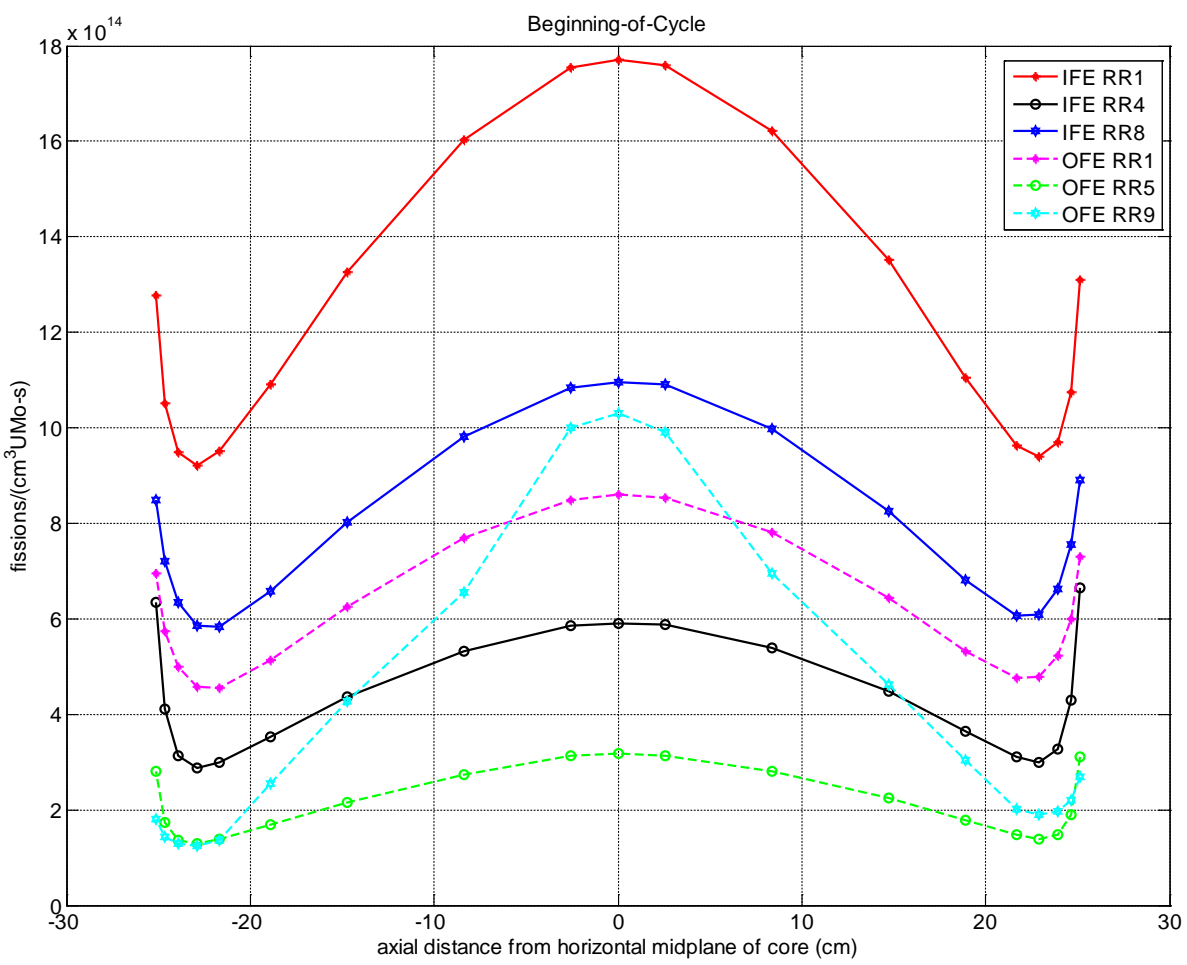

Fig. 5.5. BOC axial distribution of fission rate densities for flat fuel zone design.

A maximum BOC local fission rate density of $1.77 \times 10^{15}$ fissions $/\left(\mathrm{cm}^{3} \mathrm{U}-10 \mathrm{Mo} \cdot \mathrm{s}\right)$ was calculated, and this maximum is located at the inner radial edge of the IFE on the core horizontal midplane. Assuming conservatively that $100 \%$ of the total reactor power $(100 \mathrm{MW})$ is deposited in the fuel meat, this maximum fission rate density would correspond to a power density of about $56.96 \mathrm{~kW} /\left(\mathrm{cm}^{3} \mathrm{UMo}\right)$.

Thus, the maximum fission rate density and power density of the flat fuel zone design at BOC are less than those of the reference LEU design because the fuel volumes in the regions where maximum fission rate densities occur have been increased.

The HSSHTC was run for the BOC flat fuel relative power density distribution using the same input parameters as the BOC reference fuel to get a burnout power at the BOC safety limit conditions. This is essentially the beginning point on a cycle curve similar to the reference fuel in Fig. 4.2.1, which had a BOC burnout power of about 153 MW. A version of the HSSHTC as described in Section 12.2 was used to model the flat fuel, which is centered and symmetric. The converged power using the flat fuel distribution was 73.26 MW, which is a power that is far below the existing SL for HEU fuel and, thus, the flat fuel zone is not an acceptable alternative. 


\section{EVALUATION OF ALTERNATE 1 (NO AXIAL CONTOURING)}

\subsection{NEUTRONICS}

In Alternate Design 1 there is no axial fuel contouring, as applied at the bottom $3 \mathrm{~cm}$ of the fuel zone in the reference LEU design. This is the only difference between this alternate and the reference design. The addition of extra fuel at the bottom in Alternate 1 results in an increase of the initial ${ }^{235} \mathrm{U}$ core load from $25.27 \mathrm{~kg}$ to $26.04 \mathrm{~kg}$ and a slight decrease in the total amount of ${ }^{10} \mathrm{~B}$ in the IFE fuel plates compared to the reference, from $5.40 \mathrm{~g}$ to $5.29 \mathrm{~g}$.

A comparison of the $\mathrm{k}_{\text {eff }}$ values as a function of irradiation time, for the reference and Alternate 1 , is presented in Fig. 6.1.1. The VESTA depletion simulation was performed for Alternate 1 using the critical control search option[8], which is described in Section 3. As expected, the addition of fuel leads to an increase, estimated here as $\sim 2 \mathrm{~d}$, in the cycle length.

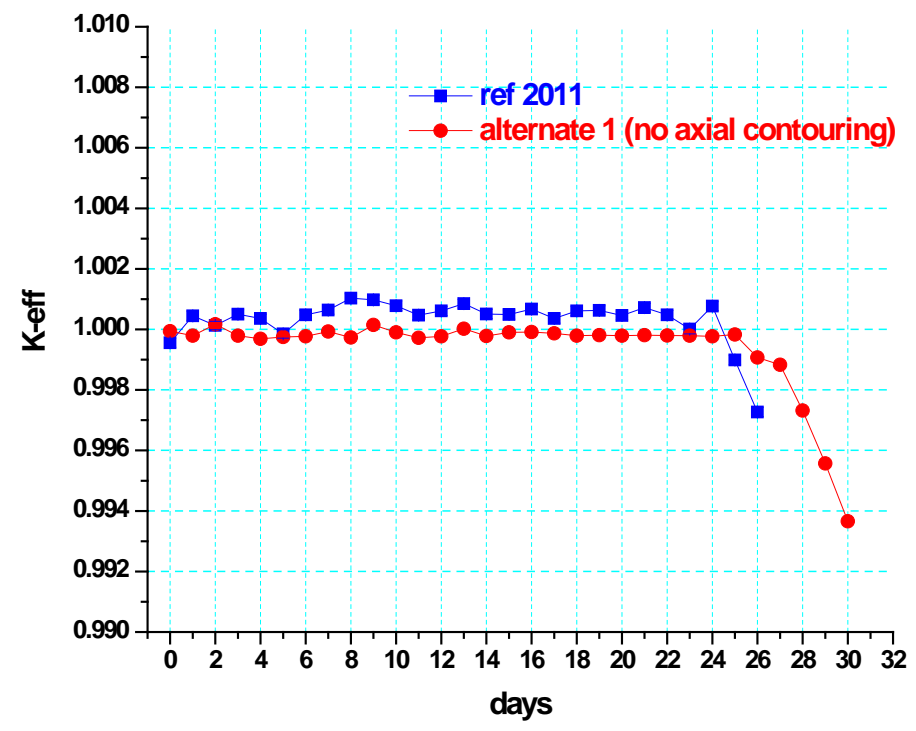

Fig. 6.1.1. Effective multiplication factor for LEU reference and Alternate Design 1.

The BOC and EOC (28d) relative fission density data are illustrated, as surface plots, in Fig. 6.1.2 and listed in Tables 6.1.1 and 6.1.2. The maximum value for the relative fission density at BOC and EOC is 1.531 and 1.461, respectively. The maximum relative fission density at BOC occurs in the uppermost axial region (i.e., at the coolant inlet) of the IFE, whereas at EOC it occurs at the bottom axial region (i.e., at the coolant outlet) of the OFE. 

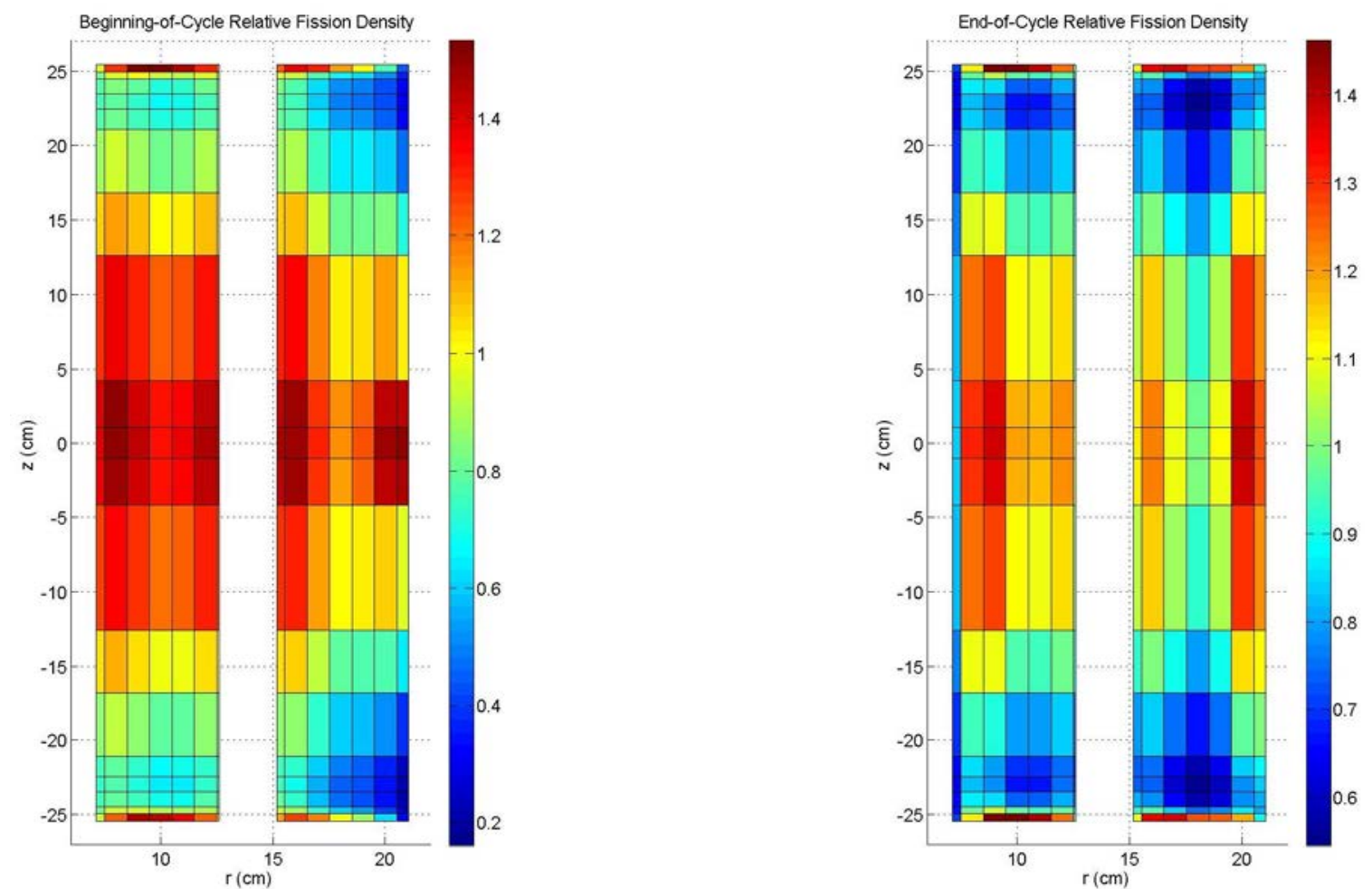

Fig. 6.1.2. Relative fission density for LEU Alternate 1 at BOC (left) and EOC (right). 
ORNL/TM-2014/154

Table 6.1.1 Relative fission densities for LEU Alternate Design 1 at BOC

\begin{tabular}{|c|c|c|c|c|c|c|c|c|c|c|c|c|c|c|c|c|c|}
\hline \multirow{2}{*}{$\begin{array}{l}\text { Axial } \\
\text { region \# }\end{array}$} & \multicolumn{8}{|c|}{ IFE } & \multicolumn{9}{|c|}{ OFE } \\
\hline & $\mathrm{r}=1^{a}$ & $r=2$ & $r=3$ & $r=4$ & $r=5$ & $r=6$ & $\mathrm{r}=7$ & $r=8$ & $r=1$ & $r=2$ & $r=3$ & $r=4$ & $r=5$ & $r=6$ & $\mathrm{r}=7$ & $\mathrm{r}=8$ & $\mathrm{r}=9$ \\
\hline 1 & 0.973 & 1.284 & 1.531 & 1.527 & 1.454 & 1.309 & 1.113 & 1.118 & 1.176 & 1.211 & 1.360 & 1.297 & 1.127 & 1.016 & 0.774 & 0.458 & 0.343 \\
\hline 2 & 0.842 & 0.974 & 1.001 & 0.940 & 0.919 & 0.958 & 0.926 & 0.946 & 0.997 & 0.972 & 0.935 & 0.779 & 0.659 & 0.616 & 0.522 & 0.360 & 0.289 \\
\hline 3 & 0.768 & 0.831 & 0.783 & 0.717 & 0.720 & 0.807 & 0.815 & 0.838 & 0.868 & 0.843 & 0.777 & 0.621 & 0.517 & 0.490 & 0.434 & 0.316 & 0.258 \\
\hline 4 & 0.742 & 0.786 & 0.729 & 0.665 & 0.678 & 0.759 & 0.757 & 0.775 & 0.802 & 0.783 & 0.740 & 0.596 & 0.496 & 0.474 & 0.421 & 0.306 & 0.252 \\
\hline 5 & 0.761 & 0.811 & 0.754 & 0.697 & 0.708 & 0.775 & 0.757 & 0.768 & 0.796 & 0.784 & 0.763 & 0.632 & 0.531 & 0.510 & 0.452 & 0.326 & 0.263 \\
\hline 6 & 0.874 & 0.937 & 0.884 & 0.822 & 0.835 & 0.893 & 0.849 & 0.861 & 0.885 & 0.885 & 0.892 & 0.759 & 0.645 & 0.632 & 0.596 & 0.464 & 0.387 \\
\hline 7 & 1.065 & 1.143 & 1.082 & 1.010 & 1.025 & 1.090 & 1.030 & 1.042 & 1.070 & 1.077 & 1.098 & 0.948 & 0.817 & 0.820 & 0.829 & 0.707 & 0.606 \\
\hline 8 & 1.279 & 1.373 & 1.304 & 1.220 & 1.242 & 1.322 & 1.253 & 1.266 & 1.302 & 1.310 & 1.342 & 1.170 & 1.020 & 1.051 & 1.130 & 1.031 & 0.905 \\
\hline 9 & 1.387 & 1.491 & 1.417 & 1.328 & 1.352 & 1.443 & 1.367 & 1.382 & 1.426 & 1.435 & 1.474 & 1.295 & 1.147 & 1.222 & 1.436 & 1.442 & 1.304 \\
\hline 10 & 1.396 & 1.499 & 1.426 & 1.337 & 1.364 & 1.454 & 1.377 & 1.393 & 1.438 & 1.447 & 1.486 & 1.305 & 1.160 & 1.244 & 1.476 & 1.500 & 1.361 \\
\hline 11 & 1.381 & 1.483 & 1.408 & 1.322 & 1.345 & 1.435 & 1.361 & 1.376 & 1.417 & 1.428 & 1.467 & 1.287 & 1.141 & 1.218 & 1.437 & 1.450 & 1.312 \\
\hline 12 & 1.260 & 1.353 & 1.283 & 1.200 & 1.220 & 1.298 & 1.228 & 1.242 & 1.279 & 1.287 & 1.316 & 1.145 & 0.997 & 1.018 & 1.078 & 0.966 & 0.841 \\
\hline 13 & 1.039 & 1.115 & 1.052 & 0.982 & 0.993 & 1.054 & 0.997 & 1.008 & 1.038 & 1.042 & 1.062 & 0.912 & 0.782 & 0.779 & 0.777 & 0.649 & 0.549 \\
\hline 14 & 0.857 & 0.913 & 0.856 & 0.792 & 0.801 & 0.856 & 0.818 & 0.829 & 0.847 & 0.848 & 0.853 & 0.722 & 0.607 & 0.582 & 0.523 & 0.384 & 0.310 \\
\hline 15 & 0.749 & 0.789 & 0.728 & 0.665 & 0.675 & 0.738 & 0.722 & 0.733 & 0.755 & 0.745 & 0.726 & 0.595 & 0.491 & 0.456 & 0.367 & 0.230 & 0.174 \\
\hline 16 & 0.729 & 0.763 & 0.698 & 0.632 & 0.644 & 0.722 & 0.721 & 0.734 & 0.757 & 0.740 & 0.695 & 0.557 & 0.456 & 0.421 & 0.339 & 0.212 & 0.161 \\
\hline 17 & 0.746 & 0.801 & 0.752 & 0.681 & 0.684 & 0.763 & 0.771 & 0.787 & 0.817 & 0.792 & 0.729 & 0.577 & 0.472 & 0.431 & 0.347 & 0.217 & 0.165 \\
\hline 18 & 0.813 & 0.936 & 0.953 & 0.890 & 0.868 & 0.901 & 0.876 & 0.897 & 0.942 & 0.916 & 0.873 & 0.719 & 0.596 & 0.533 & 0.416 & 0.249 & 0.186 \\
\hline 19 & 0.941 & 1.230 & 1.453 & 1.443 & 1.365 & 1.230 & 1.052 & 1.059 & 1.108 & 1.129 & 1.263 & 1.184 & 1.003 & 0.870 & 0.618 & 0.321 & 0.223 \\
\hline
\end{tabular}

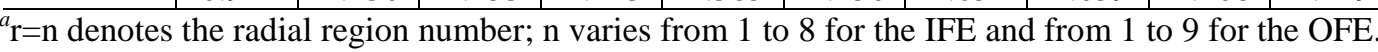


ORNL/TM-2014/154

Table 6.1.2 Relative fission densities for LEU Alternate Design 1 at EOC (28d)

\begin{tabular}{|c|c|c|c|c|c|c|c|c|c|c|c|c|c|c|c|c|c|}
\hline \multirow{2}{*}{$\begin{array}{c}\text { Axial } \\
\text { region \# }\end{array}$} & \multicolumn{8}{|c|}{ IFE } & \multicolumn{9}{|c|}{ OFE } \\
\hline & $\mathrm{r}=1^{a}$ & $r=2$ & $r=3$ & $r=4$ & $r=5$ & $r=6$ & $r=7$ & $r=8$ & $r=1$ & $r=2$ & $r=3$ & $r=4$ & $r=5$ & $r=6$ & $\mathrm{r}=7$ & $r=8$ & $r=9$ \\
\hline 1 & 0.703 & 1.118 & 1.456 & 1.459 & 1.399 & 1.239 & 0.992 & 0.999 & 1.061 & 1.100 & 1.356 & 1.383 & 1.284 & 1.289 & 1.216 & 0.928 & 0.776 \\
\hline 2 & 0.668 & 0.968 & 1.060 & 0.971 & 0.943 & 0.962 & 0.863 & 0.886 & 0.928 & 0.916 & 0.956 & 0.840 & 0.754 & 0.789 & 0.884 & 0.823 & 0.736 \\
\hline 3 & 0.643 & 0.865 & 0.848 & 0.736 & 0.733 & 0.810 & 0.769 & 0.798 & 0.827 & 0.800 & 0.787 & 0.650 & 0.574 & 0.625 & 0.775 & 0.802 & 0.740 \\
\hline 4 & 0.635 & 0.825 & 0.778 & 0.667 & 0.670 & 0.747 & 0.716 & 0.747 & 0.771 & 0.742 & 0.735 & 0.614 & 0.546 & 0.601 & 0.773 & 0.825 & 0.767 \\
\hline 5 & 0.641 & 0.835 & 0.792 & 0.687 & 0.689 & 0.752 & 0.711 & 0.742 & 0.759 & 0.734 & 0.748 & 0.644 & 0.575 & 0.637 & 0.825 & 0.878 & 0.815 \\
\hline 6 & 0.690 & 0.934 & 0.909 & 0.794 & 0.791 & 0.840 & 0.773 & 0.810 & 0.831 & 0.802 & 0.845 & 0.746 & 0.671 & 0.745 & 0.957 & 0.988 & 0.909 \\
\hline 7 & 0.764 & 1.088 & 1.092 & 0.949 & 0.942 & 0.984 & 0.891 & 0.940 & 0.970 & 0.928 & 0.996 & 0.887 & 0.799 & 0.889 & 1.131 & 1.111 & 1.001 \\
\hline 8 & 0.818 & 1.234 & 1.281 & 1.110 & 1.098 & 1.133 & 1.011 & 1.075 & 1.110 & 1.057 & 1.150 & 1.028 & 0.927 & 1.033 & 1.303 & 1.216 & 1.074 \\
\hline 9 & 0.837 & 1.298 & 1.371 & 1.188 & 1.173 & 1.204 & 1.069 & 1.144 & 1.178 & 1.118 & 1.224 & 1.095 & 0.987 & 1.100 & 1.383 & 1.262 & 1.109 \\
\hline 10 & 0.839 & 1.305 & 1.382 & 1.198 & 1.180 & 1.212 & 1.080 & 1.155 & 1.182 & 1.123 & 1.232 & 1.102 & 0.992 & 1.109 & 1.394 & 1.269 & 1.116 \\
\hline 11 & 0.838 & 1.298 & 1.373 & 1.187 & 1.171 & 1.206 & 1.069 & 1.142 & 1.181 & 1.120 & 1.226 & 1.096 & 0.989 & 1.102 & 1.386 & 1.264 & 1.109 \\
\hline 12 & 0.818 & 1.233 & 1.282 & 1.110 & 1.098 & 1.133 & 1.012 & 1.076 & 1.110 & 1.059 & 1.151 & 1.028 & 0.928 & 1.033 & 1.303 & 1.217 & 1.076 \\
\hline 13 & 0.768 & 1.093 & 1.094 & 0.951 & 0.943 & 0.982 & 0.889 & 0.939 & 0.967 & 0.926 & 0.996 & 0.889 & 0.801 & 0.891 & 1.136 & 1.116 & 1.004 \\
\hline 14 & 0.701 & 0.945 & 0.916 & 0.795 & 0.792 & 0.838 & 0.771 & 0.809 & 0.833 & 0.802 & 0.844 & 0.746 & 0.673 & 0.747 & 0.964 & 0.998 & 0.918 \\
\hline 15 & 0.652 & 0.849 & 0.797 & 0.690 & 0.691 & 0.752 & 0.708 & 0.741 & 0.764 & 0.737 & 0.747 & 0.641 & 0.574 & 0.638 & 0.833 & 0.887 & 0.825 \\
\hline 16 & 0.637 & 0.829 & 0.780 & 0.668 & 0.671 & 0.748 & 0.718 & 0.751 & 0.777 & 0.742 & 0.733 & 0.613 & 0.545 & 0.602 & 0.782 & 0.841 & 0.783 \\
\hline 17 & 0.646 & 0.870 & 0.851 & 0.735 & 0.732 & 0.810 & 0.773 & 0.801 & 0.832 & 0.804 & 0.786 & 0.648 & 0.574 & 0.622 & 0.775 & 0.810 & 0.749 \\
\hline 18 & 0.673 & 0.975 & 1.064 & 0.971 & 0.942 & 0.964 & 0.868 & 0.888 & 0.928 & 0.920 & 0.956 & 0.832 & 0.746 & 0.777 & 0.868 & 0.816 & 0.735 \\
\hline 19 & 0.708 & 1.129 & 1.461 & 1.461 & 1.405 & 1.236 & 0.982 & 0.995 & 1.057 & 1.103 & 1.354 & 1.369 & 1.261 & 1.259 & 1.181 & 0.901 & 0.755 \\
\hline
\end{tabular}

${ }^{a} \mathrm{r}=\mathrm{n}$ denotes the radial region number; $\mathrm{n}$ varies from 1 to 8 for the IFE and from 1 to 9 for the OFE. 
Fission rate density profiles, at BOC and EOC, for select axial regions (core horizontal midplane, upper edge of the active fuel region, lower edge of the active fuel region, and average over active fuel height) are shown in Fig. 6.1.3 as a function of the radial distance from the longitudinal centerline of the core. A similar plot, illustrating the fission rate density profiles for select radial regions (innermost, outermost, and central radial meshes) in the IFE and OFE is provided in Fig. 6.1.4 as a function of the axial distance from the core horizontal midplane.
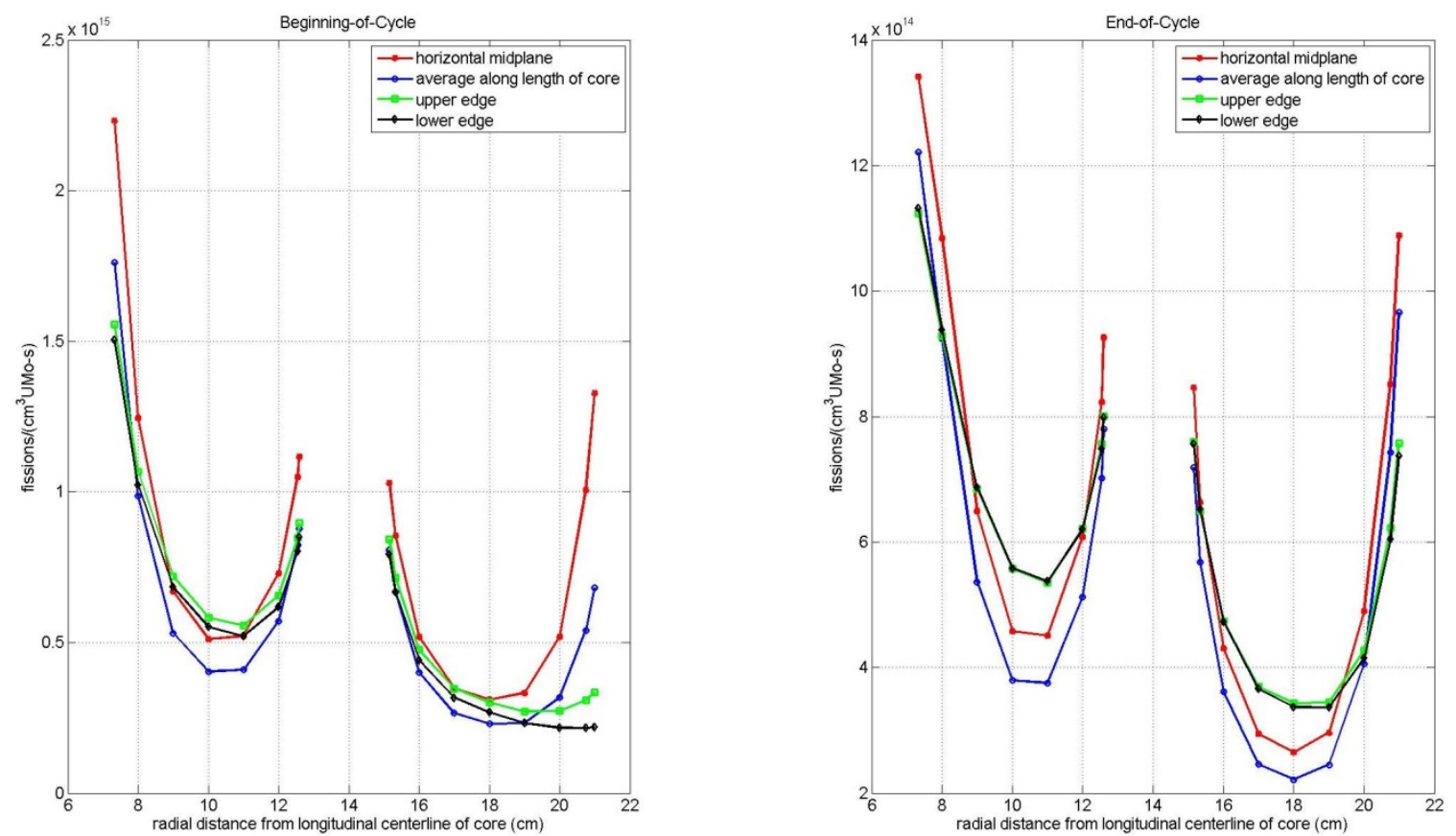

Fig. 6.1.3. Radial distribution of fission rate densities for LEU Alternate Design 1.
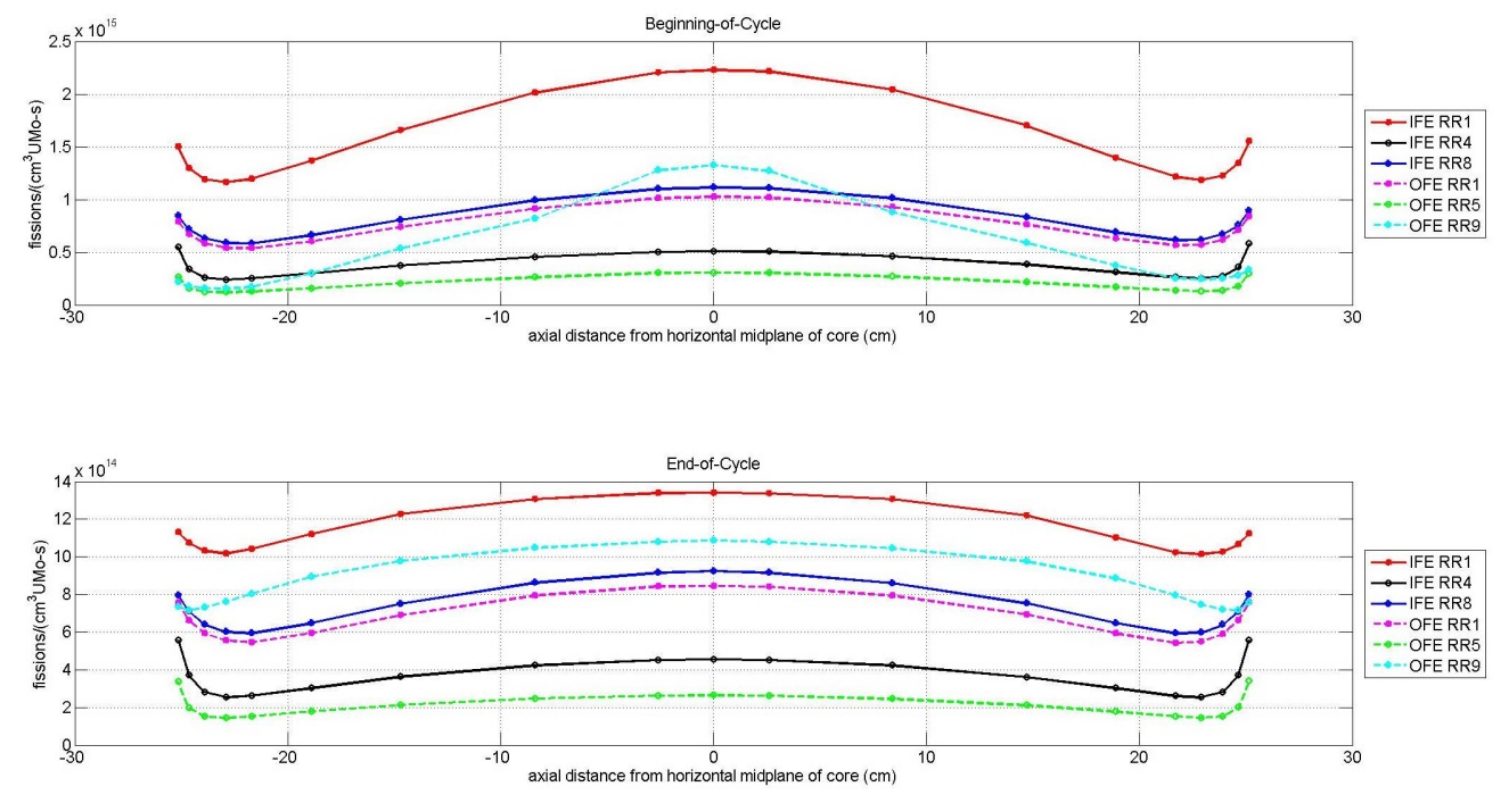

Fig. 6.1.4 Axial distribution of fission rate densities for LEU Alternate Design 1. 
Maximum local fission rate densities of $2.23 \times 10^{15}$ and $1.34 \times 10^{15}$ fissions $/\left(\mathrm{cm}^{3} \mathrm{U}-10 \mathrm{Mo} \bullet \mathrm{s}\right)$ were calculated for the BOC and EOC cores, respectively; both of these maxima are located at the inner radial edge of the IFE on the core horizontal midplane. Assuming conservatively that $100 \%$ of the total reactor power (100 MW) is deposited in the fuel meat, these maximum fission rate densities would correspond to power densities of $\sim 71.53$ and $42.99 \mathrm{~kW} /\left(\mathrm{cm}^{3} \mathrm{UMo}\right)$, respectively.

There are $5.29 \mathrm{~g}{ }^{10} \mathrm{~B}$ in the IFE fuel plates at BOC. Approximately $70 \%$ of this burnable absorber is consumed during the $28 \mathrm{~d}$ reactor cycle.

The minimum and maximum calculated local burnups, in terms of percent ${ }^{235} \mathrm{U}$ removed during the irradiation cycle, compared to the content at BOC, are 5.0 and $61.2 \%$, respectively. The maximum burnup occurs at the innermost edge of the IFE, at the core midline. Approximately $12.8 \%$ of the initial ${ }^{235} \mathrm{U}$ is consumed during the cycle, with $22.69 \mathrm{~kg}$ remaining in the core at EOC.

\subsection{STEADY-STATE TH WITH SAFETY CASE ASSUMPTIONS (USING HSSHTC)}

Figure 6.2 shows results for the LEU reference fuel, compared to a fuel design that involves no axial contouring (i.e., the "no toe" case). This was the first alternative considered, and as expected, this fuel fails the safety design criteria because it is below the existing flux-to-flow ratio SL of 1.36 over the entire cycle. The difference in burnout power between the reference case and the "no toe" case over the cycle shows the degree of safety margin provided by limiting the power density peak at the exit of the fuel where the coolant exit temperature is the highest and the local coolant pressure is the lowest. The minimum calculated burnout power of 125.6 MW occurs in the inner element at day 28 at radial node 7 (r $=9.00 \mathrm{~cm})$ and axial node $40(\mathrm{z}=50.55 \mathrm{~cm})$. 


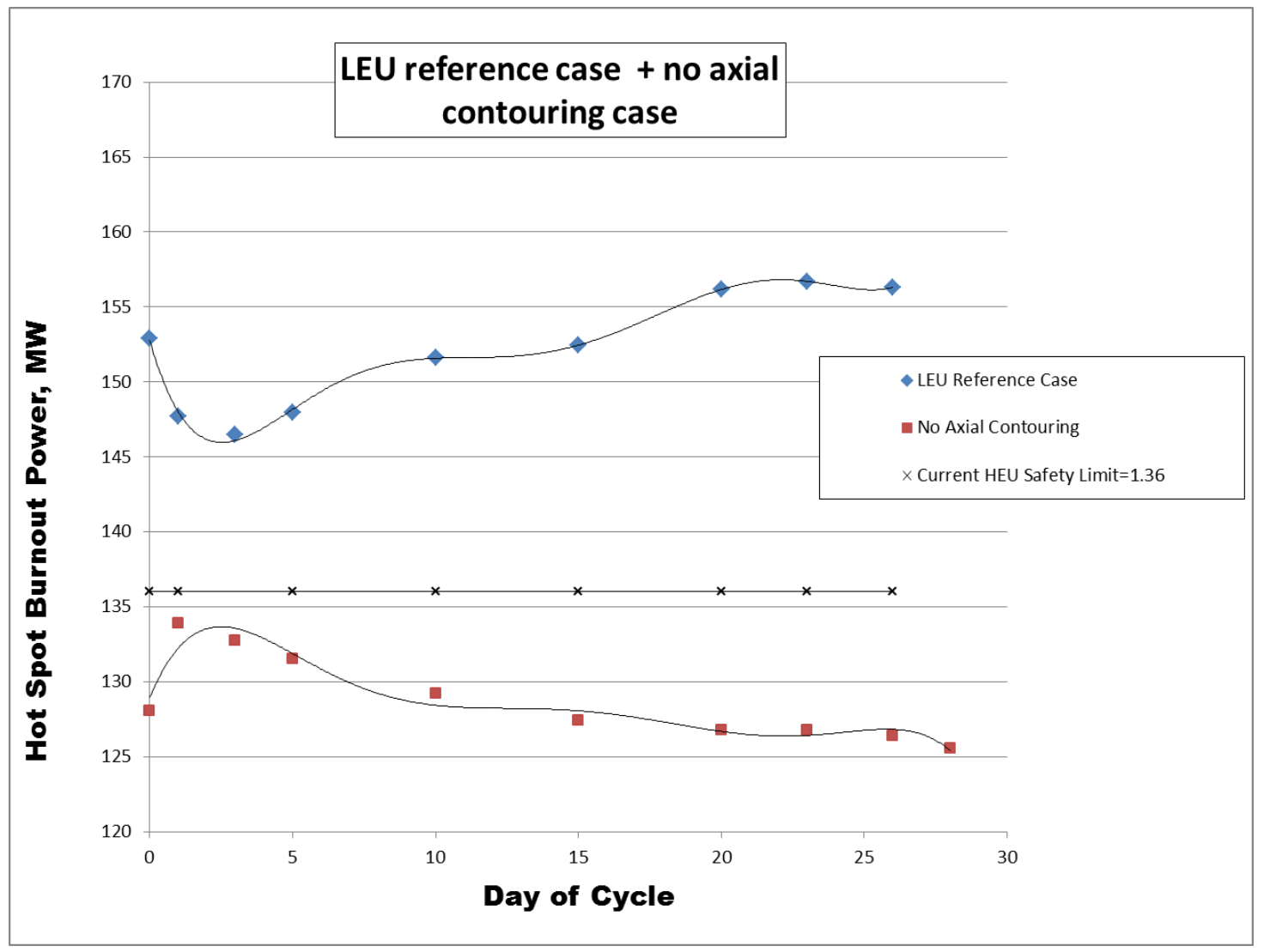

Fig. 6.2. Hot spot burnout power versus day in the cycle for the reference fuel and Alternative 1- reference fuel with no axial contouring case.

\subsection{STEADY-STATE EVALUATION OF ALTERNATIVE 1A-REFERENCE FUEL WITH NO AXIAL CONTOURING AND CENTERED, SYMMETRIC FUEL}

Figure 6.3 shows results for the LEU reference fuel compared to the Alternative 1 case and includes a case named Alternative 1A, which involves Alternative 1 with symmetric and centered fuel. Alternative $1 \mathrm{~A}$ was run to determine if there was enough margin gained by assuming symmetric and centered fuel to result in an acceptable fuel design. As shown in Fig. 6.3, the roughly $10 \mathrm{MW}$ increase in burnout power gained with the symmetric and centered fuel assumption provides enough margin to stay just above the current 136 MW HEU SL until the end of cycle. The Alternative 1A design would be acceptable if some additional margin is gained by another design feature or through improvements in analysis. 


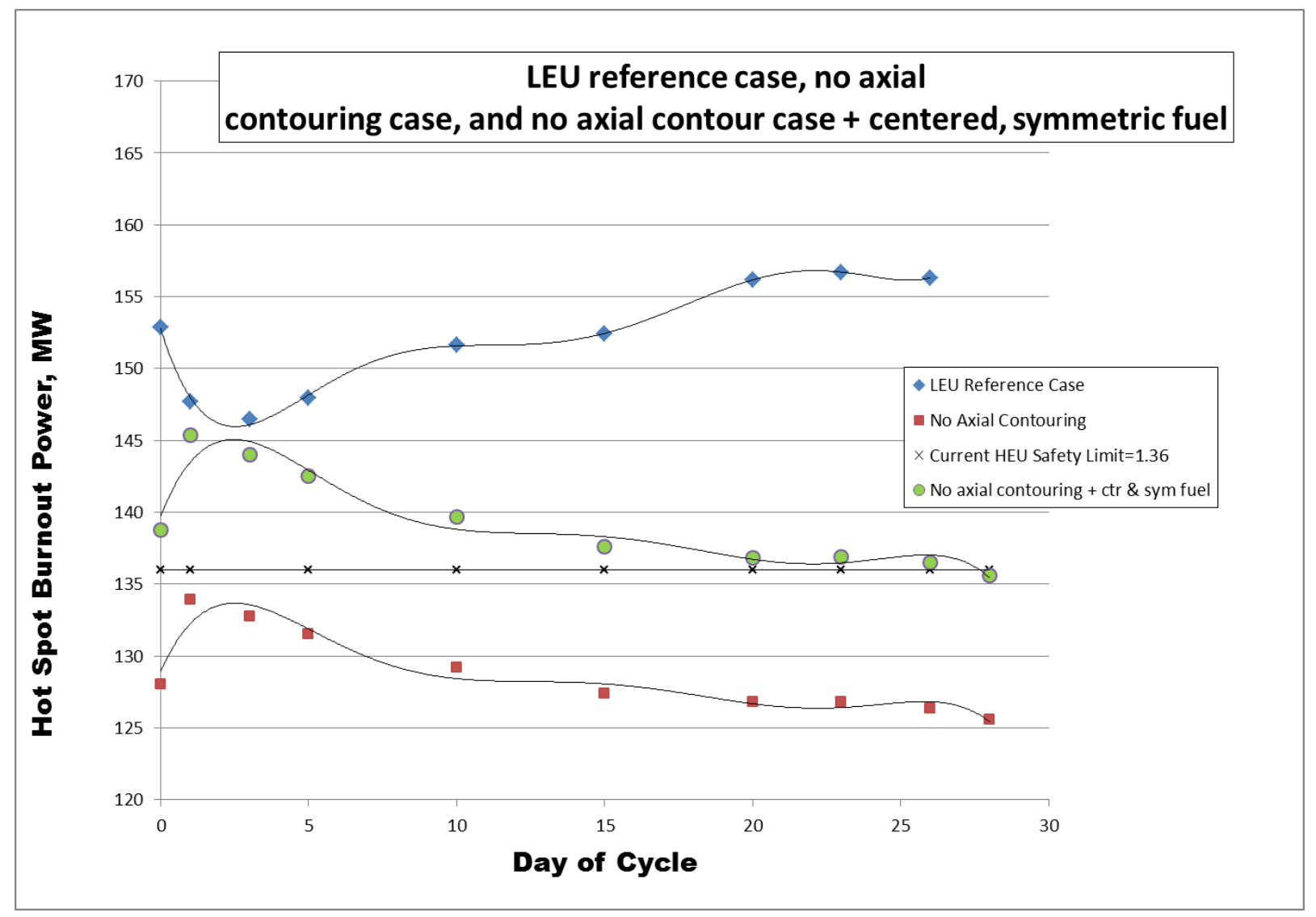

Fig. 6.3. Hot spot burnout power versus day in the cycle for the reference fuel, Alternative 1, and Alternative 1A-reference fuel with no axial contouring and symmetric, centered fuel. 


\section{EVALUATION OF ALTERNATE 2 (PERMANENT HF ABSORBER INSTEAD OF AXIAL CONTOURING)}

\subsection{NEUTRONICS}

As previously described, Alternate Fuel Design 2 includes 124.43 and 237.82 grams of natural hafnium in the IFE and OFE fuel plate lower unfueled regions, respectively, to compensate for the removal of the axial fuel contouring associated with the reference LEU fuel design. An initial core loading of $26.04 \mathrm{~kg}$ ${ }^{235} \mathrm{U}$ fueled the 26-day cycle modeled, which utilized the control element withdrawal curve generated and reported in [2]. Approximately $12.38 \%$ of the initial ${ }^{235} \mathrm{U}$ was consumed; thus, $22.81 \mathrm{~kg}{ }^{235} \mathrm{U}$ remained at the end of the cycle. The minimum and maximum calculated local burn-ups, in terms of percent ${ }^{235} \mathrm{U}$ removed during the cycle, were calculated to be 4.31 and 58.29\%, respectively. The variation of the effective multiplication factor for the Alternate 2 design during the 26-day fuel cycle is compared to the reference design curve in Fig. 7.1.1.

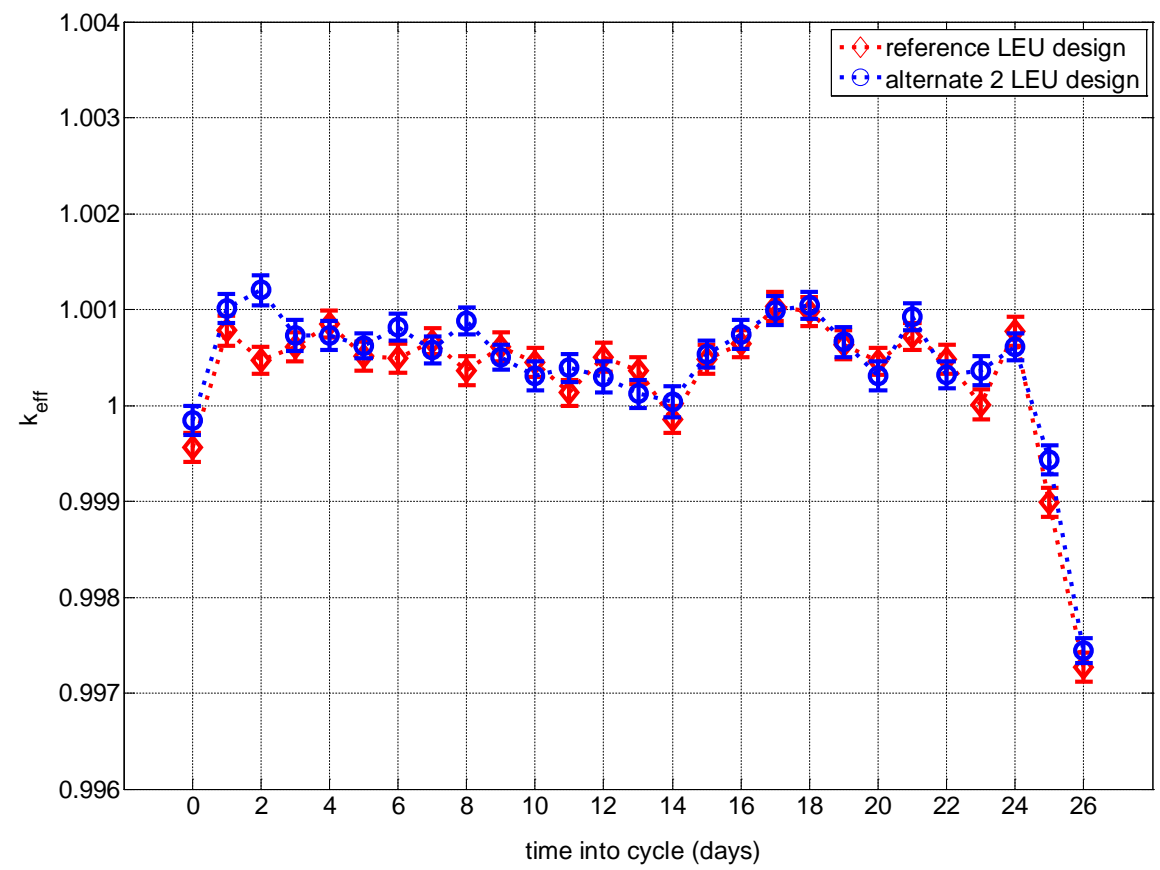

Fig. 7.1.1. Effective multiplication factor for reference design and Alternate Fuel Design 2.

The BOC and EOC relative fission density profiles are illustrated in the form of surface plots in Fig. 7.1.2 and they are tabulated in Tables 7.1.1 and 7.1.2. Maximum local BOC and EOC relative fission densities of 1.555 and 1.498, respectively, were calculated for this design. Both of these "hot spots" are located in the uppermost axial region (i.e., at the coolant inlet) of the IFE. It is evident from comparing Figs. 7.1.2 to 4.1.1 that placing Hf poison in the bottom unfueled regions of the fuel plates is not as effective as physically removing fuel at the bottom of the plates. However, the power spikes at the bottom of the fuel plates are smaller than those that would be generated without neutron poisons or axial contouring of the fuel at the bottom of the plates (see Section 6.1). 

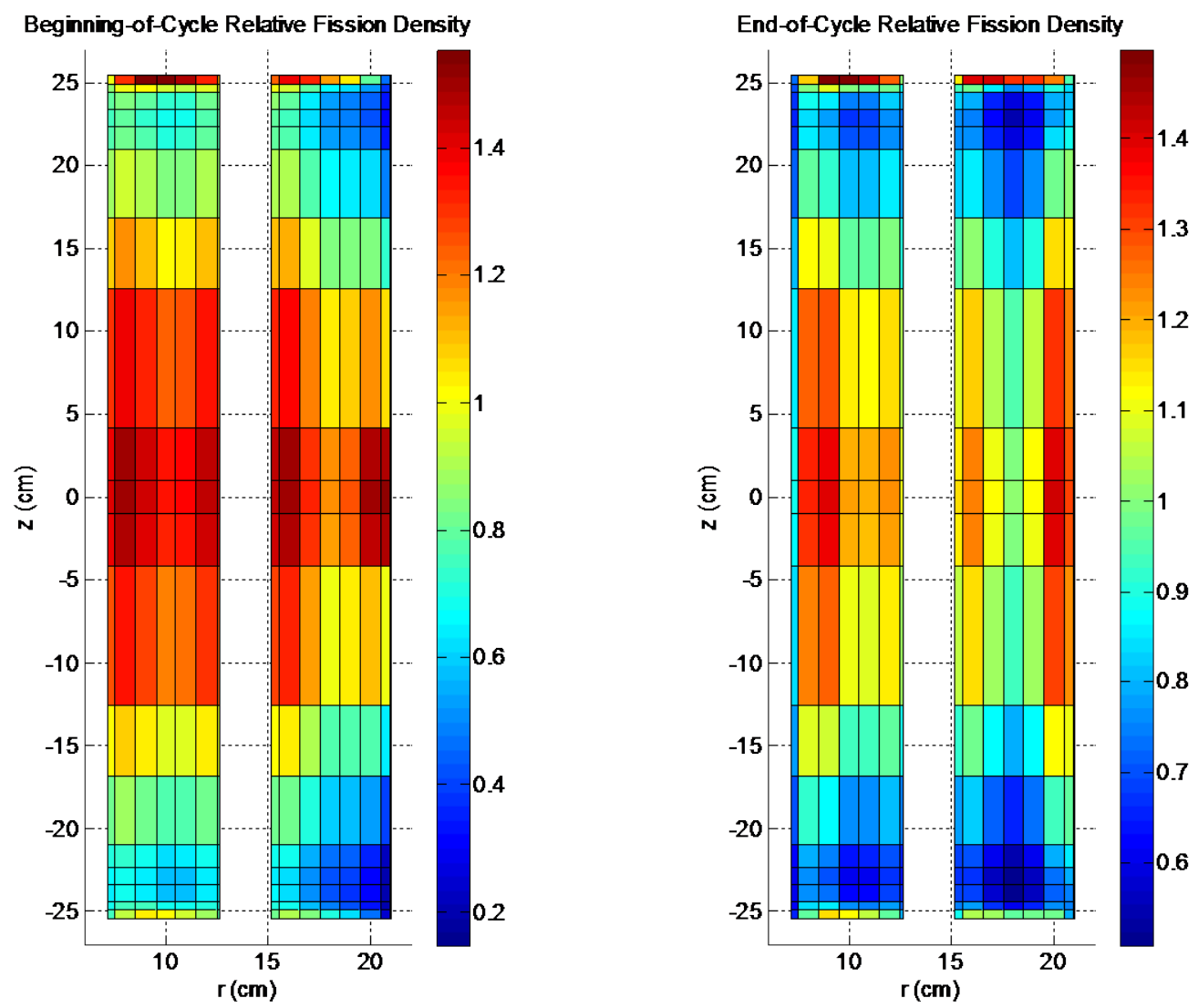

Fig. 7.1.2. Relative fission density for LEU Alternate Fuel Design 2 at BOC (left) and EOC (right). 
ORNL/TM-2014/154

Table 7.1.1 Relative fission densities for LEU Alternate Fuel Design 2 at BOC

\begin{tabular}{|c|c|c|c|c|c|c|c|c|c|c|c|c|c|c|c|c|c|}
\hline \multirow{2}{*}{$\begin{array}{c}\text { Axial } \\
\text { region \# }\end{array}$} & \multicolumn{8}{|c|}{ IFE } & \multicolumn{9}{|c|}{ OFE } \\
\hline & $\mathrm{r}=1^{a}$ & $r=2$ & $r=3$ & $r=4$ & $r=5$ & $r=6$ & $r=7$ & $r=8$ & $r=1$ & $r=2$ & $r=3$ & $r=4$ & $r=5$ & $r=6$ & $r=7$ & $r=8$ & $r=9$ \\
\hline 1 & 0.992 & 1.308 & 1.555 & 1.547 & 1.478 & 1.329 & 1.126 & 1.134 & 1.190 & 1.225 & 1.383 & 1.321 & 1.146 & 1.033 & 0.788 & 0.466 & 0.352 \\
\hline 2 & 0.856 & 0.991 & 1.018 & 0.954 & 0.932 & 0.969 & 0.942 & 0.959 & 1.008 & 0.984 & 0.947 & 0.797 & 0.673 & 0.624 & 0.531 & 0.369 & 0.296 \\
\hline 3 & 0.785 & 0.847 & 0.798 & 0.729 & 0.736 & 0.819 & 0.828 & 0.847 & 0.885 & 0.855 & 0.788 & 0.631 & 0.530 & 0.497 & 0.441 & 0.323 & 0.264 \\
\hline 4 & 0.761 & 0.805 & 0.738 & 0.677 & 0.688 & 0.770 & 0.772 & 0.787 & 0.804 & 0.789 & 0.750 & 0.609 & 0.506 & 0.482 & 0.431 & 0.315 & 0.258 \\
\hline 5 & 0.775 & 0.820 & 0.768 & 0.708 & 0.721 & 0.788 & 0.768 & 0.781 & 0.799 & 0.795 & 0.778 & 0.645 & 0.542 & 0.519 & 0.463 & 0.337 & 0.273 \\
\hline 6 & 0.888 & 0.951 & 0.896 & 0.835 & 0.846 & 0.907 & 0.866 & 0.875 & 0.900 & 0.898 & 0.905 & 0.773 & 0.658 & 0.647 & 0.617 & 0.490 & 0.410 \\
\hline 7 & 1.082 & 1.160 & 1.094 & 1.024 & 1.039 & 1.106 & 1.050 & 1.065 & 1.087 & 1.093 & 1.116 & 0.964 & 0.831 & 0.836 & 0.849 & 0.727 & 0.624 \\
\hline 8 & 1.293 & 1.389 & 1.319 & 1.234 & 1.256 & 1.338 & 1.267 & 1.281 & 1.318 & 1.328 & 1.360 & 1.188 & 1.037 & 1.071 & 1.161 & 1.069 & 0.941 \\
\hline 9 & 1.397 & 1.499 & 1.426 & 1.340 & 1.364 & 1.459 & 1.381 & 1.397 & 1.441 & 1.452 & 1.490 & 1.312 & 1.162 & 1.245 & 1.469 & 1.481 & 1.341 \\
\hline 10 & 1.407 & 1.510 & 1.438 & 1.348 & 1.372 & 1.466 & 1.387 & 1.401 & 1.447 & 1.459 & 1.501 & 1.320 & 1.175 & 1.261 & 1.504 & 1.530 & 1.392 \\
\hline 11 & 1.385 & 1.488 & 1.412 & 1.327 & 1.352 & 1.443 & 1.370 & 1.386 & 1.423 & 1.434 & 1.476 & 1.298 & 1.153 & 1.235 & 1.464 & 1.487 & 1.346 \\
\hline 12 & 1.253 & 1.345 & 1.277 & 1.197 & 1.216 & 1.295 & 1.226 & 1.240 & 1.273 & 1.282 & 1.314 & 1.145 & 0.998 & 1.027 & 1.098 & 0.995 & 0.868 \\
\hline 13 & 1.018 & 1.090 & 1.034 & 0.963 & 0.975 & 1.037 & 0.982 & 0.996 & 1.022 & 1.026 & 1.044 & 0.898 & 0.775 & 0.772 & 0.775 & 0.652 & 0.553 \\
\hline 14 & 0.826 & 0.879 & 0.824 & 0.763 & 0.772 & 0.823 & 0.780 & 0.793 & 0.812 & 0.814 & 0.820 & 0.698 & 0.591 & 0.572 & 0.525 & 0.396 & 0.324 \\
\hline 15 & 0.700 & 0.738 & 0.682 & 0.626 & 0.633 & 0.684 & 0.661 & 0.669 & 0.685 & 0.684 & 0.675 & 0.563 & 0.468 & 0.436 & 0.353 & 0.222 & 0.170 \\
\hline 16 & 0.659 & 0.690 & 0.635 & 0.581 & 0.584 & 0.643 & 0.630 & 0.645 & 0.661 & 0.649 & 0.630 & 0.515 & 0.426 & 0.393 & 0.317 & 0.199 & 0.151 \\
\hline 17 & 0.652 & 0.693 & 0.645 & 0.585 & 0.584 & 0.642 & 0.636 & 0.653 & 0.671 & 0.658 & 0.621 & 0.506 & 0.418 & 0.382 & 0.307 & 0.192 & 0.147 \\
\hline 18 & 0.676 & 0.762 & 0.752 & 0.695 & 0.676 & 0.703 & 0.678 & 0.690 & 0.715 & 0.704 & 0.688 & 0.573 & 0.477 & 0.429 & 0.337 & 0.204 & 0.152 \\
\hline 19 & 0.744 & 0.938 & 1.044 & 1.016 & 0.960 & 0.883 & 0.765 & 0.762 & 0.811 & 0.822 & 0.912 & 0.845 & 0.714 & 0.628 & 0.455 & 0.245 & 0.175 \\
\hline
\end{tabular}

${ }^{a} \mathrm{r}=\mathrm{n}$ denotes the radial region number; $\mathrm{n}$ varies from 1 to 8 for the IFE and from 1 to 9 for the OFE. 
ORNL/TM-2014/154

Table 7.1.2 Relative fission densities for LEU Alternate Fuel Design 2 at EOC (26d).

\begin{tabular}{|c|c|c|c|c|c|c|c|c|c|c|c|c|c|c|c|c|c|}
\hline \multirow{2}{*}{$\begin{array}{c}\text { Axial } \\
\text { region \# }\end{array}$} & \multicolumn{8}{|c|}{ IFE } & \multicolumn{9}{|c|}{ OFE } \\
\hline & $r=1^{a}$ & $r=2$ & $r=3$ & $r=4$ & $r=5$ & $r=6$ & $r=7$ & $r=8$ & $r=1$ & $r=2$ & $r=3$ & $r=4$ & $r=5$ & $r=6$ & $r=7$ & $r=8$ & $r=9$ \\
\hline 1 & 0.738 & 1.161 & 1.491 & 1.498 & 1.429 & 1.268 & 1.010 & 1.023 & 1.090 & 1.134 & 1.391 & 1.408 & 1.313 & 1.314 & 1.244 & 0.945 & 0.790 \\
\hline 2 & 0.695 & 0.994 & 1.084 & 0.989 & 0.965 & 0.986 & 0.892 & 0.919 & 0.950 & 0.941 & 0.980 & 0.850 & 0.768 & 0.804 & 0.899 & 0.839 & 0.745 \\
\hline 3 & 0.665 & 0.884 & 0.863 & 0.750 & 0.747 & 0.827 & 0.795 & 0.820 & 0.845 & 0.821 & 0.802 & 0.663 & 0.587 & 0.634 & 0.790 & 0.816 & 0.746 \\
\hline 4 & 0.651 & 0.841 & 0.787 & 0.678 & 0.683 & 0.764 & 0.735 & 0.768 & 0.794 & 0.764 & 0.752 & 0.626 & 0.555 & 0.614 & 0.787 & 0.840 & 0.785 \\
\hline 5 & 0.670 & 0.859 & 0.809 & 0.701 & 0.703 & 0.768 & 0.727 & 0.760 & 0.793 & 0.759 & 0.767 & 0.657 & 0.589 & 0.648 & 0.843 & 0.895 & 0.830 \\
\hline 6 & 0.725 & 0.958 & 0.921 & 0.808 & 0.807 & 0.858 & 0.794 & 0.831 & 0.852 & 0.823 & 0.864 & 0.763 & 0.687 & 0.760 & 0.974 & 1.009 & 0.927 \\
\hline 7 & 0.806 & 1.122 & 1.111 & 0.969 & 0.961 & 1.002 & 0.909 & 0.957 & 0.989 & 0.953 & 1.018 & 0.906 & 0.816 & 0.907 & 1.152 & 1.134 & 1.020 \\
\hline 8 & 0.862 & 1.268 & 1.297 & 1.129 & 1.117 & 1.156 & 1.039 & 1.105 & 1.130 & 1.083 & 1.172 & 1.046 & 0.943 & 1.051 & 1.325 & 1.245 & 1.105 \\
\hline 9 & 0.881 & 1.333 & 1.387 & 1.203 & 1.190 & 1.229 & 1.095 & 1.165 & 1.197 & 1.142 & 1.242 & 1.111 & 1.000 & 1.113 & 1.400 & 1.295 & 1.143 \\
\hline 10 & 0.882 & 1.339 & 1.394 & 1.210 & 1.195 & 1.232 & 1.098 & 1.170 & 1.203 & 1.144 & 1.249 & 1.115 & 1.005 & 1.121 & 1.408 & 1.299 & 1.145 \\
\hline 11 & 0.878 & 1.326 & 1.381 & 1.195 & 1.182 & 1.218 & 1.087 & 1.157 & 1.191 & 1.136 & 1.237 & 1.106 & 0.995 & 1.109 & 1.395 & 1.291 & 1.138 \\
\hline 12 & 0.848 & 1.247 & 1.278 & 1.106 & 1.096 & 1.135 & 1.019 & 1.080 & 1.113 & 1.064 & 1.151 & 1.028 & 0.927 & 1.032 & 1.303 & 1.227 & 1.086 \\
\hline 13 & 0.776 & 1.081 & 1.071 & 0.934 & 0.929 & 0.971 & 0.884 & 0.929 & 0.953 & 0.917 & 0.982 & 0.876 & 0.789 & 0.877 & 1.118 & 1.104 & 0.996 \\
\hline 14 & 0.695 & 0.917 & 0.877 & 0.768 & 0.765 & 0.810 & 0.744 & 0.777 & 0.804 & 0.778 & 0.819 & 0.725 & 0.653 & 0.726 & 0.938 & 0.972 & 0.895 \\
\hline 15 & 0.626 & 0.796 & 0.743 & 0.647 & 0.651 & 0.704 & 0.661 & 0.685 & 0.707 & 0.683 & 0.700 & 0.611 & 0.549 & 0.611 & 0.800 & 0.854 & 0.795 \\
\hline 16 & 0.612 & 0.763 & 0.704 & 0.609 & 0.612 & 0.676 & 0.644 & 0.671 & 0.699 & 0.672 & 0.666 & 0.570 & 0.509 & 0.566 & 0.739 & 0.798 & 0.741 \\
\hline 17 & 0.607 & 0.771 & 0.731 & 0.631 & 0.628 & 0.691 & 0.661 & 0.685 & 0.719 & 0.694 & 0.679 & 0.573 & 0.510 & 0.561 & 0.712 & 0.755 & 0.701 \\
\hline 18 & 0.624 & 0.837 & 0.861 & 0.771 & 0.750 & 0.776 & 0.712 & 0.733 & 0.774 & 0.756 & 0.775 & 0.676 & 0.613 & 0.649 & 0.757 & 0.743 & 0.671 \\
\hline 19 & 0.656 & 0.958 & 1.147 & 1.116 & 1.064 & 0.970 & 0.797 & 0.805 & 0.860 & 0.882 & 1.040 & 1.031 & 0.959 & 0.982 & 0.980 & 0.791 & 0.670 \\
\hline
\end{tabular}

${ }^{a} \mathrm{r}=\mathrm{n}$ denotes the radial region number; $\mathrm{n}$ varies from 1 to 8 for the IFE and from 1 to 9 for the OFE. 
Fission rate density profiles, at BOC and EOC, for select axial regions (core horizontal midplane, upper edge of the active fuel region, lower edge of the active fuel region, and average over active fuel height) as a function of radial distance from the longitudinal centerline of the core are shown in Fig. 7.1.3. A similar plot, illustrating the fission rate density profiles for select radial regions (innermost, outermost, and central radial meshes) as a function of axial distance from the core horizontal midplane of the core, is provided in Fig. 7.1.4. Maximum local fission rate densities of $2.24 \mathrm{E}+15$ and $1.41 \mathrm{E}+15$ fissions/ $\left(\mathrm{cm}^{3} \mathrm{U}-\right.$ $10 \mathrm{Mo} \mathrm{s}$ ) were calculated for the BOC and EOC cores, respectively, and both of these maxima are located at the inner radial edge of the IFE on the core horizontal midplane. Conservatively assuming that $100 \%$ of the total reactor power (100 MW) is deposited in the fuel meat, these fission rate densities correspond to power densities of about 72.10 and $45.20 \mathrm{~kW} /\left(\mathrm{cm}^{3} \mathrm{U}-10 \mathrm{Mo}\right)$, respectively.
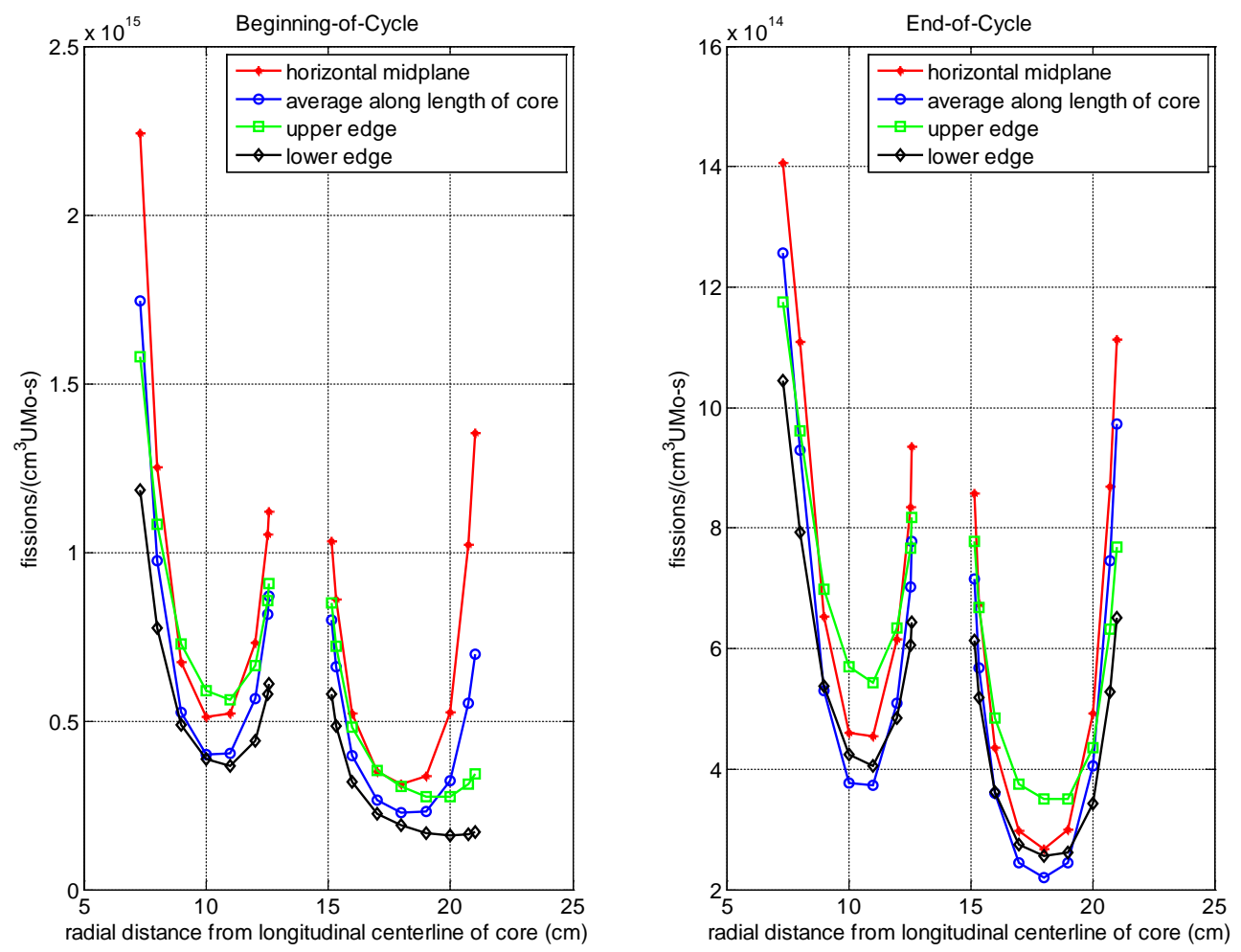

Fig. 7.1.3. Radial distribution of fission rate densities for LEU Alternate Fuel Design 2. 

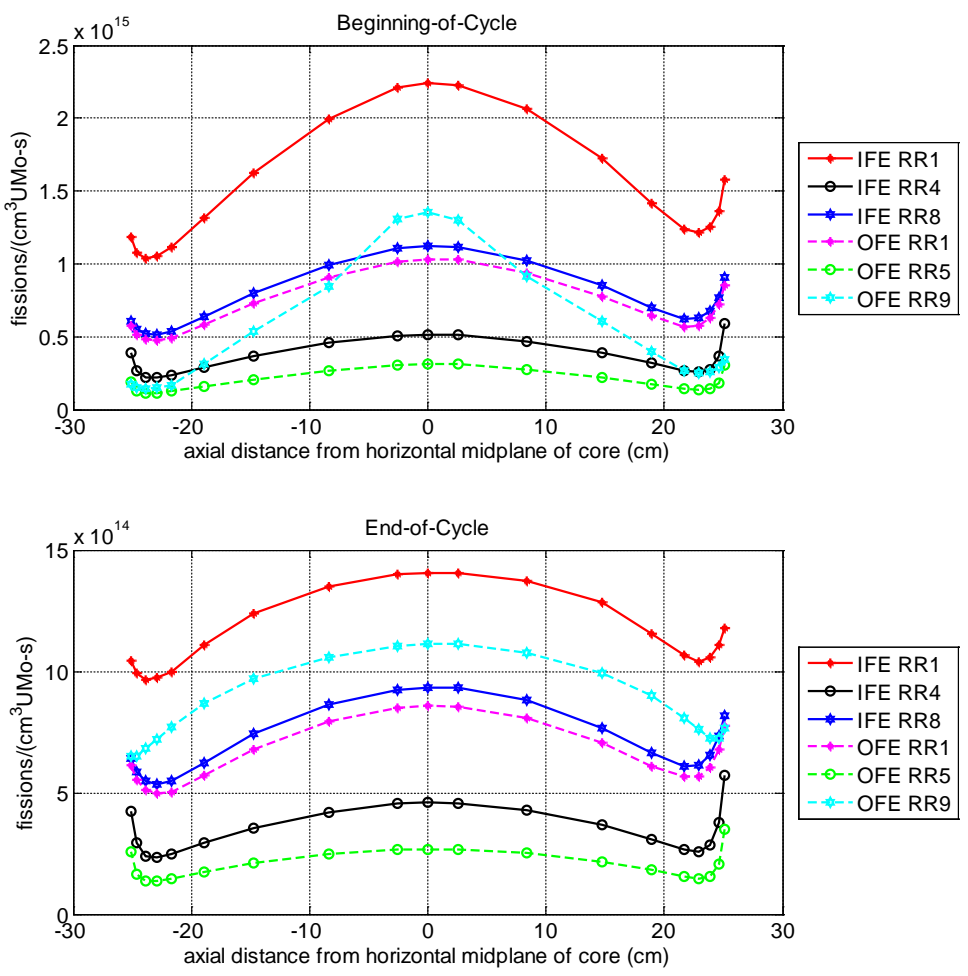

Fig. 7.1.4. Axial distribution of fission rate densities for LEU Alternate Fuel Design 2.

\subsection{STEADY-STATE TH WITH SAFETY CASE ASSUMPTIONS (USING HSSHTC)}

Figure 7.2 shows the results of calculations with Hf absorber added to the unfueled region of the plates at the bottom of the core, as compared to the LEU reference case. As shown in Fig 7.2, the safety limit for all portions of the cycle is above the existing HEU safety limit of 1.36, which confirms that this alternative is a viable option to the axial contouring. The early portion of the cycle matches the reference fuel design for hot spot burnout power, but the safety margin falls off toward the 1.36 HEU limit after 10 days of operation. The dip in burnout power is likely due to burnup of the Hf. Alternative 5 in Section 10 examines the results with additional Hf to improve performance in the last part of the cycle. The minimum calculated burnout power of $126.8 \mathrm{MW}$ occurs in the inner element at day 26 at radial node 7 $(\mathrm{r}=9.00 \mathrm{~cm})$ and axial node $40(\mathrm{z}=50.55 \mathrm{~cm})$. 


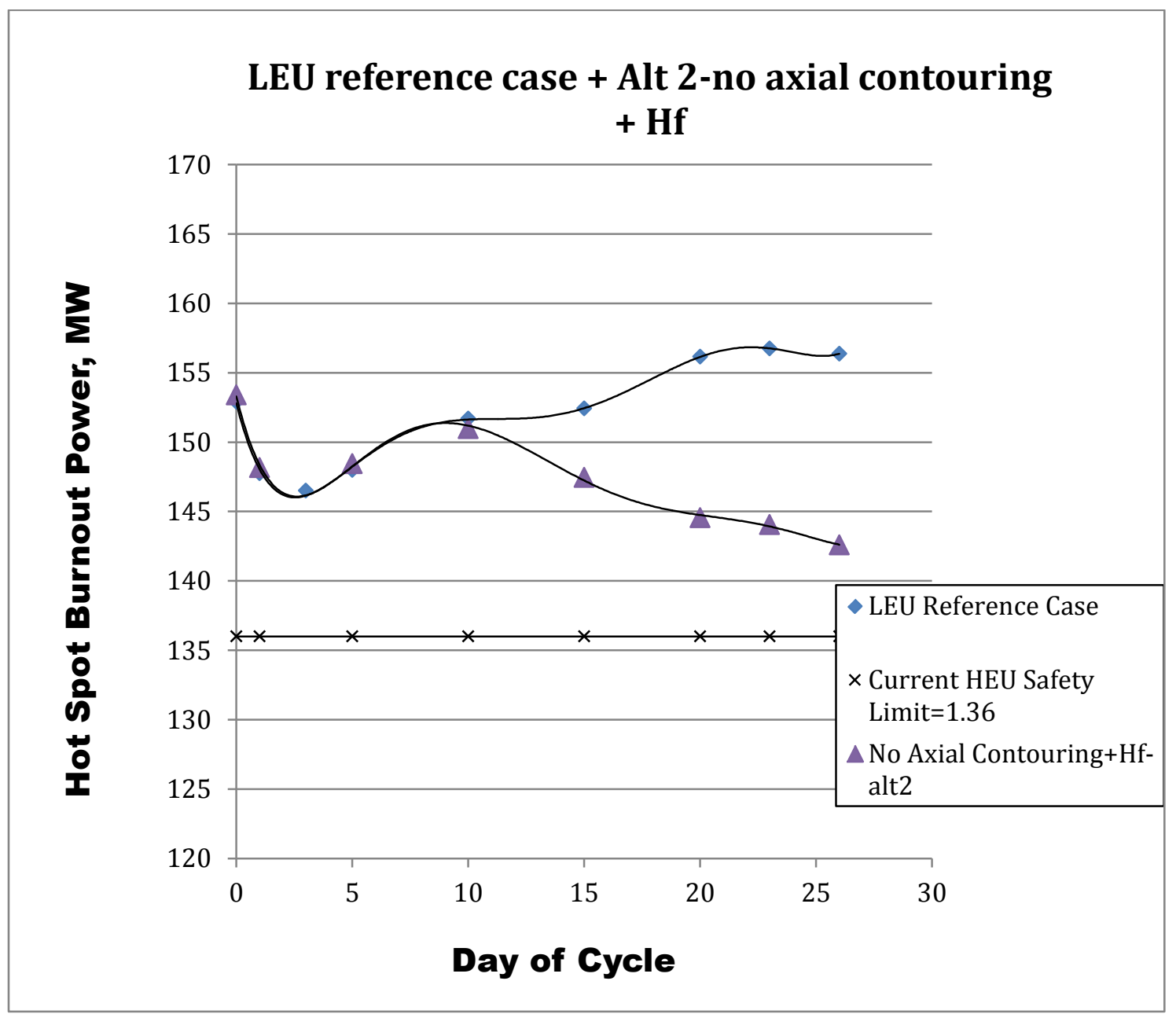

Fig. 7.2. Hot spot burnout power versus day in the cycle for the reference fuel and Alternative 2 no axial contouring plus $\mathrm{Hf}$ in the lower unfueled region of the plate. 
This page intentionally blank 
ORNL/TM-2014/154

\section{EVALUATION OF ALTERNATE 3 (BURNABLE B ABSORBER IN SIDE PLATES INSTEAD OF FUEL PLATES)}

\subsection{NEUTRONICS}

In Alternate Design 3, the boron burnable absorber is removed from the IFE fuel plates and relocated to the inner and outer side plates of the IFE. The side plates of the IFE have the boron burnable absorber uniformly dispersed in the Al-based material along their axial lengths of $60.96 \mathrm{~cm}$. Various combinations have been considered for the boron content and its distribution in the inner and outer side plates of the IFE, as discussed in detail in [21]. The results obtained[21] indicated that the use of 3.4 to $4.6 \mathrm{~g}$ of ${ }^{10} \mathrm{~B}$ with a distribution of $25 \%$ in the inner and $75 \%$ in the outer side plate of the IFE would provide a core performance similar to that of the reference LEU core[2]. The former case $\left(3.4 \mathrm{~g}{ }^{10} \mathrm{~B}\right)$ would correspond to borated aluminum with a content of $\sim 1500 \mathrm{wt}$ ppm boron in the inner and outer side plate, respectively; whereas, the latter $\left(4.6 \mathrm{~g}^{10} \mathrm{~B}\right)$ would correspond to $\sim 2000 \mathrm{wt}$ ppm boron in the inner and outer side plate, respectively.

A comparison of $\mathrm{k}_{\text {eff }}$ values as a function of irradiation time, for the reference and Alternate Design 3 , is presented in Fig. 8.1.1 for two values of the ${ }^{10} \mathrm{~B}$ content in the IFE side plates. The VESTA depletion simulation for which results are shown in Fig. 8.1.1 were performed for Alternate 3 using the critical control search option[8], which is described in Section 3. As noticed, the relocation of boron from the IFE fuel plates to the IFE side plates leads for Alternate Design 3 to an increase, estimated here as $\sim 2-3 \mathrm{~d}$, in the cycle length. For the metrics discussed further in this Section 8.1, a value of $28 \mathrm{~d}$ was selected as EOC for presentation of the Alternate Design 3 EOC metrics data.

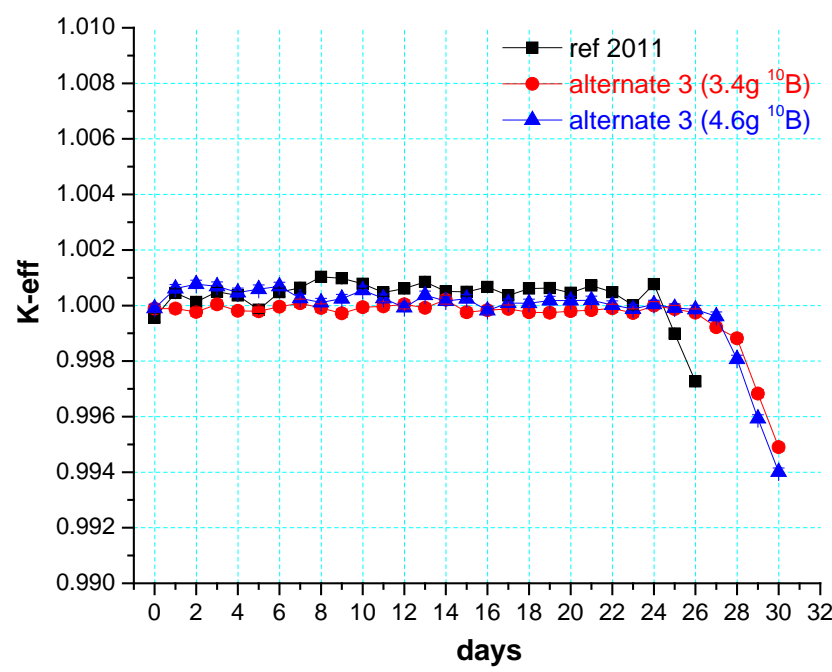

Fig. 8.1.1. Effective multiplication factor for LEU reference and Alternate Design 3.

The BOC and EOC (28d) relative fission density data are illustrated, as surface plots, in Figs. 8.1.2 and 8.1.3 for the two Alternate Design 3 cases (3.4g and $4.6 \mathrm{~g}{ }^{10} \mathrm{~B}$ ) and listed in Tables 8.1.1 to 8.1.4. The maximum value for the relative fission density at BOC and EOC is 1.652 and 1.528, respectively for Alternate 3 with $3.4 \mathrm{~g}{ }^{10} \mathrm{~B}$. The "hot spot" at BOC in this case is located close to the IFE innermost radial mesh at the core horizontal midline, whereas at EOC it occurs at the uppermost axial region (i.e., at the coolant inlet) of the OFE. The maximum value for the relative fission density at BOC and EOC is 1.573 and 1.535 , respectively, for Alternate 3 with $4.6 \mathrm{~g}{ }^{10} \mathrm{~B}$. The "hot spot" at BOC in this case is located close 
to the IFE innermost radial mesh at the core horizontal midline, whereas at EOC it occurs at the uppermost axial region (i.e., at the coolant inlet) of the OFE. The hot spots in the case with $4.6 \mathrm{~g}{ }^{10} \mathrm{~B}$ occur at the same locations as for the $3.4 \mathrm{~g}{ }^{10} \mathrm{~B}$ case.
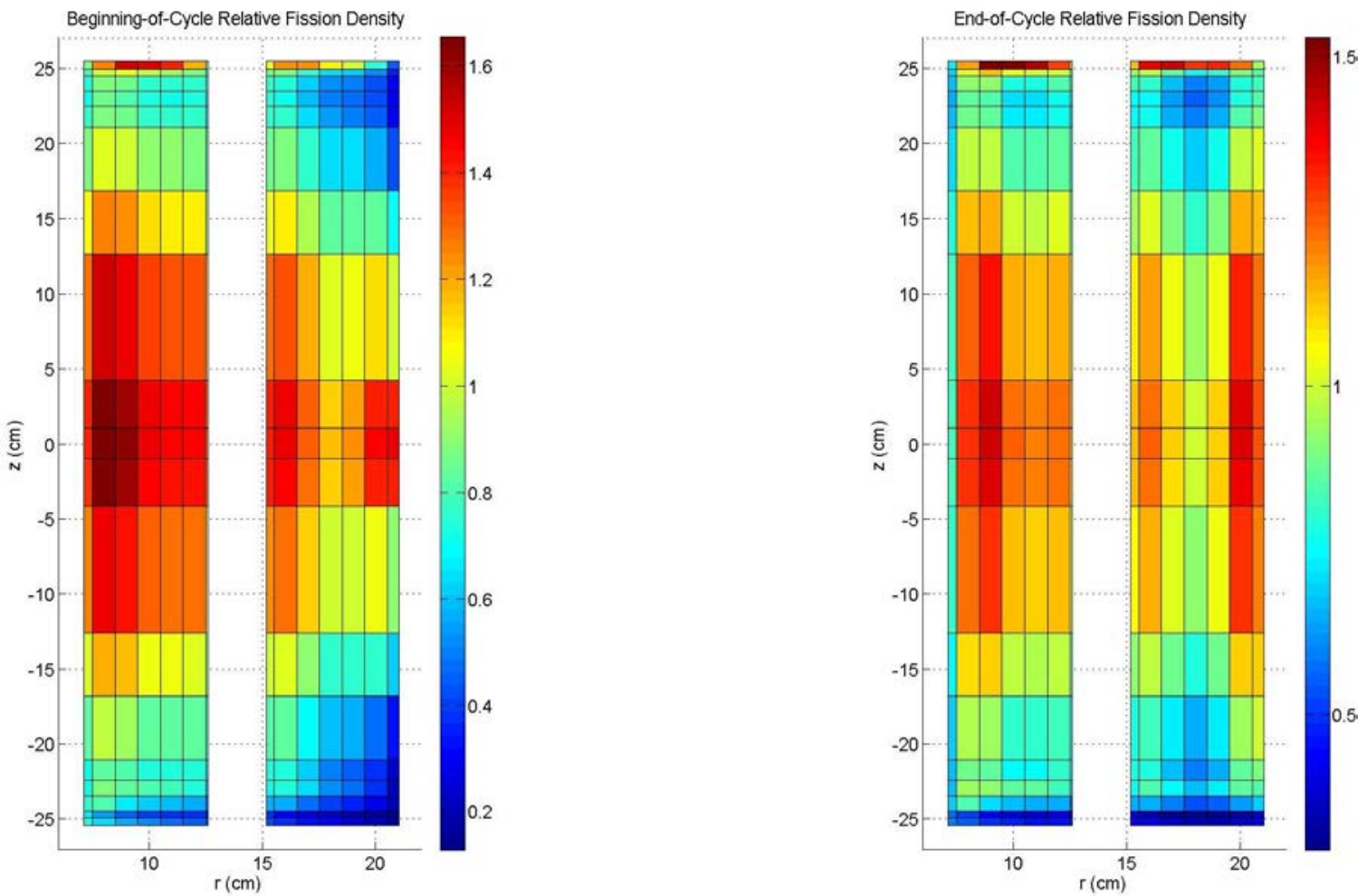

Fig. 8.1.2. Relative fission density for LEU Alternate $3\left(3.4 \mathrm{~g}{ }^{10} \mathrm{~B}\right)$ at BOC (left) and EOC (right).
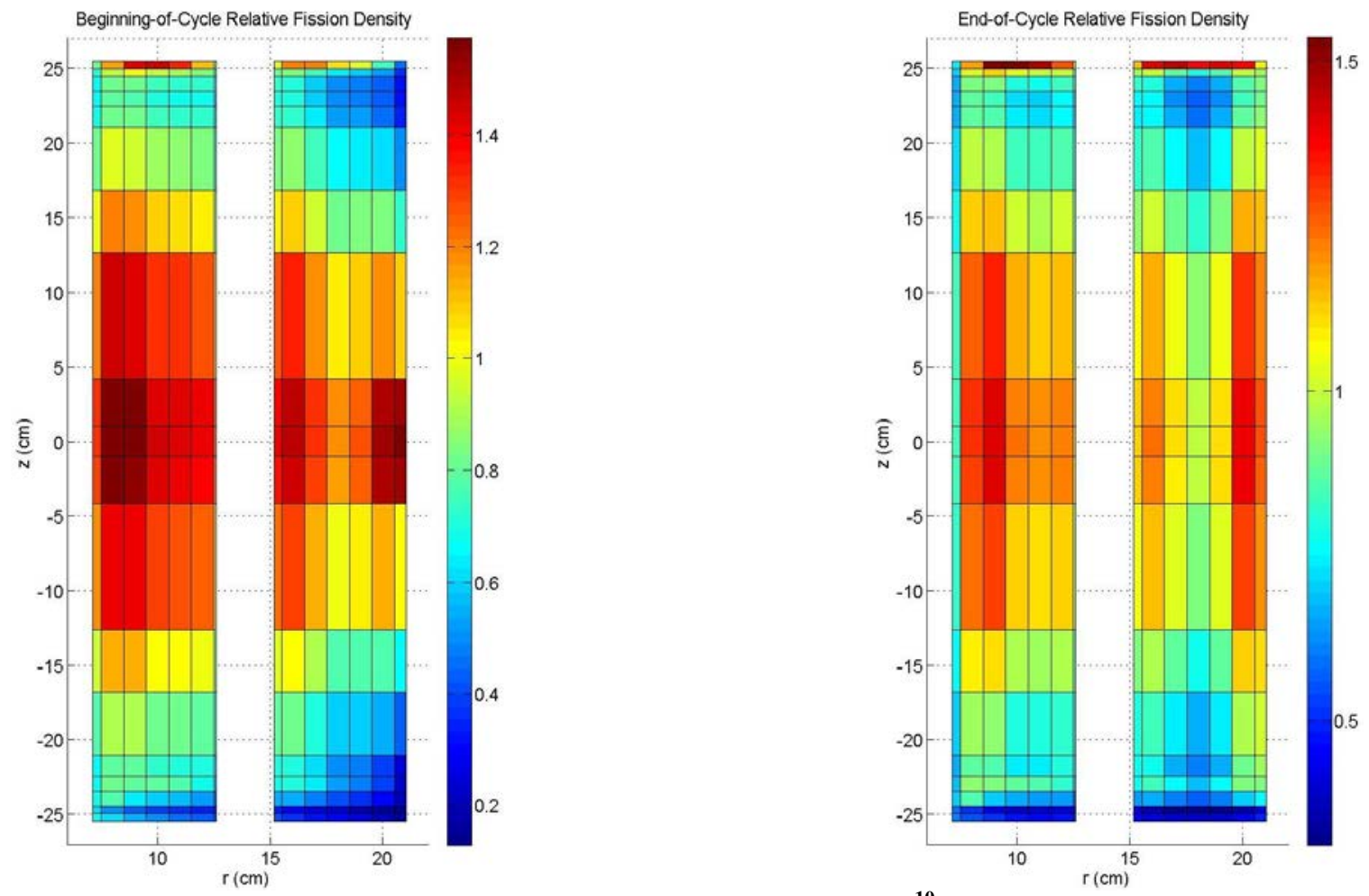

Fig. 8.1.3. Relative fission density for LEU Alternate $3\left(4.6 \mathrm{~g}^{10} \mathrm{~B}\right)$ at BOC (left) and EOC (right). 
ORNL/TM-2014/154

Table 8.1.1. Relative fission densities for LEU Alternate Design $3\left(3.4 \mathrm{~g}{ }^{10} \mathrm{~B}\right)$ at BOC

\begin{tabular}{|c|c|c|c|c|c|c|c|c|c|c|c|c|c|c|c|c|c|}
\hline \multirow{2}{*}{$\begin{array}{c}\text { Axial } \\
\text { region \# }\end{array}$} & \multicolumn{8}{|c|}{ IFE } & \multicolumn{9}{|c|}{ OFE } \\
\hline & $\mathrm{r}=1^{a}$ & $r=2$ & $r=3$ & $r=4$ & $r=5$ & $r=6$ & $r=7$ & $r=8$ & $r=1$ & $r=2$ & $r=3$ & $r=4$ & $r=5$ & $r=6$ & $r=7$ & $r=8$ & $r=9$ \\
\hline 1 & 0.883 & 1.255 & 1.521 & 1.509 & 1.406 & 1.186 & 0.913 & 0.902 & 0.990 & 1.043 & 1.237 & 1.235 & 1.093 & 0.996 & 0.761 & 0.454 & 0.339 \\
\hline 2 & 0.782 & 0.998 & 1.054 & 0.971 & 0.932 & 0.888 & 0.766 & 0.762 & 0.859 & 0.854 & 0.869 & 0.757 & 0.650 & 0.608 & 0.516 & 0.356 & 0.286 \\
\hline 3 & 0.732 & 0.875 & 0.859 & 0.770 & 0.750 & 0.761 & 0.677 & 0.675 & 0.773 & 0.763 & 0.740 & 0.611 & 0.516 & 0.488 & 0.430 & 0.312 & 0.255 \\
\hline 4 & 0.720 & 0.848 & 0.808 & 0.726 & 0.714 & 0.728 & 0.644 & 0.648 & 0.741 & 0.734 & 0.716 & 0.594 & 0.499 & 0.473 & 0.418 & 0.302 & 0.246 \\
\hline 5 & 0.749 & 0.879 & 0.844 & 0.764 & 0.754 & 0.754 & 0.658 & 0.654 & 0.749 & 0.750 & 0.753 & 0.634 & 0.533 & 0.508 & 0.446 & 0.317 & 0.255 \\
\hline 6 & 0.870 & 1.026 & 0.996 & 0.906 & 0.892 & 0.884 & 0.761 & 0.755 & 0.857 & 0.863 & 0.886 & 0.764 & 0.650 & 0.629 & 0.579 & 0.437 & 0.359 \\
\hline 7 & 1.074 & 1.264 & 1.227 & 1.116 & 1.100 & 1.085 & 0.933 & 0.928 & 1.045 & 1.056 & 1.095 & 0.957 & 0.824 & 0.822 & 0.821 & 0.692 & 0.590 \\
\hline 8 & 1.290 & 1.519 & 1.476 & 1.348 & 1.332 & 1.319 & 1.133 & 1.125 & 1.269 & 1.284 & 1.340 & 1.178 & 1.027 & 1.049 & 1.109 & 0.994 & 0.867 \\
\hline 9 & 1.396 & 1.644 & 1.604 & 1.466 & 1.450 & 1.438 & 1.235 & 1.225 & 1.386 & 1.403 & 1.466 & 1.302 & 1.151 & 1.216 & 1.406 & 1.393 & 1.255 \\
\hline 10 & 1.402 & 1.652 & 1.608 & 1.471 & 1.455 & 1.443 & 1.243 & 1.237 & 1.391 & 1.411 & 1.476 & 1.312 & 1.162 & 1.237 & 1.456 & 1.463 & 1.323 \\
\hline 11 & 1.385 & 1.633 & 1.590 & 1.453 & 1.436 & 1.420 & 1.224 & 1.215 & 1.372 & 1.391 & 1.454 & 1.289 & 1.138 & 1.207 & 1.403 & 1.396 & 1.258 \\
\hline 12 & 1.252 & 1.475 & 1.433 & 1.308 & 1.291 & 1.277 & 1.095 & 1.087 & 1.227 & 1.242 & 1.294 & 1.137 & 0.987 & 1.003 & 1.042 & 0.912 & 0.787 \\
\hline 13 & 1.017 & 1.196 & 1.160 & 1.053 & 1.037 & 1.023 & 0.879 & 0.875 & 0.983 & 0.994 & 1.030 & 0.895 & 0.767 & 0.760 & 0.750 & 0.621 & 0.526 \\
\hline 14 & 0.824 & 0.963 & 0.928 & 0.840 & 0.826 & 0.821 & 0.710 & 0.704 & 0.800 & 0.804 & 0.820 & 0.699 & 0.587 & 0.557 & 0.483 & 0.337 & 0.267 \\
\hline 15 & 0.718 & 0.839 & 0.818 & 0.737 & 0.724 & 0.735 & 0.645 & 0.642 & 0.738 & 0.733 & 0.725 & 0.605 & 0.501 & 0.461 & 0.369 & 0.228 & 0.172 \\
\hline 16 & 0.708 & 0.868 & 0.835 & 0.809 & 0.792 & 0.725 & 0.602 & 0.591 & 0.669 & 0.702 & 0.731 & 0.636 & 0.531 & 0.480 & 0.373 & 0.223 & 0.157 \\
\hline 17 & 0.749 & 0.816 & 0.657 & 0.620 & 0.595 & 0.568 & 0.488 & 0.459 & 0.490 & 0.580 & 0.564 & 0.479 & 0.409 & 0.359 & 0.290 & 0.208 & 0.134 \\
\hline 18 & 0.668 & 0.544 & 0.448 & 0.401 & 0.378 & 0.374 & 0.387 & 0.394 & 0.394 & 0.367 & 0.308 & 0.262 & 0.227 & 0.195 & 0.162 & 0.135 & 0.128 \\
\hline 19 & 0.743 & 0.650 & 0.567 & 0.514 & 0.477 & 0.452 & 0.442 & 0.444 & 0.442 & 0.421 & 0.382 & 0.338 & 0.299 & 0.256 & 0.205 & 0.163 & 0.148 \\
\hline
\end{tabular}

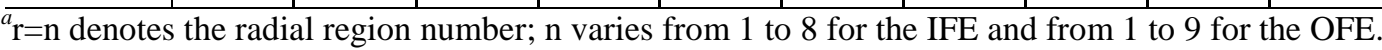


ORNL/TM-2014/154

Table 8.1.2. Relative fission densities for LEU Alternate Design $3\left(3.4 \mathrm{~g}{ }^{10} \mathrm{~B}\right)$ at EOC (28d)

\begin{tabular}{|c|c|c|c|c|c|c|c|c|c|c|c|c|c|c|c|c|c|}
\hline \multirow{2}{*}{$\begin{array}{c}\text { Axial } \\
\text { region \# }\end{array}$} & \multicolumn{8}{|c|}{ IFE } & \multicolumn{9}{|c|}{ OFE } \\
\hline & $\mathrm{r}=1^{a}$ & $r=2$ & $r=3$ & $r=4$ & $r=5$ & $r=6$ & $r=7$ & $r=8$ & $r=1$ & $r=2$ & $r=3$ & $r=4$ & $r=5$ & $r=6$ & $\mathrm{r}=7$ & $r=8$ & $r=9$ \\
\hline 1 & 0.731 & 1.166 & 1.521 & 1.528 & 1.461 & 1.282 & 1.018 & 1.024 & 1.077 & 1.126 & 1.388 & 1.415 & 1.310 & 1.326 & 1.238 & 0.947 & 0.793 \\
\hline 2 & 0.696 & 1.016 & 1.130 & 1.029 & 0.999 & 0.998 & 0.888 & 0.909 & 0.944 & 0.936 & 0.975 & 0.858 & 0.769 & 0.804 & 0.895 & 0.838 & 0.751 \\
\hline 3 & 0.670 & 0.914 & 0.915 & 0.789 & 0.778 & 0.841 & 0.785 & 0.815 & 0.844 & 0.818 & 0.803 & 0.666 & 0.588 & 0.635 & 0.788 & 0.818 & 0.758 \\
\hline 4 & 0.657 & 0.871 & 0.840 & 0.716 & 0.711 & 0.775 & 0.727 & 0.752 & 0.785 & 0.756 & 0.749 & 0.629 & 0.558 & 0.614 & 0.790 & 0.841 & 0.785 \\
\hline 5 & 0.665 & 0.883 & 0.854 & 0.735 & 0.729 & 0.774 & 0.712 & 0.740 & 0.775 & 0.746 & 0.762 & 0.660 & 0.589 & 0.652 & 0.840 & 0.896 & 0.835 \\
\hline 6 & 0.717 & 0.981 & 0.974 & 0.846 & 0.836 & 0.862 & 0.779 & 0.814 & 0.847 & 0.816 & 0.862 & 0.763 & 0.686 & 0.759 & 0.974 & 1.013 & 0.938 \\
\hline 7 & 0.781 & 1.127 & 1.155 & 1.003 & 0.988 & 1.010 & 0.904 & 0.955 & 0.984 & 0.943 & 1.013 & 0.904 & 0.815 & 0.902 & 1.147 & 1.142 & 1.037 \\
\hline 8 & 0.824 & 1.256 & 1.337 & 1.161 & 1.139 & 1.161 & 1.033 & 1.098 & 1.128 & 1.072 & 1.165 & 1.043 & 0.939 & 1.044 & 1.318 & 1.234 & 1.094 \\
\hline 9 & 0.833 & 1.307 & 1.420 & 1.234 & 1.209 & 1.227 & 1.088 & 1.164 & 1.194 & 1.128 & 1.235 & 1.108 & 0.996 & 1.111 & 1.394 & 1.274 & 1.121 \\
\hline 10 & 0.833 & 1.310 & 1.429 & 1.242 & 1.213 & 1.232 & 1.090 & 1.166 & 1.198 & 1.131 & 1.240 & 1.111 & 1.001 & 1.115 & 1.399 & 1.274 & 1.122 \\
\hline 11 & 0.829 & 1.301 & 1.411 & 1.226 & 1.202 & 1.221 & 1.081 & 1.158 & 1.187 & 1.125 & 1.231 & 1.102 & 0.991 & 1.107 & 1.387 & 1.268 & 1.117 \\
\hline 12 & 0.808 & 1.234 & 1.314 & 1.141 & 1.120 & 1.139 & 1.014 & 1.079 & 1.111 & 1.056 & 1.148 & 1.027 & 0.924 & 1.029 & 1.297 & 1.217 & 1.080 \\
\hline 13 & 0.757 & 1.092 & 1.116 & 0.970 & 0.954 & 0.976 & 0.873 & 0.923 & 0.956 & 0.914 & 0.980 & 0.874 & 0.789 & 0.876 & 1.120 & 1.117 & 1.015 \\
\hline 14 & 0.699 & 0.951 & 0.937 & 0.810 & 0.801 & 0.833 & 0.755 & 0.791 & 0.827 & 0.794 & 0.830 & 0.730 & 0.656 & 0.730 & 0.948 & 0.998 & 0.926 \\
\hline 15 & 0.665 & 0.886 & 0.868 & 0.752 & 0.747 & 0.801 & 0.740 & 0.771 & 0.812 & 0.779 & 0.786 & 0.670 & 0.597 & 0.661 & 0.856 & 0.910 & 0.848 \\
\hline 16 & 0.671 & 0.933 & 0.920 & 0.869 & 0.859 & 0.829 & 0.714 & 0.727 & 0.749 & 0.768 & 0.836 & 0.747 & 0.670 & 0.721 & 0.859 & 0.848 & 0.732 \\
\hline 17 & 0.691 & 0.846 & 0.707 & 0.670 & 0.652 & 0.650 & 0.582 & 0.563 & 0.552 & 0.647 & 0.661 & 0.590 & 0.545 & 0.559 & 0.634 & 0.689 & 0.532 \\
\hline 18 & 0.576 & 0.511 & 0.441 & 0.401 & 0.389 & 0.406 & 0.444 & 0.458 & 0.434 & 0.400 & 0.350 & 0.313 & 0.296 & 0.295 & 0.324 & 0.386 & 0.433 \\
\hline 19 & 0.598 & 0.553 & 0.505 & 0.472 & 0.457 & 0.463 & 0.483 & 0.495 & 0.473 & 0.448 & 0.415 & 0.386 & 0.370 & 0.367 & 0.381 & 0.414 & 0.443 \\
\hline
\end{tabular}

${ }^{a} \mathrm{r}=\mathrm{n}$ denotes the radial region number; $\mathrm{n}$ varies from 1 to 8 for the IFE and from 1 to 9 for the OFE. 
ORNL/TM-2014/154

Table 8.1.3. Relative fission densities for LEU Alternate Design $3\left(4.6 \mathrm{~g}{ }^{10} \mathrm{~B}\right)$ at BOC

\begin{tabular}{|c|c|c|c|c|c|c|c|c|c|c|c|c|c|c|c|c|c|}
\hline \multirow{2}{*}{$\begin{array}{c}\text { Axial } \\
\text { region \# }\end{array}$} & \multicolumn{8}{|c|}{ IFE } & \multicolumn{9}{|c|}{ OFE } \\
\hline & $\mathrm{r}=1^{a}$ & $r=2$ & $r=3$ & $r=4$ & $r=5$ & $r=6$ & $r=7$ & $r=8$ & $r=1$ & $r=2$ & $r=3$ & $r=4$ & $r=5$ & $r=6$ & $=7$ & $=8$ & $=9$ \\
\hline 1 & 0.806 & & & & & & & & 38 & & & & & 2 & 56 & 53 & 341 \\
\hline 2 & 17 & 31 & & & & 36 & 05 & 99 & 805 & 310 & 334 & 741 & 639 & 602 & 515 & 358 & 290 \\
\hline 3 & 0.669 & 0.815 & 0.818 & 0.741 & 724 & 0.717 & 0.626 & 523 & 0.736 & 727 & 0.713 & 0.600 & .509 & .486 & .433 & 318 & 261 \\
\hline 4 & 0.660 & 0.789 & 0.775 & 0.701 & 0.689 & 0.689 & 0.598 & 594 & 0.705 & .701 & 0.697 & 0.586 & .497 & 476 & .427 & .313 & .256 \\
\hline 5 & 0.688 & 0.822 & 0.809 & 0.739 & 726 & 0.716 & 0.612 & 607 & 0.721 & 725 & 0.734 & 0.629 & 0.534 & .516 & 465 & 342 & 279 \\
\hline 6 & 0.807 & 0. & 0. & 0.879 & ס/ & 0.845 & & & 0 & 38 & 0.870 & 0 & 0.652 & 645 & .623 & 503 & 423 \\
\hline 7 & 0.998 & 1.194 & 1.184 & 1.088 & 1.072 & 1.046 & 0.882 & 0.874 & 1.020 & .034 & 1.081 & 0.954 & 0.827 & .834 & .850 & .731 & .630 \\
\hline 8 & 1.204 & 1.444 & 1.432 & 1.321 & 1.307 & 1.275 & 1.076 & 1.064 & 1.243 & 1.263 & 1.327 & 1.180 & 1.039 & 78 & 178 & 95 & .966 \\
\hline 9 & 1.309 & 1.569 & 1.560 & 1.437 & 124 & 1.394 & 1.176 & 1.165 & 1.360 & 384 & 1.461 & 1.309 & 1.168 & 253 & .488 & 508 & .367 \\
\hline 10 & 1.313 & 1.573 & & 1.443 & U2 & 1.401 & & & & & 1.470 & & 1.179 & & .519 & 52 & .410 \\
\hline 1 & 1.295 & 1.555 & 1.5 & 1.428 & & 1.378 & 1.164 & 153 & 1.346 & .369 & 1.446 & 1.298 & 1.157 & 243 & 1.485 & 13 & 375 \\
\hline 12 & 1.173 & 1.405 & 1.393 & 1.286 & 1.269 & 1.239 & 1.045 & 1.035 & 1.209 & 1.226 & 1.288 & 1.144 & 1.004 & 038 & 1.123 & 30 & 0.903 \\
\hline $1:$ & & & & 1.031 & & 0.987 & 0.835 & 0.826 & 0.963 & 0.978 & 1.020 & 0.897 & 0.776 & 0.777 & .781 & 660 & .561 \\
\hline 14 & 0.768 & 0.915 & 0.899 & 0.821 & 0.8 & 0.789 & 0.672 & 0.666 & 0.782 & 078 & 0.810 & 0.699 & 0.596 & 0.580 & 0.545 & 425 & .351 \\
\hline 15 & 0.667 & & & 0.719 & & 0.704 & & & & & 0.712 & & 0.505 & 0.471 & .387 & 246 & .188 \\
\hline 16 & 0.658 & 0.818 & 0.802 & 0.784 & 0.768 & 0.686 & 0.557 & 0.547 & 0.644 & 0.673 & 0.714 & 0.630 & 0.530 & 0.484 & 0.380 & .231 & 0.164 \\
\hline 17 & 0.691 & & & 0.594 & & & & & 0.468 & & 0.547 & 0.469 & 0.403 & 0.357 & 0.291 & 0.212 & 0.135 \\
\hline 18 & 0.615 & 0.509 & 0.427 & 0.383 & 0.359 & 0.351 & & & 0.372 & & 0.297 & 0.256 & 0.223 & 0.194 & 0.161 & 0.136 & 0.128 \\
\hline 19 & 0.680 & 0.608 & 0.539 & 0.491 & 0.455 & 0.423 & 0.409 & 0.411 & 0.414 & 0.400 & 0.367 & 0.330 & 0.293 & 0.252 & 0.203 & 0.163 & 0.149 \\
\hline
\end{tabular}

${ }_{\mathrm{a}} \mathrm{r}=\mathrm{n}$ denotes the radial region number; $\mathrm{n}$ varies from 1 to 8 for the IFE and from 1 to 9 for the OFE. 
ORNL/TM-2014/154

Table 8.1.4. Relative fission densities for LEU Alternate Design $3\left(4.6 \mathrm{~g}{ }^{10} \mathrm{~B}\right)$ at EOC (28d)

\begin{tabular}{|c|c|c|c|c|c|c|c|c|c|c|c|c|c|c|c|c|c|}
\hline \multirow{2}{*}{$\begin{array}{c}\text { Axial } \\
\text { region \# }\end{array}$} & \multicolumn{8}{|c|}{ IFE } & \multicolumn{9}{|c|}{ OFE } \\
\hline & $\mathrm{r}=1^{a}$ & $r=2$ & $r=3$ & $r=4$ & $r=5$ & $r=6$ & $\mathrm{r}=7$ & $r=8$ & $r=1$ & $\mathbf{r}=2$ & $r=3$ & $r=4$ & $r=5$ & $r=6$ & $\mathrm{r}=7$ & $r=8$ & $\mathbf{r}=9$ \\
\hline 1 & 0.794 & 1.239 & 1.576 & 1.574 & 1.526 & 1.455 & 1.226 & 1.111 & 1.115 & 1.183 & 1.437 & 1.440 & 1.317 & 1.327 & 1.255 & 0.961 & 0.823 \\
\hline 2 & 0.737 & 1.042 & 1.129 & 1.030 & 1.012 & 1.048 & 0.983 & 0.951 & 0.959 & 0.957 & 0.983 & 0.853 & 0.760 & 0.801 & 0.912 & 0.853 & 0.780 \\
\hline 3 & 0.695 & 0.915 & 0.900 & 0.775 & 0.779 & 0.846 & 0.830 & 0.830 & 0.843 & 0.831 & 0.805 & 0.656 & 0.580 & 0.638 & 0.809 & 0.830 & 0.775 \\
\hline 4 & 0.672 & 0.871 & 0.821 & 0.699 & 0.707 & 0.775 & 0.756 & 0.755 & 0.777 & 0.763 & 0.750 & 0.618 & 0.550 & 0.616 & 0.810 & 0.858 & 0.808 \\
\hline 5 & 0.680 & 0.879 & 0.838 & 0.723 & 0.724 & 0.778 & 0.742 & 0.736 & 0.757 & 0.746 & 0.756 & 0.647 & 0.581 & 0.654 & 0.866 & 0.913 & 0.857 \\
\hline 6 & 0.738 & 0.989 & 0.971 & 0.843 & 0.843 & 0.885 & 0.828 & 0.817 & 0.825 & 0.822 & 0.867 & 0.764 & 0.691 & 0.779 & 1.025 & 1.046 & 0.969 \\
\hline 7 & 0.813 & 1.159 & 1.176 & 1.021 & 1.014 & 1.059 & 0.983 & 0.976 & 0.975 & 0.966 & 1.039 & 0.923 & 0.837 & 0.949 & 1.230 & 1.174 & 1.059 \\
\hline 8 & 0.844 & 1.259 & 1.318 & 1.141 & 1.132 & 1.184 & 1.092 & 1.090 & 1.081 & 1.068 & 1.158 & 1.030 & 0.934 & 1.059 & 1.364 & 1.252 & 1.114 \\
\hline 9 & 0.857 & 1.309 & 1.388 & 1.203 & 1.196 & 1.247 & 1.149 & 1.149 & 1.134 & 1.116 & 1.216 & 1.085 & 0.983 & 1.119 & 1.433 & 1.291 & 1.140 \\
\hline 10 & 0.856 & 1.320 & 1.402 & 1.213 & 1.208 & 1.256 & 1.158 & 1.160 & 1.147 & 1.126 & 1.227 & 1.094 & 0.991 & 1.131 & 1.446 & 1.294 & 1.142 \\
\hline 11 & 0.849 & 1.295 & 1.377 & 1.195 & 1.185 & 1.238 & 1.138 & 1.141 & 1.125 & 1.112 & 1.209 & 1.075 & 0.975 & 1.110 & 1.422 & 1.279 & 1.130 \\
\hline 12 & 0.829 & 1.233 & 1.287 & 1.116 & 1.111 & 1.163 & 1.073 & 1.071 & 1.060 & 1.047 & 1.136 & 1.010 & 0.914 & 1.040 & 1.340 & 1.233 & 1.098 \\
\hline 13 & 0.782 & 1.116 & 1.134 & 0.985 & 0.981 & 1.027 & 0.950 & 0.941 & 0.939 & 0.932 & 1.001 & 0.892 & 0.809 & 0.915 & 1.193 & 1.143 & 1.032 \\
\hline 14 & 0.698 & 0.936 & 0.917 & 0.795 & 0.793 & 0.835 & 0.780 & 0.767 & 0.778 & 0.774 & 0.818 & 0.723 & 0.655 & 0.742 & 0.982 & 1.006 & 0.934 \\
\hline 15 & 0.623 & 0.805 & 0.766 & 0.662 & 0.664 & 0.709 & 0.675 & 0.671 & 0.675 & 0.670 & 0.689 & 0.597 & 0.539 & 0.612 & 0.818 & 0.866 & 0.815 \\
\hline 16 & 0.600 & 0.767 & 0.726 & 0.622 & 0.630 & 0.684 & 0.651 & 0.644 & 0.667 & 0.661 & 0.661 & 0.561 & 0.498 & 0.563 & 0.754 & 0.805 & 0.758 \\
\hline 17 & 0.590 & 0.765 & 0.741 & 0.641 & 0.647 & 0.700 & 0.677 & 0.673 & 0.691 & 0.687 & 0.678 & 0.566 & 0.504 & 0.559 & 0.724 & 0.755 & 0.707 \\
\hline 18 & 0.596 & 0.811 & 0.852 & 0.764 & 0.760 & 0.796 & 0.747 & 0.721 & 0.756 & 0.757 & 0.785 & 0.683 & 0.609 & 0.652 & 0.768 & 0.735 & 0.675 \\
\hline 19 & 0.608 & 0.900 & 1.085 & 1.064 & 1.038 & 1.018 & 0.882 & 0.821 & 0.838 & 0.888 & 1.071 & 1.049 & 0.957 & 0.986 & 0.975 & 0.780 & 0.677 \\
\hline
\end{tabular}

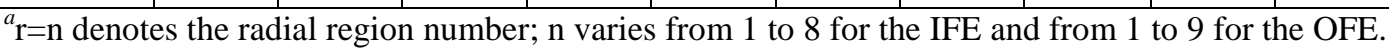


Fission rate density profiles, at BOC and EOC, for select axial regions (core horizontal midplane, upper edge of the active fuel region, lower edge of the active fuel region, and average over active fuel height) are shown in Figs. 8.1.4 and 8.1.6, for the two Alternate Design 3 cases (3.4g and $4.6 \mathrm{~g}{ }^{10} \mathrm{~B}$ ), as a function of the radial distance from the longitudinal centerline of the core. Similar plots, illustrating the fission rate density profiles for select radial regions (innermost, outermost, and central radial meshes) in the IFE and OFE are provided in Figs. 8.1.5 and 8.1.7 as a function of the axial distance from the core horizontal midplane.
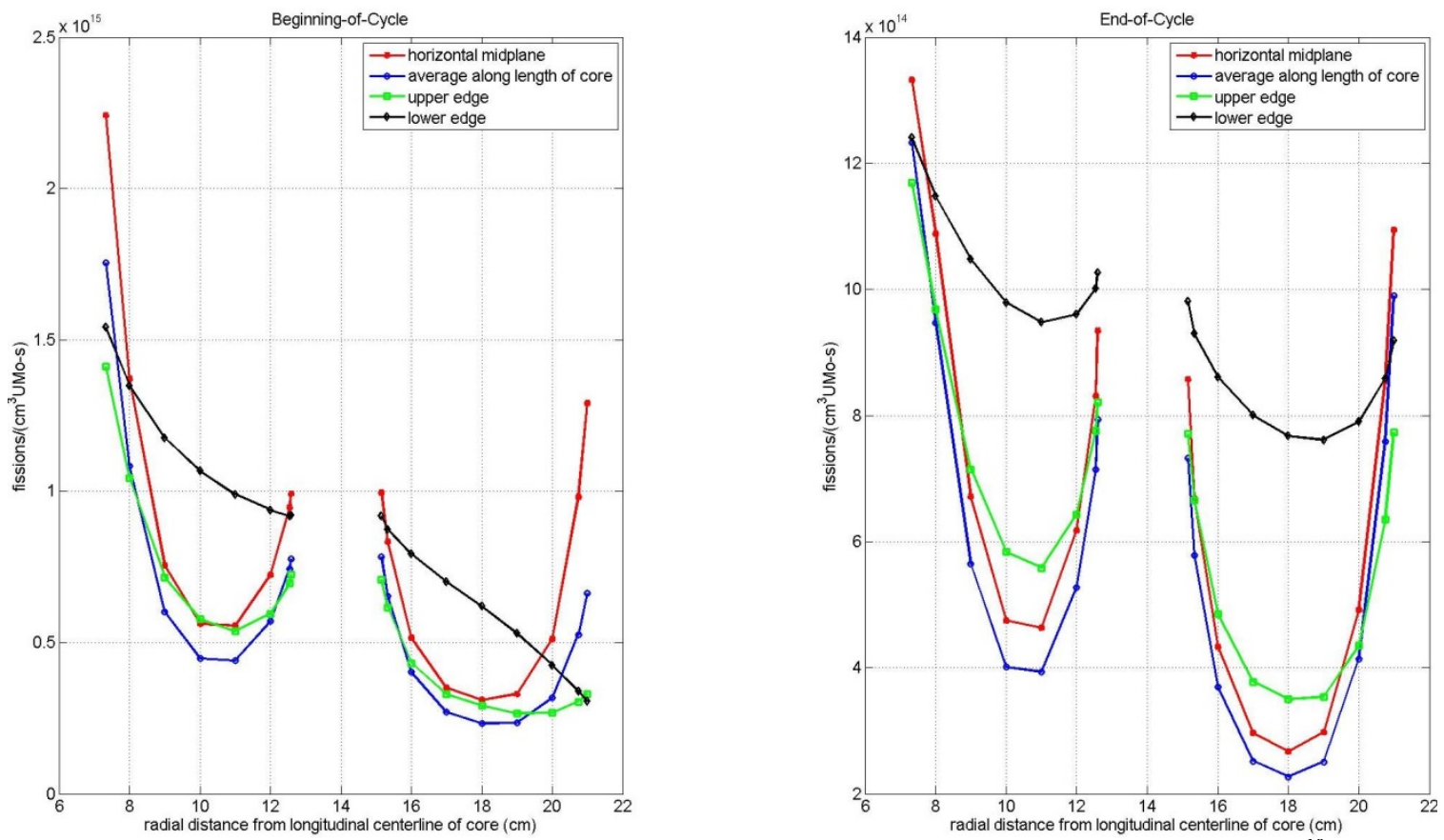

Fig. 8.1.4 Radial distribution of fission rate densities for LEU Alternate Design $3\left(3.4 \mathrm{~g}^{10} \mathrm{~B}\right)$.
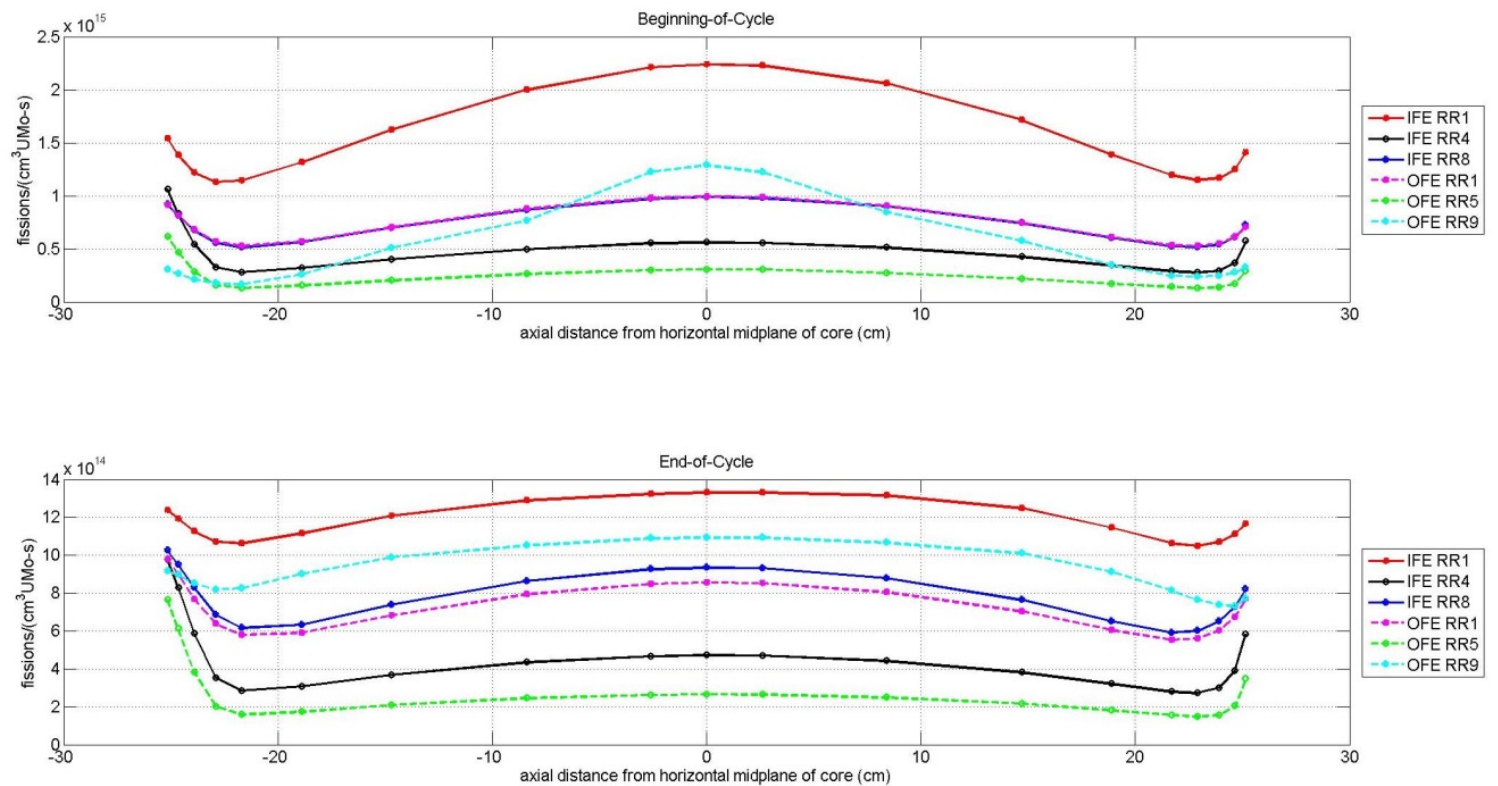

Fig. 8.1.5. Axial distribution of fission rate densities for LEU Alternate Design $3\left(3.4 \mathrm{~g}^{10} \mathrm{~B}\right)$. 

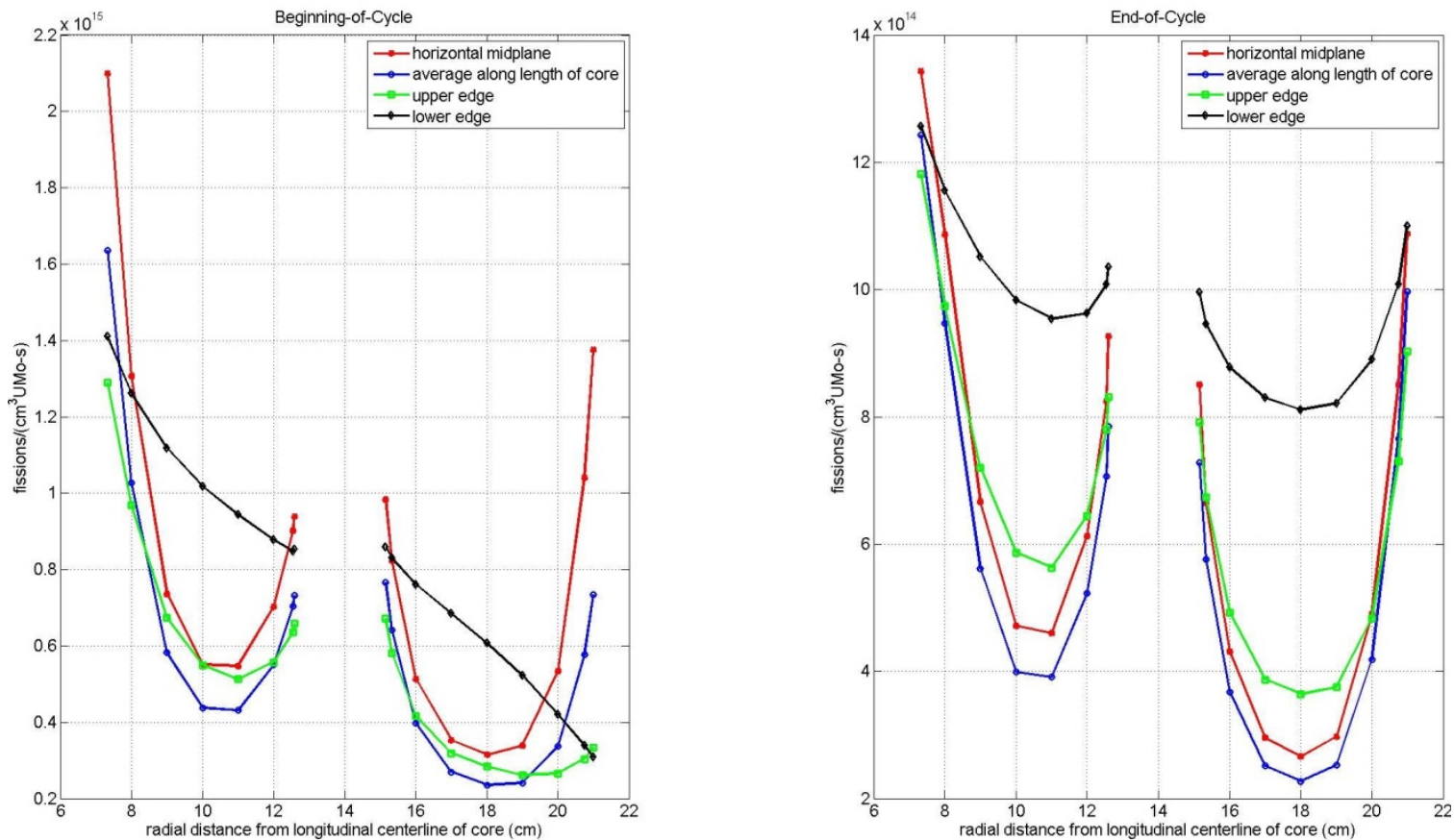

Fig. 8.1.6 Radial distribution of fission rate densities for LEU Alternate Design $3\left(4.6 \mathrm{~g}{ }^{10} \mathrm{~B}\right)$.
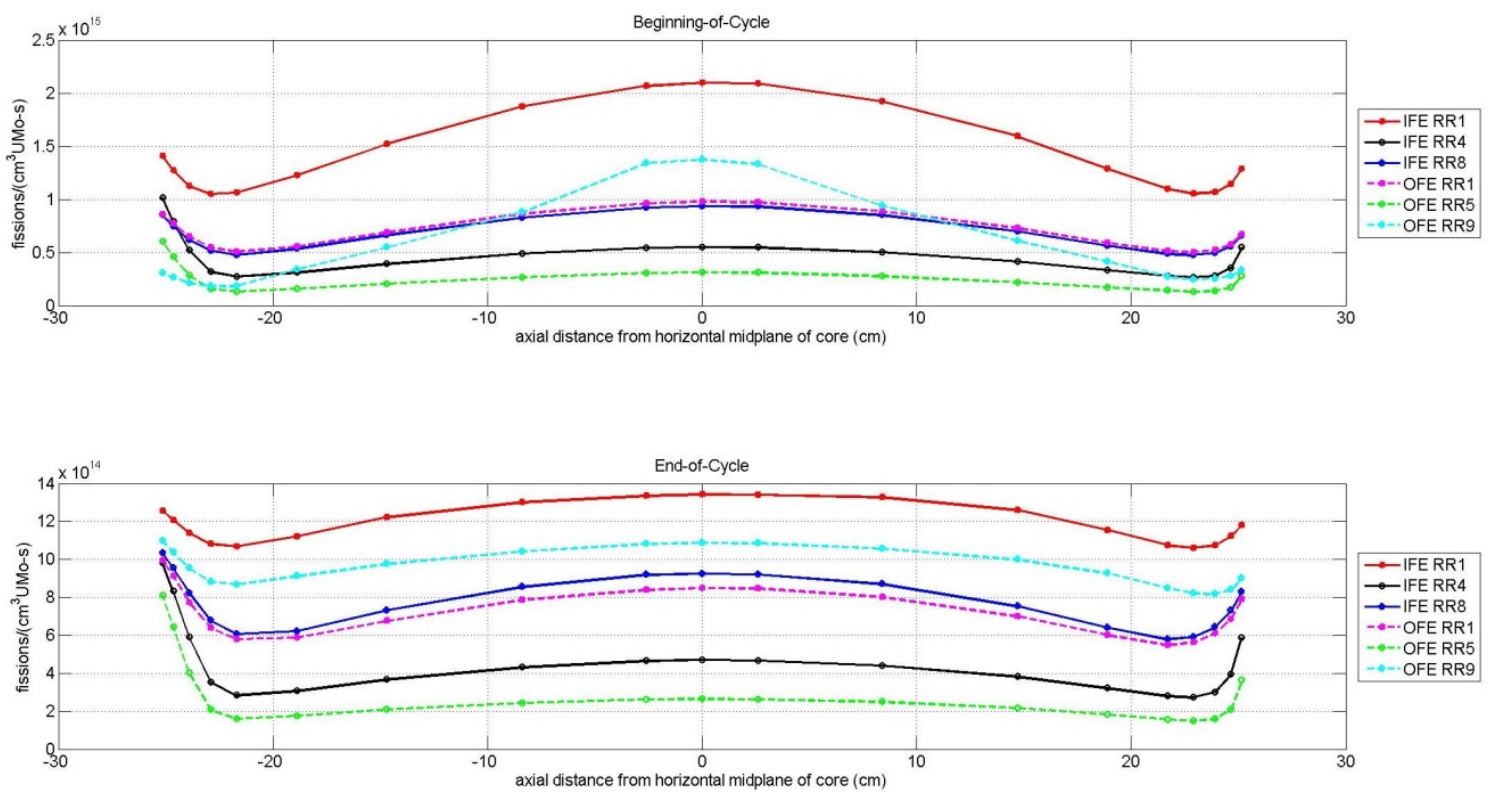

Fig. 8.1.7. Axial distribution of fission rate densities for LEU Alternate Design $3\left(4.6 \mathrm{~g}{ }^{10} \mathrm{~B}\right)$.

Maximum local fission rate densities of $2.24 \times 10^{15}$ and $1.33 \times 10^{15}$ fissions/( $\left.\mathrm{cm}^{3} \mathrm{U}-10 \mathrm{Mo} \cdot \mathrm{s}\right)$ were calculated for the BOC and EOC cores, respectively, for Alternate Design 3 with $3.4 \mathrm{~g}{ }^{10} \mathrm{~B}$; both of these maxima are located at the inner radial edge of the IFE on the core horizontal midplane. For Alternate 3 with $4.6 \mathrm{~g}{ }^{10} \mathrm{~B}$, the maximum local fission rate densities at BOC and EOC are $2.10 \times 10^{15}$ and $1.34 \times 10^{15}$ fissions $/\left(\mathrm{cm}^{3} \mathrm{UMo} \mathrm{s}\right)$; the locations of these maxima are the same as for the case with $3.4 \mathrm{~g}{ }^{10} \mathrm{~B}$.

Assuming conservatively that $100 \%$ of the total reactor power (100 MW) is deposited in the fuel meat, the maximum fission rate densities would correspond to power densities of $\sim 71.84$ and $42.68 \mathrm{~kW} /\left(\mathrm{cm}^{3}\right.$ 
$\mathrm{UMo}$ ), respectively, for Alternate 3 with $3.4 \mathrm{~g}{ }^{10} \mathrm{~B}$ and to $\sim 67.28$ and $43.04 \mathrm{~kW} /\left(\mathrm{cm}^{3} \mathrm{UMo}\right)$, respectively, for Alternate 3 with $4.6 \mathrm{~g}{ }^{10} \mathrm{~B}$.

The minimum and maximum calculated local burnups, in terms of percent ${ }^{235} \mathrm{U}$ removed during the irradiation cycle, compared to the content at BOC, are 5.1 and 63.3\%, respectively, for Alternate 3 with $3.4 \mathrm{~g}{ }^{10} \mathrm{~B}$; the maximum burnup occurs at the innermost edge of the IFE, at the core midline. The minimum and maximum calculated local burnups are 5.1 and 62.3\%, respectively, for Alternate 3 with $4.6 \mathrm{~g}{ }^{10} \mathrm{~B}$; the maximum burnup location is the same as for the $3.4 \mathrm{~g}{ }^{10} \mathrm{~B}$ case.

Approximately $13.7 \%$ of the initial ${ }^{235} \mathrm{U}$ is consumed during the cycle for Alternate 3 for both the $3.4 \mathrm{~g}{ }^{10} \mathrm{~B}$ and the $4.6 \mathrm{~g}{ }^{10} \mathrm{~B}$ cases.

For both cases considered for Alternate 3 , almost all the ${ }^{10} \mathrm{~B}$ present at BOC in the IFE inner side plate is consumed by the EOC ( 99\%). In the outer side plate of the IFE, $\sim 85-86 \%$ of the initial ${ }^{10} \mathrm{~B}$ is consumed during the cycle.

\subsection{STEADY-STATE TH WITH SAFETY CASE ASSUMPTIONS (USING HSSHTC)}

Figure 8.2.1 shows results for the LEU reference fuel compared to a case with the power densities determined for fuel with boron relocated from the inner element fuel plates to the side plateside plates. A concentration of $1500 \mathrm{ppm}$, yielding an element total of $3.4 \mathrm{~g}$, was evaluated first. For the $1500 \mathrm{ppm}$ case, the hot spot burnout power remains above the existing HEU SL and matches the reference fuel safety margin at the end of the cycle and during the day 1-3 timeframe. In order to gain more safety margin at BOC and during the middle portion of the cycle, a fuel design with additional boron was evaluated-2000 ppm, yielding an element total of $4.6 \mathrm{~g}$. As shown in Fig 8.2.2, the $2000 \mathrm{ppm}$ boron design brings the cycle safety margin closer to the reference fuel curve at the BOC point and at mid-cycle. For the $1500 \mathrm{ppm}$ case (3A), the minimum calculated burnout power of $140.2 \mathrm{MW}$ occurs in the inner element at day 10 at radial node $5(\mathrm{r}=7.50 \mathrm{~cm})$ and axial node $26(\mathrm{z}=33.90 \mathrm{~cm})$. For the $2000 \mathrm{ppm}$ case (3B), a slightly higher minimum calculated burnout power of $142.75 \mathrm{MW}$ occurs in the inner element at day 10 at radial node $5(\mathrm{r}=7.50 \mathrm{~cm})$ and axial node $26(\mathrm{z}=33.90 \mathrm{~cm})$. 


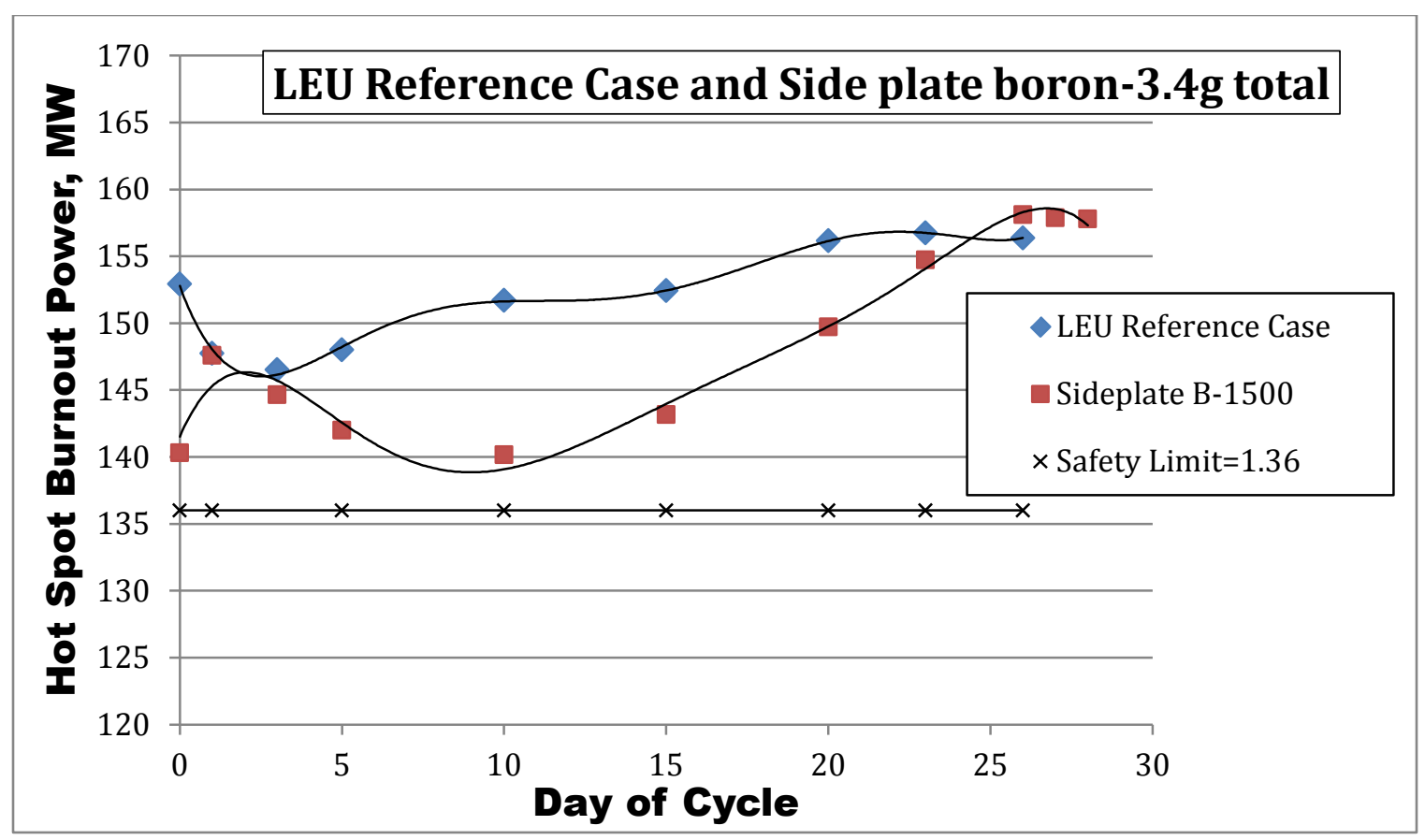

Fig. 8.2.1. Hot spot burnout power versus day in the cycle for the reference fuel plus inner element side plate boron-3.4g total.

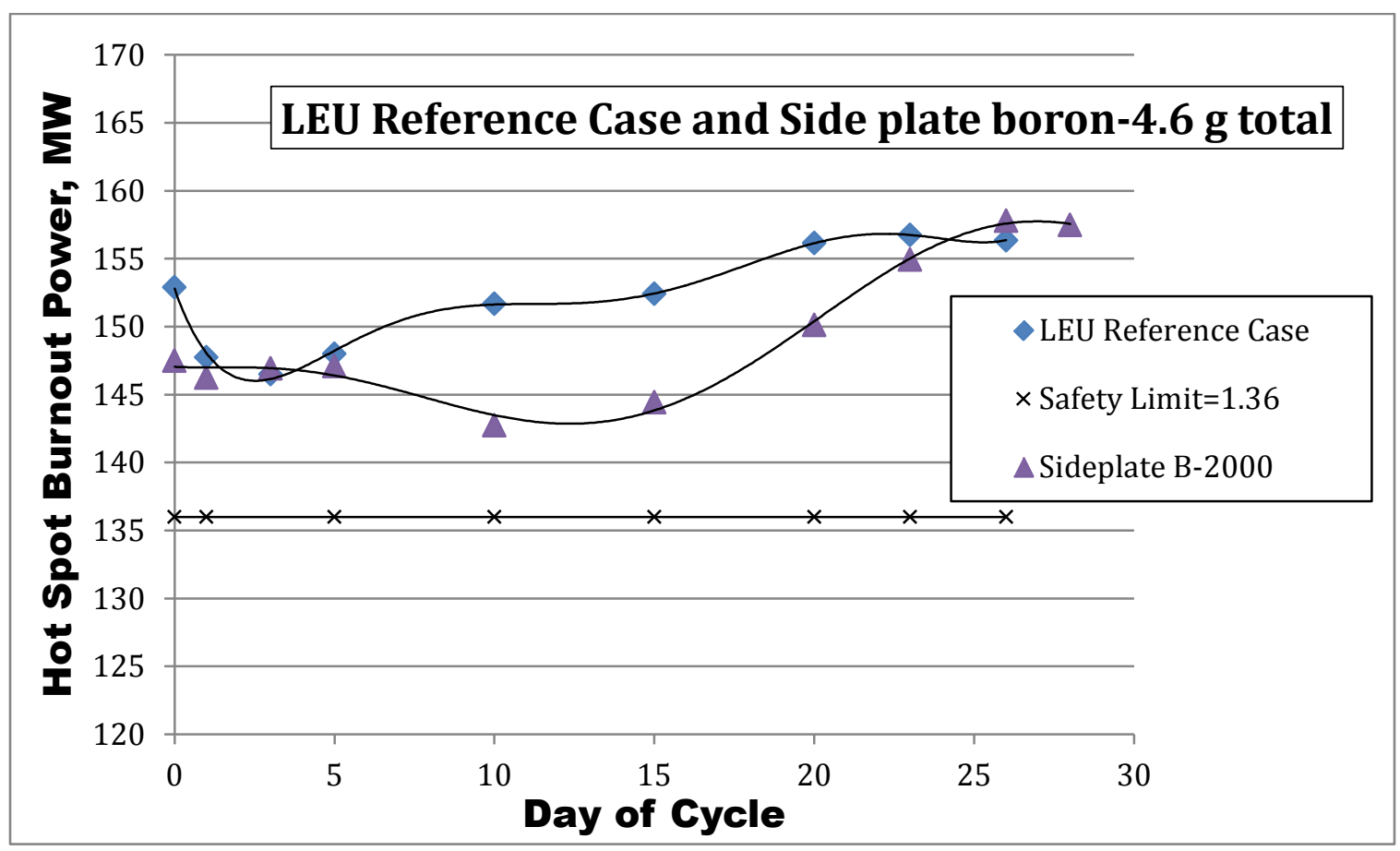

Fig. 8.2.2. Hot spot burnout power versus day in the cycle for the reference fuel plus inner element side plate boron- $4.6 \mathrm{~g}$ total. 


\section{EVALUATION OF ALTERNATE 4 (ZR CLAD INSTEAD OF AL)}

\subsection{NEUTRONICS}

In Alternate Design 4, the Al cladding and filler as well as the $\mathrm{Zr}$ diffusion barrier layer considered in the reference design were replaced with Zircaloy 4. All the other design features are the same as for the reference design.

The VESTA depletion simulation was performed for Alternate 4 using the critical control search option[8], which is described in Section 3. The control element location as a function of irradiation time that resulted from this depletion simulation was used also for the depletion simulation of the corresponding reference model. As mentioned in Section 2, the reference model used as a basis for the studies of Alternate 4 was slightly changed with respect to the original reference model[2] as part of the general effort of HFIR model revision and improvement. The small changes involved only some geometry data for regions located outside the fuel elements.

A comparison of the $\mathrm{k}_{\mathrm{eff}}$ values as a function of irradiation time, for the reference and Alternate 4 , is presented in Fig. 9.1.1. As observed from this figure, both designs show the same $k_{\text {eff }}$ variation as a function of time and would approximately predict the same cycle length, within $\pm 1 \mathrm{~d}$. The small difference observed in cycle length estimates is of the order of magnitude expected for cycle length estimation through this type of depletion simulation. Note that the control element location was optimized just for the Alternate 4 depletion, for which the VESTA simulation was used with a critical search option. For the reference case, no critical search was employed with the VESTA simulation; the control element location used in this simulation was that obtained from the critical search for Alternate 4.

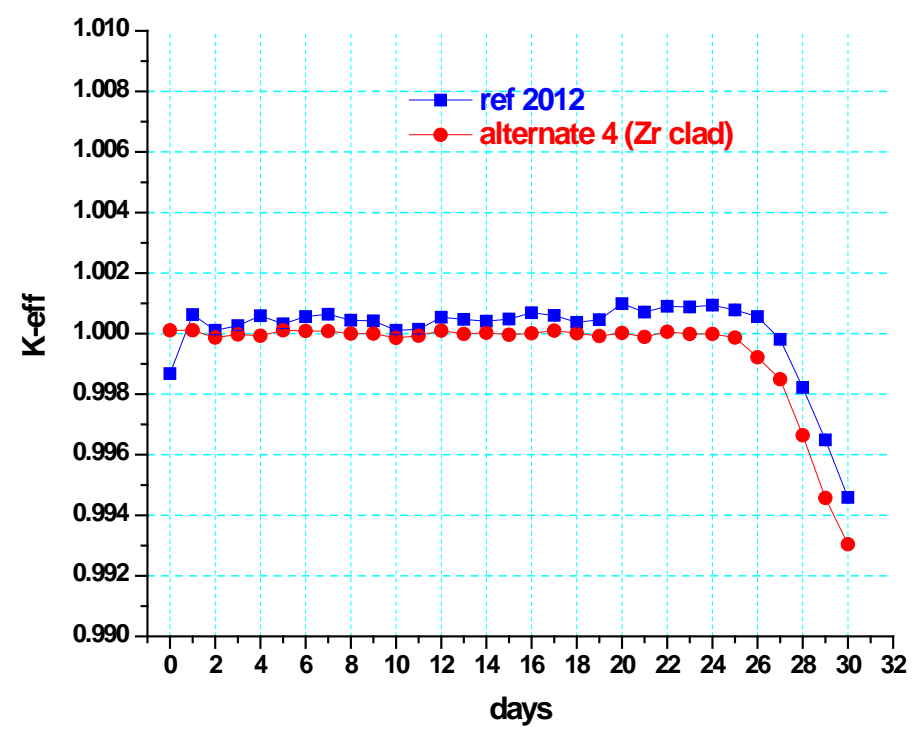

Fig. 9.1.1. Effective multiplication factor for LEU reference and Alternate Design 4. 
The BOC and EOC (considered here at 27d) relative fission density data are illustrated, as surface plots, in Fig. 9.1.2 and listed in Tables 9.1.1 and 9.1.2. The maximum value for the relative fission density at BOC and EOC is 1.636 and 1.466, respectively. The "hot spot" at BOC is located close to the outer radial edge of the OFE, at the core horizontal midline, whereas at EOC it occurs at the top axial edge (i.e., at the coolant inlet) of the IFE.
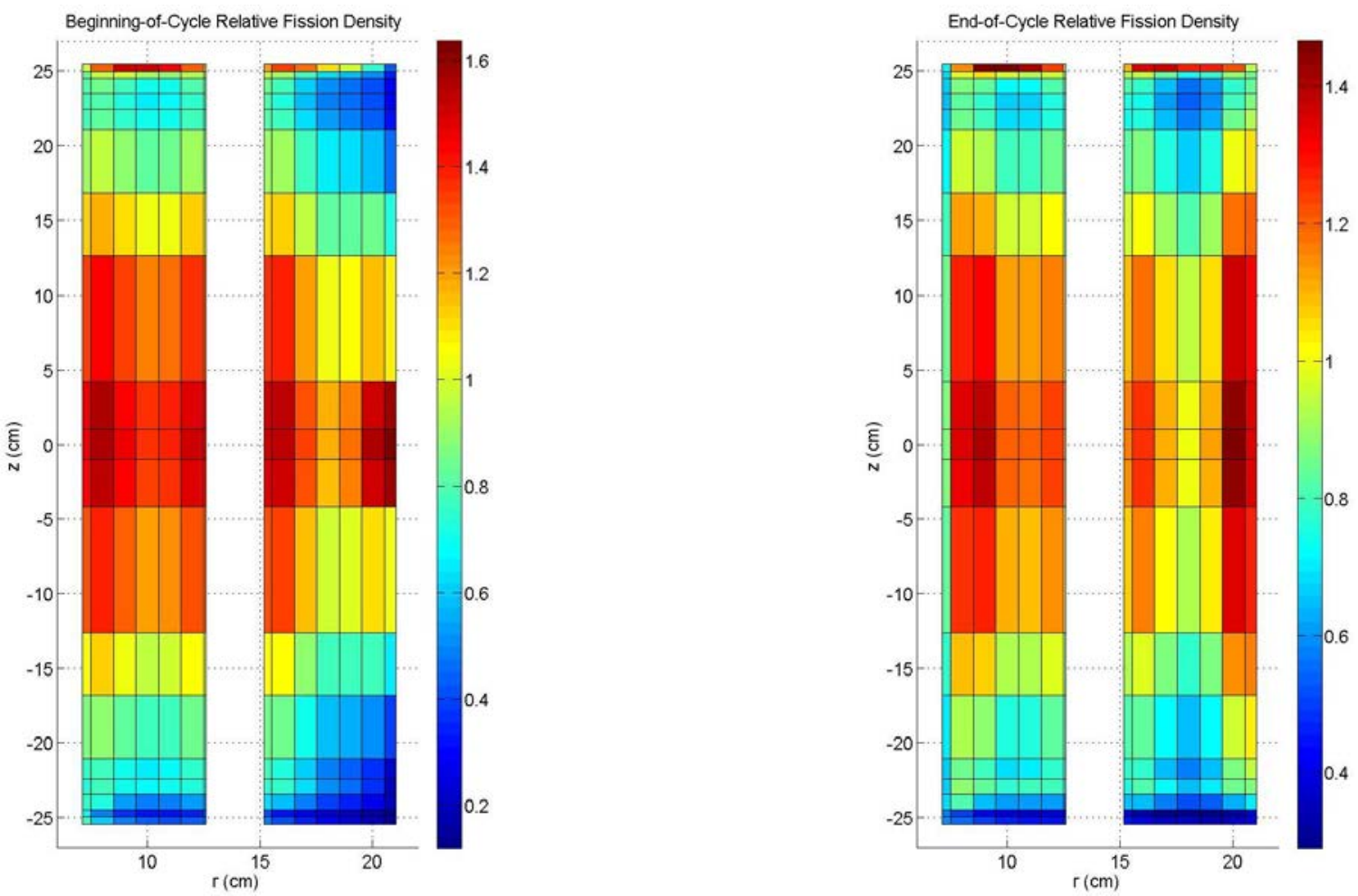

Fig. 9.1.2. Relative fission density for LEU Alternate 4 at BOC (left) and EOC (right). 
Table 9.1.1. Relative fission densities for LEU Alternate Design 4 at BOC

\begin{tabular}{|c|c|c|c|c|c|c|c|c|c|c|c|c|c|c|c|c|c|}
\hline \multirow{2}{*}{$\begin{array}{c}\text { Axial } \\
\text { region \# }\end{array}$} & \multicolumn{8}{|c|}{ IFE } & \multicolumn{9}{|c|}{ OFE } \\
\hline & $=1^{a}$ & $r=2$ & 3 & $r=4$ & $r=5$ & $r=6$ & $\mathbf{r}=7$ & $r=8$ & $\mathbf{r}=\mathbf{1}$ & $\mathrm{r}=2$ & $r=3$ & $r=4$ & $r=5$ & $r=6$ & $r=7$ & $r=8$ & $r=9$ \\
\hline 1 & 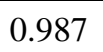 & & & & 3 & 1.287 & 996 & & 160 & 132 & 1.334 & 265 & 1.093 & 984 & .745 & 442 & .331 \\
\hline 2 & 0.853 & & 0.982 & 24 & 00 & 0.944 & 24 & 0.940 & & & 913 & & 635 & 592 & 502 & 347 & 278 \\
\hline 3 & 0.785 & 0.833 & 0.771 & 0.705 & 0.709 & 0.796 & 0.811 & 0.834 & 863 & 34 & 0.764 & 604 & 0.501 & .472 & .416 & .304 & 251 \\
\hline 4 & & & & & & & & & & & 0.732 & & 0.485 & 461 & 407 & 296 & 244 \\
\hline 5 & 0.782 & 0.821 & 0.753 & 0.692 & 0.705 & 0.779 & 0.766 & 0.780 & 04 & 0.793 & 0.764 & 627 & 0.524 & & 41 & 20 & 260 \\
\hline 6 & & & & & & & & & & & & & & & & & \\
\hline 7 & 1.115 & 1.181 & 1.100 & 1.024 & 1.041 & 1.117 & 1.066 & 1.082 & 1.113 & 1.114 & 1.122 & 0.957 & 0.819 & 0.819 & 0.835 & 0.728 & 0.630 \\
\hline 8 & & & & & 1.267 & & & & & & 1.380 & & 1. & & & 89 & .967 \\
\hline s & 57 & 1.545 & 1.446 & 1.353 & 1.384 & 1.492 & 1.424 & 1.442 & 1.488 & 1.495 & 1.519 & 2 & 1.167 & 15 & 1.503 & 1.570 & .441 \\
\hline 10 & 1.469 & & & 1.362 & 1.391 & & 1.433 & & & & 1.530 & 1.3 & 1.179 & 1.267 & 1.548 & .636 & 1.506 \\
\hline 1. & 1.445 & 1.532 & 1.436 & 1.343 & 1.373 & 1.478 & 1.413 & 1.434 & 1.479 & 1.482 & 1.505 & 1.308 & 1.156 & 1.237 & 1.503 & 1.578 & 1.450 \\
\hline 12 & 1.307 & 1.383 & 1.290 & 1.205 & 1.229 & & 1.262 & 1.276 & 1.319 & 1.321 & 1.335 & 1,1 & 0.996 & 19 & 1.100 & .020 & 0.899 \\
\hline 13 & & & & & & & & & & & 52 & & 63 & & & 58 & \\
\hline 14 & 0.854 & 0.895 & 0.823 & 0.761 & 0.774 & 0.841 & 0.813 & 0.827 & 0.849 & 0.843 & 0.835 & 0.694 & 0.581 & 0.556 & 0.506 & .382 & 0.312 \\
\hline 15 & 0.741 & 0.772 & 0.704 & & & & & & & & & & & & & & \\
\hline 16 & 0.729 & 0.779 & 0.695 & 0.680 & 0.697 & 0.719 & 0.689 & 0.696 & 0.720 & 0.743 & 0.746 & 0.626 & 0.515 & 0.461 & 0.358 & 0.213 & 0.151 \\
\hline 17 & 0.756 & 0.715 & 0.524 & 0.492 & 0.494 & 0.542 & 0.544 & & & 0.627 & 0.587 & & 0.400 & & 0.277 & .197 & 0.127 \\
\hline 18 & 0.678 & 0.479 & 0.365 & 0.322 & 0.313 & 0.354 & 0.428 & 0.442 & 0.439 & 0.405 & 0.328 & 0.267 & 0.227 & 0.192 & 0.156 & 0.129 & 0.119 \\
\hline 19 & 0.772 & 0.606 & 0.494 & 0.445 & 0.424 & 0.443 & 0.493 & 0.507 & 0.503 & 0.475 & 0.410 & 0.349 & 0.302 & 0.253 & 0.200 & 0.155 & 0.141 \\
\hline
\end{tabular}

${ }^{a} \mathrm{r}=\mathrm{n}$ denotes the radial region number; $\mathrm{n}$ varies from 1 to 8 for the IFE and from 1 to 9 for the OFE. 
ORNL/TM-2014/154

Table 9.1.2. Relative fission densities for LEU Alternate Design 4 at EOC (27d)

\begin{tabular}{|c|c|c|c|c|c|c|c|c|c|c|c|c|c|c|c|c|c|}
\hline \multirow{2}{*}{$\begin{array}{c}\text { Axial } \\
\text { region \# }\end{array}$} & \multicolumn{8}{|c|}{ IFE } & \multicolumn{9}{|c|}{ OFE } \\
\hline & $\mathrm{r}=1^{a}$ & $r=2$ & $r=3$ & $r=4$ & $r=5$ & $r=6$ & $r=7$ & $r=8$ & $r=1$ & $r=2$ & $r=3$ & $r=4$ & $r=5$ & $r=6$ & $\mathrm{r}=7$ & $r=8$ & $r=9$ \\
\hline 1 & 0.722 & 1.141 & 1.457 & 1.466 & 1.401 & 1.240 & 0.993 & 1.006 & 1.067 & 1.104 & 1.351 & 1.371 & 1.272 & 1.278 & 1.219 & 0.948 & 0.800 \\
\hline 2 & 0.686 & 0.982 & 1.055 & 0.958 & 0.932 & 0.958 & 0.870 & 0.894 & 0.938 & 0.923 & 0.948 & 0.825 & 0.741 & 0.775 & 0.883 & 0.850 & 0.768 \\
\hline 3 & 0.661 & 0.875 & 0.839 & 0.723 & 0.723 & 0.810 & 0.781 & 0.810 & 0.840 & 0.809 & 0.781 & 0.640 & 0.565 & 0.614 & 0.780 & 0.835 & 0.778 \\
\hline 4 & 0.649 & 0.834 & 0.768 & 0.658 & 0.667 & 0.753 & 0.728 & 0.760 & 0.783 & 0.753 & 0.735 & 0.609 & 0.539 & 0.598 & 0.791 & 0.870 & 0.822 \\
\hline 5 & 0.663 & 0.852 & 0.793 & 0.684 & 0.693 & 0.760 & 0.720 & 0.750 & 0.777 & 0.749 & 0.756 & 0.645 & 0.573 & 0.635 & 0.847 & 0.932 & 0.873 \\
\hline 6 & 0.723 & 0.962 & 0.917 & 0.798 & 0.802 & 0.858 & 0.795 & 0.834 & 0.861 & 0.828 & 0.862 & 0.754 & 0.675 & 0.750 & 0.992 & 1.061 & 0.985 \\
\hline 7 & 0.800 & 1.128 & 1.110 & 0.962 & 0.961 & 1.010 & 0.922 & 0.973 & 1.006 & 0.963 & 1.020 & 0.902 & 0.808 & 0.902 & 1.181 & 1.195 & 1.081 \\
\hline 8 & 0.853 & 1.279 & 1.305 & 1.126 & 1.118 & 1.165 & 1.048 & 1.114 & 1.153 & 1.097 & 1.180 & 1.044 & 0.936 & 1.049 & 1.363 & 1.301 & 1.149 \\
\hline 9 & 0.866 & 1.338 & 1.392 & 1.200 & 1.190 & 1.238 & 1.107 & 1.182 & 1.219 & 1.157 & 1.254 & 1.110 & 0.996 & 1.116 & 1.446 & 1.347 & 1.178 \\
\hline 10 & 0.864 & 1.342 & 1.402 & 1.206 & 1.194 & 1.239 & 1.108 & 1.185 & 1.223 & 1.160 & 1.257 & 1.114 & 0.998 & 1.122 & 1.450 & 1.350 & 1.180 \\
\hline 11 & 0.862 & 1.332 & 1.385 & 1.193 & 1.182 & 1.228 & 1.097 & 1.171 & 1.214 & 1.152 & 1.247 & 1.104 & 0.990 & 1.111 & 1.439 & 1.340 & 1.172 \\
\hline 12 & 0.837 & 1.255 & 1.279 & 1.103 & 1.095 & 1.144 & 1.030 & 1.096 & 1.132 & 1.078 & 1.159 & 1.025 & 0.920 & 1.031 & 1.342 & 1.282 & 1.131 \\
\hline 13 & 0.774 & 1.089 & 1.071 & 0.928 & 0.925 & 0.976 & 0.891 & 0.943 & 0.973 & 0.930 & 0.986 & 0.869 & 0.780 & 0.873 & 1.148 & 1.168 & 1.057 \\
\hline 14 & 0.702 & 0.931 & 0.880 & 0.762 & 0.767 & 0.829 & 0.773 & 0.813 & 0.841 & 0.806 & 0.831 & 0.721 & 0.646 & 0.722 & 0.963 & 1.041 & 0.967 \\
\hline 15 & 0.659 & 0.849 & 0.794 & 0.689 & 0.700 & 0.783 & 0.750 & 0.787 & 0.812 & 0.780 & 0.775 & 0.655 & 0.583 & 0.647 & 0.862 & 0.945 & 0.884 \\
\hline 16 & 0.664 & 0.888 & 0.836 & 0.783 & 0.789 & 0.794 & 0.714 & 0.727 & 0.745 & 0.766 & 0.818 & 0.721 & 0.646 & 0.701 & 0.857 & 0.871 & 0.760 \\
\hline 17 & 0.683 & 0.814 & 0.655 & 0.612 & 0.604 & 0.620 & 0.569 & 0.551 & 0.546 & 0.640 & 0.648 & 0.572 & 0.527 & 0.545 & 0.631 & 0.701 & 0.545 \\
\hline 18 & 0.571 & 0.502 & 0.426 & 0.383 & 0.371 & 0.394 & 0.433 & 0.448 & 0.424 & 0.395 & 0.344 & 0.306 & 0.290 & 0.291 & 0.323 & 0.389 & 0.437 \\
\hline 19 & 0.592 & 0.549 & 0.497 & 0.463 & 0.446 & 0.452 & 0.474 & 0.487 & 0.465 & 0.442 & 0.407 & 0.380 & 0.365 & 0.362 & 0.377 & 0.415 & 0.446 \\
\hline
\end{tabular}

${ }^{a} \mathrm{r}=\mathrm{n}$ denotes the radial region number; $\mathrm{n}$ varies from 1 to 8 for the IFE and from 1 to 9 for the OFE. 
Fission rate density profiles, at BOC and EOC, for select axial regions (core horizontal midplane, upper edge of the active fuel region, lower edge of the active fuel region, and average over active fuel height) are shown in Fig. 9.1.3 as a function of the radial distance from the longitudinal centerline of the core. A similar plot, illustrating the fission rate density profiles for select radial regions (innermost, outermost, and central radial meshes) in the IFE and OFE is provided in Fig. 9.1.4 as a function of the axial distance from the core horizontal midplane.
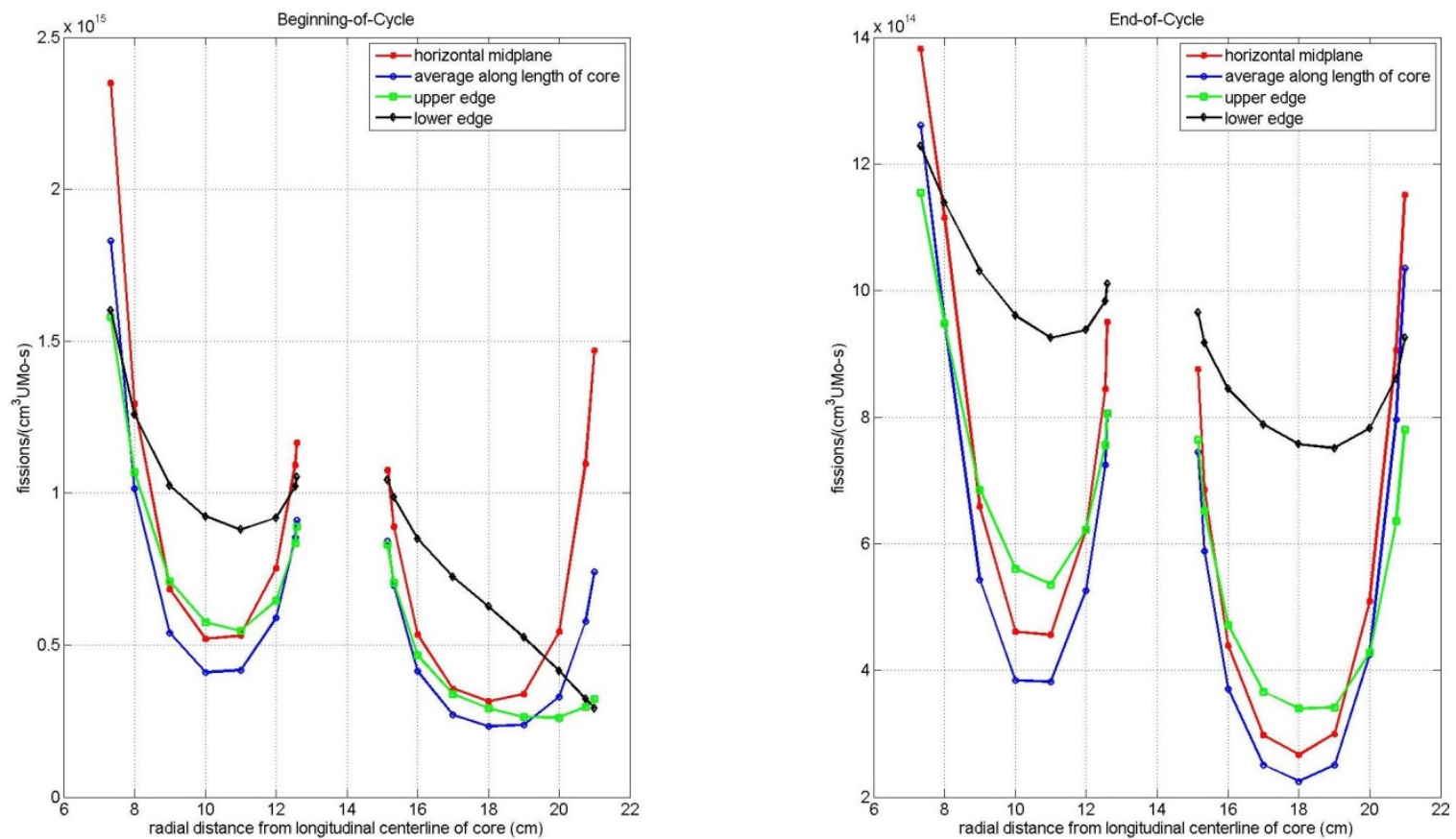

Fig. 9.1.3 Radial distribution of fission rate densities for LEU Alternate Design 4.
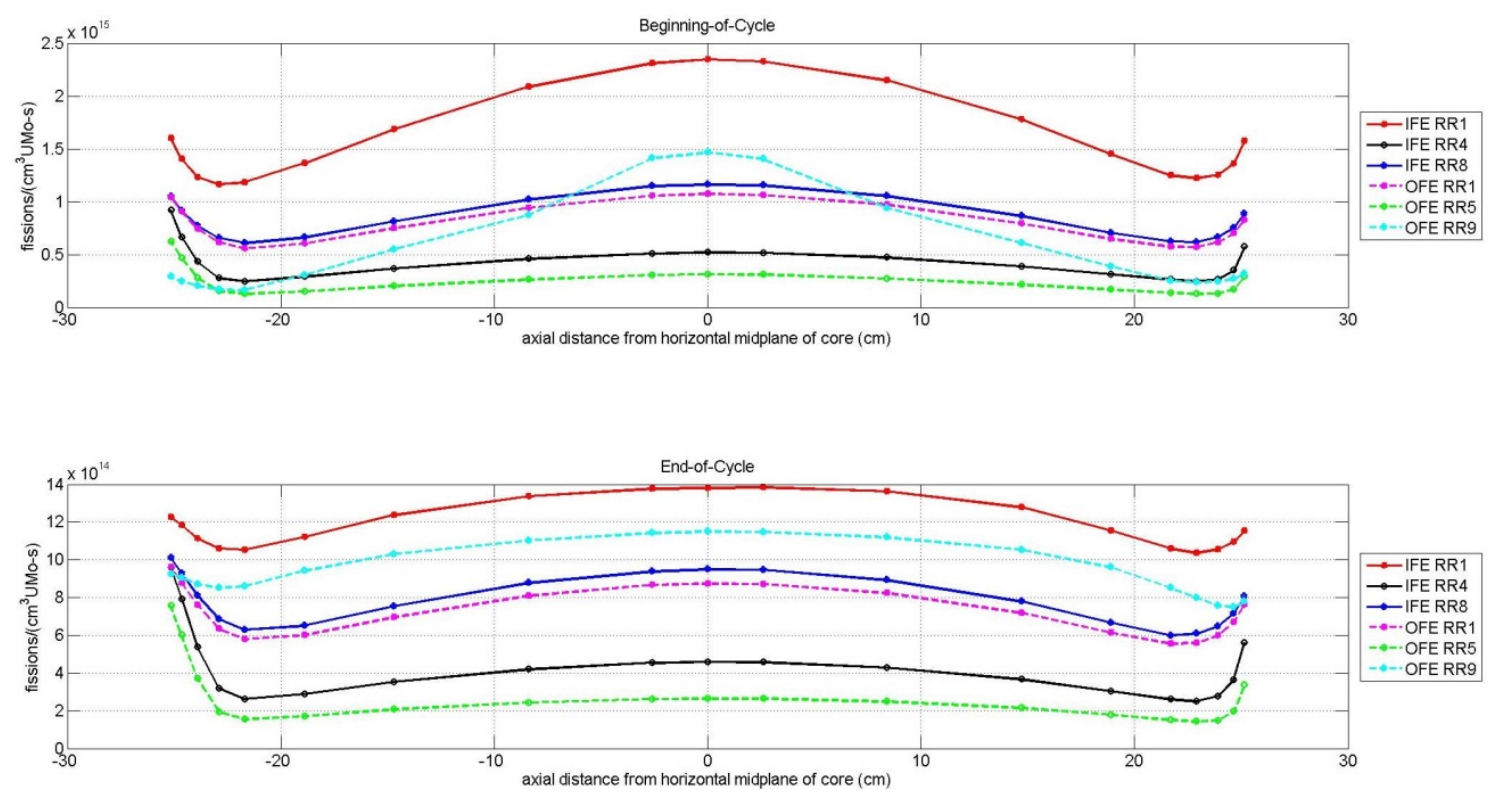

Fig. 9.1.4. Axial distribution of fission rate densities for LEU Alternate Design 4. 
Maximum local fission rate densities of $2.35 \times 10^{15}$ and $1.34 \times 10^{15}$ fissions/( $\left.\mathrm{cm}^{3} \mathrm{U}-10 \mathrm{Mo} \cdot \mathrm{s}\right)$ were calculated for the BOC and EOC cores, respectively; both of these maxima are located at or close to the inner radial edge of the IFE on the core horizontal midplane. Assuming conservatively that $100 \%$ of the total reactor power (100 MW) is deposited in the fuel meat, these maximum fission rate densities would correspond to power densities of $\sim 75.28$ and $43.38 \mathrm{~kW} /\left(\mathrm{cm}^{3} \mathrm{UMo}\right)$, respectively.

There are $5.40 \mathrm{~g}{ }^{10} \mathrm{~B}$ in the IFE fuel plates at BOC. Approximately $70 \%$ of this burnable absorber is consumed during the $27 \mathrm{~d}$ reactor cycle.

The minimum and maximum calculated local burnups, in terms of percent ${ }^{235} \mathrm{U}$ removed during the irradiation cycle, compared to the content at BOC, are 4.8 and $61.6 \%$, respectively. The maximum burnup occurs at the innermost edge of the IFE, at the core midline. Approximately $13.2 \%$ of the initial ${ }^{235} \mathrm{U}$ is consumed during the cycle, with $21.92 \mathrm{~kg}$ remaining in the core at EOC.

\subsection{STEADY-STATE TH WITH SAFETY CASE ASSUMPTIONS (USING HSSHTC)}

For the Zr-clad LEU fuel calculations, the HSSHTC uncertainties were used to simulate Zr cladding behavior by (1) using a very low oxide correlation uncertainty, 0.001 , to mimic the low oxide growth rate behavior of Zr cladding at HFIR fuel surface temperatures, and (2) adding an uncertainty factor of 0.5 to the hardwired HEU-fuel thermal deflection correlations to simulate the expected lower degree of $\mathrm{Zr}$ deflection. (When the deflection of Zr-clad LEU was compared to that of Al-clad HEU using the COMSOL code, it was found that the plate deflections due to the temperature distribution in the fuel was about a factor 0.5 lower with Zr cladding.)

Figure 9.2 shows results for the LEU reference fuel, compared to a design with Zr cladding. The Zr-clad fuel results stayed above the Safety Limit of 1.36, but were consistently closer to the Safety Limit over the cycle because of higher MCNP-calculated power densities. For the $\mathrm{Zr}$ clad case, a calculated burnout power of 140.4 MW occurs in the outer element at day 1 at radial node $18(\mathrm{r}=20.70 \mathrm{~cm})$ and axial node $24(\mathrm{z}=28.90 \mathrm{~cm})$, 


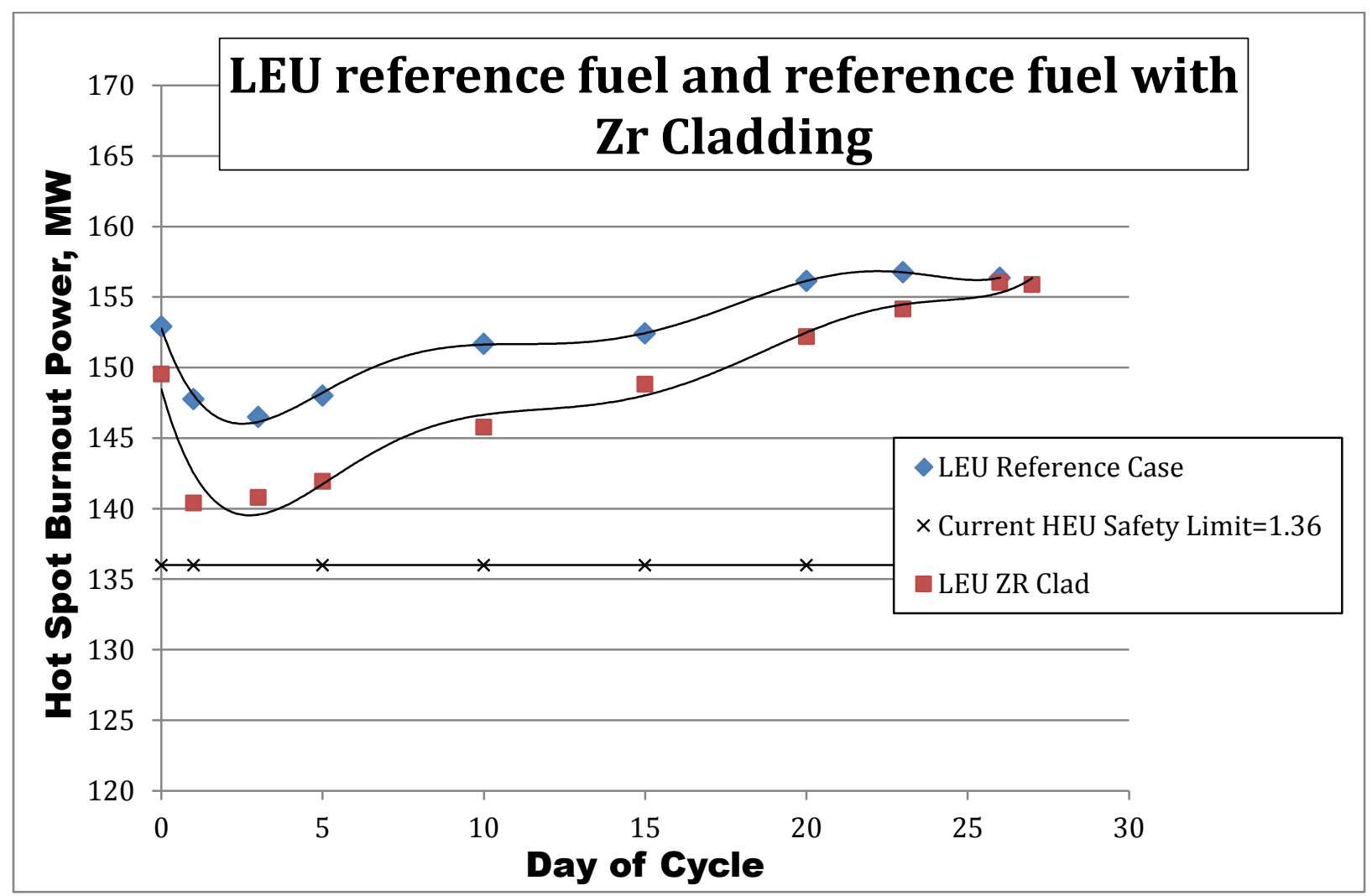

Fig.9.2. Hot spot burnout power versus day in the cycle for the reference fuel with $\mathrm{Zr}$ cladding. 
This page intentionally blank 


\section{EVAUATION OF ALTERNATE 5 (ADDITIONAL HF ABSORBER)}

\subsection{NEUTRONICS}

As previously described, Alternate Fuel Design 5 includes 174.20 and 190.26 grams of natural hafnium in the lower IFE and OFE fuel follower regions, respectively, designed to replace the need for axial fuel contouring used to reduce power spiking that occurs at the bottom of the active fuel region. In comparison to Alternate Design 2, Alternate Design 5 has about 49.77 more grams of Hf in the IFE fuel plate lower unfueled region and about 47.57 less in the OFE fuel plate lower unfueled region. The total amount of Hf remained nearly equal, but the amount in the IFE was increased to further reduce the power spiking at the bottom of the IFE active fuel region. As expected, the Alternate Design 5 peaking factors are nearly identical to those calculated for Alternate 2, but the increase of Hf in the IFE does further reduce the power spiking at the bottom of the IFE during the entire cycle.

Again, an initial core loading of $26.04 \mathrm{~kg}{ }^{235} \mathrm{U}$ fueled the 26-day cycle modeled, which utilized the control element withdrawal curve generated and reported in [2]. Approximately $22.81 \mathrm{~kg}^{235} \mathrm{U}$ remained at the end of the cycle, and thus, about $12.38 \%$ of the initial ${ }^{235} \mathrm{U}$ was consumed. The minimum and maximum calculated local burn-ups, in terms of percent ${ }^{235} \mathrm{U}$ removed during the cycle, were 4.33 and $58.29 \%$, respectively. The variation of the effective multiplication factor for the Alternate 5 design during the 26day fuel cycle is compared to the reference design curve in Fig. 10.1.1.

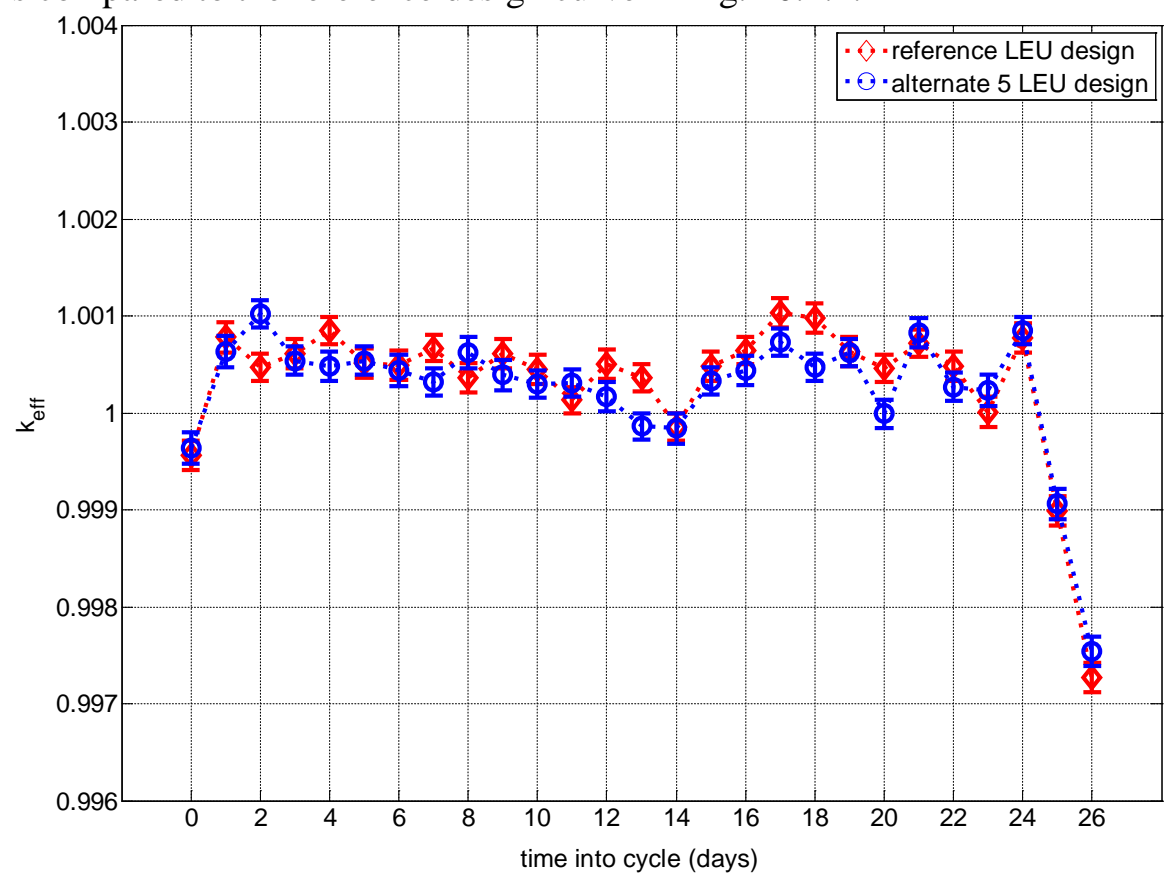

Fig. 10.1.1. Effective multiplication factor for reference design and Alternate Fuel Design 5.

The BOC and EOC relative fission density profiles are illustrated in the form of surface plots in Fig. 10.1.2 and they are tabulated in Tables 10.1.1 and 10.1.2. Maximum local BOC and EOC relative fission densities of 1.553 and 1.497, respectively, were calculated for this design, and again, both of these "hot spots" are located in the uppermost axial region (i.e., at the coolant inlet) of the IFE. Although placing Hf poison in the bottom unfueled regions of the fuel plates is not as effective as physically removing fuel at the bottom of the plates, it is again shown that the power spikes at the bottom of the fuel plates are much smaller than those generated without the use of neutron poisons in the fuel follower regions or axially contouring of the fuel (see Section 6.1). 

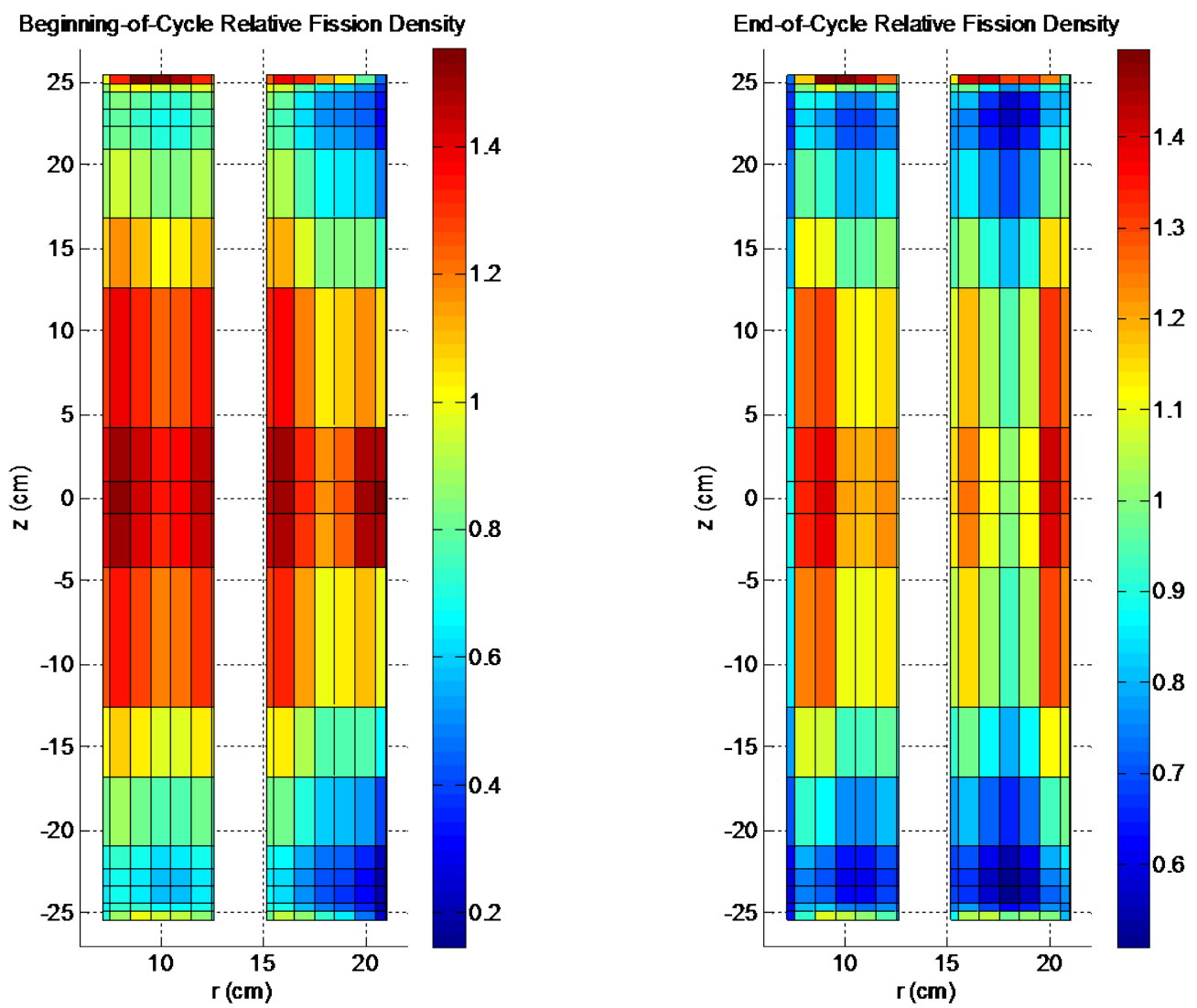

Fig. 10.1.2. Relative fission density for LEU Alternate Fuel Design 5 at BOC (left) and EOC (right). 
ORNL/TM-2014/154

Table 10.1.1. Relative fission densities for LEU Alternate Fuel Design 5 at BOC

\begin{tabular}{|c|c|c|c|c|c|c|c|c|c|c|c|c|c|c|c|c|c|}
\hline \multirow{2}{*}{$\begin{array}{c}\text { Axial } \\
\text { region \# }\end{array}$} & \multicolumn{8}{|c|}{ IFE } & \multicolumn{9}{|c|}{ OFE } \\
\hline & $\mathrm{r}=\mathbf{1}^{a}$ & $r=2$ & $r=3$ & $r=4$ & $r=5$ & $r=6$ & $r=7$ & $r=8$ & $r=1$ & $r=2$ & $r=3$ & $r=4$ & $r=5$ & $r=6$ & $r=7$ & $r=8$ & $r=9$ \\
\hline 1 & 0.991 & 1.312 & 1.553 & 1.549 & 1.480 & 1.331 & 1.131 & 1.136 & 1.189 & 1.224 & 1.384 & 1.322 & 1.149 & 1.039 & 0.784 & 0.468 & 0.356 \\
\hline 2 & 0.855 & 0.990 & 1.020 & 0.949 & 0.934 & 0.968 & 0.936 & 0.958 & 1.005 & 0.982 & 0.950 & 0.795 & 0.675 & 0.626 & 0.532 & 0.370 & 0.294 \\
\hline 3 & 0.783 & 0.845 & 0.798 & 0.725 & 0.727 & 0.821 & 0.834 & 0.848 & 0.876 & 0.853 & 0.791 & 0.634 & 0.527 & 0.501 & 0.442 & 0.326 & 0.268 \\
\hline 4 & 0.755 & 0.803 & 0.737 & 0.674 & 0.688 & 0.769 & 0.774 & 0.788 & 0.808 & 0.792 & 0.751 & 0.608 & 0.507 & 0.485 & 0.433 & 0.316 & 0.259 \\
\hline 5 & 0.778 & 0.827 & 0.767 & 0.705 & 0.716 & 0.787 & 0.766 & 0.779 & 0.800 & 0.794 & 0.775 & 0.643 & 0.542 & 0.520 & 0.465 & 0.338 & 0.276 \\
\hline 6 & 0.887 & 0.947 & 0.897 & 0.837 & 0.848 & 0.908 & 0.866 & 0.875 & 0.896 & 0.899 & 0.905 & 0.773 & 0.658 & 0.647 & 0.615 & 0.489 & 0.409 \\
\hline 7 & 1.083 & 1.161 & 1.098 & 1.025 & 1.042 & 1.106 & 1.048 & 1.062 & 1.089 & 1.096 & 1.115 & 0.964 & 0.831 & 0.835 & 0.848 & 0.726 & 0.624 \\
\hline 8 & 1.294 & 1.389 & 1.319 & 1.236 & 1.257 & 1.338 & 1.263 & 1.278 & 1.319 & 1.327 & 1.358 & 1.186 & 1.038 & 1.072 & 1.161 & 1.069 & 0.941 \\
\hline 9 & 1.398 & 1.502 & 1.428 & 1.338 & 1.367 & 1.462 & 1.384 & 1.402 & 1.443 & 1.451 & 1.490 & 1.312 & 1.164 & 1.245 & 1.472 & 1.485 & 1.346 \\
\hline 10 & 1.406 & 1.510 & 1.434 & 1.347 & 1.371 & 1.464 & 1.391 & 1.405 & 1.444 & 1.458 & 1.502 & 1.322 & 1.177 & 1.265 & 1.505 & 1.534 & 1.392 \\
\hline 11 & 1.385 & 1.489 & 1.416 & 1.328 & 1.356 & 1.443 & 1.364 & 1.383 & 1.426 & 1.434 & 1.476 & 1.296 & 1.154 & 1.236 & 1.466 & 1.486 & 1.347 \\
\hline 12 & 1.254 & 1.345 & 1.278 & 1.196 & 1.215 & 1.294 & 1.224 & 1.239 & 1.274 & 1.283 & 1.316 & 1.147 & 0.998 & 1.027 & 1.099 & 0.996 & 0.869 \\
\hline 13 & 1.019 & 1.091 & 1.033 & 0.965 & 0.978 & 1.037 & 0.983 & 0.993 & 1.016 & 1.024 & 1.043 & 0.899 & 0.773 & 0.771 & 0.774 & 0.652 & 0.552 \\
\hline 14 & 0.820 & 0.874 & 0.822 & 0.763 & 0.771 & 0.822 & 0.780 & 0.787 & 0.813 & 0.815 & 0.821 & 0.698 & 0.592 & 0.572 & 0.525 & 0.397 & 0.325 \\
\hline 15 & 0.692 & 0.730 & 0.678 & 0.622 & 0.631 & 0.685 & 0.658 & 0.669 & 0.692 & 0.679 & 0.670 & 0.562 & 0.470 & 0.436 & 0.356 & 0.223 & 0.171 \\
\hline 16 & 0.648 & 0.687 & 0.630 & 0.576 & 0.582 & 0.636 & 0.625 & 0.638 & 0.658 & 0.650 & 0.627 & 0.515 & 0.428 & 0.395 & 0.319 & 0.198 & 0.149 \\
\hline 17 & 0.632 & 0.674 & 0.632 & 0.574 & 0.576 & 0.633 & 0.628 & 0.642 & 0.667 & 0.653 & 0.620 & 0.504 & 0.419 & 0.384 & 0.309 & 0.193 & 0.146 \\
\hline 18 & 0.653 & 0.728 & 0.723 & 0.670 & 0.652 & 0.688 & 0.664 & 0.678 & 0.711 & 0.700 & 0.682 & 0.576 & 0.485 & 0.441 & 0.345 & 0.207 & 0.158 \\
\hline 19 & 0.710 & 0.882 & 0.984 & 0.953 & 0.917 & 0.854 & 0.739 & 0.741 & 0.784 & 0.810 & 0.916 & 0.856 & 0.735 & 0.645 & 0.468 & 0.252 & 0.180 \\
\hline
\end{tabular}

${ }^{a} \mathrm{r}=\mathrm{n}$ denotes the radial region number; $\mathrm{n}$ varies from 1 to 8 for the IFE and from 1 to 9 for the OFE. 
ORNL/TM-2014/154

Table 10.1.2. Relative fission densities for LEU Alternate Fuel Design 5 at EOC

\begin{tabular}{|c|c|c|c|c|c|c|c|c|c|c|c|c|c|c|c|c|c|}
\hline \multirow{2}{*}{$\begin{array}{c}\text { Axial } \\
\text { region \# }\end{array}$} & \multicolumn{8}{|c|}{ IFE } & \multicolumn{9}{|c|}{ OFE } \\
\hline & $\mathrm{r}=1^{a}$ & $r=2$ & $r=3$ & $r=4$ & $r=5$ & $r=6$ & $r=7$ & $r=8$ & $r=1$ & $r=2$ & $r=3$ & $r=4$ & $r=5$ & $r=6$ & $r=7$ & $r=8$ & $r=9$ \\
\hline 1 & 0.734 & 1.161 & 1.492 & 1.497 & 1.435 & 1.270 & 1.015 & 1.022 & 1.084 & 1.133 & 1.392 & 1.413 & 1.311 & 1.324 & 1.248 & 0.946 & 0.792 \\
\hline 2 & 0.692 & 0.995 & 1.087 & 0.988 & 0.969 & 0.986 & 0.890 & 0.912 & 0.954 & 0.942 & 0.976 & 0.854 & 0.766 & 0.806 & 0.903 & 0.838 & 0.744 \\
\hline 3 & 0.665 & 0.882 & 0.862 & 0.752 & 0.747 & 0.826 & 0.786 & 0.816 & 0.848 & 0.825 & 0.803 & 0.663 & 0.584 & 0.636 & 0.790 & 0.813 & 0.749 \\
\hline 4 & 0.653 & 0.841 & 0.786 & 0.678 & 0.685 & 0.764 & 0.733 & 0.760 & 0.792 & 0.762 & 0.752 & 0.627 & 0.557 & 0.614 & 0.791 & 0.838 & 0.780 \\
\hline 5 & 0.673 & 0.862 & 0.804 & 0.697 & 0.705 & 0.768 & 0.731 & 0.764 & 0.782 & 0.757 & 0.765 & 0.659 & 0.590 & 0.651 & 0.843 & 0.897 & 0.829 \\
\hline 6 & 0.726 & 0.959 & 0.922 & 0.809 & 0.807 & 0.856 & 0.791 & 0.827 & 0.853 & 0.823 & 0.863 & 0.761 & 0.685 & 0.760 & 0.976 & 1.009 & 0.926 \\
\hline 7 & 0.806 & 1.120 & 1.108 & 0.966 & 0.962 & 1.005 & 0.914 & 0.965 & 0.987 & 0.950 & 1.018 & 0.906 & 0.816 & 0.905 & 1.150 & 1.132 & 1.021 \\
\hline 8 & 0.864 & 1.272 & 1.299 & 1.128 & 1.117 & 1.156 & 1.039 & 1.101 & 1.136 & 1.085 & 1.173 & 1.048 & 0.944 & 1.050 & 1.324 & 1.248 & 1.105 \\
\hline 9 & 0.882 & 1.335 & 1.388 & 1.206 & 1.189 & 1.225 & 1.093 & 1.166 & 1.197 & 1.144 & 1.247 & 1.114 & 1.005 & 1.119 & 1.405 & 1.295 & 1.139 \\
\hline 10 & 0.882 & 1.336 & 1.399 & 1.212 & 1.195 & 1.230 & 1.103 & 1.175 & 1.205 & 1.149 & 1.251 & 1.116 & 1.007 & 1.122 & 1.411 & 1.300 & 1.144 \\
\hline 11 & 0.879 & 1.329 & 1.380 & 1.198 & 1.185 & 1.222 & 1.089 & 1.160 & 1.195 & 1.138 & 1.237 & 1.105 & 0.996 & 1.113 & 1.399 & 1.291 & 1.137 \\
\hline 12 & 0.849 & 1.247 & 1.276 & 1.107 & 1.096 & 1.135 & 1.020 & 1.081 & 1.112 & 1.064 & 1.153 & 1.029 & 0.927 & 1.033 & 1.304 & 1.229 & 1.090 \\
\hline 13 & 0.777 & 1.080 & 1.069 & 0.932 & 0.927 & 0.967 & 0.881 & 0.927 & 0.954 & 0.919 & 0.980 & 0.873 & 0.789 & 0.876 & 1.116 & 1.102 & 0.993 \\
\hline 14 & 0.694 & 0.912 & 0.877 & 0.764 & 0.762 & 0.806 & 0.744 & 0.777 & 0.802 & 0.776 & 0.816 & 0.723 & 0.653 & 0.726 & 0.938 & 0.974 & 0.896 \\
\hline 15 & 0.619 & 0.788 & 0.736 & 0.642 & 0.645 & 0.698 & 0.656 & 0.689 & 0.701 & 0.680 & 0.700 & 0.610 & 0.549 & 0.611 & 0.799 & 0.856 & 0.794 \\
\hline 16 & 0.599 & 0.750 & 0.695 & 0.604 & 0.604 & 0.671 & 0.643 & 0.666 & 0.686 & 0.666 & 0.671 & 0.568 & 0.508 & 0.566 & 0.740 & 0.800 & 0.744 \\
\hline 17 & 0.595 & 0.753 & 0.711 & 0.619 & 0.618 & 0.680 & 0.655 & 0.674 & 0.709 & 0.689 & 0.677 & 0.573 & 0.511 & 0.564 & 0.715 & 0.756 & 0.703 \\
\hline 18 & 0.609 & 0.811 & 0.828 & 0.741 & 0.730 & 0.762 & 0.704 & 0.728 & 0.767 & 0.749 & 0.773 & 0.685 & 0.618 & 0.661 & 0.769 & 0.747 & 0.677 \\
\hline 19 & 0.636 & 0.919 & 1.088 & 1.053 & 1.014 & 0.942 & 0.786 & 0.802 & 0.854 & 0.872 & 1.046 & 1.052 & 0.980 & 1.011 & 0.998 & 0.806 & 0.685 \\
\hline
\end{tabular}

${ }^{a} \mathrm{r}=\mathrm{n}$ denotes the radial region number; $\mathrm{n}$ varies from 1 to 8 for the IFE and from 1 to 9 for the OFE. 
Fission rate density profiles, at BOC and EOC, for select axial regions (core horizontal midplane, upper edge of the active fuel region, lower edge of the active fuel region, and average over active fuel height) as a function of radial distance from the longitudinal centerline of the core are shown in Fig. 10.1.3. A similar plot, illustrating the fission rate density profiles for select radial regions (innermost, outermost, and central radial meshes) as a function of axial distance from the core horizontal midplane of the core, is provided in Fig. 10.1.4. Maximum local fission rate densities of $2.24 \mathrm{E}+15$ and $1.41 \mathrm{E}+15$ fissions/( $\mathrm{cm}^{3}$ $\mathrm{U}-10 \mathrm{Mo} \cdot \mathrm{s}$ ) were calculated for the BOC and EOC cores, respectively, and both of these maximums are located at the inner radial edge of the IFE on the core horizontal midplane. Conservatively assuming $100 \%$ of the total reactor power is deposited in the fuel meat, these fission rate densities correspond to power densities of about 72.05 and $45.20 \mathrm{~kW} /\left(\mathrm{cm}^{3} \mathrm{U}-10 \mathrm{Mo}\right)$, respectively.
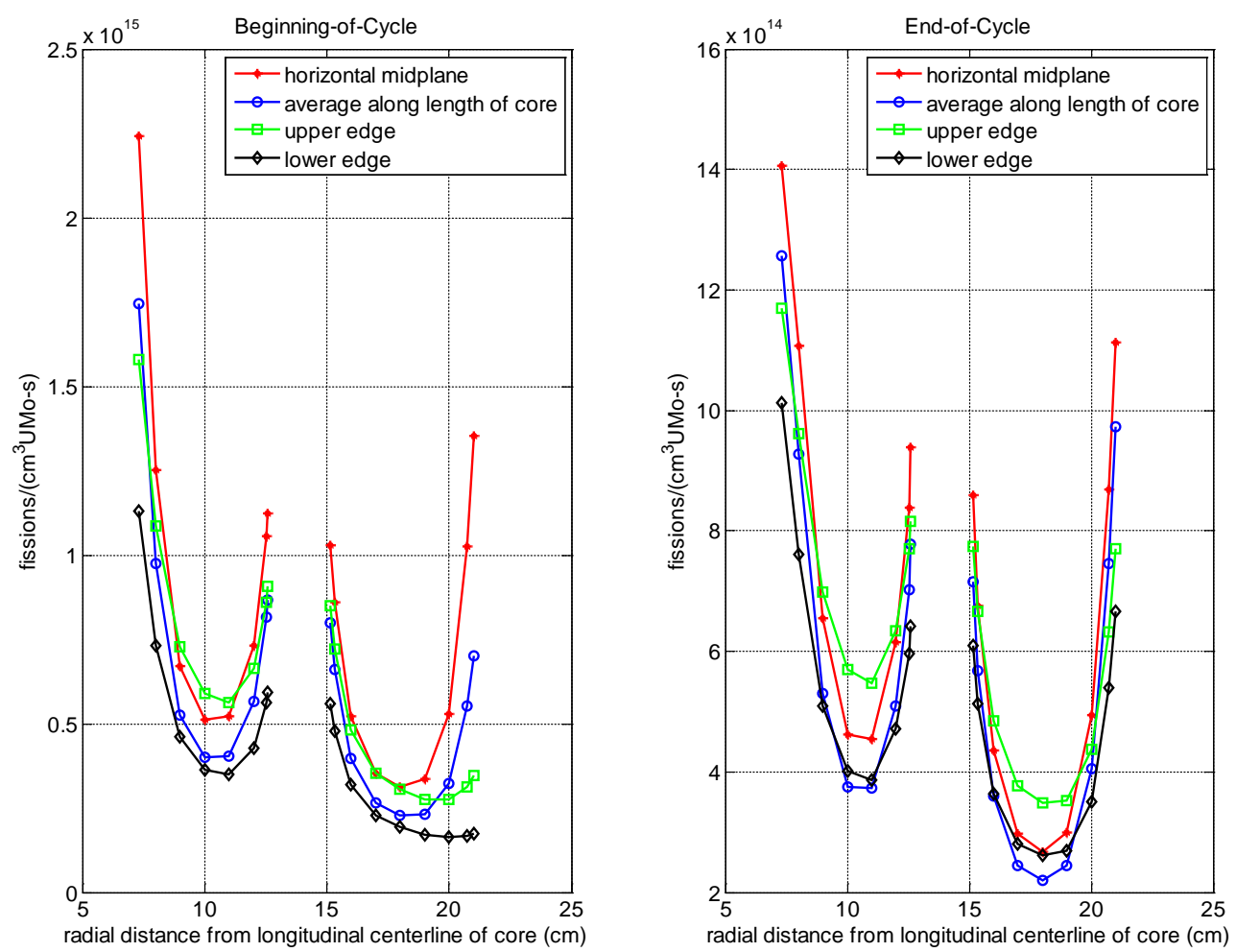

Fig. 10.1.3. Radial distribution of fission rate densities for LEU Alternate Fuel Design 5. 

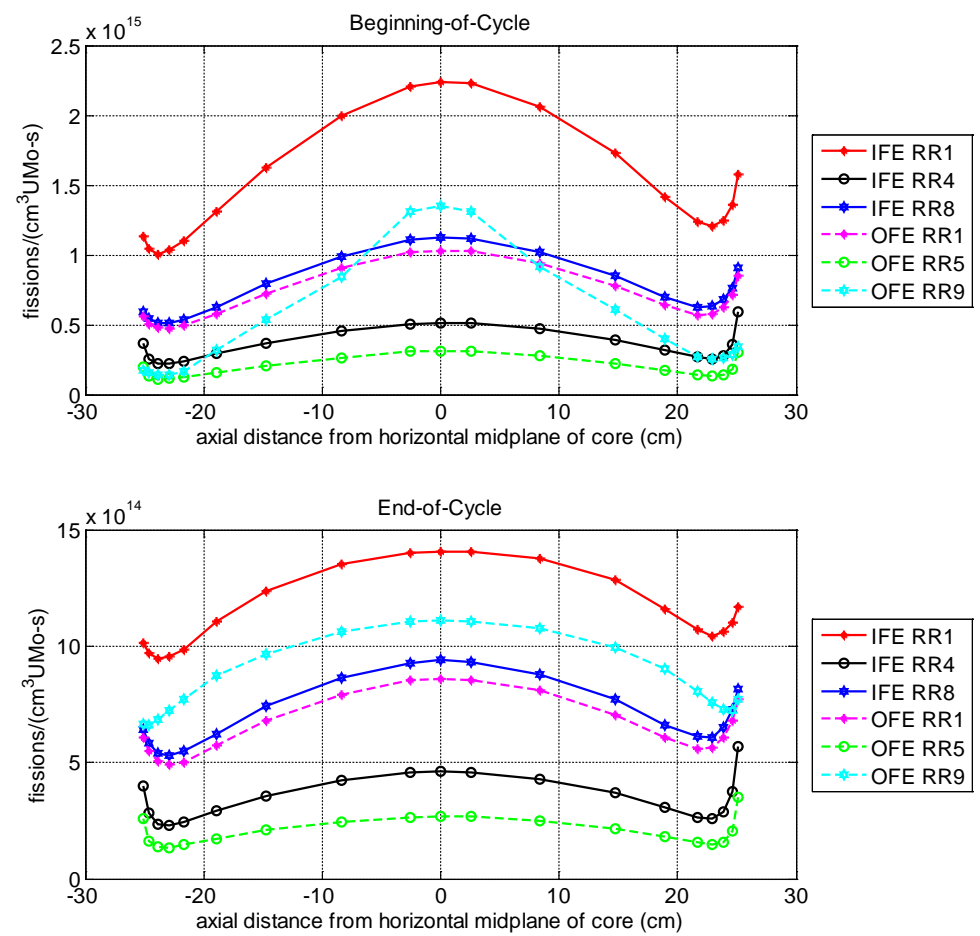

Fig. 10.1.4. Axial distribution of fission rate densities for LEU Alternate Fuel Design 5.

\subsection{STEADY-STATE TH WITH SAFETY CASE ASSUMPTIONS (USING HSSHTC)}

Figure 10.2 shows results for the LEU reference fuel compared to Alternative 5, which involves no axial contouring plus more $\mathrm{Hf}$ added in the lower unfueled region of the plates than was considered in Alternative 2. With ALT 5, all portions of the cycle are above the existing safety limit and there is better thermal performance over the middle portion of the cycle than with Alternative 2 and slightly better performance at the EOC conditions. For the ALT5 case, a calculated burnout power of $143.8 \mathrm{MW}$ occurs in the outer element at day 26 at radial node $16(\mathrm{r}=20.00 \mathrm{~cm})$ and axial node $40(\mathrm{z}=50.55 \mathrm{~cm})$. 


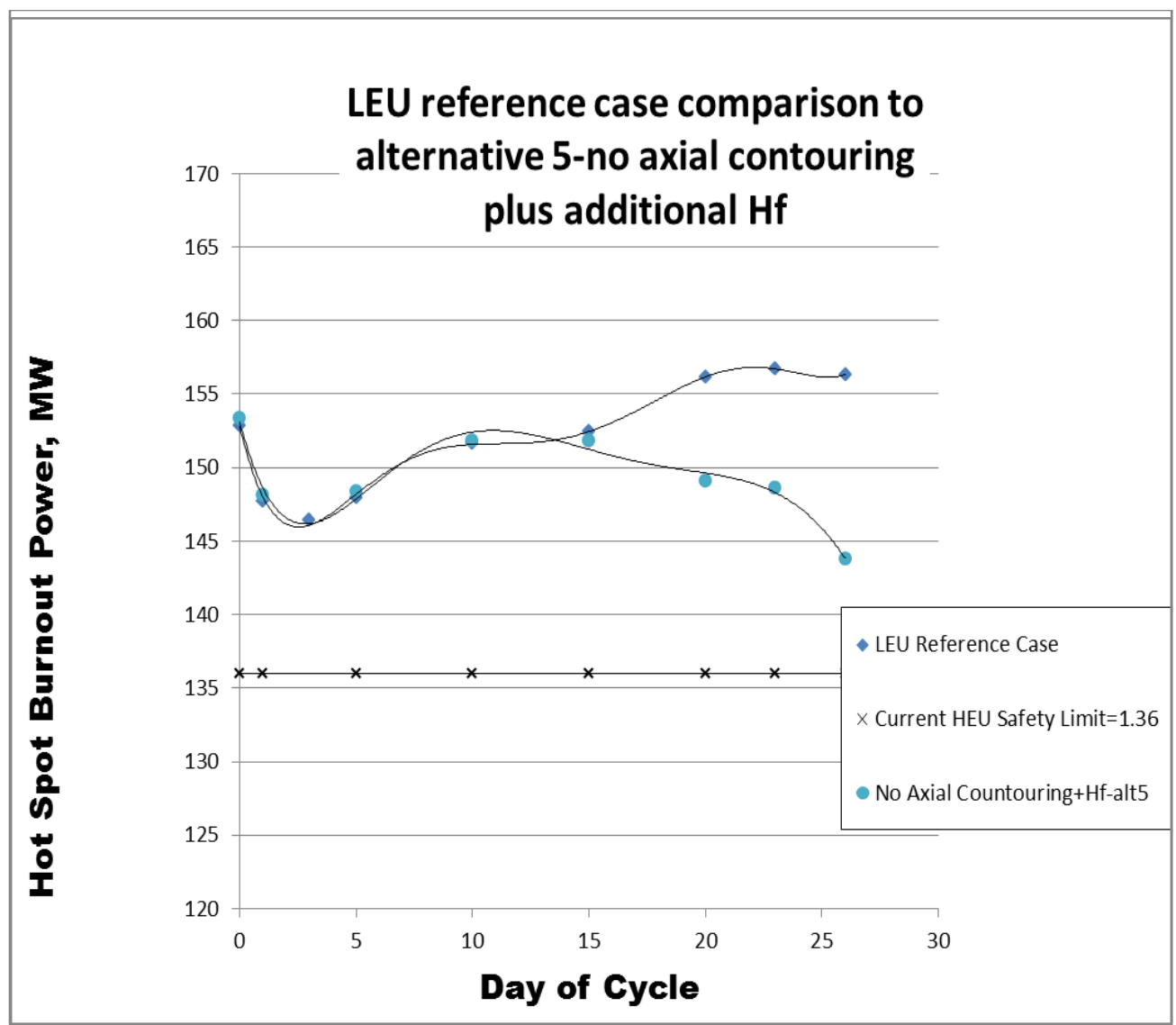

Fig. 10.2. Hot spot burnout power versus day in the cycle for Alternative 5the reference fuel with no axial contouring plus additional $\mathrm{Hf}$. 
This page intentionally blank 
ORNL/TM-2014/154

\section{EVALUATION OF ALTERNATE 6 (COMBINATION OF ALTERNATES 3 AND 5)}

\subsection{NEUTRONICS}

The Alternate Design 6 is based on a combination of the Alternate Designs 3 and 5 . Therefore, the boron burnable absorber is removed from the IFE fuel plates and relocated to the inner and outer side plates of the IFE; no axial fuel contouring is applied, instead Hf is used at the bottom unfueled regions of the IFE and OFE fuel plates to reduce the power peaking. Three values are used for the B content in the IFE side plates: 3.4, 3.6, and $4.6 \mathrm{~g}{ }^{10} \mathrm{~B}$, respectively; in each of these three cases, $25 \mathrm{wt} \%$ of the boron is included in the inner side plate and $75 \mathrm{wt} \%$ in the outer side plate of the IFE. The content of $\mathrm{Hf}$ and its distribution between the IFE and OFE is the same as for Alternate 5 - the total content of Hf is $364.46 \mathrm{~g}$, with $174.20 \mathrm{~g}(\sim 48 \mathrm{wt} \%)$ in the IFE and 190.26g ( 52 wt\%) in the OFE bottom unfueled regions.

A comparison of the $\mathrm{k}_{\mathrm{eff}}$ values as a function of irradiation time, for the reference and Alternate Design 6 , is presented in Fig. 11.1.1 for three values of the ${ }^{10} \mathrm{~B}$ content in the IFE side plates. As mentioned in Section 2, the reference model used as a basis for the studies of Alternate Design 6 was slightly changed with respect to the original reference model[2] as part of the general effort of HFIR model revision and improvement. The revised reference model is labeled "ref 2013" in Fig. 11.1.1. In this model, the spatial fuel mesh was slightly changed to optimize depletion simulations and to enable a more consistent comparison with the HFIR HEU model. A comparison of the thermal-hydraulic safety limit results obtained from the original and improved neutronics reference models is made in Section 11.2.

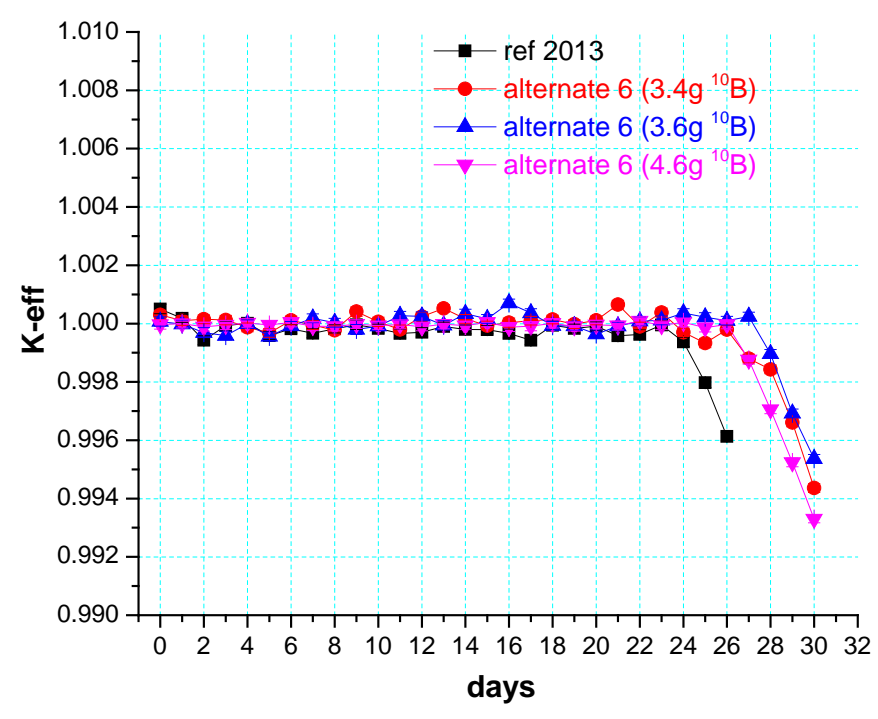

Fig. 11.1.1. Effective multiplication factor for LEU reference and Alternate Design 6.

As applicable to all alternate designs with no axial fuel contouring, addition of extra fuel at the bottom leads to a slight increase of the initial ${ }^{235} \mathrm{U}$ core load from $25.27 \mathrm{~kg}$ as present in the reference design to $26.04 \mathrm{~kg}$. It was noted for Alternate 1 that this addition would lead, as expected, to a slight increase in cycle length (see Section 6.1). A cycle length increase was also observed when relocating the boron from the IFE fuel plates to the IFE side plates (see Section 8.1). The cycle length increase for Alternate 6, with respect to the corresponding reference, is 2-3d. For the metrics discussed further in this Section 11.1, a value of 28d was selected as EOC for presentation of EOC metrics data for Alternate Design 6. 
The BOC and EOC (28d) relative fission density data are illustrated, as surface plots, in Figs. 11.1.2 to 11.1.4 for the Alternate Design 6 cases (3.4 g, $3.6 \mathrm{~g}$ and $4.6 \mathrm{~g}{ }^{10} \mathrm{~B}$ ) and listed in Tables 11.1.1 to 11.1.6. The maximum value for the relative fission density at BOC and EOC is: 1.621 and 1.580, respectively for Alternate 6 with $3.4 \mathrm{~g}{ }^{10} \mathrm{~B}$; 1.605 and 1.583 for Alternate 6 with $3.6 \mathrm{~g}{ }^{10} \mathrm{~B}$; and 1.642 and 1.576 for Alternate 6 with $4.6 \mathrm{~g}{ }^{10} \mathrm{~B}$. The "hot spot" location for each of the three cases is the same at the EOC - at the uppermost axial region (i.e., at the coolant inlet) of the IFE. However, at BOC the hot spot is located close to the IFE innermost radial mesh at the core horizontal midline for the cases with $3.4 \mathrm{~g}{ }^{10} \mathrm{~B}$ and $3.6 \mathrm{~g}$ ${ }^{10} \mathrm{~B}$, whereas for the other case, with $4.6 \mathrm{~g}{ }^{10} \mathrm{~B}$, it shifts close to the OFE outermost radial mesh at the core horizontal midline.
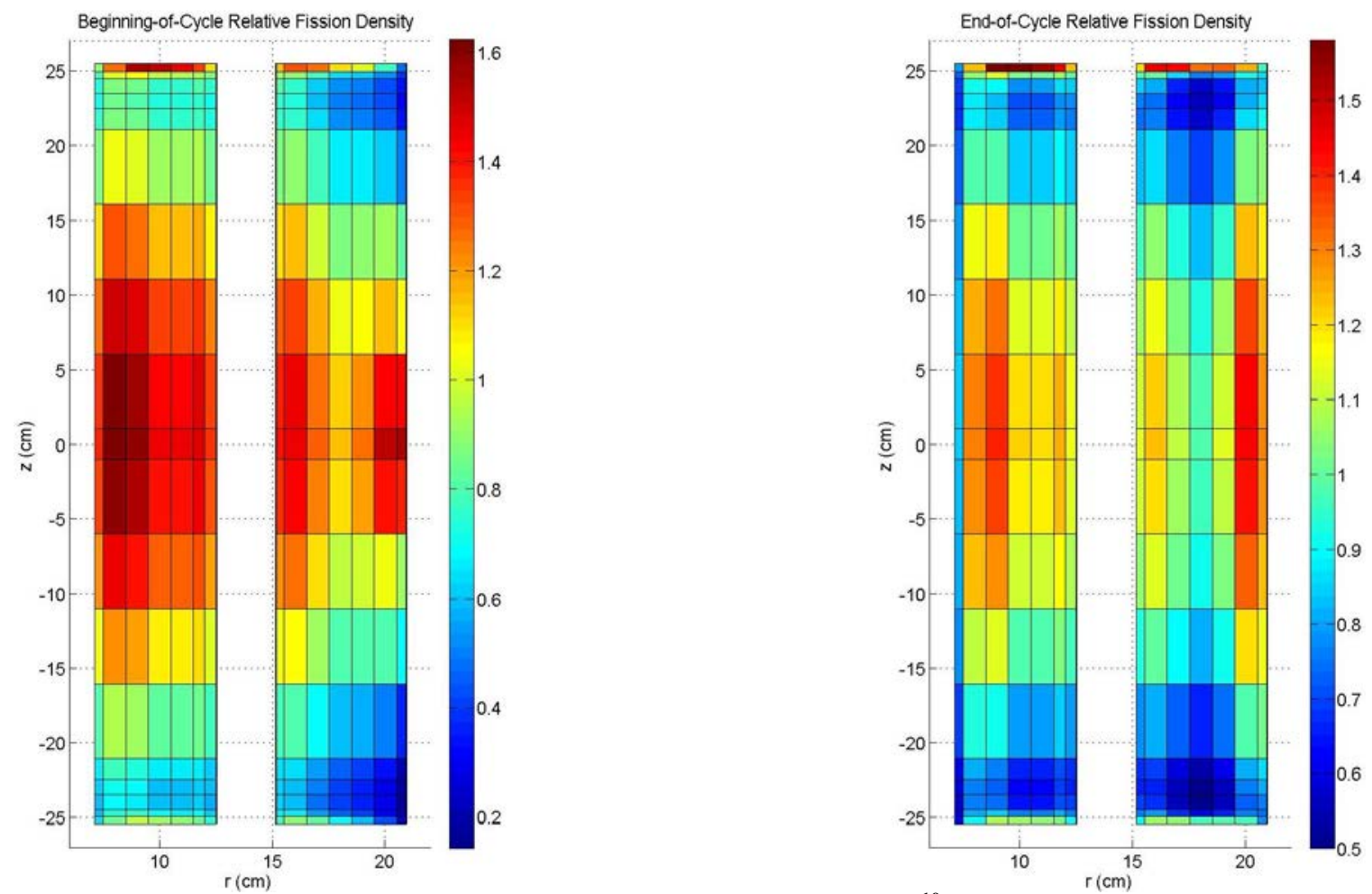

Fig. 11.1.2 Relative fission density for LEU Alternate $6\left(3.4 \mathrm{~g}{ }^{10} \mathrm{~B}\right)$ at BOC (left) and EOC (right). 

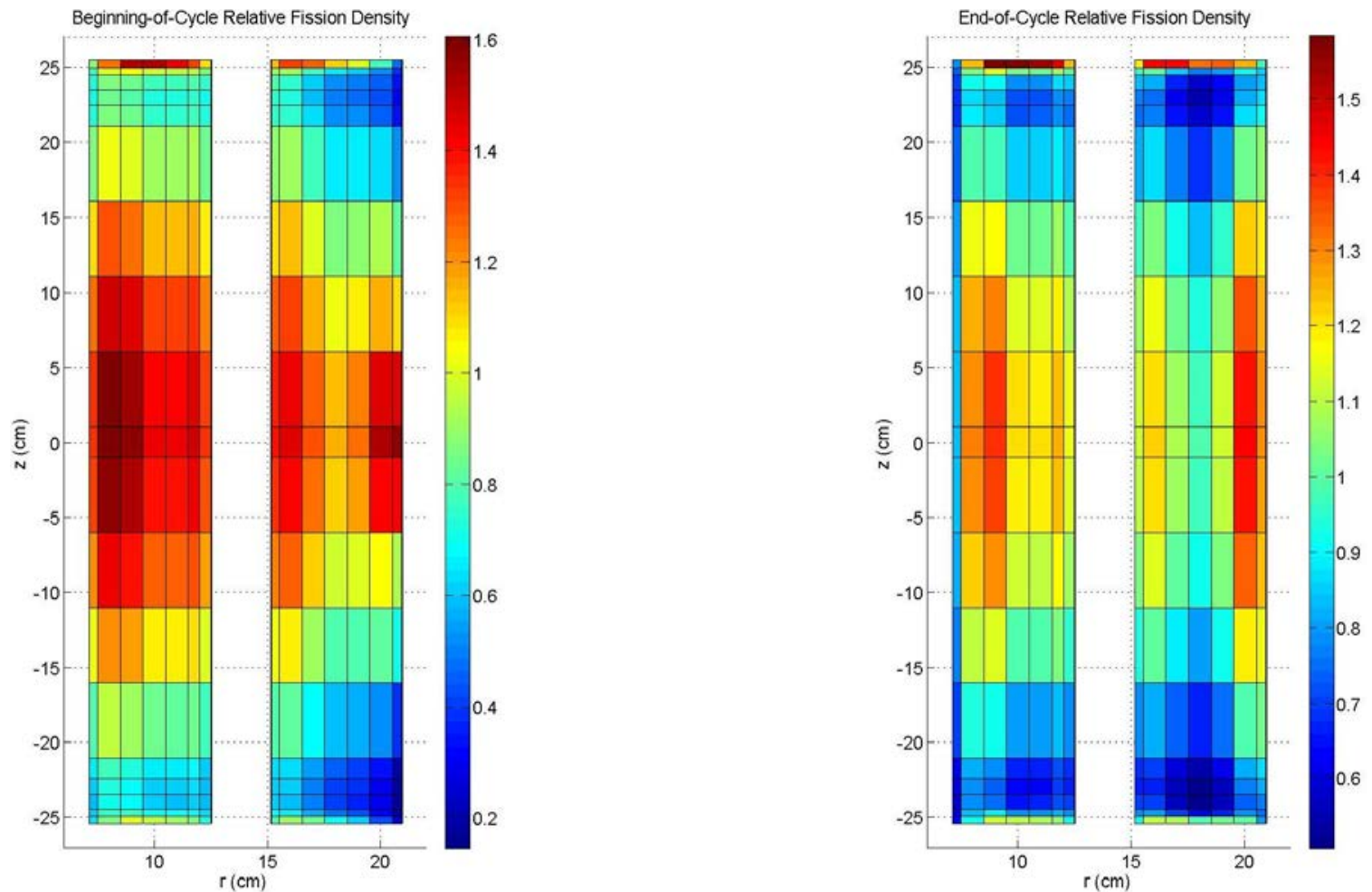

Fig. 11.1.3. Relative fission density for LEU Alternate $6\left(3.6 \mathrm{~g}{ }^{10} \mathrm{~B}\right)$ at BOC (left) and EOC (right).
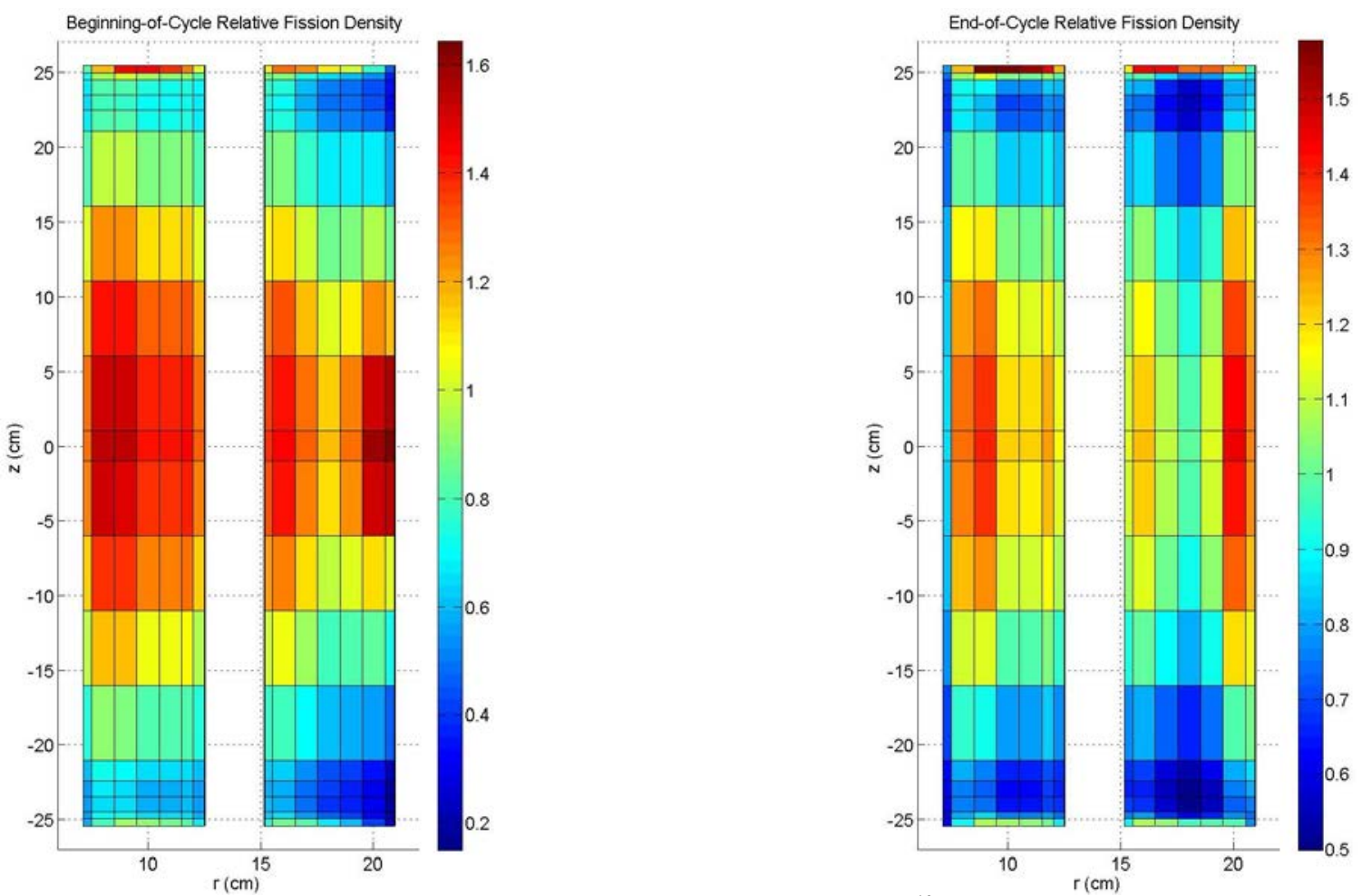

Fig. 11.1.4. Relative fission density for LEU Alternate $6\left(4.6 \mathrm{~g}{ }^{10} \mathrm{~B}\right)$ at BOC (left) and EOC (right). 
ORNL/TM-2014/154

Table 11.1.1 Relative fission densities for LEU Alternate Design $6\left(3.4 \mathrm{~g}{ }^{10} \mathrm{~B}\right)$ at BOC

\begin{tabular}{|c|c|c|c|c|c|c|c|c|c|c|c|c|c|c|c|c|c|}
\hline \multirow{2}{*}{$\begin{array}{c}\text { Axial } \\
\text { region \# }\end{array}$} & \multicolumn{8}{|c|}{ IFE } & \multicolumn{9}{|c|}{ OFE } \\
\hline & $\mathrm{r}=1^{a}$ & $=2$ & $r=3$ & $r=4$ & $r=5$ & $=6$ & $r=7$ & $r=8$ & $r=1$ & $r=2$ & 3 & $r=4$ & $r=5$ & $=6$ & $=7$ & $=8$ & $=9$ \\
\hline 1 & 0 & & & & & & & & & 138 & & - & & 004 & .767 & 471 & .373 \\
\hline 2 & 87 & 98 & & 72 & 47 & 48 & 0.867 & & 04 & 905 & 901 & 769 & 550 & 511 & 523 & 374 & 313 \\
\hline 3 & 0.729 & 0.870 & 0.852 & 0.765 & 59 & 0.795 & 0.752 & 16 & 0.794 & 794 & 0.756 & 613 & 513 & 492 & 39 & 329 & 281 \\
\hline 4 & & & & & & & & & & & & & & & & 321 & 273 \\
\hline 5 & 0.745 & 0.873 & 0.840 & 0.755 & 0.754 & 0.778 & 0.724 & 0.680 & 0.747 & 0.756 & 0.752 & 631 & 0.530 & 510 & 156 & 340 & 287 \\
\hline 6 & 0.881 & 1. & 1.010 & 0. & & & & & & 0.881 & & & 0.664 & & 24 & 03 & .435 \\
\hline 7 & 1.107 & 1.303 & 1.269 & 1.154 & 50 & 1.174 & 1.074 & 0.996 & 1.069 & 1.101 & 1.143 & 0.997 & 0.865 & 0.883 & 923 & .820 & .732 \\
\hline 8 & 1.272 & & 1.464 & 1.333 & & 1.362 & & & & 1.280 & 31 & 1.167 & 1.023 & 1.064 & 5 & 63 & .960 \\
\hline . & 1.360 & 1.607 & 1.566 & 1.426 & 1.427 & 1.464 & 1.338 & 1.242 & 1.336 & 1.379 & 1.441 & 1.273 & 1.130 & 1.213 & .431 & .425 & 1.315 \\
\hline 10 & 1.374 & 1.621 & 1.586 & 1.444 & & 1.482 & 1.352 & & & 1.397 & 1.459 & 1.292 & 1.154 & 1.253 & 1.521 & 1.550 & \\
\hline & & & & 1.407 & & & & & & 1.356 & 1.415 & 1.249 & 1.109 & 1.186 & .396 & .388 & \\
\hline 12 & 1.224 & 1.445 & 1.407 & 1.278 & & 1.306 & & & & 1.225 & 72 & & 70 & & 1 & 15 & .812 \\
\hline 13 & & & & & & & & & & & & & & & & & \\
\hline 14 & 0.806 & 0.947 & 0.916 & 0.827 & 0.821 & 0.839 & 0.767 & 0.712 & 0.765 & 0.785 & 0.806 & 0.689 & 0.583 & 0.559 & 0.499 & .369 & 0.309 \\
\hline 15 & 0.657 & 0.767 & 0.734 & 0.658 & 0.652 & 0.672 & 0.621 & 0.579 & 0.627 & 0.640 & 0.643 & 0.539 & 0.444 & & 0.327 & 204 & 0.161 \\
\hline 16 & 0.612 & 0.713 & 0.677 & 0.604 & 0.603 & 0.625 & 0.584 & 0.550 & 0.605 & 0.611 & 0.599 & 0.491 & 0.406 & 0.373 & 0.295 & .185 & 0.146 \\
\hline 17 & & 0.694 & 0.671 & 0.598 & & 0.619 & & & & 0.612 & & & & & & 181 & 0.142 \\
\hline 18 & 0.598 & 0.735 & 0.746 & 0.676 & 0.662 & 0.675 & 0.618 & 0.580 & 0.650 & 0.658 & 0.657 & 0.552 & 0.459 & 0.414 & 0.320 & 0.194 & 0.150 \\
\hline 19 & .638 & 0.854 & 0.968 & 0.927 & 0.897 & 0.856 & 0.727 & 0.653 & 0.739 & 0.777 & 0.882 & 0.818 & 0.688 & 0.602 & 0.426 & 0.234 & 0.174 \\
\hline
\end{tabular}

${ }^{a} \mathrm{r}=\mathrm{n}$ denotes the radial region number; $\mathrm{n}$ varies from 1 to 8 for the IFE and from 1 to 9 for the OFE. 
Table 11.1.2 Relative fission densities for LEU Alternate Design $6\left(3.4 \mathrm{~g}{ }^{10} \mathrm{~B}\right)$ at EOC (28d)

\begin{tabular}{|c|c|c|c|c|c|c|c|c|c|c|c|c|c|c|c|c|c|}
\hline \multirow{2}{*}{$\begin{array}{c}\text { Axial } \\
\text { region \# }\end{array}$} & \multicolumn{8}{|c|}{ IFE } & \multicolumn{9}{|c|}{ OFE } \\
\hline & $\mathbf{r}=1^{a}$ & $=2$ & $r=3$ & $r=4$ & $r=5$ & $r=6$ & $\mathrm{r}=7$ & $r=8$ & $r=1$ & $r=2$ & $r=3$ & $r=4$ & $r=5$ & $r=6$ & $r=7$ & $r=8$ & $r=9$ \\
\hline 1 & 年 & & 1.580 & 1.580 & זכטסו & 1.461 & 237 & & 1.119 & 1.100 & 1.445 & .442 & 20 & .328 & .251 & 0.971 & .838 \\
\hline 2 & 0.733 & 1.041 & 31 & 1.034 & 19 & 1.062 & 995 & 64 & 67 & 974 & 0.994 & 855 & 760 & 801 & 909 & 856 & .785 \\
\hline 3 & 0.693 & 0.919 & 0.900 & 0.779 & 0.790 & 0.862 & 0.849 & 0.847 & 0.852 & 0.839 & 0.807 & 0.658 & 0.580 & 0.636 & .806 & 0.834 & 783 \\
\hline 4 & 0.674 & 0.873 & 0.826 & 0.707 & 0.718 & 0.786 & 772 & 775 & 0.779 & .766 & 0.750 & 0.621 & .551 & .615 & 812 & 362 & 315 \\
\hline 5 & 0.678 & 0.881 & 0.844 & 0.725 & 0.729 & 0.787 & 0.761 & 0.756 & 0.762 & 0.753 & 0.761 & 0.650 & 0.581 & 0.653 & .865 & 0.916 & .863 \\
\hline 6 & 0.730 & 0.989 & 0.976 & 0.847 & 0.850 & 0.897 & 0.843 & & 0.836 & 0.829 & 0.871 & 0.766 & 0.693 & 0.780 & .024 & 1.052 & 81 \\
\hline 7 & 0.799 & 1.149 & 1.176 & 1.020 & 1.017 & 1.070 & 0.992 & 0.986 & 0.979 & 0.970 & 1.040 & 0.923 & 0.835 & 0.946 & 1.229 & 1.189 & 1.080 \\
\hline 8 & 0.834 & 1.252 & 1.314 & 1.140 & 1.13 & 1.191 & 1.099 & & 1.081 & 1.06 & 1.158 & 1.028 & 0.931 & 1.059 & 361 & 1.255 & 9 \\
\hline J & 0.844 & 1.299 & 1.385 & 1.202 & 1.195 & 1.251 & 1.150 & 1.150 & 1.133 & 1.116 & 1.216 & 1.081 & 0.979 & 1.115 & 1.430 & 1.290 & 1.141 \\
\hline 10 & 0.841 & 1.305 & 1.396 & 1.210 & 1.202 & 1.258 & 1.155 & 1.158 & 1.140 & 1.125 & 1.227 & 1.091 & 0.988 & 1.125 & 1.441 & 1.294 & 1.144 \\
\hline 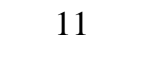 & 0.837 & 1.289 & 1.374 & 1.190 & 1.184 & 1.242 & 1.141 & 1.139 & 1.125 & 1.108 & 1.208 & 1.072 & 0.972 & 1.107 & 1.421 & 1.281 & .134 \\
\hline 12 & 0.816 & 1.227 & 1.287 & 1.116 & 1.112 & & 1.075 & & $1 .($ & 1.047 & 1.134 & 1.007 & 0.912 & 38 & 38 & .236 & .102 \\
\hline 13 & & & 1.132 & 0.982 & & & & & & & & & 7 & & & 57 & \\
\hline 14 & 0.691 & 0.934 & 0.919 & 0.797 & 0.796 & 0.841 & 0.788 & 0.781 & 0.780 & 0.776 & 0.820 & 0.723 & 0.654 & 0.740 & 0.981 & 1.012 & 0.944 \\
\hline 15 & 0.618 & 0.804 & 0.764 & 0.660 & 0.663 & 0.714 & 0.683 & 0.676 & 0.685 & 0.677 & 0.692 & 0.598 & 0.537 & 0.609 & 0.817 & 0.870 & 0.821 \\
\hline 16 & 0.594 & 0.767 & 0.725 & 0.623 & 0.630 & 0.686 & 0.668 & 0.663 & 0.674 & 0.665 & 0.664 & 0.560 & 0.500 & 0.563 & 0.754 & 0.810 & 0.765 \\
\hline 17 & & 0.766 & 0.743 & 0.641 & 0.647 & 0.709 & 0.692 & 0.687 & 0.696 & 0.693 & 0.683 & 0.567 & 0.503 & 0.559 & 0.722 & 0.758 & 0.712 \\
\hline 18 & 0.587 & 0.807 & 0.852 & 0.764 & 0.767 & 0.807 & 0.762 & 0.745 & 0.752 & 0.761 & 0.789 & 0.681 & 0.609 & 0.653 & 0.764 & 0.737 & 0.677 \\
\hline 19 & .602 & 0.898 & 1.087 & 1.061 & 1.051 & 1.028 & 0.890 & 0.821 & 0.850 & 0.894 & 1.072 & 1.051 & 0.960 & 0.980 & 0.971 & 0.782 & 0.684 \\
\hline
\end{tabular}

${ }^{a} \mathrm{r}=\mathrm{n}$ denotes the radial region number; $\mathrm{n}$ varies from 1 to 8 for the IFE and from 1 to 9 for the OFE. 
ORNL/TM-2014/154

Table 11.1.3 Relative fission densities for LEU Alternate Design $6\left(3.6 \mathrm{~g}{ }^{10} \mathrm{~B}\right)$ at BOC

\begin{tabular}{|c|c|c|c|c|c|c|c|c|c|c|c|c|c|c|c|c|c|}
\hline \multirow{2}{*}{$\begin{array}{c}\text { Axial } \\
\text { region \# }\end{array}$} & \multicolumn{8}{|c|}{ IFE } & \multicolumn{9}{|c|}{ OFE } \\
\hline & $\mathrm{r}=1^{a}$ & $=2$ & $r=3$ & $r=4$ & $r=5$ & $=6$ & $r=7$ & $r=8$ & $r=1$ & $r=2$ & 3 & $r=4$ & $r=5$ & $=6$ & $=7$ & $=8$ & $=9$ \\
\hline 1 & 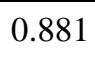 & & & 1.522 & & & 1.088 & & & 133 & & 27 & & 009 & .771 & 476 & .377 \\
\hline 2 & 78 & 98 & & 0.977 & 49 & 44 & 0.860 & 04 & 05 & 907 & 398 & 769 & 656 & 617 & 525 & 378 & 316 \\
\hline 3 & 0.725 & 0.873 & 0.850 & 0.768 & 62 & 0.789 & 0.748 & 07 & 0.801 & 0.789 & 0.751 & 613 & 0.516 & 493 & 42 & 332 & .282 \\
\hline 4 & & & & 0.717 & & & & & & 43 & & 591 & & & & 322 & 273 \\
\hline 5 & 0.736 & 0.869 & 0.841 & 0.753 & 54 & 0.778 & 0.720 & 0.673 & 0.743 & 0.754 & 0.750 & 0.629 & 0.532 & 514 & 61 & 344 & .292 \\
\hline 6 & 0.867 & 1.027 & 1.005 & 0.911 & & & 0.847 & & & 0.875 & & 0.774 & 0.663 & & 34 & 15 & .447 \\
\hline 7 & 1.089 & 1.289 & 1.258 & 1.146 & 1.142 & 1.168 & 1.063 & 0.982 & 1.061 & 1.094 & 1.136 & 0.992 & 0.864 & 0.885 & 929 & .827 & .740 \\
\hline 8 & 1.251 & & & 1.321 & & & 1.227 & & & 1.270 & & 1.164 & 1.024 & 1.066 & 7 & 81 & 0.974 \\
\hline . & 1.335 & 1.586 & 1.555 & 1.418 & 1.419 & 1.453 & 1.325 & 1.226 & 1.329 & 1.370 & 1.435 & 1.272 & 1.132 & 1.218 & .448 & .446 & 1.336 \\
\hline 10 & 1.354 & 1.605 & 1.574 & 1.438 & & 1.478 & & & & 1.387 & 1.453 & 1.289 & 1.154 & 1.257 & 1.535 & 1.570 & \\
\hline & & & & 1.399 & & & & & & 1.348 & 1.409 & 1.248 & 1.111 & 1.193 & 1.417 & 1.415 & .307 \\
\hline 12 & 1.204 & 1.427 & 1.397 & 1.273 & & 1.294 & & & & 1.221 & 70 & 1.112 & 72 & & 1 & 929 & .826 \\
\hline 13 & 1.023 & & & & & & & & & & & & & & & & \\
\hline 14 & 0.802 & 0.946 & 0.920 & 0.832 & 0.824 & 0.841 & 0.765 & 0.707 & 0.765 & 0.787 & 0.809 & 0.692 & 0.586 & 0.565 & 0.511 & .385 & 0.324 \\
\hline 15 & 0.654 & 0.768 & 0.738 & 0.663 & 0.657 & 0.680 & & 0.582 & & 0.642 & 0.646 & 0.542 & 0.450 & 0.416 & 0.330 & .208 & 0.164 \\
\hline 16 & 0.614 & 0.716 & 0.684 & 0.610 & 0.606 & 0.630 & 0.585 & 0.545 & 0.610 & 0.611 & 0.603 & 0.498 & 0.410 & 0.379 & 0.300 & .188 & 0.148 \\
\hline 17 & & & 0.678 & 0.608 & & 0.619 & & & & 0.619 & & 0.490 & 0.403 & & & 183 & 0.145 \\
\hline 18 & 0.607 & 0.747 & 0.758 & 0.691 & 0.676 & 0.686 & 0.628 & 0.588 & 0.662 & 0.670 & 0.669 & 0.562 & 0.470 & 0.423 & 0.325 & 0.198 & 0.153 \\
\hline 19 & .646 & 0.871 & 0.992 & 0.948 & 0.917 & 0.869 & 0.734 & 0.653 & 0.756 & 0.796 & 0.907 & 0.846 & 0.709 & 0.621 & 0.438 & 0.240 & 0.178 \\
\hline
\end{tabular}

${ }^{a} \mathrm{r}=\mathrm{n}$ denotes the radial region number; $\mathrm{n}$ varies from 1 to 8 for the IFE and from 1 to 9 for the OFE. 
Table 11.1.4 Relative fission densities for LEU Alternate Design $6\left(3.6 \mathrm{~g}{ }^{10} \mathrm{~B}\right)$ at EOC (28d)

\begin{tabular}{|c|c|c|c|c|c|c|c|c|c|c|c|c|c|c|c|c|c|}
\hline \multirow{2}{*}{$\begin{array}{c}\text { Axial } \\
\text { region \# }\end{array}$} & \multicolumn{8}{|c|}{ IFE } & \multicolumn{9}{|c|}{ OFE } \\
\hline & $\mathrm{r}=1^{a}$ & $\mathrm{r}=2$ & $r=3$ & $r=4$ & $r=5$ & $r=6$ & $\mathrm{r}=7$ & $r=8$ & $\mathrm{r}=1$ & $\mathrm{r}=2$ & $r=3$ & $r=4$ & $r=5$ & $r=6$ & $r=7$ & $r=8$ & $\mathrm{r}=9$ \\
\hline 1 & 0.788 & 1.231 & 1.582 & 1.583 & 1.547 & 1.466 & 1.237 & 1.125 & 1.112 & 1.182 & 1.446 & 1.440 & 1.319 & 1.332 & 1.258 & 0.972 & 0.840 \\
\hline 2 & 0.736 & 1.042 & 1.142 & 1.035 & 1.025 & 1.065 & 0.997 & 0.974 & 0.961 & 0.970 & 0.998 & 0.857 & 0.763 & 0.802 & 0.914 & 0.860 & 0.791 \\
\hline 3 & 0.694 & 0.922 & 0.910 & 0.785 & 0.789 & 0.863 & 0.850 & 0.845 & 0.857 & 0.841 & 0.811 & 0.660 & 0.582 & 0.639 & 0.808 & 0.831 & 0.781 \\
\hline 4 & 0.676 & 0.875 & 0.831 & 0.709 & 0.717 & 0.789 & 0.774 & 0.770 & 0.781 & 0.766 & 0.753 & 0.620 & 0.551 & 0.616 & 0.813 & 0.861 & 0.812 \\
\hline 5 & 0.679 & 0.886 & 0.846 & 0.721 & 0.730 & 0.786 & 0.757 & 0.755 & 0.759 & 0.751 & 0.761 & 0.647 & 0.580 & 0.652 & 0.866 & 0.916 & 0.861 \\
\hline 6 & 0.729 & 0.989 & 0.974 & 0.844 & 0.844 & 0.891 & 0.837 & 0.827 & 0.831 & 0.825 & 0.868 & 0.762 & 0.690 & 0.779 & 1.024 & 1.051 & 0.979 \\
\hline 7 & 0.798 & 1.150 & 1.177 & 1.017 & 1.012 & 1.063 & 0.986 & 0.979 & 0.974 & 0.965 & 1.035 & 0.920 & 0.835 & 0.945 & 1.227 & 1.186 & 1.077 \\
\hline 8 & 0.834 & 1.253 & 1.313 & 1.136 & 1.131 & 1.185 & 1.093 & 1.091 & 1.076 & 1.063 & 1.153 & 1.025 & 0.929 & 1.058 & 1.362 & 1.254 & 1.118 \\
\hline 9 & 0.843 & 1.297 & 1.385 & 1.198 & 1.189 & 1.245 & 1.147 & 1.147 & 1.126 & 1.113 & 1.213 & 1.078 & 0.977 & 1.114 & 1.430 & 1.291 & 1.141 \\
\hline 10 & 0.842 & 1.306 & 1.396 & 1.206 & 1.199 & 1.257 & 1.156 & 1.155 & 1.138 & 1.121 & 1.222 & 1.085 & 0.987 & 1.125 & 1.441 & 1.296 & 1.145 \\
\hline 11 & 0.837 & 1.288 & 1.370 & 1.187 & 1.180 & 1.236 & 1.137 & 1.132 & 1.121 & 1.105 & 1.203 & 1.070 & 0.970 & 1.105 & 1.418 & 1.280 & 1.134 \\
\hline 12 & 0.816 & 1.227 & 1.286 & 1.116 & 1.110 & 1.163 & 1.072 & 1.070 & 1.056 & 1.042 & 1.130 & 1.006 & 0.912 & 1.036 & 1.338 & 1.234 & 1.099 \\
\hline 13 & 0.773 & 1.112 & 1.137 & 0.983 & 0.980 & 1.031 & 0.955 & 0.951 & 0.941 & 0.933 & 1.003 & 0.890 & 0.808 & 0.917 & 1.195 & 1.157 & 1.051 \\
\hline 14 & 0.694 & 0.939 & 0.924 & 0.800 & 0.799 & 0.842 & 0.790 & 0.783 & 0.781 & 0.778 & 0.823 & 0.726 & 0.659 & 0.744 & 0.983 & 1.015 & 0.946 \\
\hline 15 & 0.624 & 0.812 & 0.778 & 0.671 & 0.673 & 0.722 & 0.686 & 0.679 & 0.691 & 0.682 & 0.696 & 0.600 & 0.542 & 0.613 & 0.821 & 0.875 & 0.824 \\
\hline 16 & 0.603 & 0.780 & 0.734 & 0.631 & 0.640 & 0.694 & 0.674 & 0.672 & 0.683 & 0.675 & 0.670 & 0.563 & 0.507 & 0.568 & 0.760 & 0.810 & 0.766 \\
\hline 17 & 0.591 & 0.783 & 0.759 & 0.656 & 0.665 & 0.722 & 0.704 & 0.702 & 0.709 & 0.701 & 0.692 & 0.574 & 0.512 & 0.567 & 0.729 & 0.760 & 0.713 \\
\hline 18 & 0.597 & 0.833 & 0.877 & 0.790 & 0.788 & 0.826 & 0.782 & 0.764 & 0.773 & 0.780 & 0.807 & 0.700 & 0.623 & 0.667 & 0.783 & 0.754 & 0.693 \\
\hline 19 & 0.614 & 0.925 & 1.128 & 1.101 & 1.092 & 1.061 & 0.920 & 0.848 & 0.866 & 0.923 & 1.106 & 1.085 & 0.993 & 1.014 & 0.996 & 0.796 & 0.693 \\
\hline
\end{tabular}

${ }_{\mathrm{a}} \mathrm{r}=\mathrm{n}$ denotes the radial region number; $\mathrm{n}$ varies from 1 to 8 for the IFE and from 1 to 9 for the OFE. 
ORNL/TM-2014/154

Table 11.1.5 Relative fission densities for LEU Alternate Design $6\left(4.6 \mathrm{~g}{ }^{10} \mathrm{~B}\right)$ at BOC

\begin{tabular}{|c|c|c|c|c|c|c|c|c|c|c|c|c|c|c|c|c|c|}
\hline \multirow{2}{*}{$\begin{array}{c}\text { Axial } \\
\text { region \# }\end{array}$} & \multicolumn{8}{|c|}{ IFE } & \multicolumn{9}{|c|}{ OFE } \\
\hline & $\mathrm{r}=1^{a}$ & $r=2$ & $r=3$ & $r=4$ & $r=5$ & $r=6$ & $r=7$ & $r=8$ & $r=1$ & $r=2$ & $r=3$ & $r=4$ & $r=5$ & $=6$ & $=7$ & $=8$ & $=9$ \\
\hline 1 & 0.806 & & & & & & & & & & 0 & 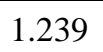 & & & 65 & 75 & .377 \\
\hline 2 & 16 & 26 & & & & 97 & 06 & 42 & 362 & 69 & 33 & 752 & 543 & 607 & 525 & 379 & .320 \\
\hline 3 & 0.669 & 0.813 & 0.810 & 0.735 & 26 & 0.751 & 0.700 & 554 & 0.760 & .760 & 0.735 & 0.605 & .510 & 490 & .444 & 338 & 289 \\
\hline 4 & 0.660 & 0.787 & 0.768 & 0.694 & 691 & 0.714 & 0.663 & 518 & 0.713 & 0.719 & 0.704 & 0.585 & 495 & 479 & .436 & 335 & .286 \\
\hline 5 & 0.685 & 0.817 & 0.803 & 0.729 & 30 & 0.746 & 0.682 & 0.629 & 0.716 & .729 & 0.735 & 0.623 & 0.530 & .517 & 477 & 367 & 314 \\
\hline 6 & 0.814 & 0. & 0.970 & 0.890 & 85 & 0.899 & 0 & 44 & 0.831 & 0 & 0.884 & .769 & 0.665 & 0 & 674 & 74 & .504 \\
\hline 7 & 1.028 & 1.233 & 1.225 & 1.125 & 1.122 & 1.138 & 1.023 & 0.938 & 1.041 & 076 & 1.127 & 0.991 & 0.867 & 895 & .955 & 862 & 0.773 \\
\hline 8 & 1.184 & 1.422 & 1.416 & 1.302 & 1.300 & 1.322 & 1.188 & 1.089 & 1.213 & 1.2 & 1.317 & 1.168 & 1.034 & 91 & 1.225 & 65 & .062 \\
\hline 9 & 1.270 & 1.525 & 1.520 & 1.400 & 02 & 1.424 & 1.284 & 1.177 & 1.314 & 58 & 1.430 & 1.277 & 1.146 & 248 & .519 & 551 & .441 \\
\hline 10 & 1.284 & 1.547 & 1. & 1.418 & 10 & 1.445 & 1.2 & & & & 1.450 & & 67 & & 1.587 & & .535. \\
\hline 1 & 1.250 & 1.504 & 1.501 & 1.382 & & 1.403 & 1.263 & 1.157 & 1.291 & 337 & 1.409 & 1.256 & 1.127 & 230 & .503 & 40 & 433 \\
\hline 12 & 1.144 & 1.376 & 1.368 & 1.256 & 1 & 1.273 & 1.145 & 1.048 & 1.166 & 1.206 & 1.266 & 1.119 & 0.986 & 030 & 1.125 & .033 & 0.929 \\
\hline $1:$ & & & 1.154 & 1.057 & 1.053 & 1.069 & 0.960 & 0.880 & 0.977 & 1.009 & 1.054 & 0.923 & 0.802 & 0.816 & 0.843 & .731 & 0.645 \\
\hline 14 & 0.751 & 0.900 & 0.888 & 0.810 & 0 & 0.815 & 0.733 & 0.672 & 0.749 & $0.7^{7}$ & 0.800 & 0.691 & 0.593 & 0.586 & 0.563 & .456 & .394 \\
\hline 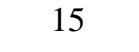 & 0.610 & & 0.708 & 0.642 & & & & & & & & & & & .347 & 25 & 0.180 \\
\hline 16 & 0.565 & 0.672 & 0.654 & 0.591 & 0.587 & 0.603 & 0.553 & 0.513 & 0.583 & 0.591 & 0.591 & 0.492 & 0.410 & 0.381 & 0.305 & .195 & 0.155 \\
\hline 17 & & & 0.644 & 0.583 & & 0.595 & & & & & 0.581 & 0.482 & 0.400 & 0.369 & 0.294 & 0.187 & 0.149 \\
\hline 18 & 0.556 & 0.694 & 0.712 & 0.655 & 0.644 & 0.648 & 0.582 & & 0.632 & 0.638 & 0.645 & 0.547 & 0.460 & 0.417 & 0.322 & 0.197 & 0.155 \\
\hline 19 & 0.589 & 0.802 & 0.922 & 0.897 & 0.861 & 0.808 & 0.674 & 0.601 & 0.709 & 0.753 & 0.861 & 0.806 & 0.685 & 0.605 & 0.427 & 0.235 & 0.177 \\
\hline
\end{tabular}

${ }_{\mathrm{a}} \mathrm{r}=\mathrm{n}$ denotes the radial region number; $\mathrm{n}$ varies from 1 to 8 for the IFE and from 1 to 9 for the OFE. 
Table 11.1.6 Relative fission densities for LEU Alternate Design $6\left(4.6 \mathrm{~g}{ }^{10} \mathrm{~B}\right)$ at EOC (28d)

\begin{tabular}{|c|c|c|c|c|c|c|c|c|c|c|c|c|c|c|c|c|c|}
\hline \multirow{2}{*}{$\begin{array}{c}\text { Axial } \\
\text { region \# }\end{array}$} & \multicolumn{8}{|c|}{ IFE } & \multicolumn{9}{|c|}{ OFE } \\
\hline & $\mathrm{r}=1^{a}$ & $r=2$ & $r=3$ & $r=4$ & $r=5$ & $r=6$ & $r=7$ & $r=8$ & $r=1$ & $r=2$ & $r=3$ & $r=4$ & $r=5$ & $r=6$ & $r=7$ & $r=8$ & $r=9$ \\
\hline 1 & 0.793 & 1.236 & 1.575 & 1.572 & 1.527 & 1.449 & 1.223 & 1.113 & 1.115 & 1.184 & 1.436 & 1.436 & 1.314 & 1.328 & 1.253 & 0.960 & 0.823 \\
\hline 2 & 0.737 & 1.037 & 1.121 & 1.026 & 1.010 & 1.046 & 0.982 & 0.949 & 0.958 & 0.958 & 0.982 & 0.851 & 0.760 & 0.802 & 0.912 & 0.852 & 0.779 \\
\hline 3 & 0.695 & 0.915 & 0.895 & 0.773 & 0.777 & 0.846 & 0.830 & 0.829 & 0.841 & 0.829 & 0.802 & 0.655 & 0.579 & 0.636 & 0.808 & 0.831 & 0.776 \\
\hline 4 & 0.673 & 0.869 & 0.821 & 0.699 & 0.707 & 0.773 & 0.753 & 0.754 & 0.775 & 0.763 & 0.748 & 0.618 & 0.550 & 0.615 & 0.811 & 0.858 & 0.809 \\
\hline 5 & 0.680 & 0.879 & 0.840 & 0.722 & 0.724 & 0.779 & 0.745 & 0.738 & 0.755 & 0.746 & 0.756 & 0.647 & 0.581 & 0.653 & 0.865 & 0.912 & 0.857 \\
\hline 6 & 0.737 & 0.989 & 0.972 & 0.844 & 0.843 & 0.886 & 0.828 & 0.818 & 0.826 & 0.821 & 0.867 & 0.764 & 0.691 & 0.780 & 1.024 & 1.044 & 0.967 \\
\hline 7 & 0.812 & 1.158 & 1.177 & 1.020 & 1.016 & 1.061 & 0.985 & 0.977 & 0.976 & 0.967 & 1.038 & 0.923 & 0.837 & 0.948 & 1.229 & 1.173 & 1.059 \\
\hline 8 & 0.845 & 1.259 & 1.317 & 1.141 & 1.134 & 1.186 & 1.094 & 1.091 & 1.080 & 1.069 & 1.158 & 1.029 & 0.933 & 1.059 & 1.364 & 1.251 & 1.112 \\
\hline 9 & 0.858 & 1.310 & 1.390 & 1.204 & 1.195 & 1.249 & 1.149 & 1.151 & 1.135 & 1.117 & 1.217 & 1.084 & 0.982 & 1.118 & 1.433 & 1.289 & 1.139 \\
\hline 10 & 0.856 & 1.318 & 1.403 & 1.214 & 1.207 & 1.258 & 1.158 & 1.160 & 1.143 & 1.124 & 1.225 & 1.092 & 0.990 & 1.129 & 1.447 & 1.294 & 1.140 \\
\hline 11 & 0.851 & 1.298 & 1.378 & 1.195 & 1.185 & 1.237 & 1.138 & 1.140 & 1.124 & 1.110 & 1.208 & 1.075 & 0.975 & 1.110 & 1.421 & 1.280 & 1.130 \\
\hline 12 & 0.829 & 1.234 & 1.290 & 1.117 & 1.111 & 1.163 & 1.072 & 1.070 & 1.061 & 1.047 & 1.135 & 1.010 & 0.915 & 1.041 & 1.341 & 1.233 & 1.097 \\
\hline 13 & 0.782 & 1.116 & 1.135 & 0.985 & 0.981 & 1.027 & 0.951 & 0.944 & 0.941 & 0.932 & 1.002 & 0.892 & 0.809 & 0.917 & 1.192 & 1.143 & 1.032 \\
\hline 14 & 0.699 & 0.937 & 0.919 & 0.797 & 0.794 & 0.835 & 0.780 & 0.768 & 0.777 & 0.774 & 0.817 & 0.723 & 0.656 & 0.743 & 0.982 & 1.006 & 0.934 \\
\hline 15 & 0.623 & 0.805 & 0.767 & 0.661 & 0.664 & 0.710 & 0.675 & 0.668 & 0.679 & 0.674 & 0.689 & 0.598 & 0.539 & 0.611 & 0.817 & 0.866 & 0.815 \\
\hline 16 & 0.598 & 0.764 & 0.724 & 0.622 & 0.630 & 0.683 & 0.654 & 0.650 & 0.666 & 0.661 & 0.661 & 0.559 & 0.500 & 0.563 & 0.755 & 0.804 & 0.756 \\
\hline 17 & 0.589 & 0.765 & 0.741 & 0.642 & 0.648 & 0.701 & 0.679 & 0.676 & 0.693 & 0.688 & 0.680 & 0.566 & 0.504 & 0.560 & 0.725 & 0.757 & 0.710 \\
\hline 18 & 0.594 & 0.809 & 0.852 & 0.765 & 0.764 & 0.799 & 0.751 & 0.727 & 0.754 & 0.758 & 0.786 & 0.683 & 0.611 & 0.654 & 0.769 & 0.739 & 0.678 \\
\hline 19 & 0.608 & 0.901 & 1.085 & 1.063 & 1.046 & 1.020 & 0.882 & 0.816 & 0.839 & 0.891 & 1.070 & 1.048 & 0.957 & 0.985 & 0.973 & 0.781 & 0.677 \\
\hline
\end{tabular}

${ }^{a} \mathrm{r}=\mathrm{n}$ denotes the radial region number; $\mathrm{n}$ varies from 1 to 8 for the IFE and from 1 to 9 for the OFE. 
Fission rate density profiles, at BOC and EOC, for select axial regions (core horizontal midplane, upper edge of the active fuel region, lower edge of the active fuel region, and average over active fuel height) are shown in Figs. 11.1.5, 11.1.7, and 11.1.9, respectively, for the Alternate Design 6 cases (3.4 g, 3.6 g, and $4.6 \mathrm{~g}{ }^{10} \mathrm{~B}$ ), as a function of the radial distance from the longitudinal centerline of the core. Similar plots, illustrating the fission rate density profiles for select radial regions (innermost, outermost, and central radial meshes) in the IFE and OFE are provided in Figs. 11.1.6, 11.1.8, and 11.1.10, respectively, as a function of the axial distance from the core horizontal midplane.
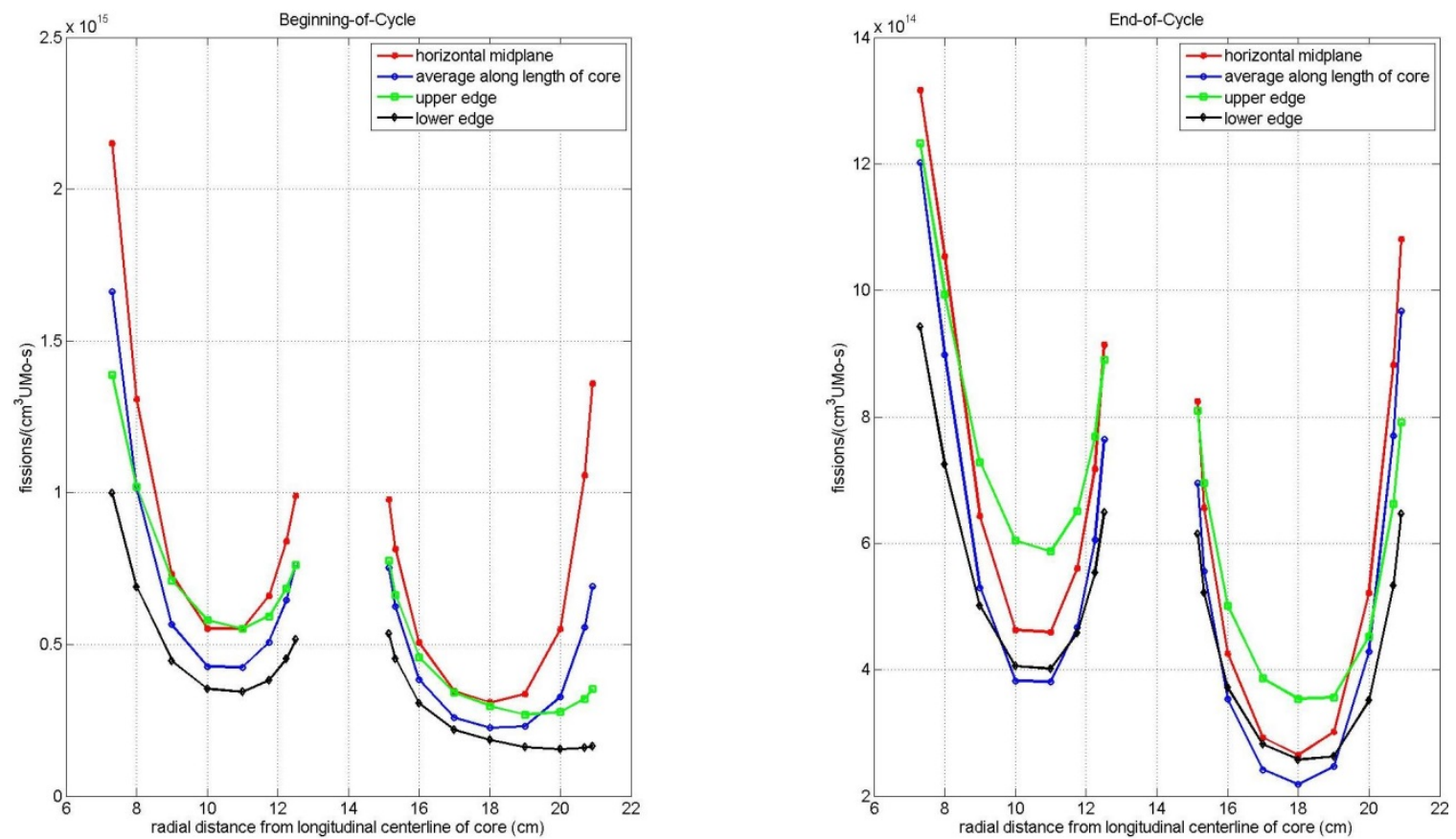

Fig. 11.1.5 Radial distribution of fission rate densities for LEU Alternate Design $3\left(3.4 \mathrm{~g}{ }^{10} \mathrm{~B}\right)$.
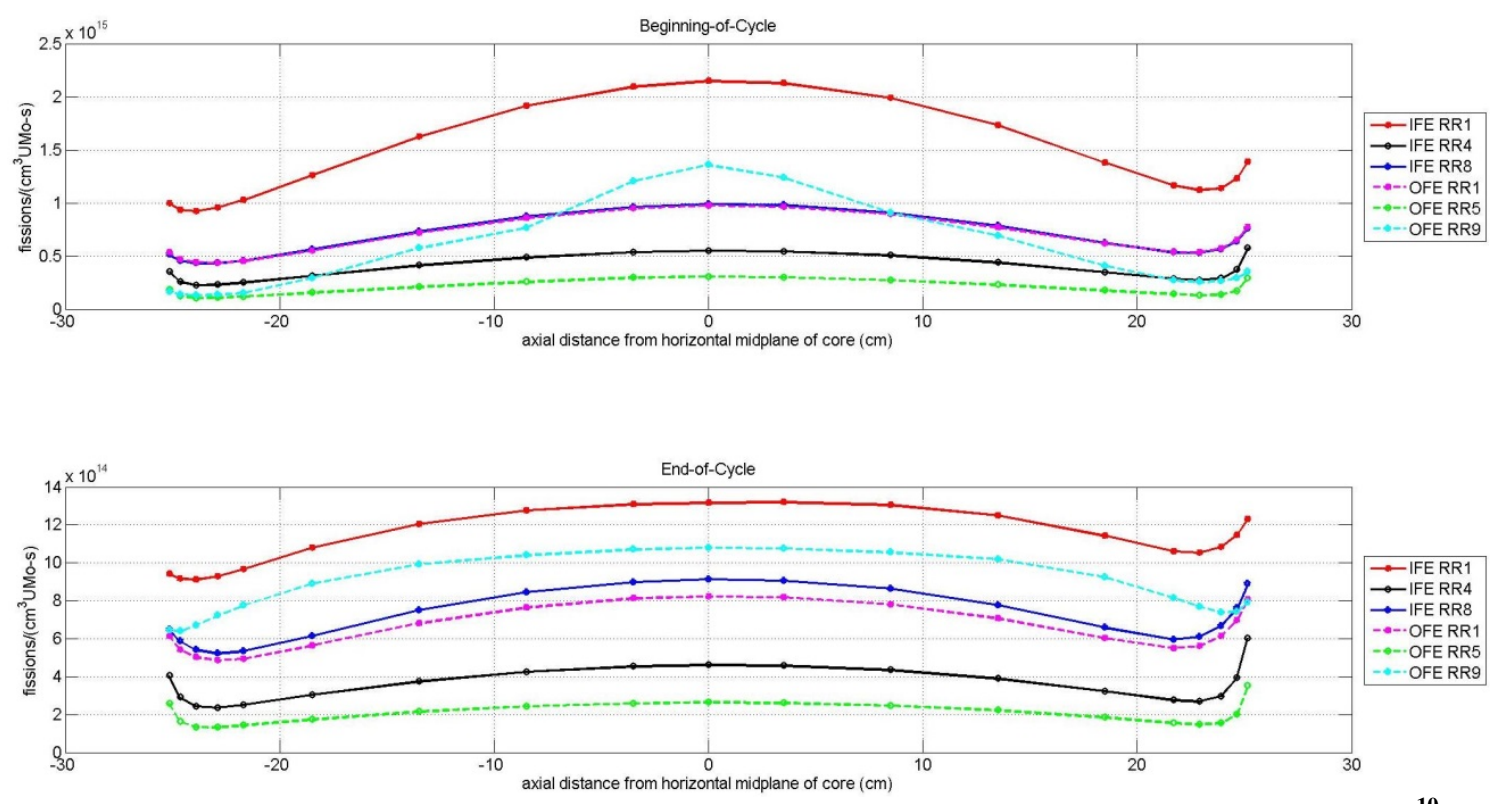

Fig. 11.1.6 Axial distribution of fission rate densities for LEU Alternate Design $3\left(3.4 \mathrm{~g}{ }^{10} \mathrm{~B}\right)$. 

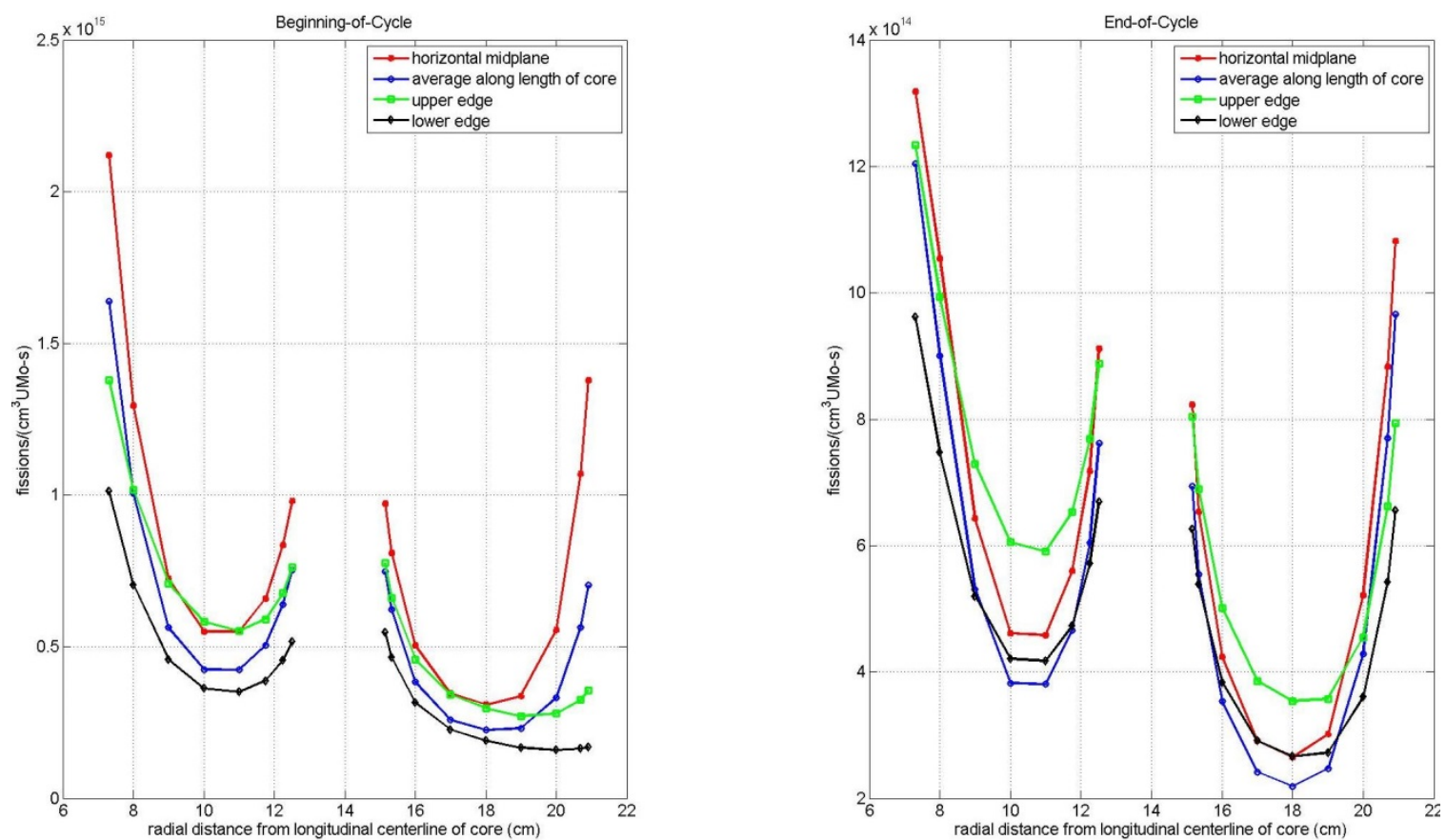

Fig. 11.1.7 Radial distribution of fission rate densities for LEU Alternate Design $3\left(3.6 \mathrm{~g}{ }^{10} \mathrm{~B}\right)$.
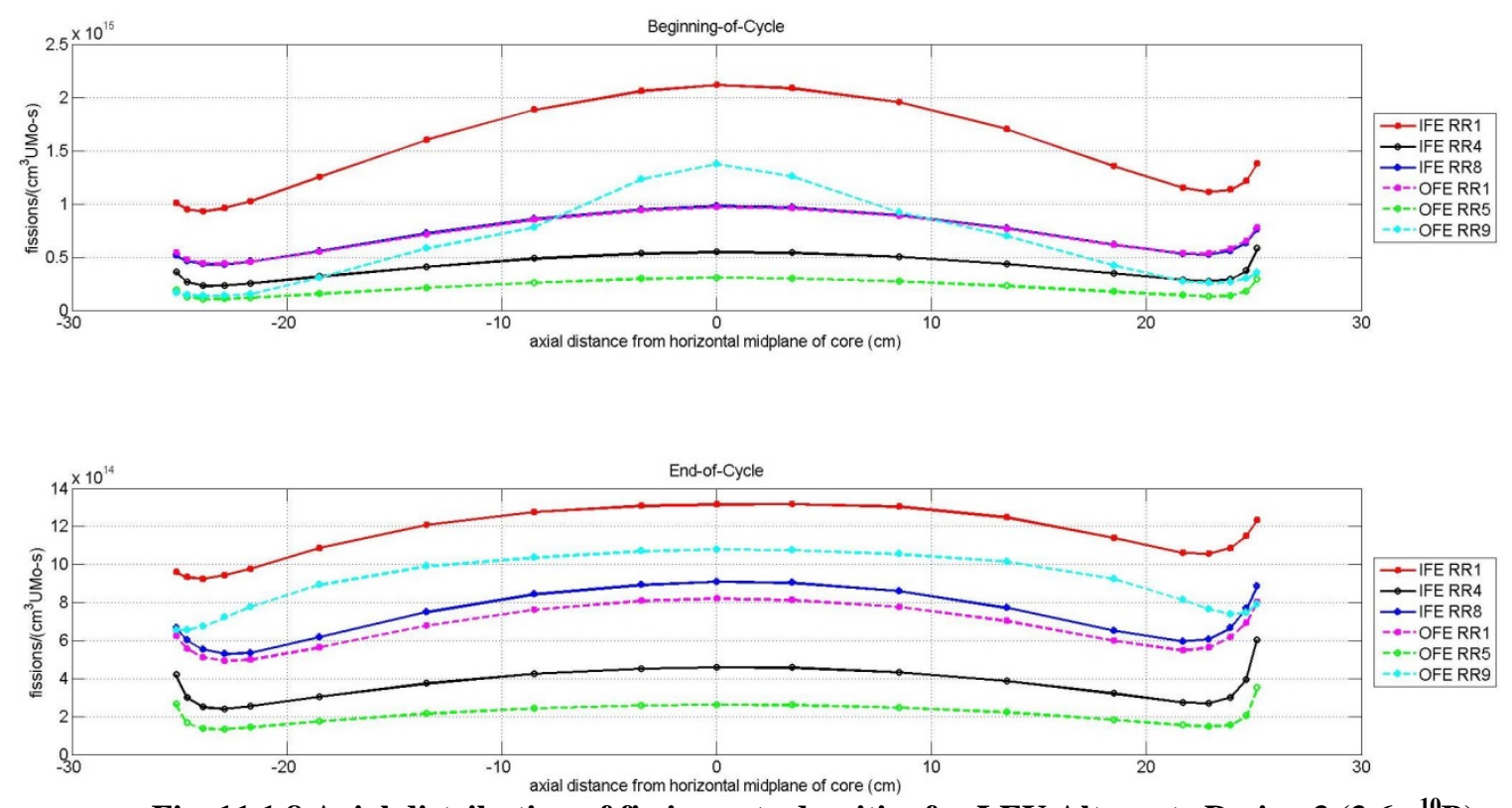

Fig. 11.1.8 Axial distribution of fission rate densities for LEU Alternate Design $3\left(3.6 \mathrm{~g}{ }^{10} \mathrm{~B}\right)$. 

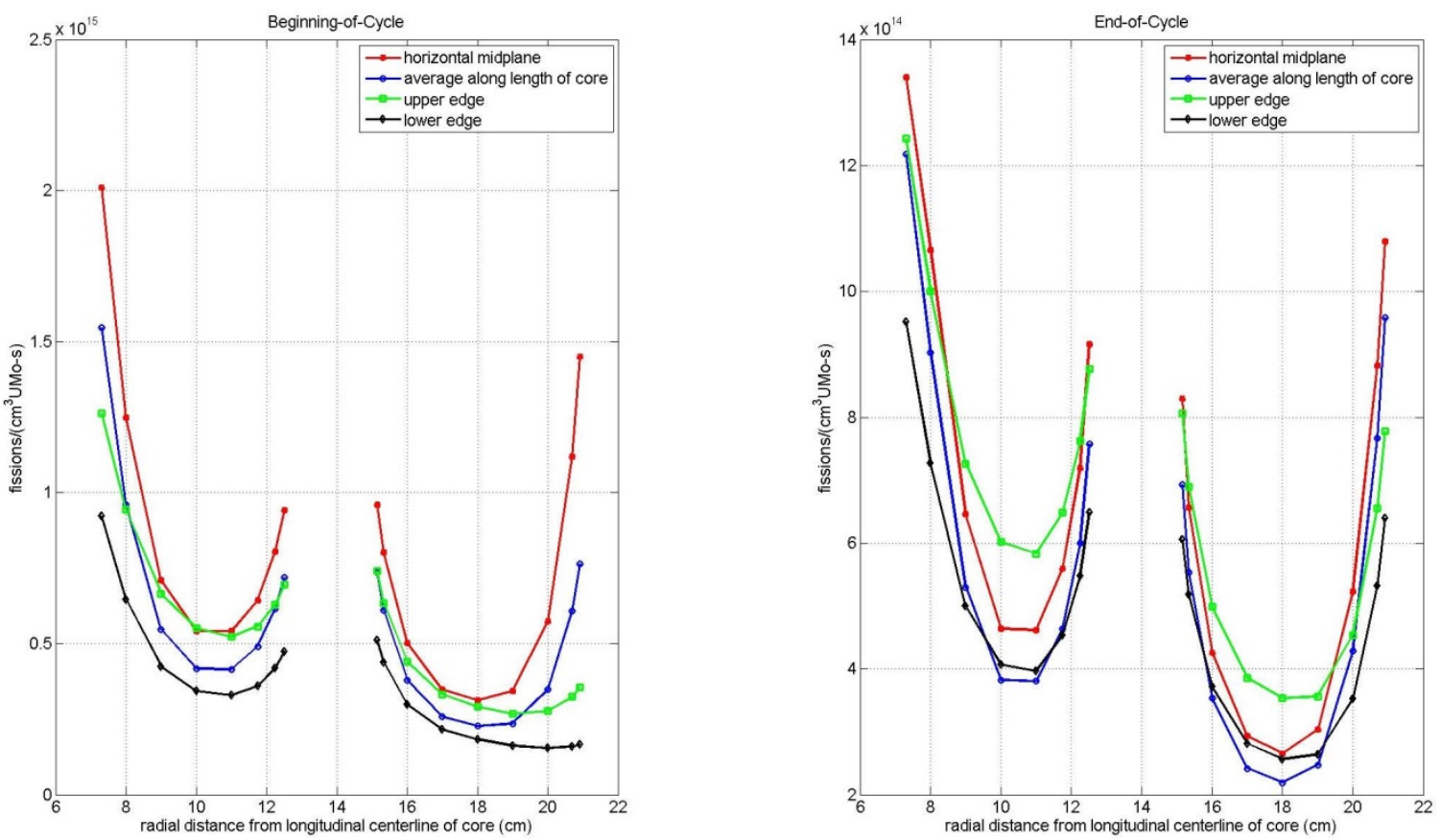

Fig. 11.1.9. Radial distribution of fission rate densities for LEU Alternate Design $3\left(4.6 \mathrm{~g}{ }^{10} \mathrm{~B}\right)$.
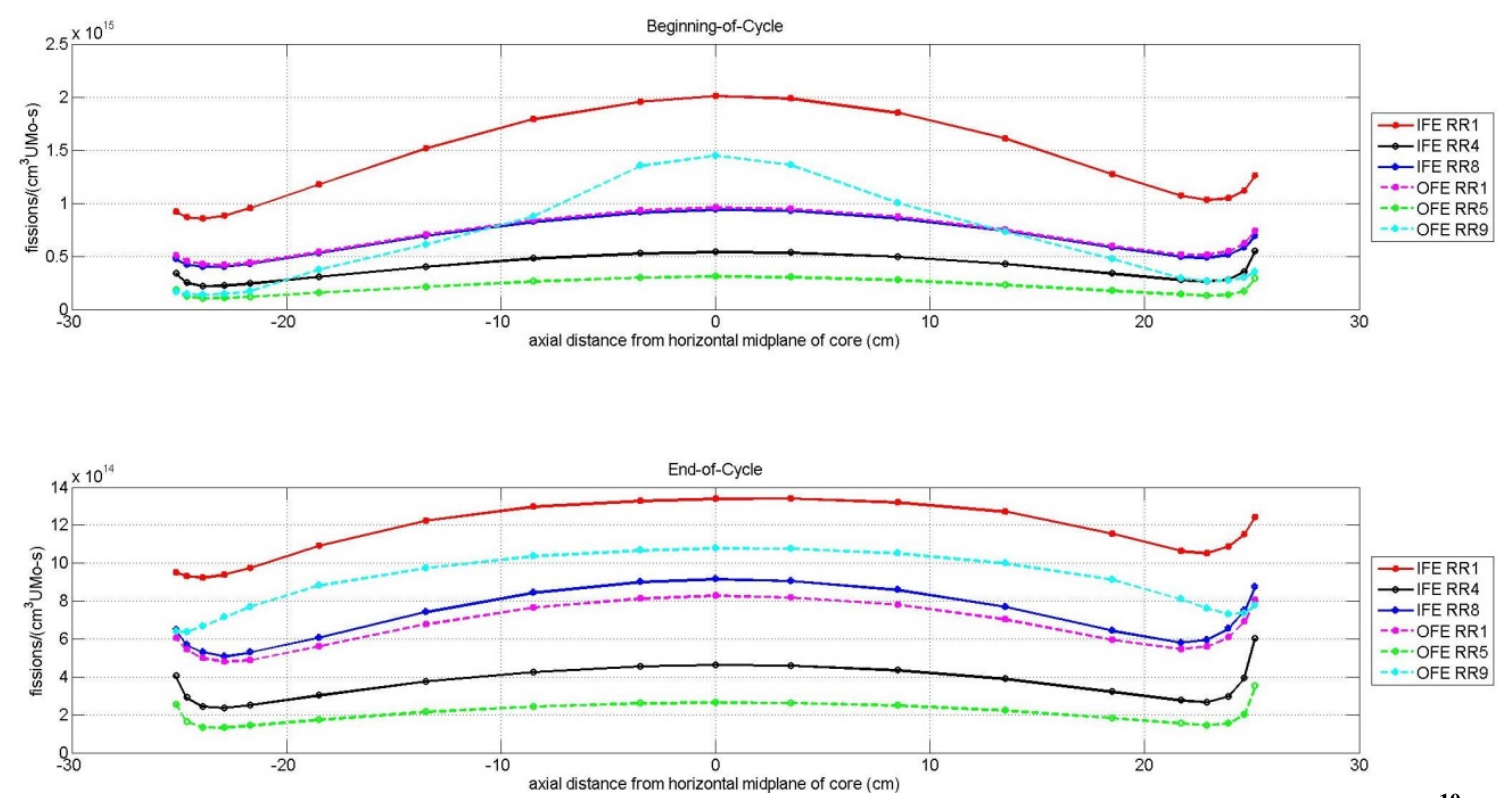

Fig. 11.1.10 Axial distribution of fission rate densities for LEU Alternate Design $3\left(4.6 \mathrm{~g}^{10} \mathrm{~B}\right)$.

Maximum local fission rate densities at BOC and EOC are: $2.15 \times 10^{15}$ and $1.32 \times 10^{15}$ fissions $/\left(\mathrm{cm}^{3} \mathrm{U}\right.$ $10 \mathrm{Mo} \cdot \mathrm{s})$ for Alternate 6 with $3.4 \mathrm{~g}{ }^{10} \mathrm{~B} ; 2.12 \times 10^{15}$ and $1.32 \times 10^{15}$ fissions/( $\left.\mathrm{cm}^{3} \mathrm{U}-10 \mathrm{Mo} \cdot \mathrm{s}\right)$ for Alternate 6 with $3.6 \mathrm{~g}{ }^{10} \mathrm{~B}$; and $2.01 \times 10^{15}$ and $1.34 \times 10^{15}$ fissions $/\left(\mathrm{cm}^{3} \mathrm{U}-10 \mathrm{Mo} \cdot \mathrm{s}\right)$ for Alternate 6 with $4.6 \mathrm{~g}{ }^{10} \mathrm{~B}$. The maximum value at BOC and EOC occurs at the same location for all of the three cases, at the inner radial edge of the IFE on the core horizontal midplane. 
Assuming conservatively that $100 \%$ of the total reactor power (100 MW) is deposited in the fuel meat, the maximum fission rate densities at BOC and EOC would correspond to power densities of: $~ 68.94$ and $42.34 \mathrm{~kW} /\left(\mathrm{cm}^{3} \mathrm{UMo}\right)$ for Alternate 6 with $3.4 \mathrm{~g}{ }^{10} \mathrm{~B}$; 67.93 and $42.29 \mathrm{~kW} /\left(\mathrm{cm}^{3} \mathrm{UMo}\right)$ for Alternate 6 with $3.6 \mathrm{~g}{ }^{10} \mathrm{~B}$; and $\sim 64.42$ and $43.00 \mathrm{~kW} /\left(\mathrm{cm}^{3} \mathrm{UMo}\right)$ for Alternate 6 with $4.6 \mathrm{~g}{ }^{10} \mathrm{~B}$.

The minimum and maximum calculated local burnups, in terms of percent ${ }^{235} \mathrm{U}$ removed during the irradiation cycle, compared to the content at BOC, are similar for the three Alternate 6 cases, with specific values of: 4.81 and $61.32 \%$ for Alternate 6 with $3.4 \mathrm{~g}{ }^{10} \mathrm{~B}$; 4.84 and $60.96 \%$ for Alternate 6 with $3.6 \mathrm{~g}{ }^{10} \mathrm{~B}$; and 4.84 and $60.45 \%$ for Alternate 6 with $4.6 \mathrm{~g}{ }^{10} \mathrm{~B}$. The maximum burnup occurs at the innermost edge of the IFE on the core horizontal midline for all three cases.

Approximately $13.3 \%$ of the initial ${ }^{235} \mathrm{U}$ is consumed during the cycle for all Alternate 6 cases. For all three cases, almost all ${ }^{10} \mathrm{~B}$ present at BOC in the IFE inner side plate is consumed by the EOC ( 99\%); in the outer side plate of the IFE, $\sim 88-89 \%$ of the initial ${ }^{10} \mathrm{~B}$ is consumed during the cycle.

\subsection{STEADY-STATE TH WITH SAFETY CASE ASSUMPTIONS (USING HSSHTC)}

During the summer of 2013, the results of the independent review of the neutronics analysis were reflected in the LEU reference fuel neutronics modeling, which changed the resultant power density matrices that are input to the HSSHTC. Subsequently, the combined alternative cases discussed in this section were produced with the upgraded neutronics model. Analyses for design alternatives 1-5, based on power densities from the previous neutronics model, were not revised. This section describes the thermal hydraulic differences between the updated reference LEU fuel and the previous one.

The updated analysis involved changes to the radial and axial meshing. The overall number of nodes did not change. The changes made to the HSSHTC input to adjust to the new reference fuel neutronics analysis involved changing the radial and axial node boundaries and adjusting the $U_{25}$ uncertainties to reflect the new radial node structure. The revised power density matrices were input to the HSSHTC and the resultant plot of burnout power vs. time is shown in Fig. 11.2.1 together with the old reference fuel case from Fig. 4.2.1. As shown in Fig. 11.2.1, there is a decrease in performance of the newly analyzed reference fuel, except at the BOC point and for a short time during mid-cycle. Investigations into the cause of the differences (particularly at day 1 of the cycle when peak xenon conditions exist) did not pinpoint the cause of the differences. Since the newly analyzed reference fuel case involves more conservative safety limit case results over most of the cycle, it was used as the basis for the 6A-6C and 7A-7C analysis in this section and in Section 12, respectively, without further efforts to determine the cause of the differences. Further study of the changes may shed light on the source of this difference and allow future corrections to the modeling, if necessary. Future evaluations of HFIR LEU fuel performance will transition to a new MCNP model with an explicit representation of key segments of the HFIR core geometry. For the updated reference case, a calculated burnout power of $140.8 \mathrm{MW}$ occurs in the outer element at day 1 at radial node $18(\mathrm{r}=20.70 \mathrm{~cm})$ and axial node $24(\mathrm{z}=28.90 \mathrm{~cm})$. 


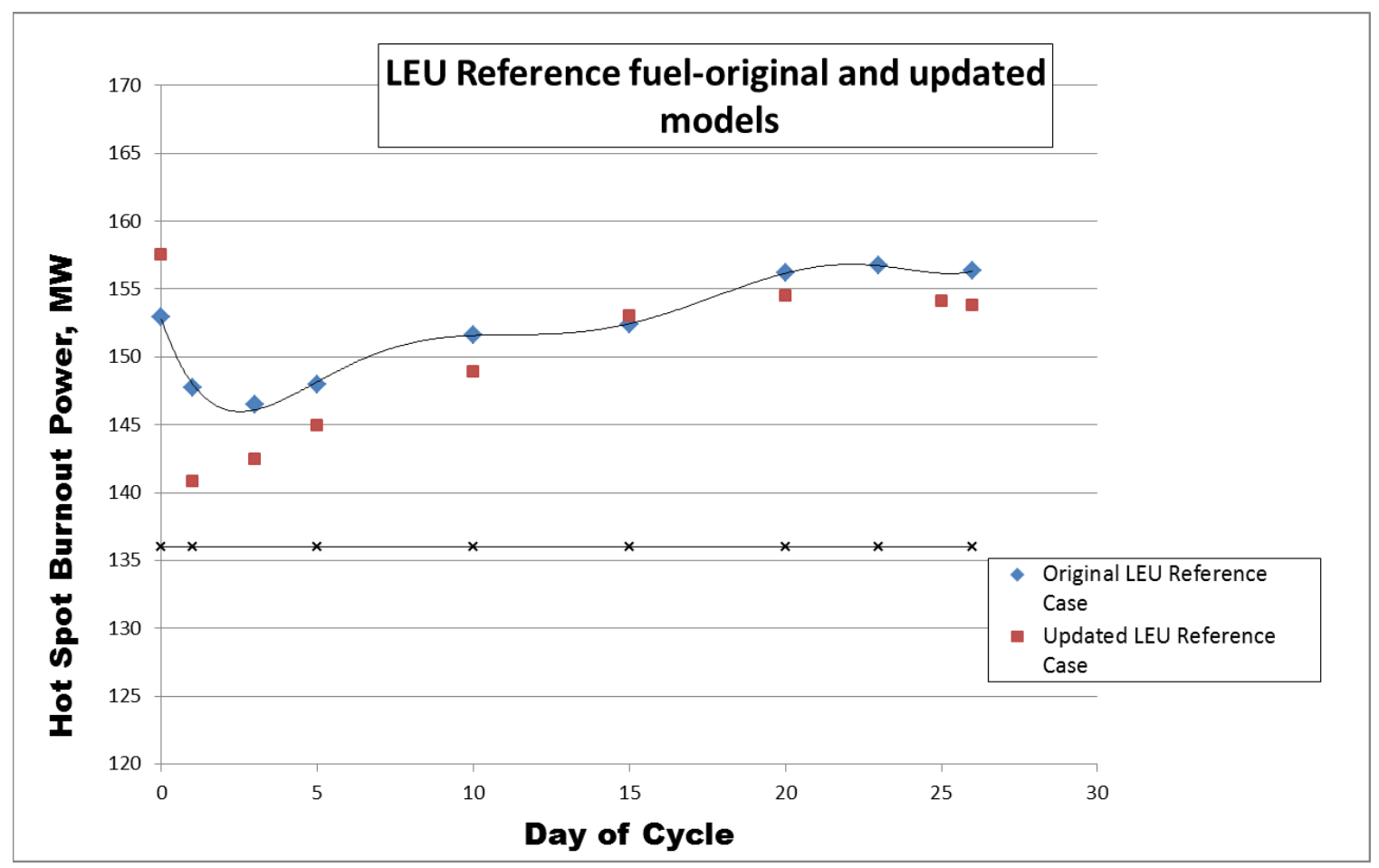

Fig. 11.2.1. Comparison of original and updated reference LEU fuel cycle cases.

Figure 11.2.2 shows results for the updated analysis of the LEU reference fuel, compared to a combination of design alternatives named ALT6A. ALT6A involves axially uniform fuel, B relocated from the inner fuel plates to the side plate of the inner fuel elements, and Hf added to the lower unfueled regions of all fuel plates. The ALT6A case evaluated total B added to the side plates of $3.4 \mathrm{~g}$. As shown in Fig. 11.2.2, the ALT6A cases remained above the safety limit over the cycle, with the ALT6A results being close to the reference fuel from days 1-5 and at the end of the cycle. At the BOC and mid-cycle, the ALT6A results were closer to the safety limit than the reference fuel. For the ALT6A case, a calculated burnout power of $142.0 \mathrm{MW}$ occurs in the outer element at day 1 at radial node 18 ( $\mathrm{r}=20.70$ $\mathrm{cm})$ and axial node $24(\mathrm{z}=28.90 \mathrm{~cm})$. 


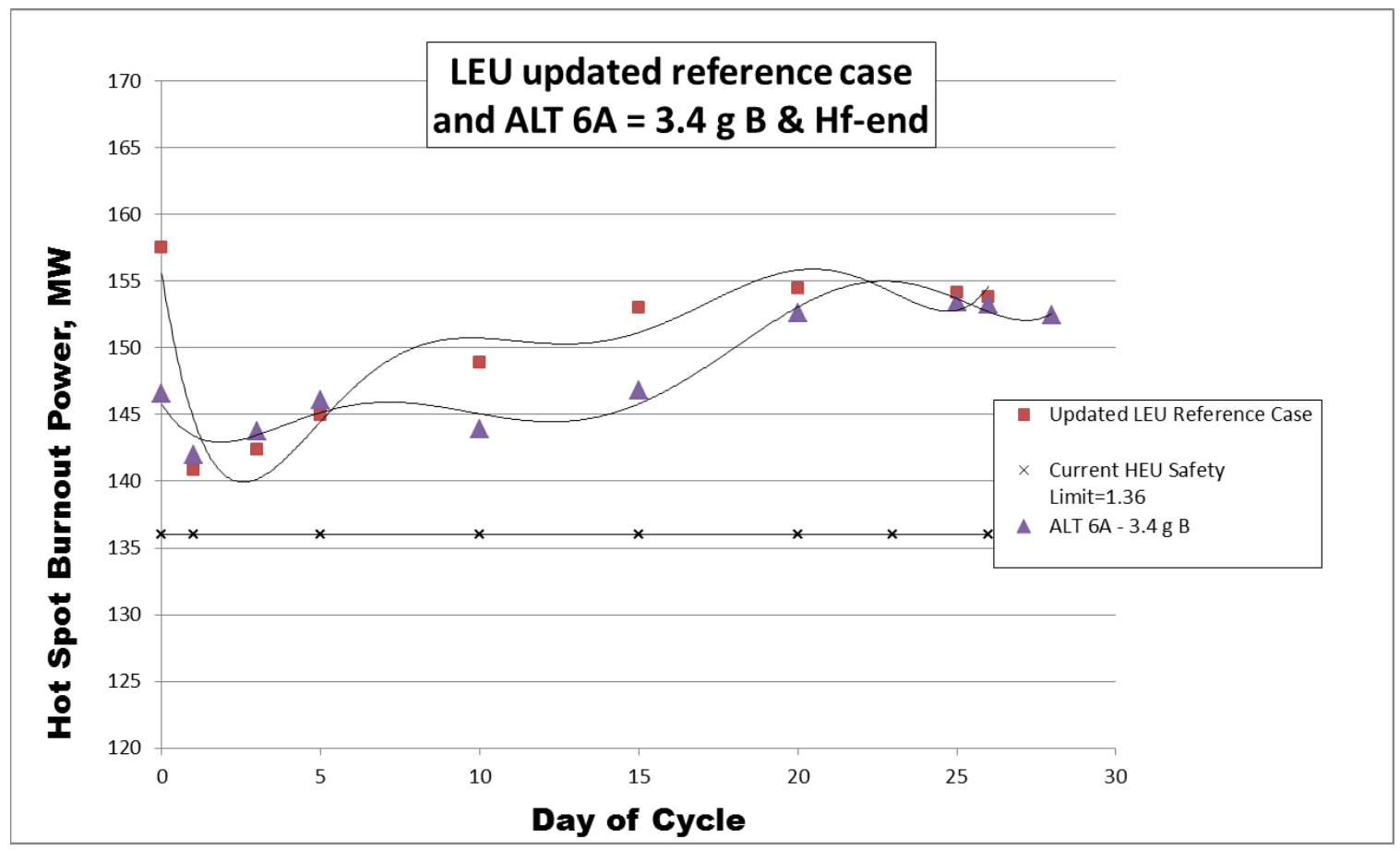

Fig.11.2.2. Hot spot burnout power versus day in the cycle for Alternative 6A-reference fuel with $3.4 \mathrm{~g} B$ in side plates and $\mathrm{Hf}$ in lower unfueled region of plates.

Figure 11.2.3 shows ALT6B, which involved slightly more B (3.6 g) added to the inner fuel element side plates. As shown in Fig. 11.2.3, the BOC and mid-cycle results are slightly farther away from the safety limit (better) than the ALT6A cases and the day 1-5 and EOC results are comparable to the ALT6A results. For the ALT6B case, a calculated burnout power of $141.3 \mathrm{MW}$ occurs in the outer element at the same time in the cycle and core location, i.e., day 1 at radial node $18(\mathrm{r}=20.70 \mathrm{~cm})$ and axial node $24(\mathrm{z}$ $=28.90 \mathrm{~cm})$. 


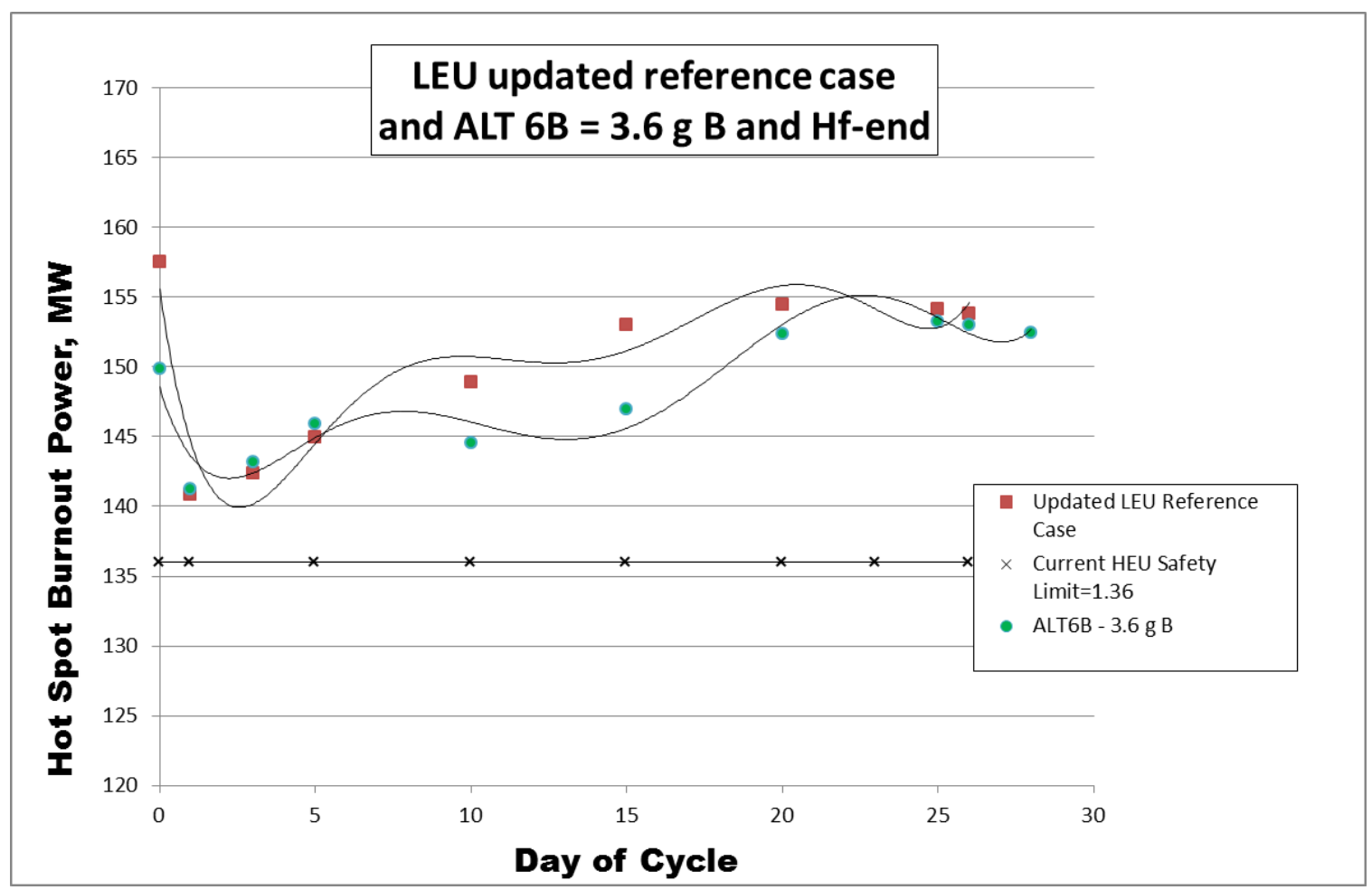

Fig.11.2.3. Hot spot burnout power versus day in the cycle for Alternative 6B-reference fuel with $3.6 \mathrm{~g} B$ in side plates and $\mathrm{Hf}$ in lower unfueled region of plates.

Figure 11.2.4 shows ALT6C, which involved a total of $4.6 \mathrm{~g} \mathrm{~B}$ added to the inner fuel element side plateside plates. As shown in Fig. 11.2.4, the BOC and days 1-5 performance is comparable to the reference fuel, but after day 5, the ALT6C fuel is consistently lower in burnout power (worse) and approaches the safety limit as the cycle proceeds. For the ALT6C case, a calculated burnout power of 140.5 MW occurs in the outer element at the same time in the cycle and core location as cases ALT6A and ALT6B, i.e., day 1 at radial node $18(\mathrm{r}=20.70 \mathrm{~cm})$ and axial node $24(\mathrm{z}=28.90 \mathrm{~cm})$. 


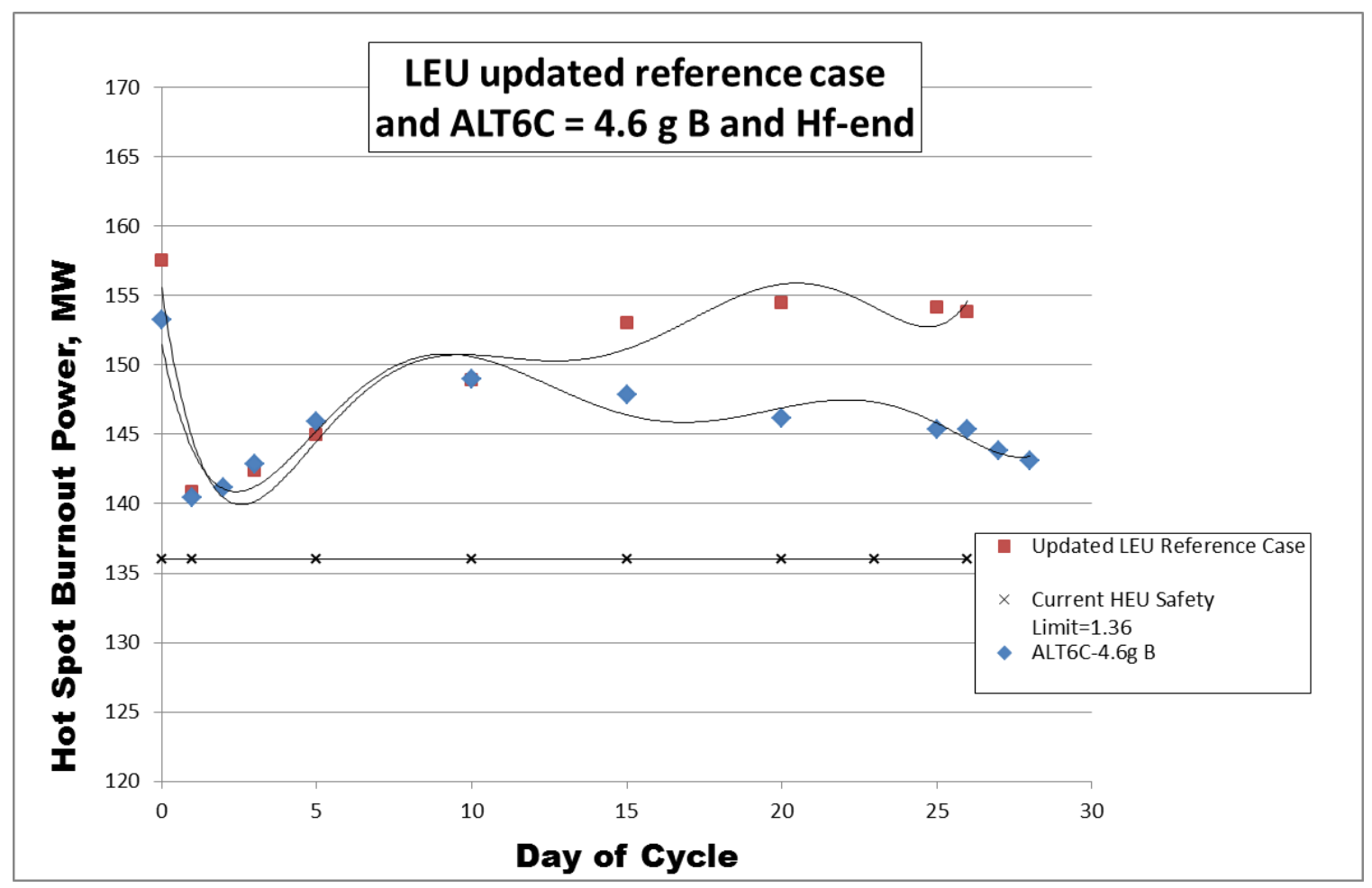

Fig.11.2.4. Hot spot burnout power versus day in the cycle for Alternative 6C-reference fuel with 4.6 $\mathrm{g} B$ in side plates and $\mathrm{Hf}$ in lower unfueled region of plates.

Table 11.2 shows the burnout powers versus day in cycle together with the location of the core hot spot that determines the minimum burnout power. As shown in Table 11.2, ALT6A and ALT6B have similar behavior in terms of the hot spot location being situated in the middle portions of the core, with a shift from the inner to the outer fuel element at about 15 days of operation. For ALT6C, Table 11.2 shows a shift in the hot spot location from the middle of the core to the bottom of the core after day 10. The drop in safety margin from day 10 to the EOC for ALT6C relative to ALT6A and ALT6B is attributable to a shift in the location of the hot spot from the middle portions of the core to the bottom of the core, which is driven by the power densities calculated with the burnup characteristics of the different alternatives.

In conclusion, all three variations of Alternate 6 (combining a permanent absorber in the lower unfueled region of all of the fuel plates with a burnable absorber in the inner element side plates and a still radially contoured fuel zone) would allow successful conversion of HFIR. 
Table 11.2. Burnout power versus day in cycle and location of node at burnout conditions for ALT6A, ALT6B, and ALT6C

\begin{tabular}{|c|c|c|c|c|c|}
\hline Day & $\begin{array}{c}\text { ALT6A } \\
\text { 3.4g B side + } \\
\text { Hf-end }\end{array}$ & $\begin{array}{l}\text { ALT6B } \\
\text { 3.6g B side + } \\
\text { Hf-end }\end{array}$ & $\begin{array}{c}\text { ALT6C } \\
\text { 4.6g B side + } \\
\text { Hf-end }\end{array}$ & & \\
\hline 0 & 146.59 & 149.83 & 153.24 & & \\
\hline 1 & 141.95 & 141.27 & 140.46 & & \\
\hline 3 & 143.72 & 143.19 & 142.83 & & \\
\hline 5 & 146.07 & 145.91 & 145.93 & $\begin{array}{c}\text { Inner } \\
\text { mid-core }\end{array}$ & $\begin{array}{l}\text { Outer } \\
\text { mid-core }\end{array}$ \\
\hline 10 & 143.89 & 144.51 & 148.97 & $\begin{array}{c}\text { Inner } \\
\text { end-core }\end{array}$ & $\begin{array}{c}\text { Outer } \\
\text { end-core }\end{array}$ \\
\hline 15 & 146.78 & 146.96 & 147.86 & & \\
\hline 20 & 152.56 & 152.32 & 146.16 & & \\
\hline 25 & 153.4 & 153.28 & 145.37 & & \\
\hline 26 & 153.26 & 153 & 145.38 & & \\
\hline 28 & 152.4 & 152.47 & 143.83 & & \\
\hline
\end{tabular}




\section{EVALUATION OF ALTERNATE 7 (no axial contouring, Hf absorber, $B$ absorber in side plates, Al clad, centered and symmetric fuel zone)}

\subsection{NEUTRONICS}

The neutronic models for Alternate Design 7 are the same as those for Alternate Design 6, since the simplified fuel modeling approach used does not explicitly represent the involute geometry of the fuel plate and the distribution of different material regions (fuel meat, clad, $\mathrm{Zr}$ ) within the fuel plate. The same results as discussed in Section 11.1 apply therefore to this section. The centered, symmetric fuel zone in Alternate 7 preserves the radial mass distribution of previously considered alternatives.

Figures 12.1.1 and 12.1.2 illustrate the inner and outer element fuel zones for Alternate 7.

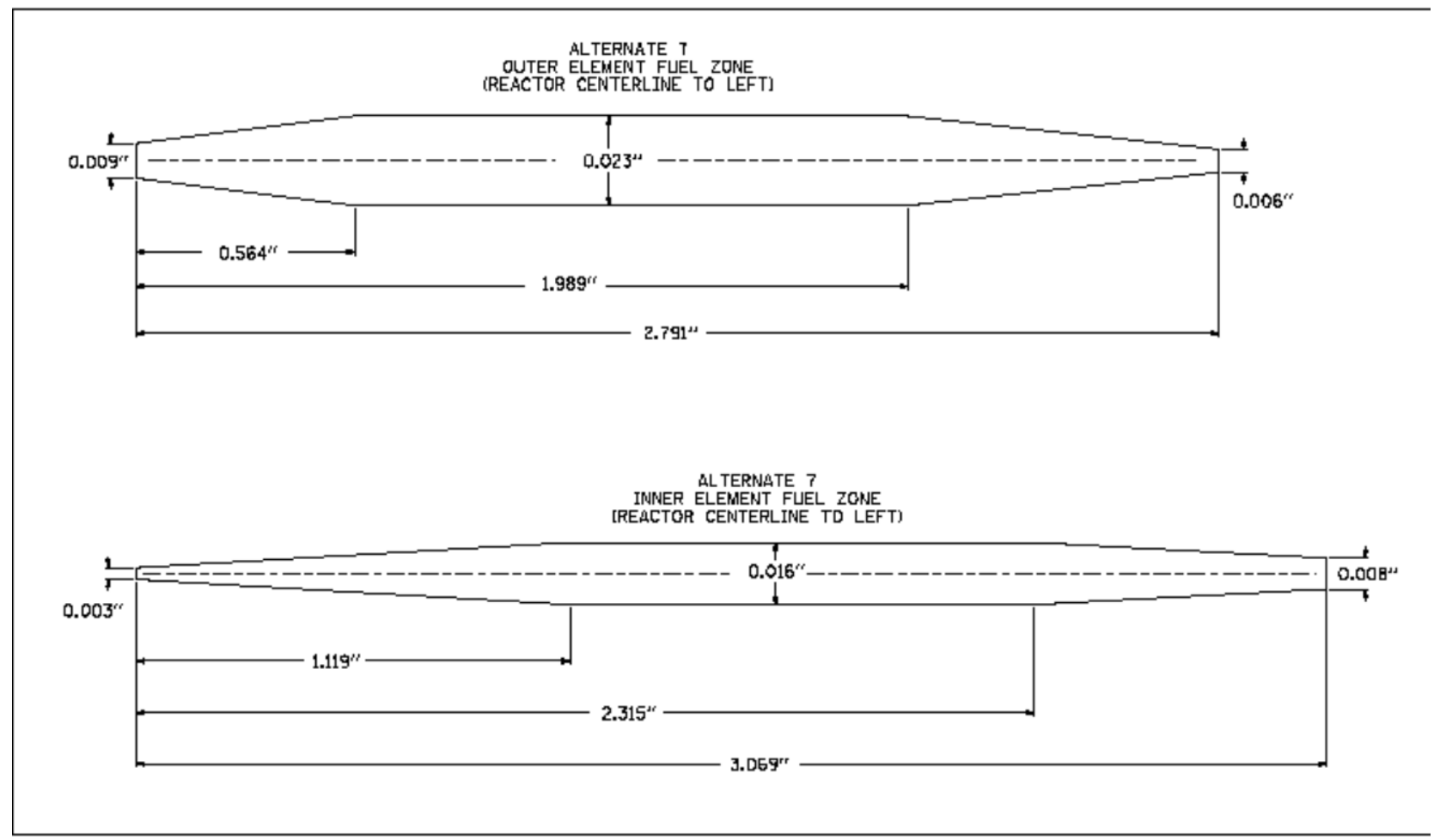

Fig.12.1.1. Sketch of fuel zones for Alternate 7 centered, symmetric fuel. 


\subsection{STEADY-STATE TH WITH SAFETY CASE ASSUMPTIONS (USING HSSHTC)}

Figure 12.2.1 shows results for the newly analyzed LEU reference fuel compared to ALT7A, which is a combination of the ALT6A fuel design option plus a fuel zone that is centered and symmetric along the center of the involute for the plates in both elements. This case was run with the HSSHTC by defining the nonbond/fuel distribution factors as 1.0 instead of letting the HSSHTC calculate them according to the original cubic polynomial fit for hotplate peaking factors (these hot side/cold side factors are $\mathbf{U}_{20}$ and $\mathbf{U}_{21}$ in the HSSHTC, as described in Section 5.4). With the centered and symmetric fuel, the cross-plate (concave side to convex side) heat flux peaking disappears, and Fig. 12.2.1 shows a much wider margin to the existing SL over the entire fuel cycle, as compared to the reference fuel.

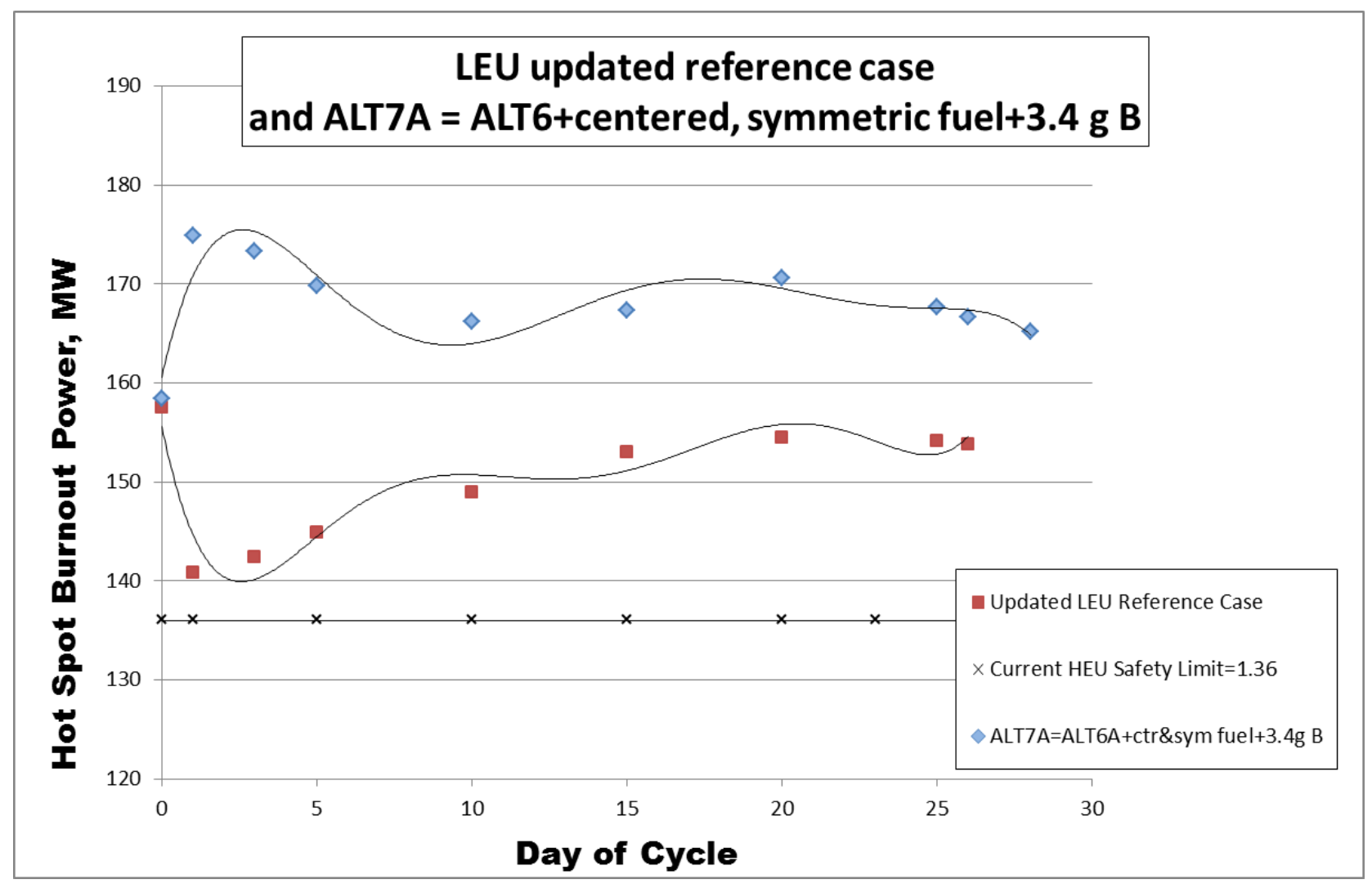

Fig.12.2.1. Hot spot burnout power versus day in the cycle for Reference Fuel and Alternative 7A = ALT6A + centered, symmetric fuel. 
Figure 12.2.2 shows a comparison of ALT7A, ALT7B, and ALT7C, which are all three ALT6 LEU fuel combinations with HSSHTC peaking factor changes that mimic the effects of centered and symmetric fuel. The power density input files and cycle time steps are identical to the ALT6 files-fuel ALT7A is $3.4 \mathrm{~g} \mathrm{~B}$, ALT7B is $3.6 \mathrm{~g} \mathrm{~B}$, and ALT7C is $4.6 \mathrm{~g} \mathrm{~B}$. As shown in Fig 12.2.2, ALT7A and ALT7B results are comparable to each other and involve a wide margin to the SL over the fuel cycle. The ALT7C case shows a shift in margin to the SL after day 5 of the cycle, similar to the ALT6C behavior shown in Fig. 11.2.3.

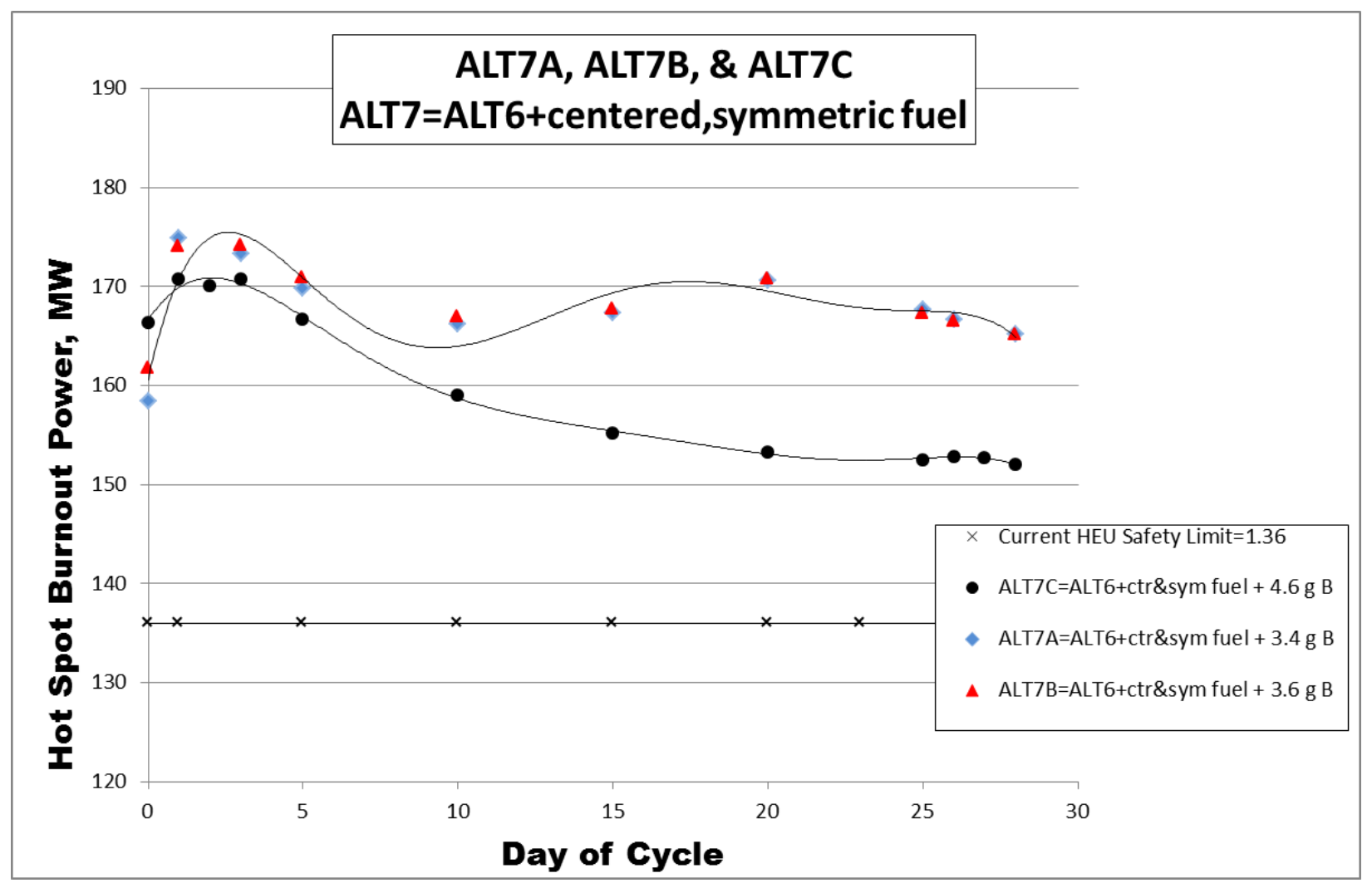

Fig. 12.2.2. Hot spot burnout power versus day in the cycle for Alternatives 7A, 7B, and 7C. 
Table 12.2 shows that the ALT7A and ALT7B hot spot locations are at the core center nodes for most of the cycle, except for the BOC, which has the hot spot at the inner fuel element lower end. For ALT7C, the core hot spot location is at the inner fuel element lower end for most of the cycle. Only on day 1 , which has peak xenon conditions, is the hot spot located at the core mid-region nodes. The minimum hot spot burnout heat fluxes of 158.5, 161.7, and $152 \mathrm{MW}$, respectively, are at the BOC for cases 7A and 7B, and at the EOC for case 7C. The hot spot location is the same for cases 7A, 7B, and 7C, occurring in the inner element at radial node $8(\mathrm{r}=9.00 \mathrm{~cm})$ and axial node $40(\mathrm{z}=50.55 \mathrm{~cm})$.

Table 12.2. Burnout power versus day in cycle and location of node at burnout conditions for ALT7A, ALT7B, and ALT7C

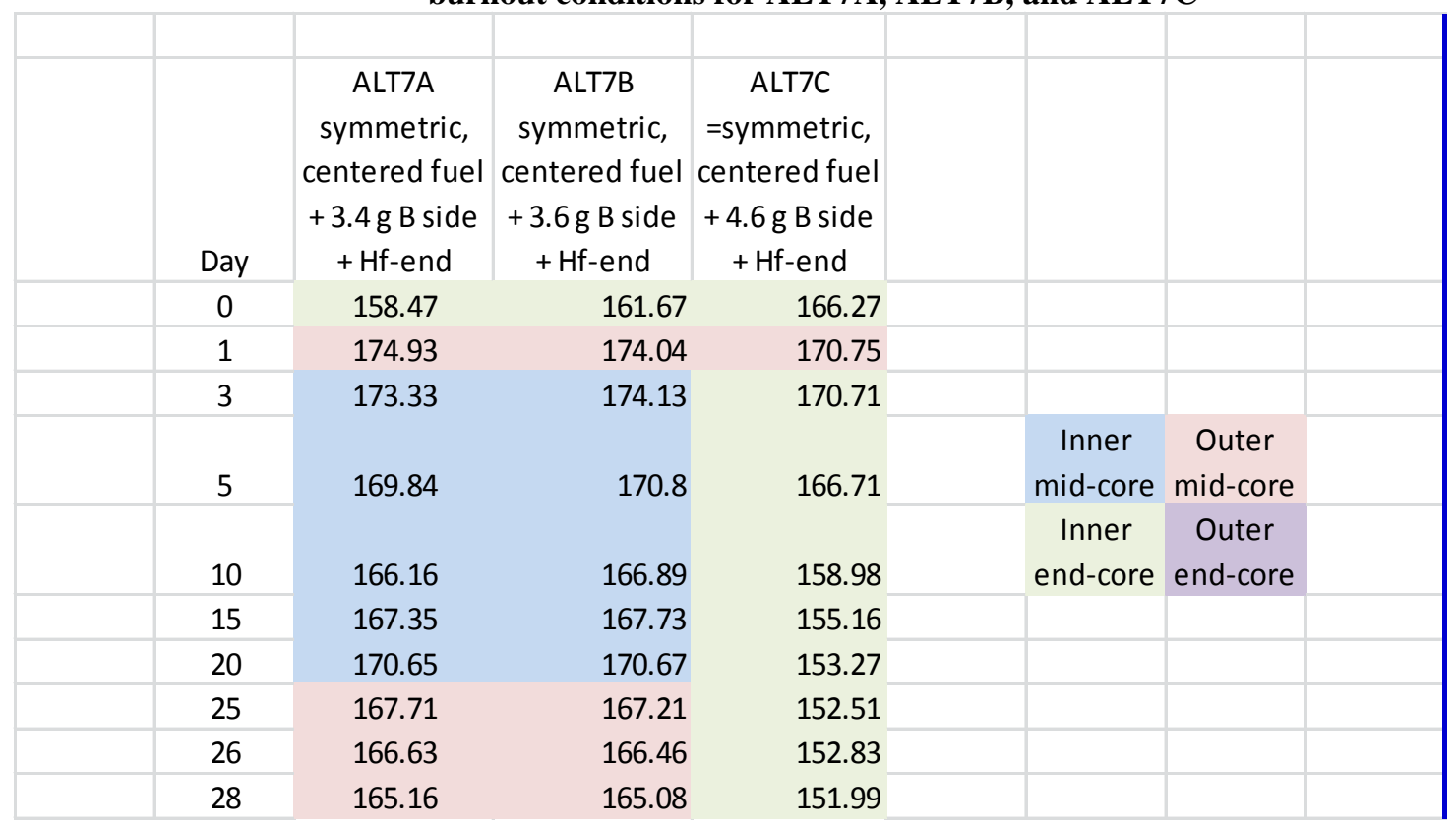

\subsection{TRANSIENT TH WITH SAFETY CASE ASSUMPTIONS (USING RELAP)}

The worst case Small Break Loss of Coolant Accident (SBLOCA) and the Loss of Off-Site AC Power (LOOP) events were executed with RELAP while modeling the Alternate-7 LEU fuel design. In addition to the assumptions already discussed in Section 3.4, assumptions specific to the LEU Alt-7 fuel design are below:

1. The hot channel gap widths of the inner and outer fuel elements are 38.4 mils and 38.5 mils, respectively.

Justification: These values were generated based on results from the HSSHTC code discussed in Section 12.2. For comparison, the hot channel gap widths for the LEU Reference fuel design for the inner and outer fuel elements are 38.8 mils and 38.5 mils, respectively.

2. The axial power peaking factors, local power peaking factors, and internal source multipliers for the average fuel channels, hot channels, and hot spot locations for the inner and outer fuel elements were revised to be consistent with the LEU Alternate-7 fuel design. Tables 12.3.1, 12.3.2, and 12.3.3 correspond to Tables 9, 10, and 11 found in INT-154[6] for the current HEU fuel design. 
Table 12.3.1. Normalized HFIR fuel axial power peaking factors for LEU Alternate-7 fuel design.

\begin{tabular}{|c|c|c|c|c|}
\hline & \multicolumn{4}{|c|}{ Peaking Factors } \\
\hline & \multicolumn{2}{|c|}{ Inner Element } & \multicolumn{2}{|c|}{ Outer Element } \\
\hline $\begin{array}{l}\text { Axial Location } \\
\text { (Top to Bottom) }\end{array}$ & $\begin{array}{l}\text { Average } \\
\text { Fuel }\end{array}$ & Hot Fuel & $\begin{array}{c}\text { Average } \\
\text { Fuel }\end{array}$ & Hot Fuel \\
\hline$N$ & $\left(P F_{A v g}{ }^{\text {Inner }}\right)_{N}$ & $\left(P F_{\text {Hot }}{ }^{\text {Inner }}\right)_{N}$ & $\left(P F_{\text {Avg }}{ }^{\text {outer }}\right)_{N}$ & $\left(P F_{\text {Hot }}^{\text {Outer }}\right)_{N}$ \\
\hline 1 & 0.0809 & 0.0163 & 0.0643 & 0.0144 \\
\hline 2 & 1.029882554 & 1.00622201 & 1.010145772 & 0.92831855 \\
\hline 3 & 1.29448845 & 1.08238843 & 1.30489772 & 1.10400823 \\
\hline 4 & 1.408536568 & 1.29075581 & 1.419869724 & 1.30241857 \\
\hline 5 & 1.262601585 & 1.41327668 & 1.274727856 & 1.41619621 \\
\hline 6 & 0.923588245 & 1.44659385 & 0.927007223 & 1.447702 \\
\hline 7 & 0.0809 & 1.39272402 & 0.0624 & 1.39935634 \\
\hline 8 & & 1.25216736 & & 1.27095659 \\
\hline 9 & & 1.03034689 & & 1.06262598 \\
\hline 10 & & 0.85754967 & & 0.84359474 \\
\hline 11 & & 0.0149 & & 0.0133 \\
\hline Entrance (local) & & 1.576 & & 1.255 \\
\hline Exit (local) & & 1.085 & & 0.975 \\
\hline
\end{tabular}

Table 12.3.2. Hot fuel regions and local power peaking factors for LEU Alternate-7 fuel design Table 10. Hot fuel regions and local power peaking factors

\begin{tabular}{|c|c|c|c|c|}
\hline \multicolumn{5}{|l|}{ Peaking Factors } \\
\hline & Hot Fuel & & & \\
\hline Power Distribution Uncertainty & 1.199 & & & \\
\hline Hot Streak ("U24" in C-HFIR-2007-005) & 1.06 & & & \\
\hline Fuel plate heated length uncertainty & 1.025 & & & \\
\hline \multirow{2}{*}{ Total (Multiplicative) } & $P F_{\text {Hot }}^{\text {Total }}$ & & & \\
\hline & 1.3027 & & & \\
\hline & & & & \\
\hline & \multicolumn{2}{|c|}{ Local - Active } & \multicolumn{2}{|c|}{ Entrance and Exit } \\
\hline & Inner & Outer & Inner & Outer \\
\hline Power Distribution Uncertainty & 1.199 & 1.199 & 1.199 & 1.199 \\
\hline Nonbond & 1 & 1 & 1 & 1 \\
\hline Fuel Segregation ("U18/U19" in C-HFIR-2007-005) & 1.27 & 1.27 & 1 & 1 \\
\hline Fuel Beyond Axial Boundary & & & 1.227 & 1.255 \\
\hline \multirow{2}{*}{ Total (Multiplicative) } & $P F_{\text {Local }}^{\text {Inner }}$ & $P F_{\text {Local }}^{\text {Outer }}$ & $P F_{\text {Loc-Entr/Exit }}^{\text {Inner }}$ & $\mathrm{PF}_{\text {Loc-Ent/Exit }}$ Outer \\
\hline & 1.52 & 1.52 & 1.47 & 1.50 \\
\hline
\end{tabular}


Table 12.3.3. Internal source multipliers for LEU Alternate-7 fuel design

Table 11. Internal Source Multipliers = Pf (area ratio $) *$ P1\% (1.01 or 0.99) * Paxial $($ Table 9) * Ppower $($ Table 10)

\begin{tabular}{|c|c|c|c|c|c|c|c|}
\hline Average Fuel & & & & & & & \\
\hline $\begin{array}{l}\text { Axial Location } \\
\text { (Top to Bottom) }\end{array}$ & Node (in) & Inner+1\% & Inner-1\% & Outer $+1 \%$ & Outer-1\% & & \\
\hline 1 & 2 & 1.15E-03 & 1.13E-03 & $1.78 \mathrm{E}-03$ & $1.75 \mathrm{E}-03$ & & \\
\hline 2 & 4 & 2.93E-02 & 2.87E-02 & 5.59E-02 & $5.48 \mathrm{E}-02$ & & \\
\hline 3 & 4 & $3.69 \mathrm{E}-02$ & $3.61 \mathrm{E}-02$ & $7.23 \mathrm{E}-02$ & $7.08 \mathrm{E}-02$ & & \\
\hline 4 & 4 & $4.01 \mathrm{E}-02$ & 3.93E-02 & $7.86 \mathrm{E}-02$ & $7.71 \mathrm{E}-02$ & & \\
\hline 5 & 4 & 3.59E-02 & $3.52 E-02$ & $7.06 \mathrm{E}-02$ & $6.92 \mathrm{E}-02$ & & \\
\hline 6 & 4 & 2.63E-02 & $2.58 \mathrm{E}-02$ & $5.13 \mathrm{E}-02$ & $5.03 \mathrm{E}-02$ & & \\
\hline 7 & 2 & 1.15E-03 & 1.13E-03 & $1.73 \mathrm{E}-03$ & 1.69E-03 & & \\
\hline & & & & & & & \\
\hline & & Hot & Fuel & Hot $\mathrm{Sp}$ & pots & & \\
\hline Axial Location & Length (in.) & Inner & Outer & Inner Local & $\begin{array}{l}\text { Outer } \\
\text { Local }\end{array}$ & & \\
\hline $\mathrm{N}$ & $\mathrm{L}_{\mathrm{N}}$ & ISM $_{\text {Hot }}{ }^{\text {Inner }}$ & ISM $_{\text {Hot }}$ Outer & ISM Local & ISM Local $_{\text {Luter }}$ & & \\
\hline 1 & 2.00 & $3.52 E-06$ & $2.79 E-06$ & $4.61 \mathrm{E}-06$ & $3.38 \mathrm{E}-06$ & & \\
\hline 2 & 2.22 & $2.42 \mathrm{E}-04$ & $2.00 \mathrm{E}-04$ & $2.82 \mathrm{E}-06$ & $2.34 \mathrm{E}-06$ & & \\
\hline 3 & 2.22 & 2.60E-04 & 2.38E-04 & $3.04 \mathrm{E}-06$ & 2.78E-06 & & \\
\hline 4 & 2.22 & $3.10 \mathrm{E}-04$ & $2.81 E-04$ & $3.62 E-06$ & $3.28 \mathrm{E}-06$ & & \\
\hline 5 & 2.22 & 3.39E-04 & 3.05E-04 & $3.96 \mathrm{E}-06$ & 3.57E-06 & & \\
\hline 6 & 2.22 & 3.47E-04 & $3.12 E-04$ & 4.06E-06 & $3.65 \mathrm{E}-06$ & & \\
\hline 7 & 2.22 & $3.34 \mathrm{E}-04$ & $3.02 E-04$ & $3.91 E-06$ & 3.53E-06 & & \\
\hline 8 & 2.22 & $3.01 E-04$ & $2.74 \mathrm{E}-04$ & 3.51E-06 & $3.20 \mathrm{E}-06$ & & \\
\hline 9 & 2.22 & 2.47E-04 & 2.29E-04 & 2.89E-06 & 2.68E-06 & & \\
\hline 10 & 2.22 & $2.06 E-04$ & $1.82 E-04$ & $2.41 E-06$ & 2.13E-06 & & \\
\hline 11 & 2.00 & $3.22 \mathrm{E}-06$ & $2.58 \mathrm{E}-06$ & $3.18 \mathrm{E}-06$ & $2.62 E-06$ & & \\
\hline Ltotal $=$ & 24.00 & & & & & & \\
\hline
\end{tabular}

Justification: These values were generated based on results from the HSSHTC discussed in Section 12.2.

\subsubsection{Results for the Worst-Case SBLOCA Event}

The reactor will automatically shut down on a low primary pressure scram signal within $0.17 \mathrm{~s}$ of the initiation of a small break LOCA occurring at the cold leg inlet. Results show that the most limiting hot spot location for the Alt-7 LEU fuel design for this event occurs in "Node-11" which is at the very bottom of the fuel. This is also the same location of the most limiting hot spot for HEU fuel.

Although the SBLOCA event is categorized as an infrequent event, the consequences of this event have historically met the acceptance criteria for a moderate frequency event. As such, the maximum fraction of incipient boiling heat flux for the inner and outer elements using the Bergles-Rohsenow/Dittus-Boelter correlation and the Bergles-Rohsenow/Hausen correlation are shown below for Nodes 07 and 11 for the Alt-7 LEU fuel design. For comparison, results for the Reference LEU fuel design and the current HEU fuel design at 85 MW for Hot Spot - Nodes 07 and 11 can be found in Section 4.3.1. 
Figure 12.3.1 shows the peak maximum fraction of incipient boiling heat flux (MFIBHF) for the LEU Alternate-7 fuel design using the Bergles-Rohsenow/Dittus-Boelter correlation is 0.71 and 0.65 for the inner and outer fuel worst Hot Spot - Node 11, respectively. The peak MFIBHF for this case as determined via the Bergles- Rohsenow/Hausen correlation is predicted to be larger at 0.78 and 0.71 for the inner and outer fuel worst Hot Spot - Node 11, respectively, than was predicted using the BerglesRohsenow/Dittus-Boelter correlation. It is expected that the actual fraction of incipient boiling heat flux that would occur in the hot inner and outer fuel channels is within the range predicted by these two correlations. As such, the peak MFIBHF remains under the limit of 1.0 indicating that boiling in the hot channel is not expected to occur and, thus, no fuel damage is predicted. Results for Node-07 show that the MFIBHF for both the inner and outer element using both correlations remains less than 1.0 at all times, with a peak value of 0.53 . 
Small Break LOCA - Worst Case
Max. Fraction of Incipient Boiling Heat Flux at Hot Spot - 07 (About 2/3 from Top of Fuel) Hot Spot - 07 is worst location for LEU Reference Design

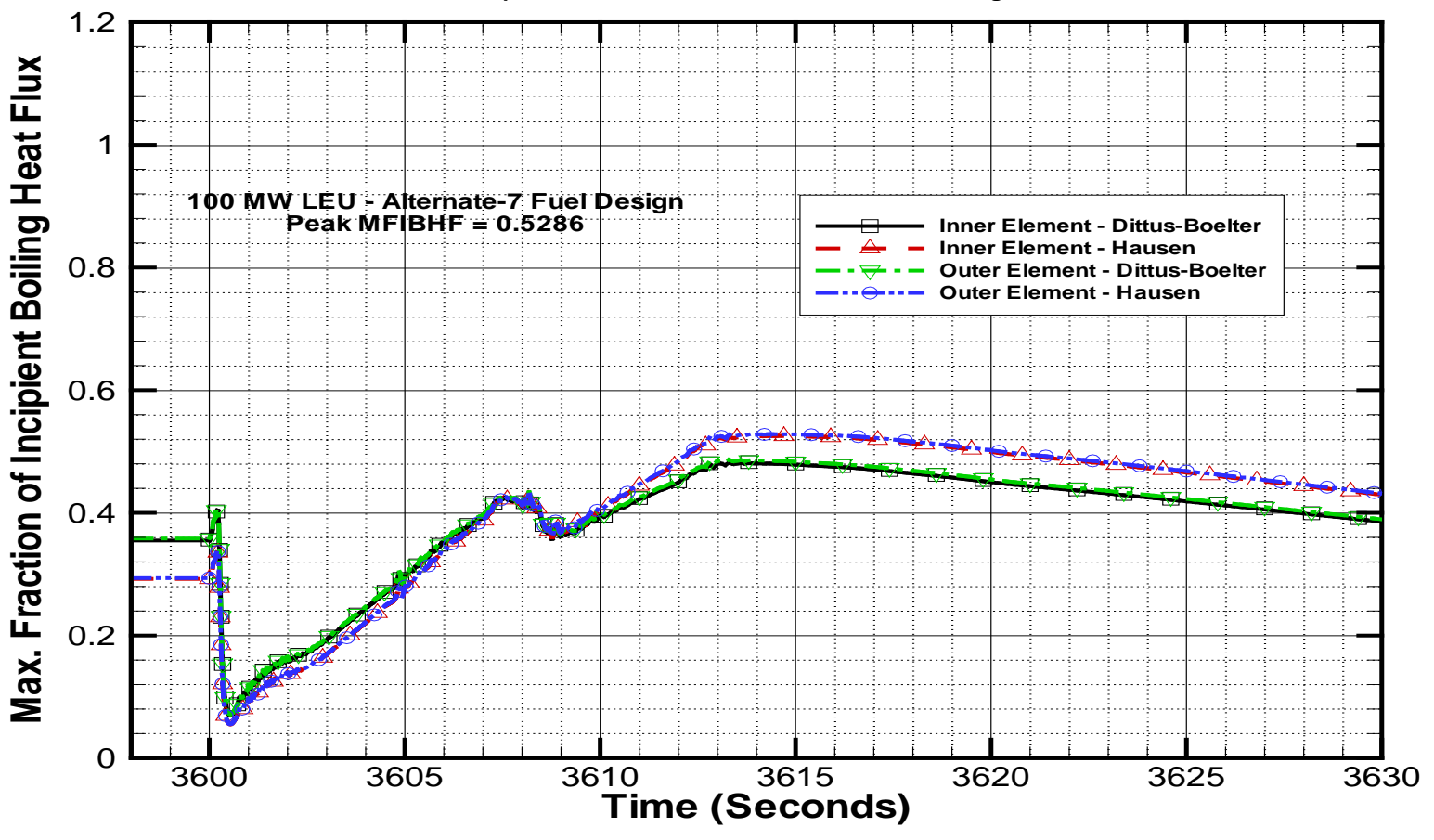

Small Break LOCA - Worst Case

Hot Spot - 11 is worst location for Lex at Hot Spot - 11 (Bottom of Fuel)

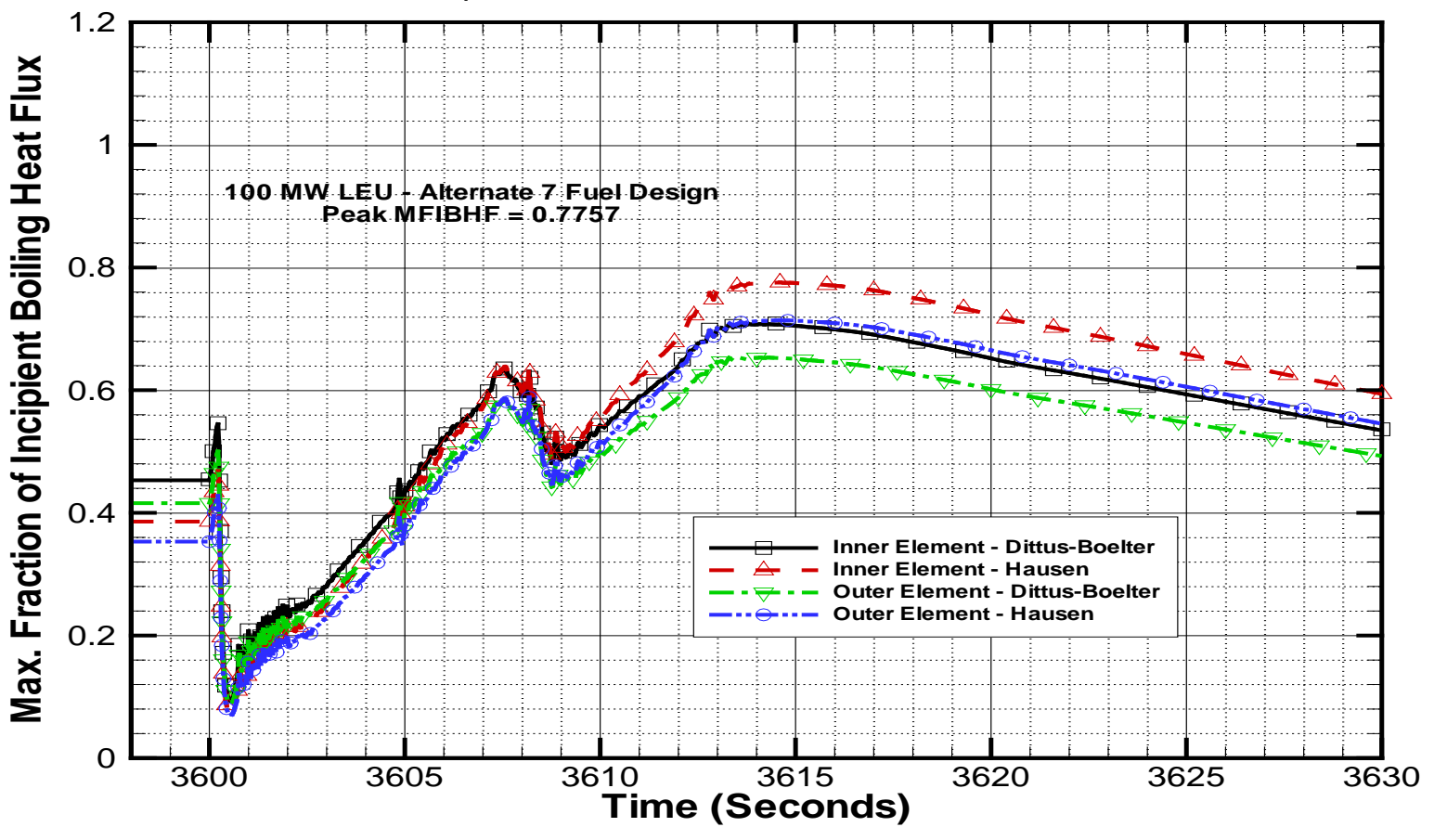

Fig. 12.3.1. Fraction of incipient boiling heat flux data for worst case 2.0 -in. diameter break in the HFIR primary coolant system pressure boundary for LEU “Alt-7” fuel design at $100 \mathrm{MW}$. 
Figure 12.3.2 shows the fuel centerline and cladding temperatures for the inner and outer fuel elements, respectively for the LEU Alternate 7 fuel design. For the most limiting Node- 11 at the bottom of the fuel, the peak cladding and peak centerline temperatures are 162.5 C and 288.7 C, respectively, in the inner element. For Node-07, the peak cladding and peak centerline temperatures are less at $143.3 \mathrm{C}$ and 256.9 $\mathrm{C}$, respectively, in the outer element. These peak temperatures occur within the first 0.2 second of the onset of the event. This figure shows that significant margin exists to cladding damage and fuel melt for the LEU Alternate 7 fuel design.

Similar to the current HEU and LEU Reference fuel designs, the temperatures decrease immediately after reactor scram. In comparing the LEU Reference fuel design to the LEU Alternate 7 design, the peak centerline temperature at the hottest locations is $\sim 7 \mathrm{C}$ hotter for the Alternate $7 \mathrm{design}$, while the peak cladding temperature is $\sim 11 \mathrm{C}$ hotter for the Alternate 7 design. In comparing the LEU Alternate 7 fuel design to the current HEU fuel design, the peak centerline temperature at the hottest location is $\sim 6 \mathrm{C}$ hotter than the HEU design, while the peak cladding temperature is 15 C cooler than the HEU design. 
Small Break LOCA - Worst Case

Fuel Centerline and Cladding Temperatures at Hot Spot - 07 (About 2/3 from Top of Fuel) Hot Spot - 07 is worst location for LEU Reference Design

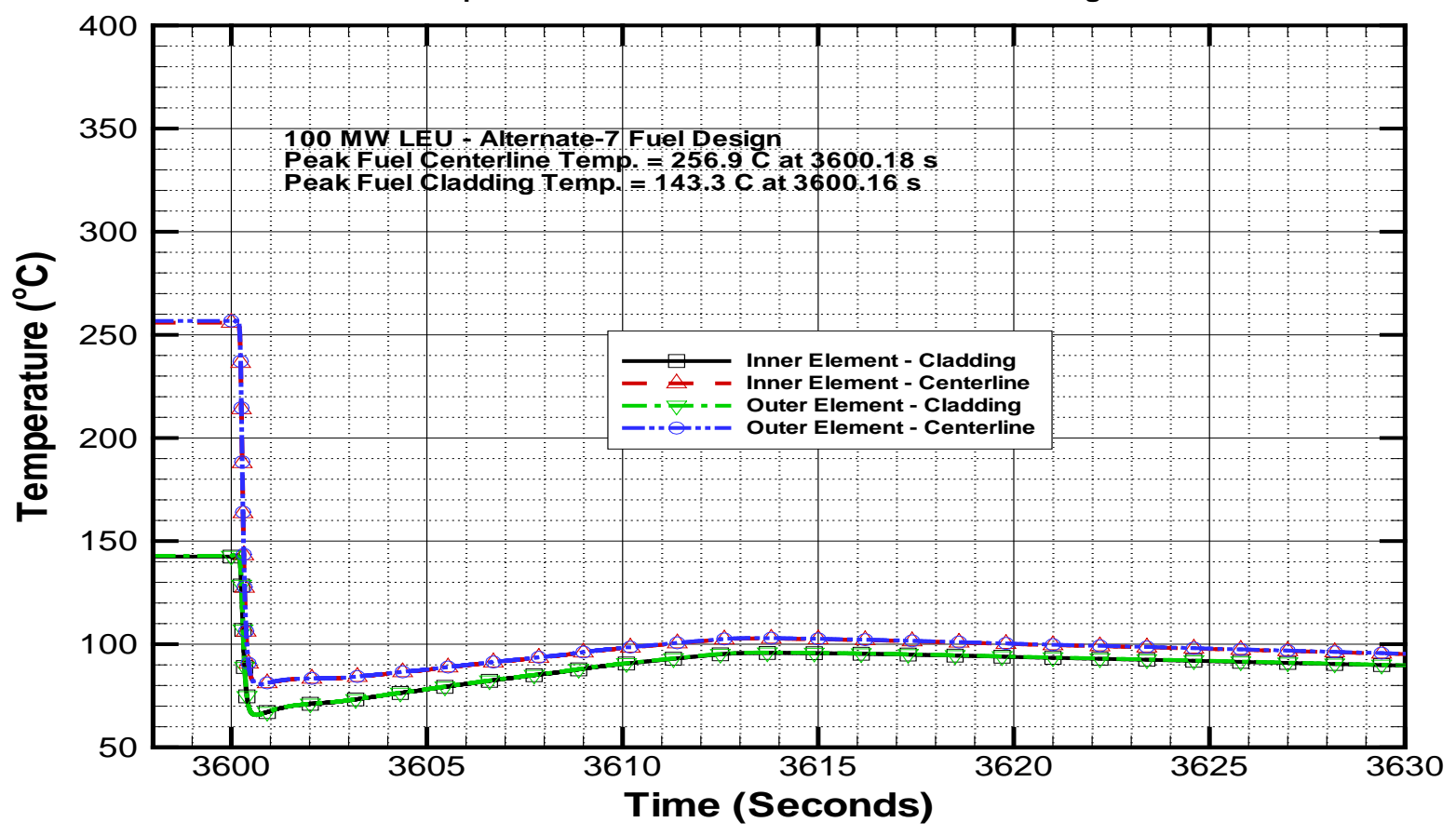

Small Break LOCA - Worst Case

Fuel Centerline and Cladding Temperatures at Hot Spot - 11 (Bottom of Fuel) Hot Spot - 11 is worst location for LEU "Alt-7" Fuel and HEU Fuel

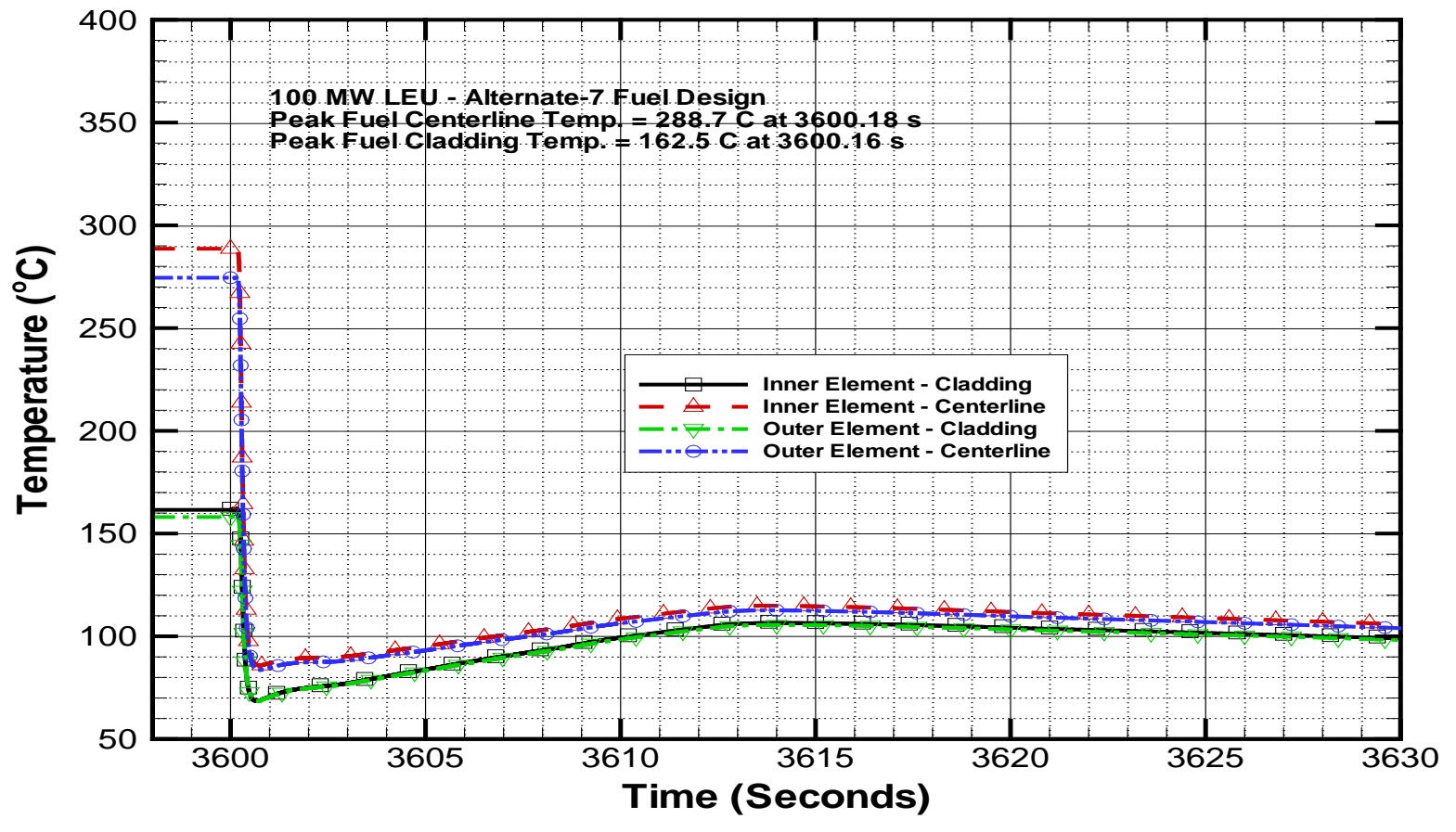

Fig. 12.3.2. Fuel temperatures for worst case 2.0-in. diameter break in the HFIR primary coolant system pressure boundary for LEU “Alt-7” fuel design at $100 \mathrm{MW}$. 


\subsubsection{Results for the LOOP Event}

The reactor will automatically shut down on a flux-to-flow scram signal within $1.28 \mathrm{~s}$ of the initiation of a loss of off-site AC power. Results show that the most limiting hot spot location for the Alt-7 LEU fuel design for this event occurs in "Node-01" which is at the very top of the fuel. It is noted that the second worst hot spot for this LEU fuel design is Node-11 which is the most limiting hot channel node for the current HEU fuel design.

The maximum fraction of incipient boiling heat flux for the inner and outer elements using the BerglesRohsenow/Dittus-Boelter correlation and the Bergles-Rohsenow/Hausen correlation are shown below in Fig. 12.3.3 for Nodes 01 and 11 for the LEU “Alt-7” fuel design. For comparison, results for the Reference LEU fuel design and the current HEU fuel design at 85 MW for Hot Spot - Nodes 07 and 11 can be found in Section 4.3.2. For this event, there are two MFIBHF peaks that must be examined. One occurs within $\sim 2 \mathrm{~s}$ of the onset of the LOOP, while the other peak occurs longer term around $50 \mathrm{~s}$ after the onset of the LOOP. As discussed in Section 3.4, these two correlations for MFIBHF are applicable for lower flow conditions such as for times after $\sim 3 \mathrm{~s}$ when the primary coolant flow rate is below $\sim 8,000$ gpm. For times between 0 and $3 \mathrm{~s}$ when the primary coolant flow rate is above $\sim 8,000 \mathrm{gpm}$, it is acceptable to have a MFIBHF greater than 1.0 as long as the hot spot heat flux remains below both the Costa flow excursion heat flux and the Gambill critical heat flux. However, if the MFIBHF does not exceed 1.0 at any time, then it can be concluded that boiling does not occur in the hot channel. 
Loss of Off-Site Power (LOOP)
Max. Fraction of Incipient Boiling Heat Flux at Hot Spot - 01 (Top of Fuel) Hot Spot - 01 is worst location for Alt-7 Design

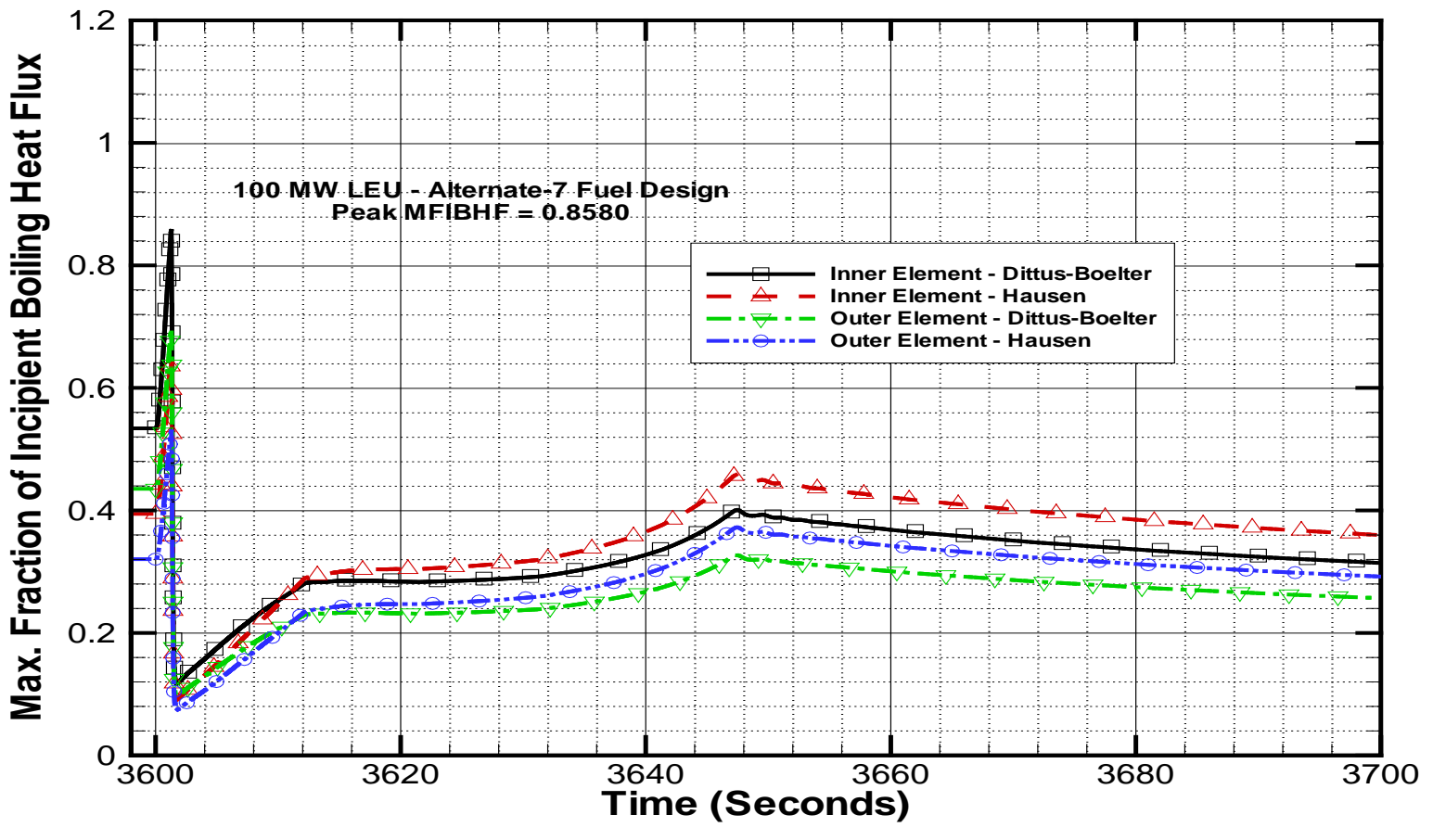

Loss of Off-Site Power (LOOP)

11 (Bottom of Fuel) Hot Spot - 11 is worst location for HEU Fuel

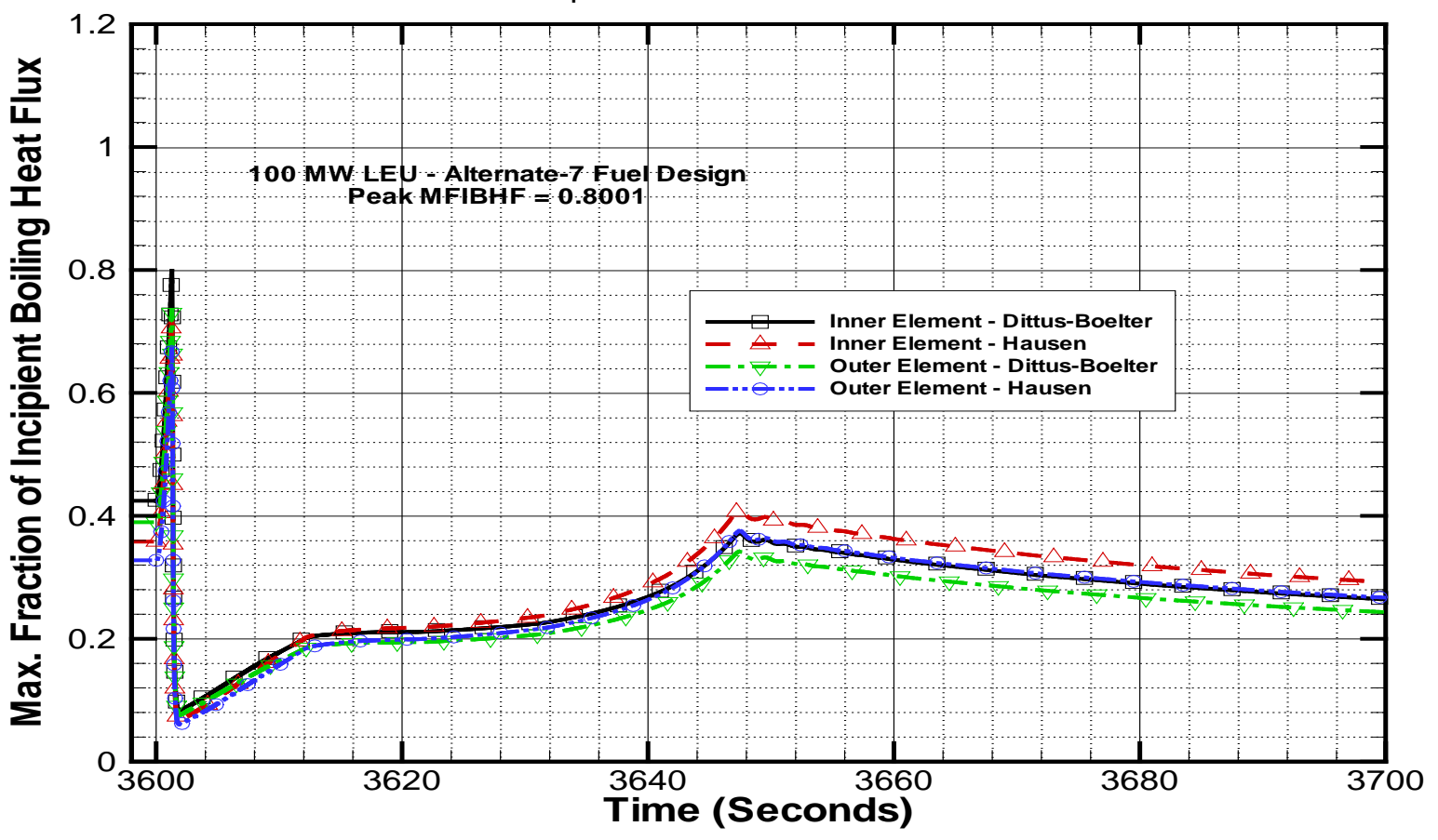

Fig. 12.3.3. Fraction of incipient boiling heat flux data for the loss of off-site ac power (LOOP) event for LEU “Alt-7” fuel design at $100 \mathrm{MW}$. 
Figure. 12.3.3 shows the maximum fraction of incipient boiling heat flux in the worst hot channel location of Node-01 (very top of fuel) using the Bergles-Rohsenow/Dittus-Boelter correlation is predicted to be 0.86 and 0.70 for the inner and outer fuel hot spots, respectively. The maximum fraction of incipient boiling heat flux using the Bergles-Rohsenow/Hausen correlation is predicted to be 0.65 and 0.53 for the inner and outer fuel hot spots, respectively. These maximum values occur at 1.3 seconds into the event. Longer term, when primary flow is provided by two pony motors, the maximum fraction of incipient boiling heat flux occurs around 50 seconds and is 0.40 and 0.33 as predicted by the Bergles-Rohsenow/ Dittus-Boelter correlation and 0.46 and 0.37 as predicted by the Bergles-Rohsenow/Hausen correlation, for the inner and outer fuel hot spots at Node 01, respectively. It is expected that the actual fraction of incipient boiling heat flux that would occur in the hot inner and outer fuel channels is within the range predicted by these two correlations. For Node-11 (very bottom of fuel) which is the worst hot channel location for the current HEU fuel design, the MFIBHF for both fuel elements and both correlations remains well below the limit of 1.0. At no time during the LOOP event is boiling expected to occur in the hot channel. As such, the acceptance criteria for this case are met.

Figure 12.3.4 shows the fuel centerline and cladding temperatures for the inner and outer fuel elements, respectively for the LEU Alternate 7 fuel design. For the most limiting Node-01 at the top of the fuel, the peak cladding and peak centerline temperatures are 205.8 C and 378.8 C, respectively, in the inner element. For Node-11, the peak cladding and peak centerline temperatures are less at $210.4 \mathrm{C}$ and $331.1 \mathrm{C}$, respectively, in the inner element. These peak temperatures occur within the first 1.3 second of the onset of the event. This figure shows that significant margin exists to cladding damage and fuel melt for the LEU Alternate 7 fuel design.

Similar to the current HEU and LEU Reference fuel designs, the temperatures decrease immediately after reactor scram. In comparing the LEU Reference fuel design to the LEU Alternate 7 design, the peak centerline temperature at the hottest locations is $\sim 60 \mathrm{C}$ hotter for the Alternate 7 design, while the peak cladding temperature is $\sim 12 \mathrm{C}$ hotter for the Alternate 7 design. In comparing the LEU Alternate 7 fuel design to the current HEU fuel design, the peak centerline temperature at the hottest locations is $\sim 46 \mathrm{C}$ hotter than the HEU design, while the peak cladding temperature is $\sim 22 \mathrm{C}$ cooler than the HEU design. 


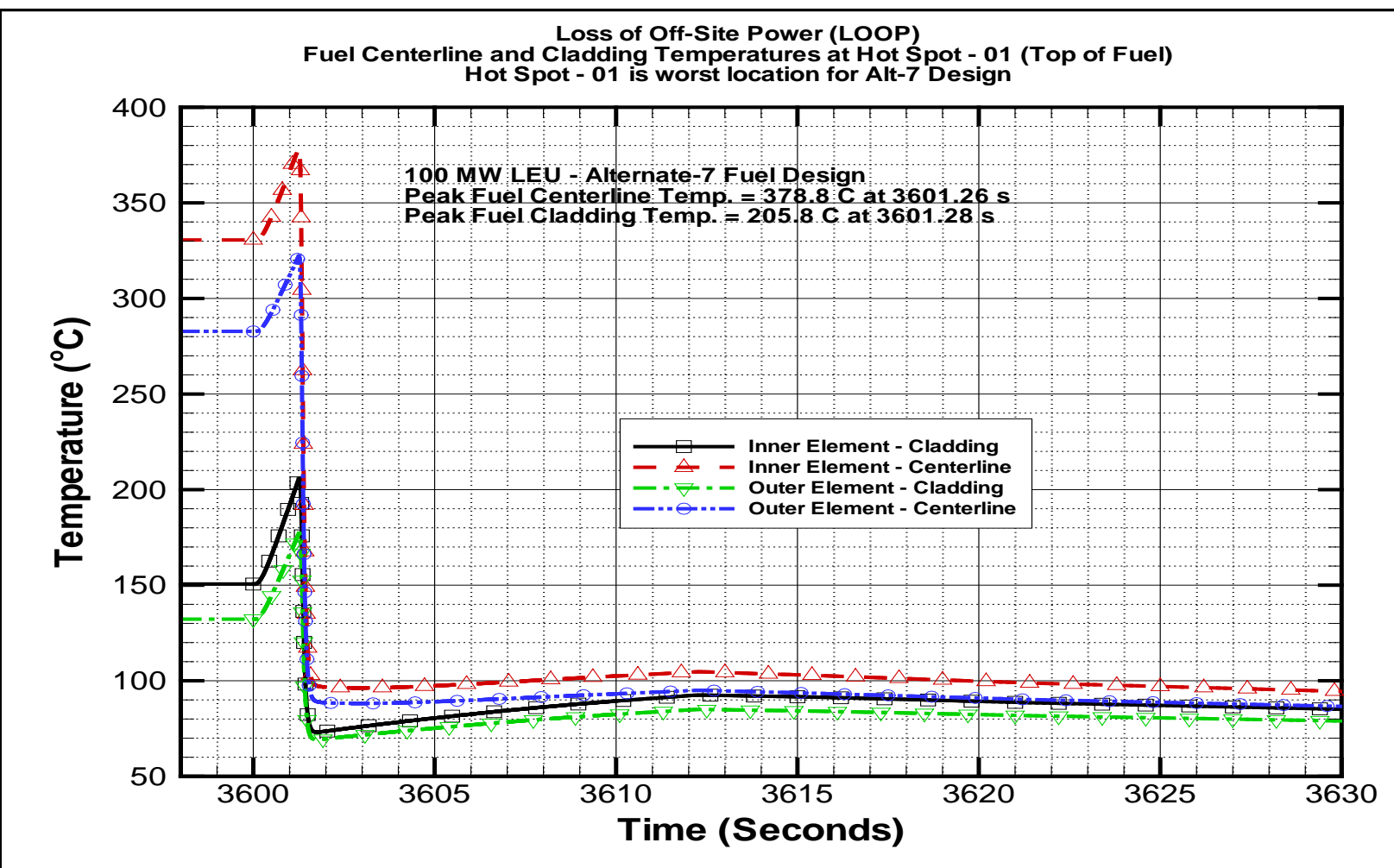

Loss of Off-Site Power (LOOP)

Fuel Centerline and Cladding Temperatures at Hot Spot - 11 (Bottom of Fuel) Hot Spot - 11 is worst location for HEU Fuel

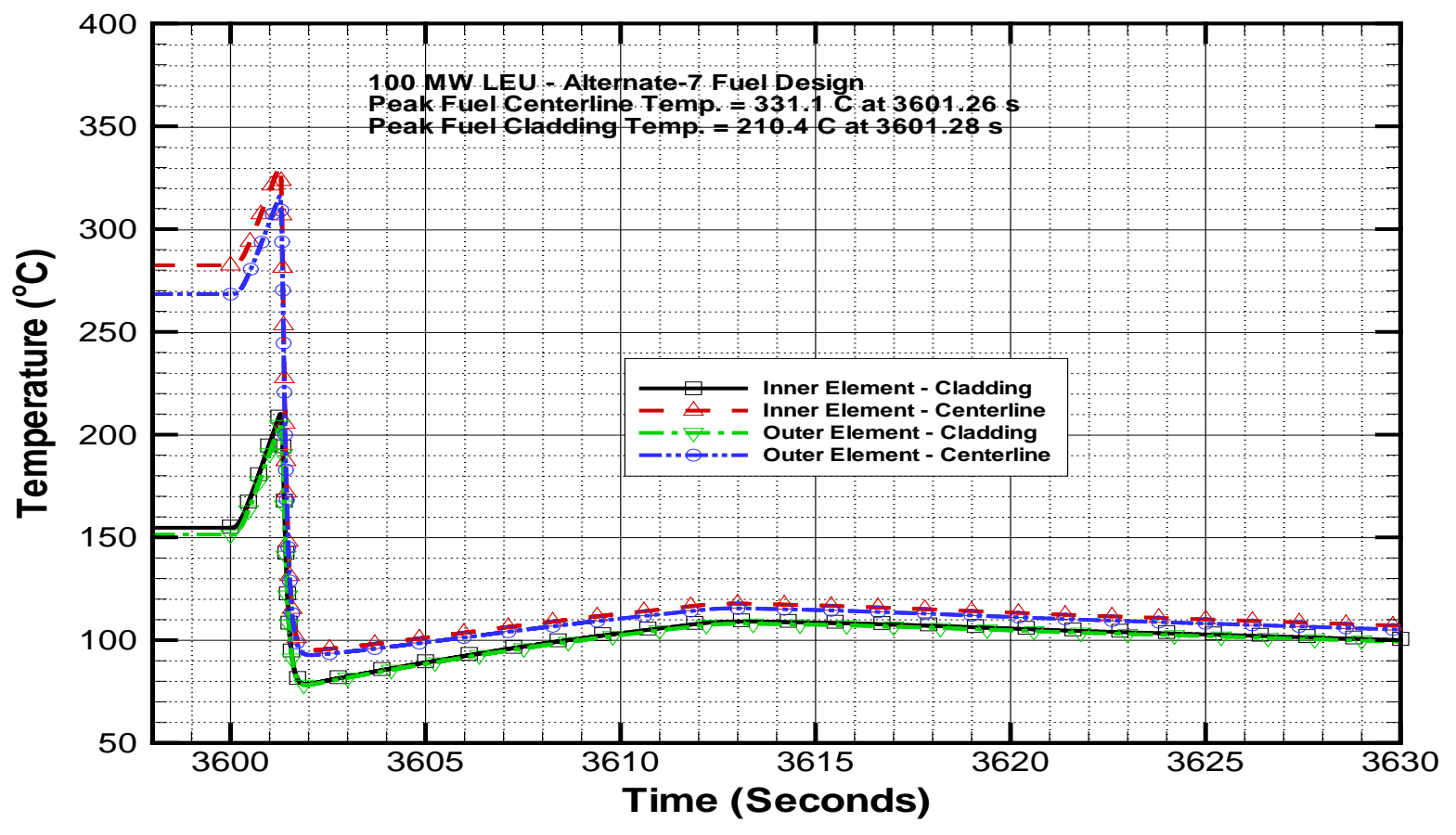

Fig. 12.3.4. Fuel temperatures for the loss of off-site ac power (LOOP) event for LEU “Alt-7” fuel design at 100 MW. 


\subsection{STEADY-STATE TH WITH NOMINAL ASSUMPTIONS (USING COMSOL)}

In the Alternate 7 design, a radially contoured and symmetric LEU fuel zone is placed at the plate's centerline through its thickness (see Fig. 12.4.1) leading to a design in which the fuel zone is equidistant from both the concave and convex clad surfaces. This design essentially eliminates the "hot-side" and "cold-side" distinction between the two clad surfaces. In addition, there is no axial contouring (no "toe") at the longitudinal bottom end of the fuel meat. Instead, there is a permanent Hf absorber located just below the bottom end of the fuel zone to provide peak reduction effects similar to a geometric "toe". In addition, there is also a B absorber distributed (4.6 g total quantity) in the IFE side plates.

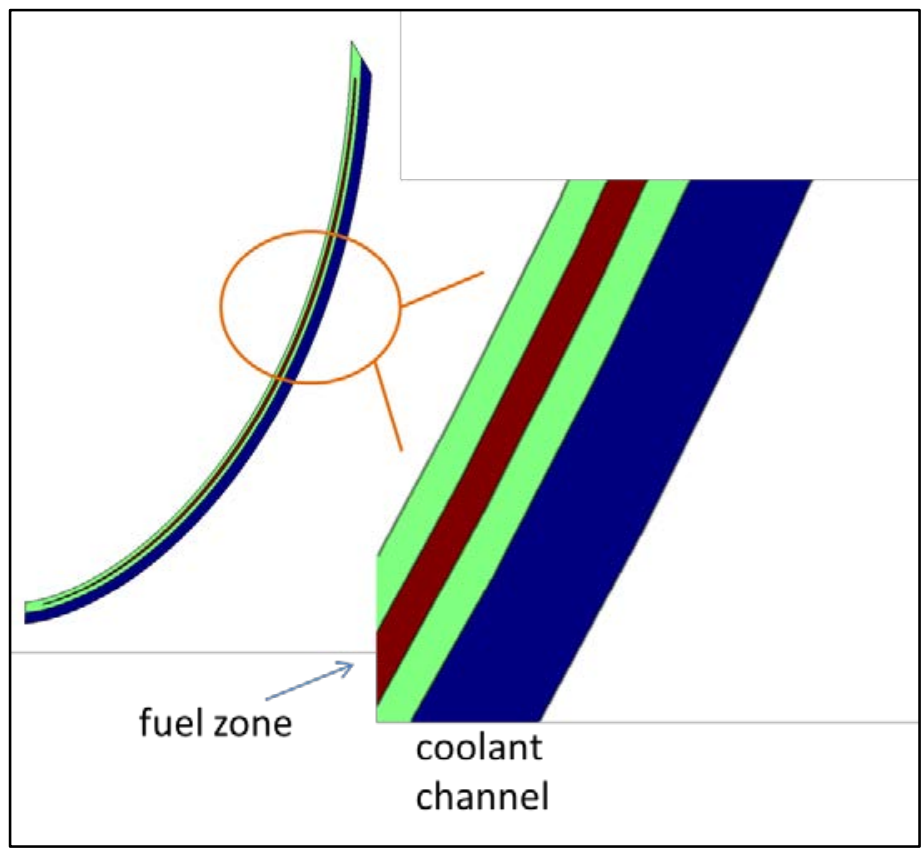

Fig. 12.4.1. Centered and symmetric fuel zone as modeled in COMSOL.

Relative fission densities for this alternate design were obtained from corresponding MCNP simulations at the beginning and end of reactor cycles. These fission densities were then converted and scaled for 100 MW nominal operating conditions of HFIR. First-order smooth interpolated values for the volumetric heat source are provided to the fuel zone region in the COMSOL model in the units of $\mathrm{kW} / \mathrm{cm}^{3}$. The heatsource terms are plotted in Fig. 12.4.2 for both the IFE and OFE at the BOC and EOC. The maximum heat source in each plate and its location is also shown in the figures by a 'max' • indicator. Notice that the effect of the permanent $\mathrm{Hf}$ absorber on the volumetric heat source distribution significantly reduces the local peaking at the bottom of the fuel meat. 


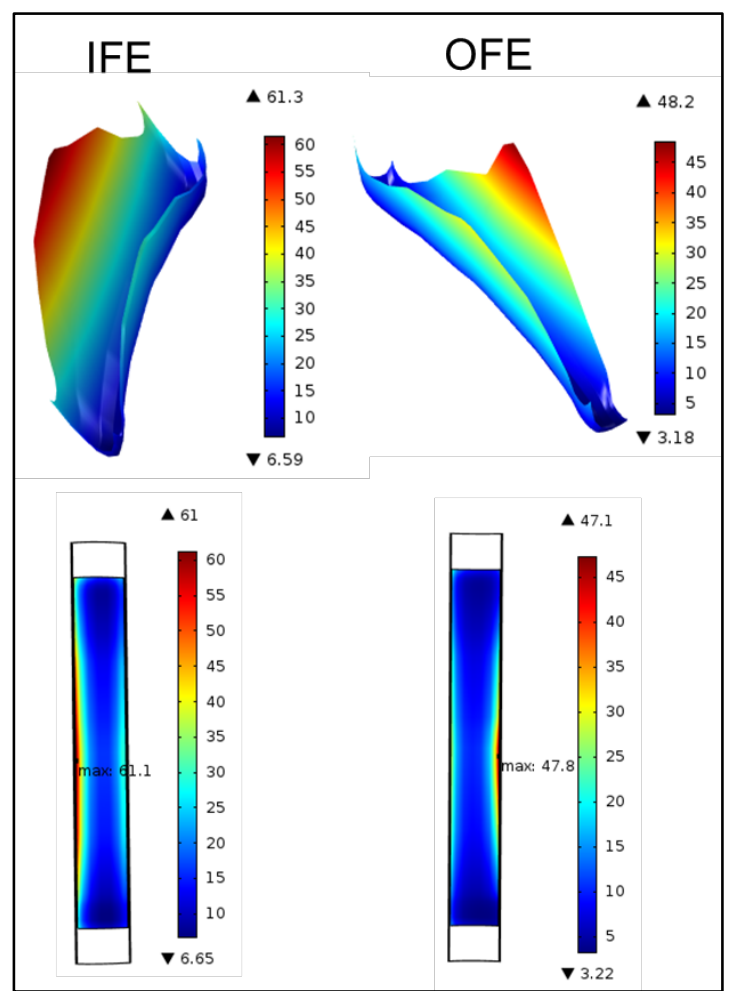

(a) beginning of cycle, BOC

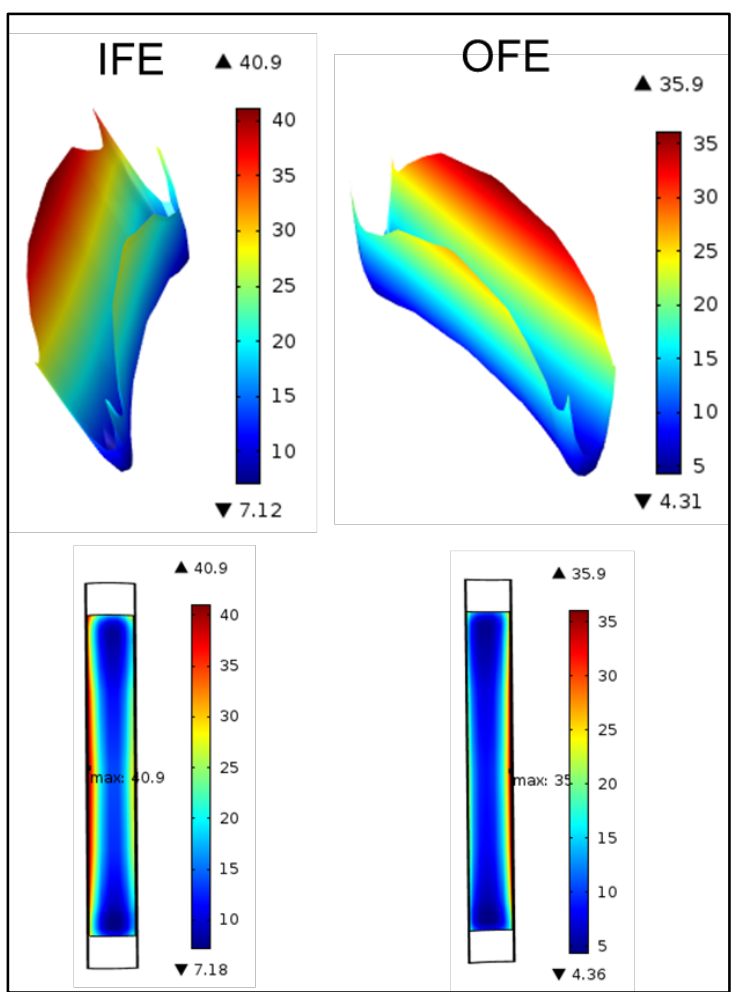

(b) end of cycle, EOC

Fig. 12.4.2. Volumetric power density (in $\mathrm{kW} / \mathrm{cm}^{3}$ ) of the Alternate $7 \mathrm{LEU}$ fuel design for 100 MW nominal HFIR operating conditions (see Fig. 4.4.1 to compare with the corresponding reference $L E U$ fuel design).

For both the IFE and OFE fuel plates, the volumetric heat source peaks at the core midplane $(\mathrm{z}=12 \mathrm{in})$. For the IFE, the peaking occurs near its inner radial edge whereas for the OFE, peaking occurs at its outer radial edge for both the BOC and EOC cases. For the IFE, the ratio of its local peaks at the inner and outer radial edges is 2.15 at the BOC and 1.47 at the EOC. For the OFE, the ratio of its local peaks at the outer and inner radial edges is 1.58 at the BOC and 1.36 at the EOC. Compared with the volumetric heat source distributions in Fig. 5.4.1 for the reference LEU fuel, the Alternate 7 distributions are very similar in profile and magnitude.

Three-dimensional surface plots for the clad surface temperatures (in ${ }^{\circ} \mathrm{C}$ ) are shown in Fig. 12.4.3 for both the IFE and OFE at the BOC and EOC. Note that due to the centerline symmetry of the fuel meat, both the concave and convex clad surfaces now have almost identical temperature distributions. 


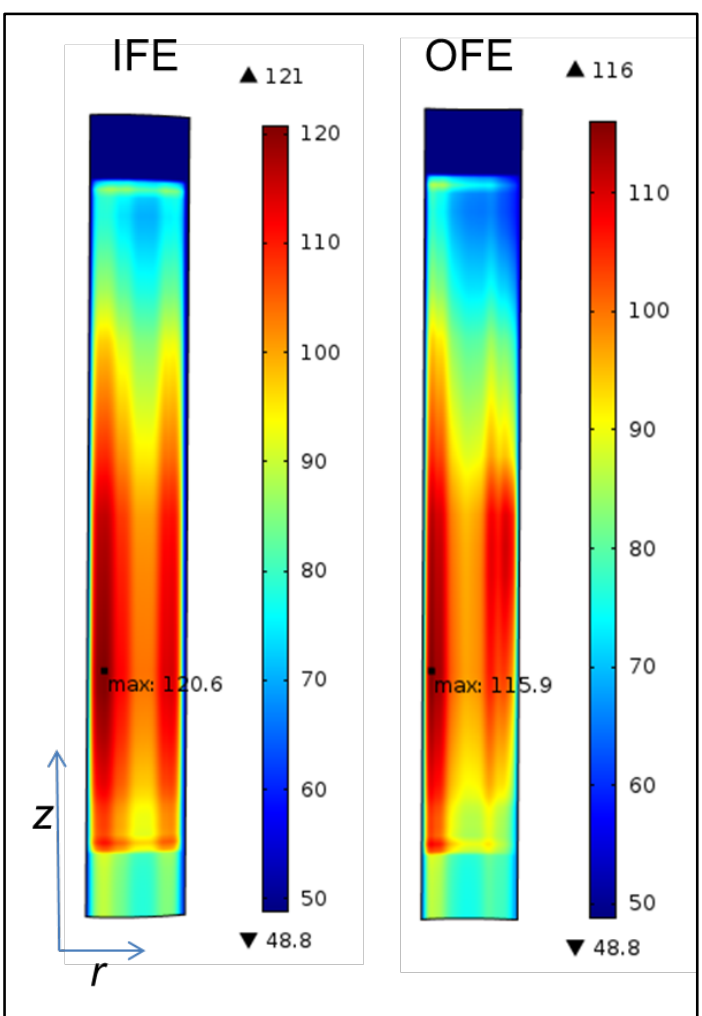

(a) beginning of cycle, BOC

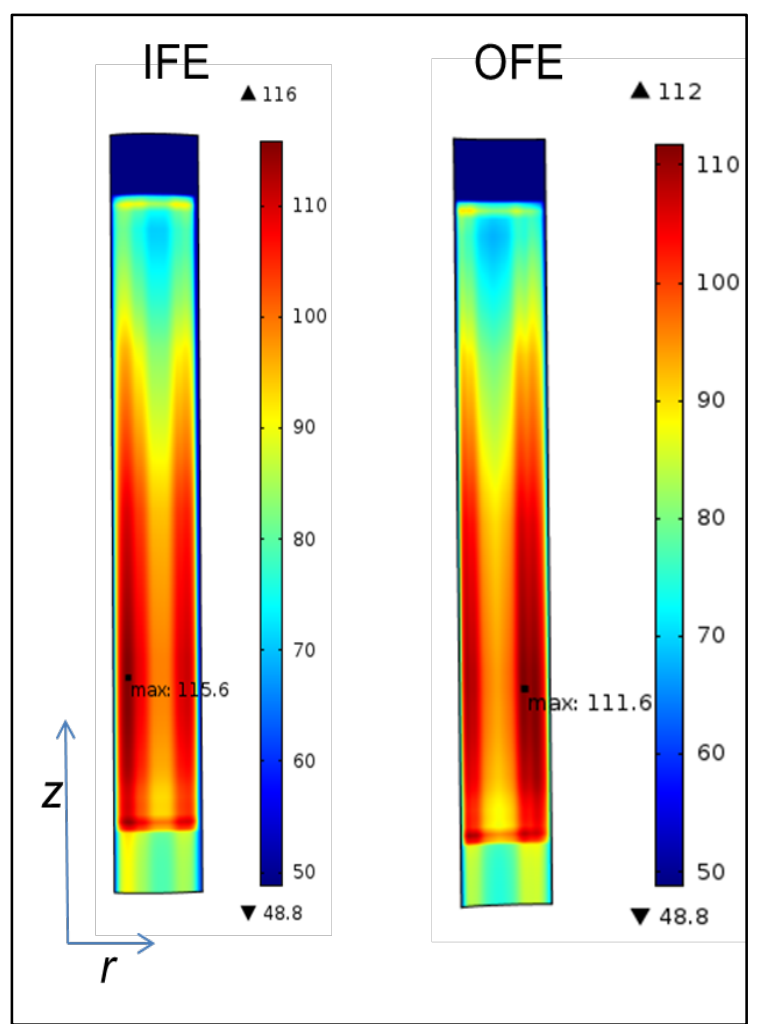

(b) end of cycle, EOC

Fig. 12.4.3. “Hot-side” clad surface temperature (in ${ }^{\circ} \mathrm{C}$ ) of the Alternate $7 \mathrm{LEU}$ fuel design for 100 MW nominal HFIR operating conditions. (See Fig. 4.4.2 to compare with the corresponding reference LEU fuel design.)

At both the BOC and EOC, the peak surface temperature occurs at the inner radial edge of the IFE plate. The peak location is about half-way between the core midplane and the bottom of the fuel zone. The peak surface temperature is higher in the IFE (by $\sim 4{ }^{\circ} \mathrm{C}$ ) than in the OFE at both the BOC and EOC.

Furthermore, the BOC peak temperatures are higher (by $\sim{ }^{\circ} \mathrm{C}$ ) than their corresponding EOC values. The location of local peaks for the OFE switches from its inner radial edge to the outer radial edge as the cycle progressed from the BOC to the EOC.

Peak fuel meat temperatures for the IFE/OFE at BOC are $150{ }^{\circ} \mathrm{C} / 159{ }^{\circ} \mathrm{C}$ and at the EOC are $143{ }^{\circ} \mathrm{C} / 153$ ${ }^{\circ} \mathrm{C}$ which are considerably less than the aluminum melting temperature of $650{ }^{\circ} \mathrm{C}$ and the $\mathrm{U}-10 \mathrm{Mo}$ melting temperature of $1090{ }^{\circ} \mathrm{C}$ for the steady-state nominal conditions.

Note that the saturation temperature corresponding to the channel outlet pressure of $374.7 \mathrm{psi}$ is $225.7^{\circ} \mathrm{C}$ and the maximum clad surface temperature under nominal HFIR operating conditions at the BOC is 121 ${ }^{\circ} \mathrm{C}$ and at the EOC is $116{ }^{\circ} \mathrm{C}$. The large difference between the saturation and peak temperatures indicates an ample thermal margin during the nominal conditions of HFIR LEU operation.

Compared with the clad surface temperature distributions in Fig. 4.4.2 for the reference LEU fuel, peak temperatures in Alternate 7 are similar in profile but lower in magnitude (by $\sim 6-8{ }^{\circ} \mathrm{C}$ at BOC). 
Three-dimensional surface plots for the clad surface heat fluxes (in $\mathrm{W} / \mathrm{cm}^{2}$ ) are shown in Fig. 12.4.4 for both the IFE and OFE at the BOC and EOC. For the IFE, peak surface heat flux is found at the core midplane and at the inner radial edge of the fuel plate; however, for the OFE it is found at its outer radial edge. The peak surface heat flux is higher in the IFE (by $\sim 18 \mathrm{~W} / \mathrm{cm}^{2}$ ) compared to the OFE at the BOC and EOC. Furthermore, the BOC peak heat fluxes are higher (by $\sim 50-60 \mathrm{~W} / \mathrm{cm}^{2}$ ) than their corresponding EOC values. Compared to the reference LEU fuel results in Fig. 4.4.3, peak surface heat flux is significantly reduced in the Alternate 7 LEU design-a 14\% reduction in magnitude at the BOC.

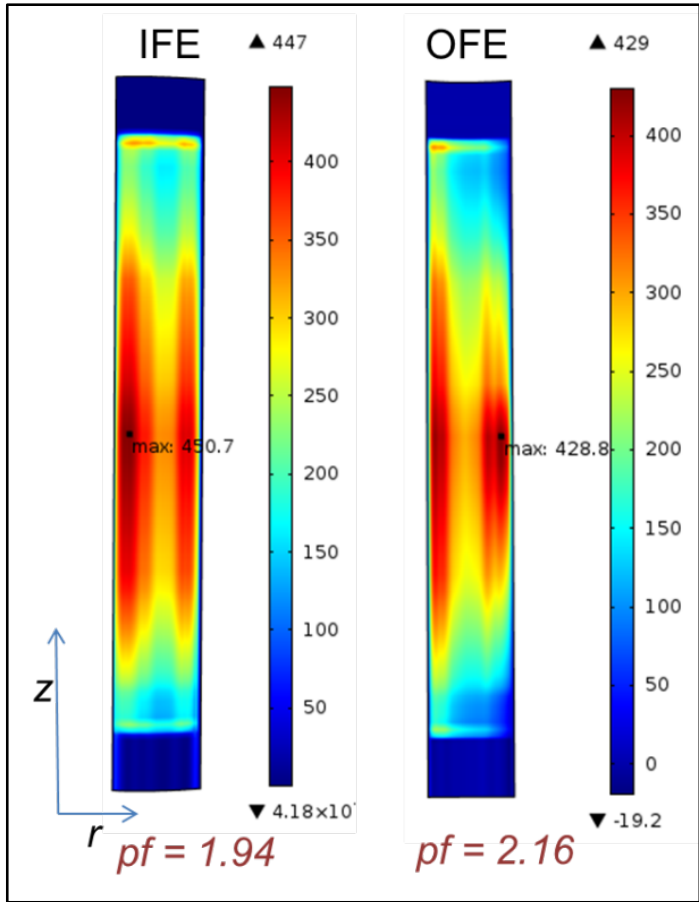

(a) beginning of cycle (BOC)

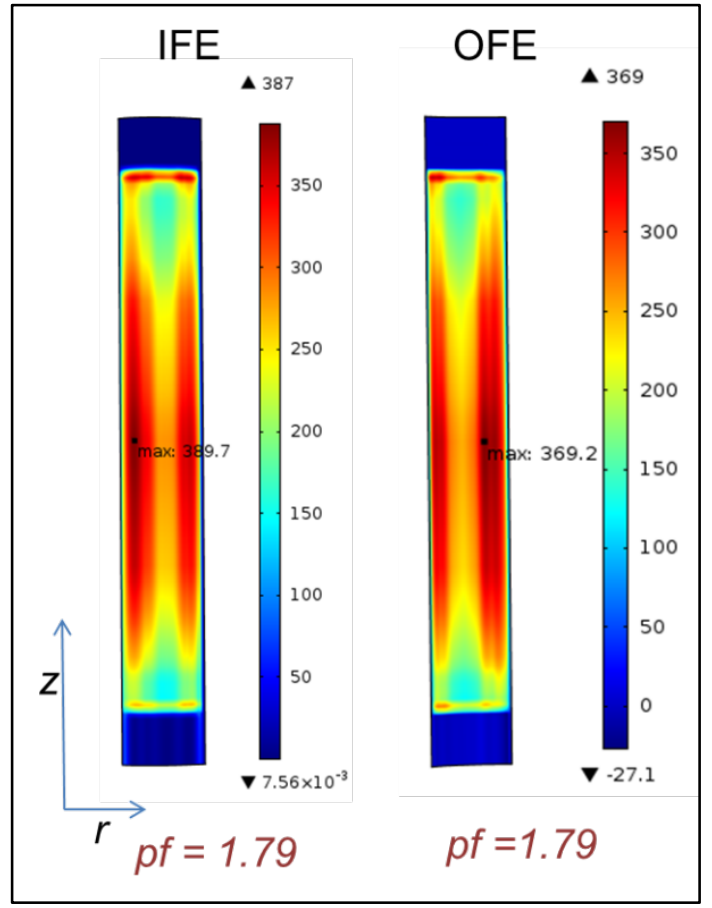

(b) end of cycle (EOC)

Fig. 12.4.4. “Hot-side” surface heat flux (in W/cm²) of the Alternate 7 LEU fuel design for $100 \mathrm{MW}$ nominal HFIR operating conditions.

(Peaking factor (pf) for each plate is obtained by dividing its maximum heat flux value by the surfaceaveraged heat flux. See Fig. 4.4.3 to compare with the corresponding reference LEU fuel design.)

Flux peaking factors ( $p f$ ) are also shown in Fig. 12.4.4 for each plate. They are calculated for each individual plate by dividing its maximum surface heat flux value by the surface-averaged value. COMSOL results show a reduction in peaking factors as the cycle progressed from the BOC to EOC for both the IFE and OFE. Coincidentally, at the EOC, the peaking factor has the same value of 1.79 for both the IFE and the OFE.

Fuel plate thermal deflections are plotted for both the IFE and OFE in Fig. 12.4.5 at the BOC and EOC. As compared to the IFE, thermal deflections are higher in the OFE because of its thicker fuel zone (i.e., a thicker high temperature region produces a larger thermal expansion) and its flatter (i.e., less plate curvature) profile. Peak deflections are found at the plate's radial centerline slightly below the core midplane. Results also indicate slightly lower deflections at the EOC than at the BOC. Compared to the reference LEU fuel results in Fig. 4.4.4, peak plate deflections are considerably reduced in the Alternate 7 LEU design-a $13 \%$ reduction in magnitude at BOC. 


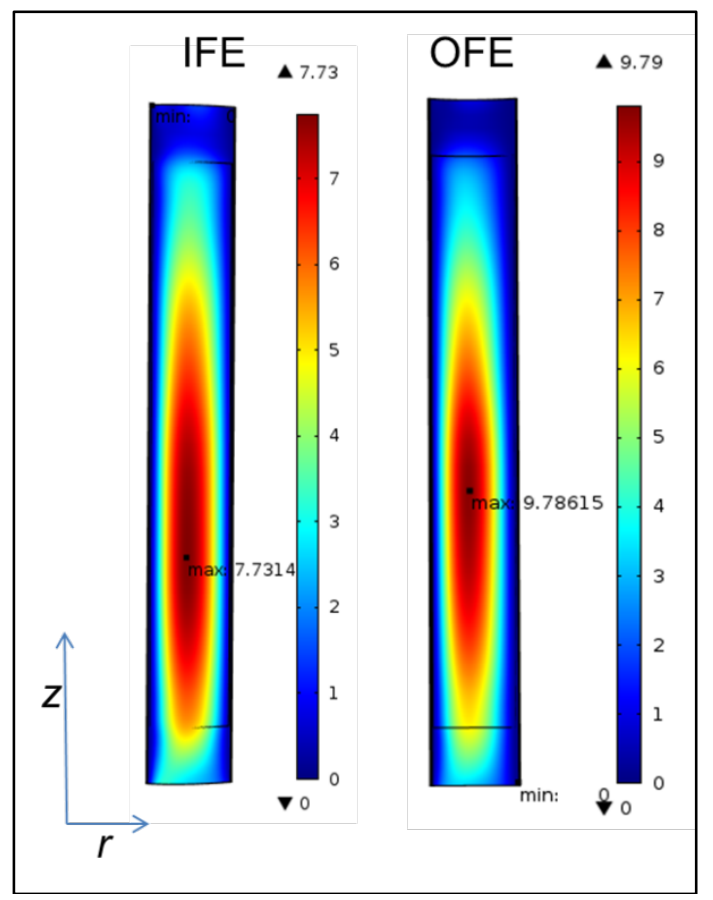

(a) beginning of cycle, BOC

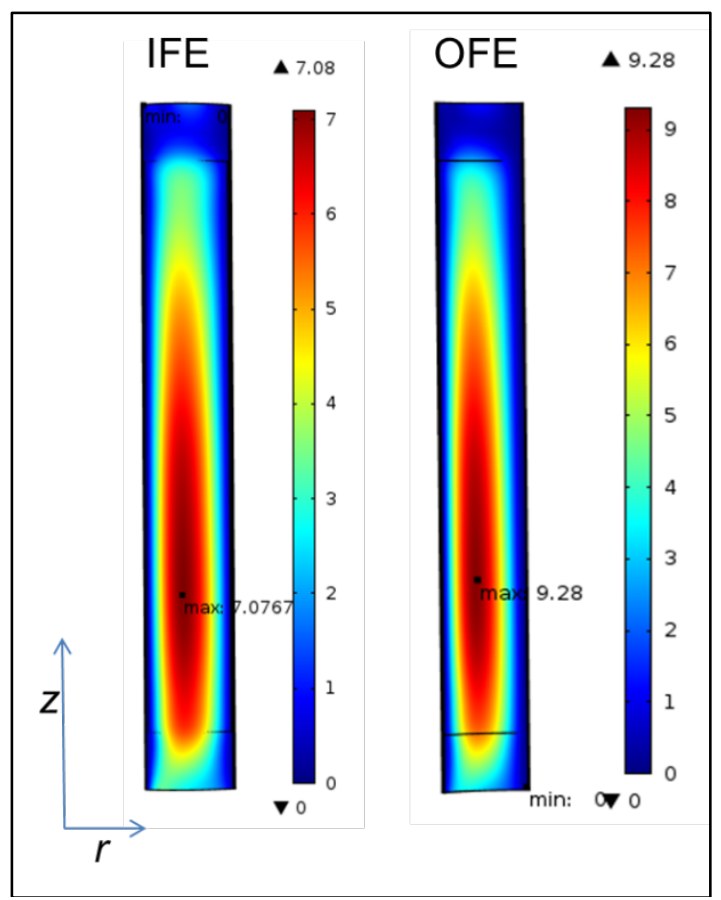

(b) end of cycle, EOC

Fig. 12.4.5. Fuel plate thermal deflection (in mil, $1 \mathrm{mil}=\mathbf{0 . 0 0 1} \mathrm{inch}$ ) of the Alternate $7 \mathrm{LEU}$ fuel design for 100 MW nominal HFIR operating conditions. (See Fig. 4.4.4 to compare with the corresponding reference $L E U$ fuel design.)

COMSOL results are summarized in Table 12.4.1 for peak values of some important thermal safety indicators for both the reference LEU fuel design (Alt. 0) and the Alternate 7 LEU fuel design (Alt. 7) at the BOC and EOC.

Table 12.4.1. Comparison of the peak values for important thermal safety variables for the reference LEU fuel design (Alt. 0) and the Alternate 7 LEU fuel design (Alt. 7) at the beginning and end of reactor cycle.

\begin{tabular}{|c|c|c|c|c|c|c|c|c|}
\hline \multirow[t]{3}{*}{$\begin{array}{c}\text { COMSOL HFIR LEU Reference } \\
\text { Analyses } \S\end{array}$} & \multicolumn{4}{|c|}{ BOC } & \multicolumn{4}{|c|}{ EOC } \\
\hline & \multicolumn{2}{|c|}{ Alt. 0} & \multicolumn{2}{|c|}{ Alt. 7} & \multicolumn{2}{|c|}{ Alt. 0} & \multicolumn{2}{|c|}{ Alt. 7} \\
\hline & IFE & OFE & IFE & OFE & IFE & OFE & IFE & OFE \\
\hline Peak fuel meat temperature $\left({ }^{\circ} \mathrm{C}\right)$ & 153 & 164 & 150 & 159 & 147 & 151 & 143 & 153 \\
\hline Peak clad surface temperature $\left({ }^{\circ} \mathrm{C}\right)$ & 129 & 122 & 121 & 116 & 120 & 112 & 116 & 112 \\
\hline $\begin{array}{l}\text { Peak clad surface heat flux } \\
\qquad\left(\mathrm{W} / \mathrm{cm}^{2}\right)\end{array}$ & 521 & 468 & 451 & 429 & 434 & 375 & 390 & 369 \\
\hline Peak fuel plate deflection (mil) & 7.8 & 11.2 & 7.7 & 9.8 & 7.0 & 10.7 & 7.1 & 9.3 \\
\hline
\end{tabular}

${ }^{\S}$ Compare red and green numbers in the respective rows of Table 12.4.1 at BOC and EOC. 
Note that under HFIR nominal operating conditions:

- Peak fuel meat temperatures in both the IFE and OFE fuel plates at the BOC or EOC are well below the melting temperature of both aluminum and U-10Mo.

- Peak clad surface temperatures are well below the coolant's saturation temperature of $225.7^{\circ} \mathrm{C}$ at the channel outlet pressure.

- $\quad$ Peak clad surface temperature always occurs in the IFE and its value is reduced in the Alternate 7 design as compared to the earlier reference design.

- Peak clad surface heat flux always occurs in the IFE and its value is significantly reduced in the Alternate 7 design as compared to the earlier reference design.

- Peak fuel plate deflection always occurs in the OFE and its value is reduced in the Alternate 7 design as compared to the earlier reference design.

Therefore, the Alternate 7 design should be considered a superior alternative when considering both thermal and structural issues under nominal operating conditions compared to the base reference design.

\subsection{STEADY-STATE TH WITH NOMINAL ASSUMPTIONS (USING HSSHTC)}

The power density profile inputs to the HSSHTC for ALT7C fuel BOC conditions are shown in Fig. 12.5.1 for both inner and outer elements. The lower end of the power density profiles show very little axial water reflector peak like the upper end because of the effect of the Hf added to the lower allaluminum section of the plate. The effect of the control plate window is seen on the outer edge of the outer element power density in the lower part of Fig. 12.5.1. 

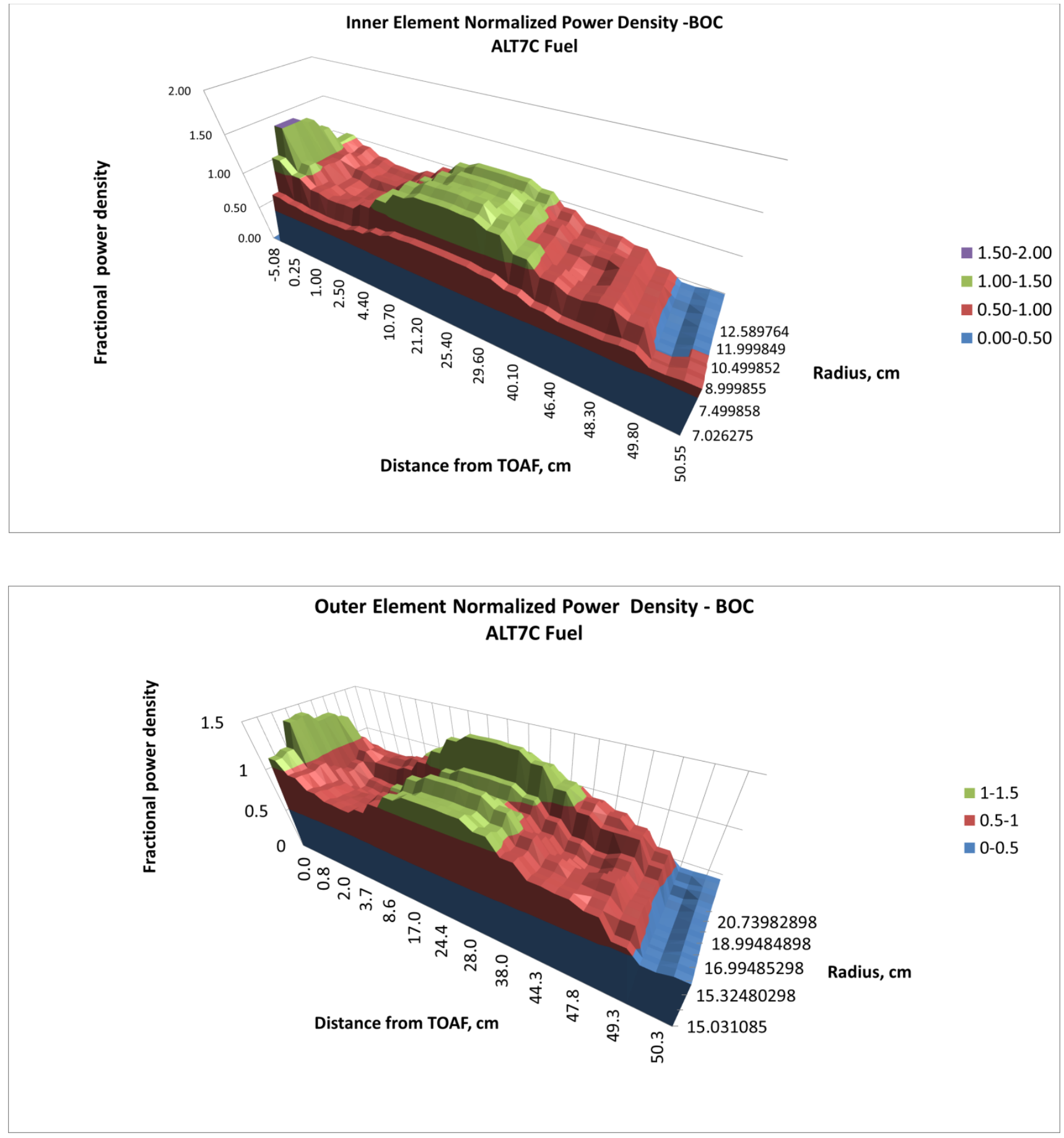

Fig. 12.5.1. LEU ALT7C fuel BOC inner and outer element relative power densities.

Axial temperature profiles for the ALT7C fuel BOC conditions are shown in Fig. 12.5.2 for both elements. The inner edge of the inner element has the highest temperatures along most of the length, as shown in the top half of Fig. 12.5.2. For the outer element, the peak temperatures alternate between the inner edge at the top and bottom of the plate and the outer edge in the middle of the plate as shown in the bottom half of Fig. 12.5.2. 


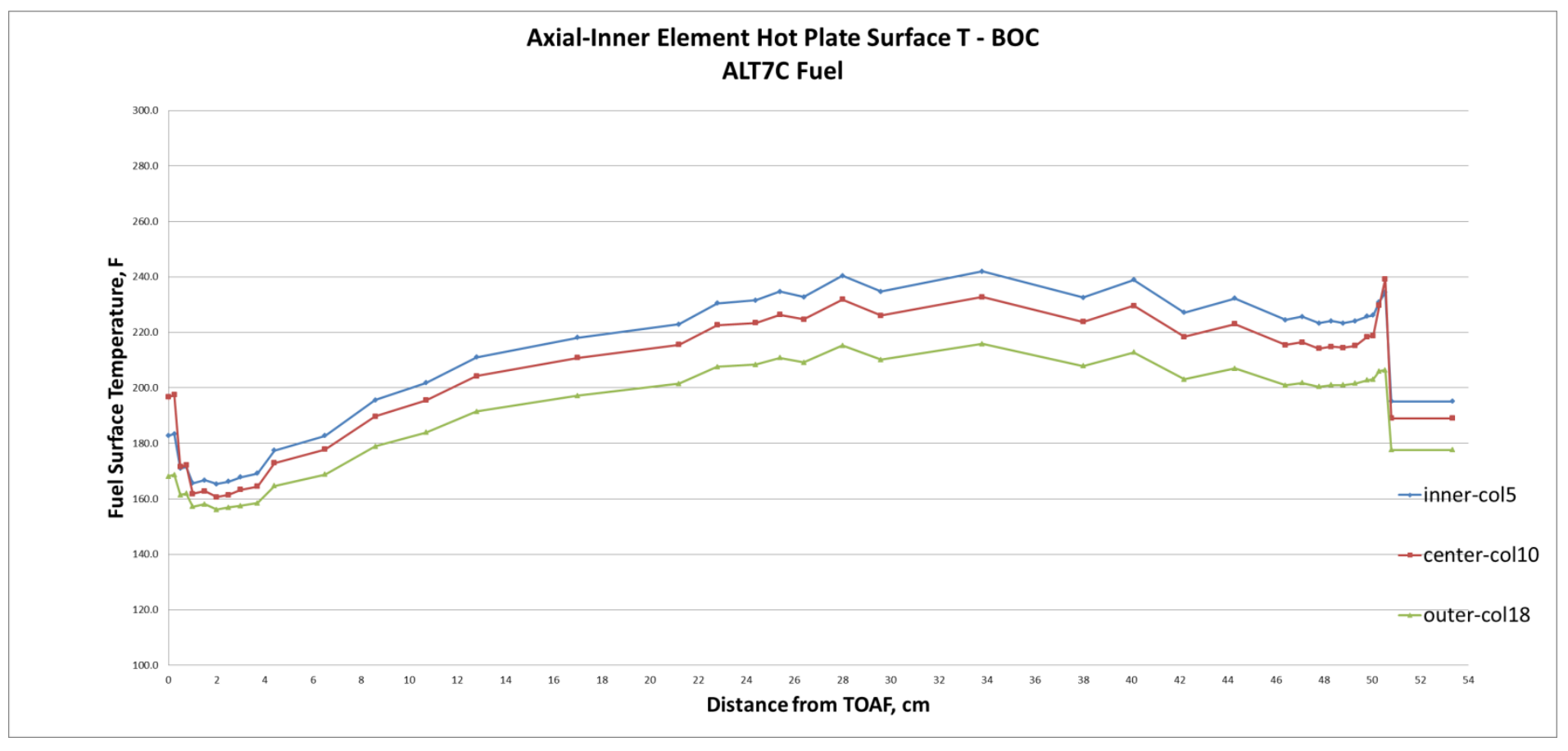

\section{Axial-Outer Element Hot Plate Surface T - BOC ALT7C Fuel}

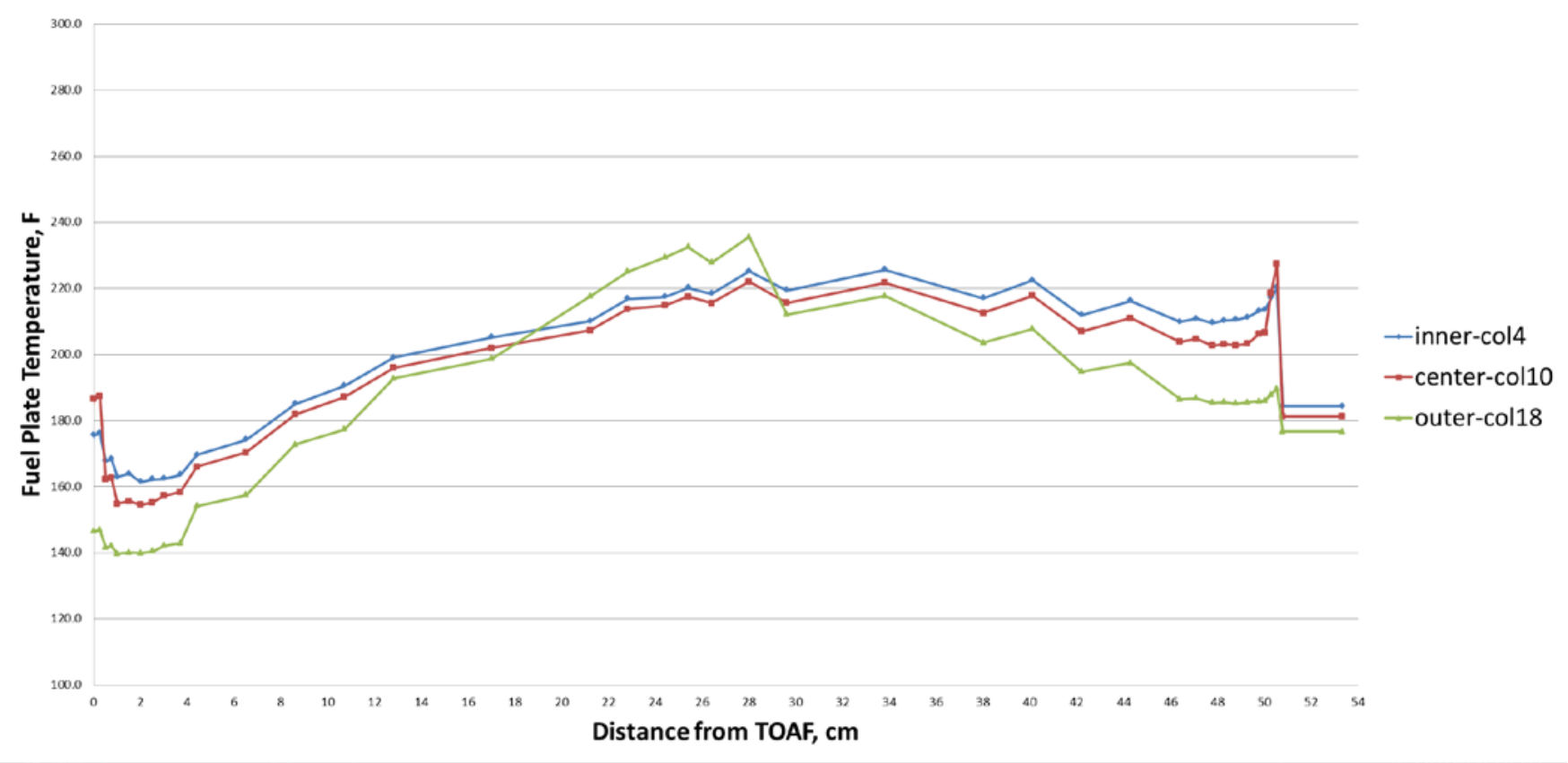

Fig. 12.5.2. LEU ALT7C fuel BOC inner and outer element hot plate surface temperature.

Axial heat flux profiles for the ALT7C fuel BOC conditions are shown in Fig. 12.5.3 for both elements. The middle portion of the inner element has the highest heat flux along the length of the plate, as shown in the top half of Fig. 12.5.3. For the outer element, the peak fluxes alternate between the inner edge at the top and bottom of the plate and the outer edge in the middle of the plate as shown in the bottom half of Fig. 12.5.3. 


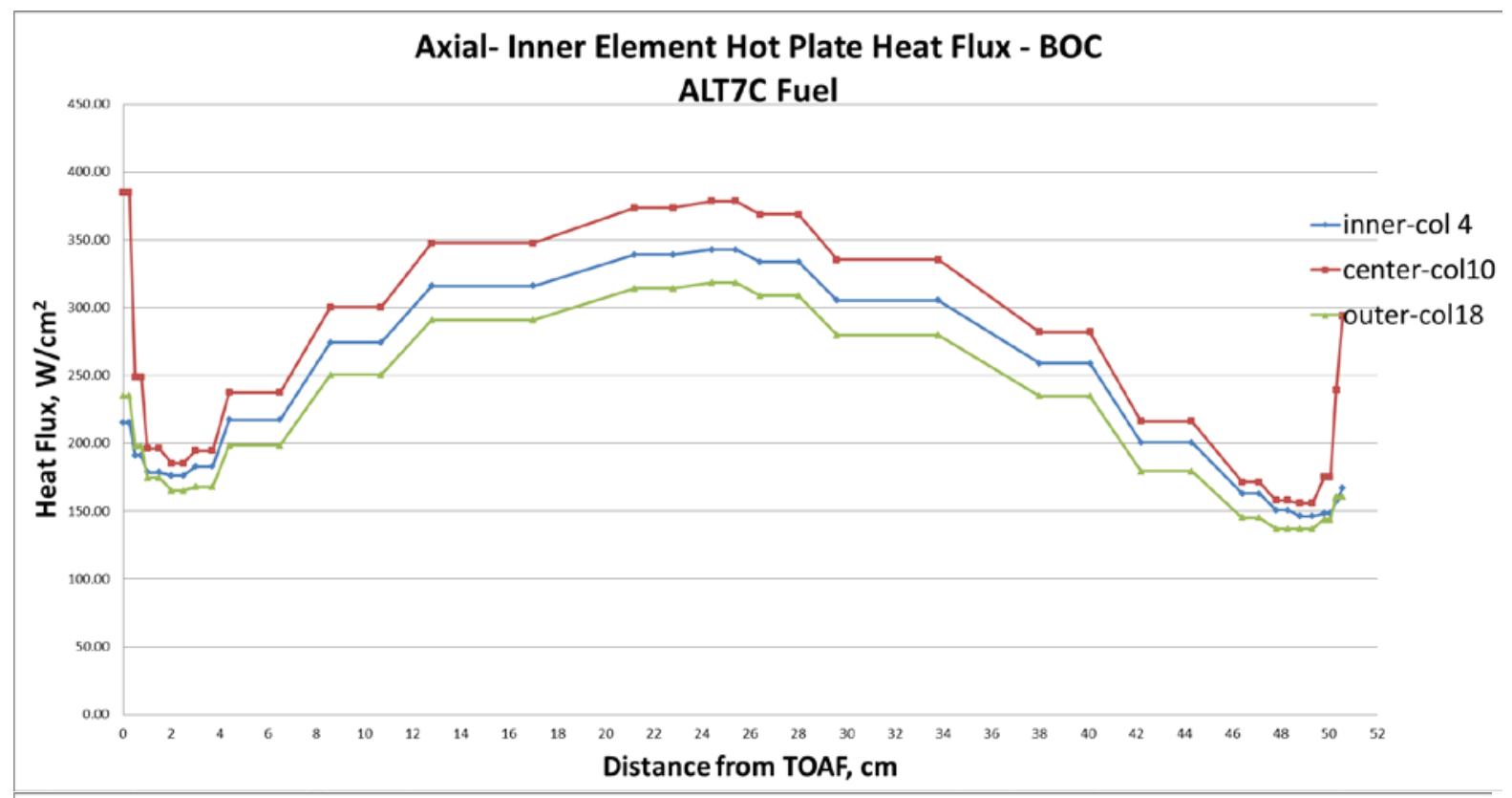

Axial - Outer Element Hot Plate Heat Flux - BOC ALT7C Fuel

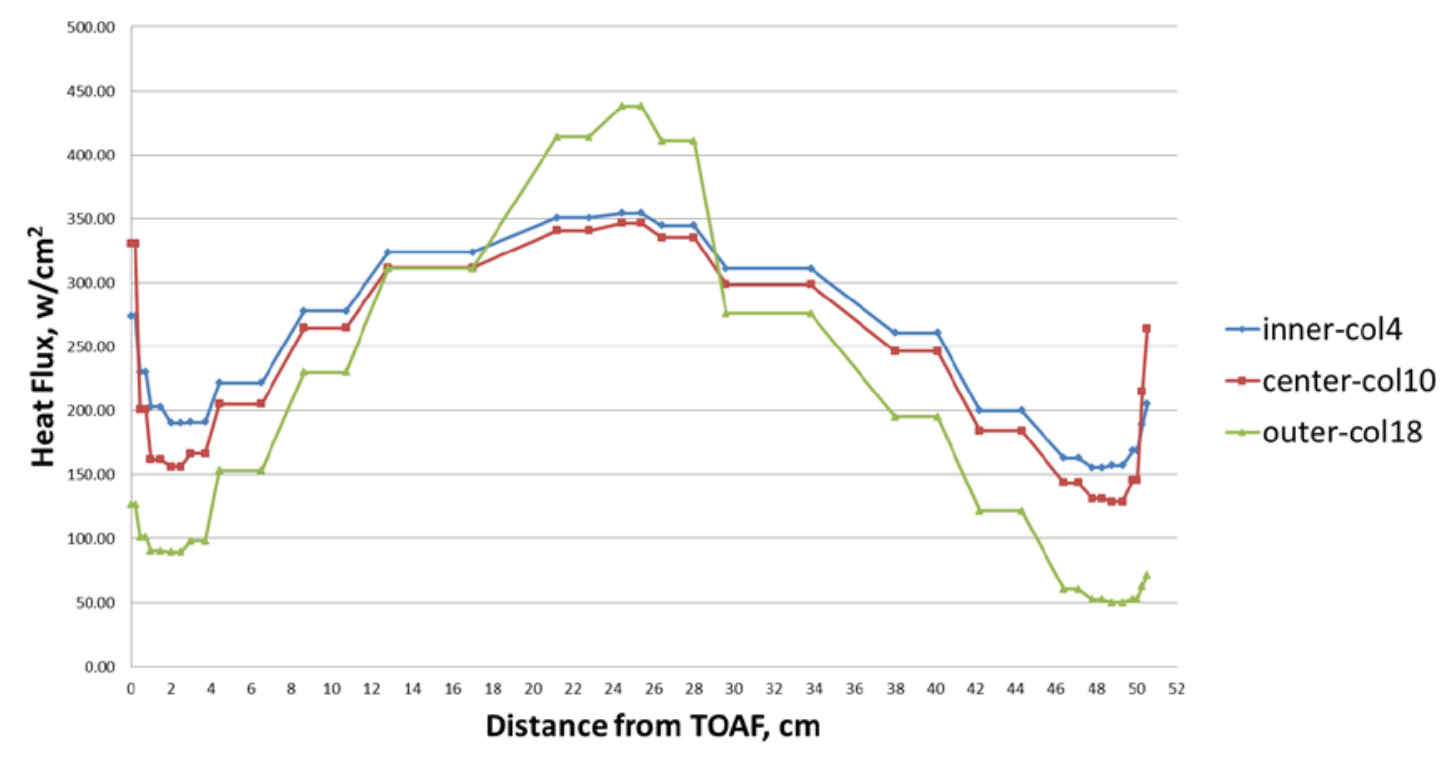

Fig. 12.5.3. LEU ALT7C fuel BOC inner and outer element hot plate heat flux.

The power density profile inputs to the HSSHTC for ALT7C fuel EOC conditions are shown in Fig. 12.5.4 for both inner and outer elements. In comparison to Fig. 12.5.1, the power density profiles in Fig. 12.5.4 are very similar over most of the plates, except for an increase in relative power density at the lower end of both plates, which is thought to be due to burnup of the Hf over the cycle. The effect of the control plate window on the outer element can still be seen on the outer edge of the power density in the lower part of Fig. 12.5.4. 

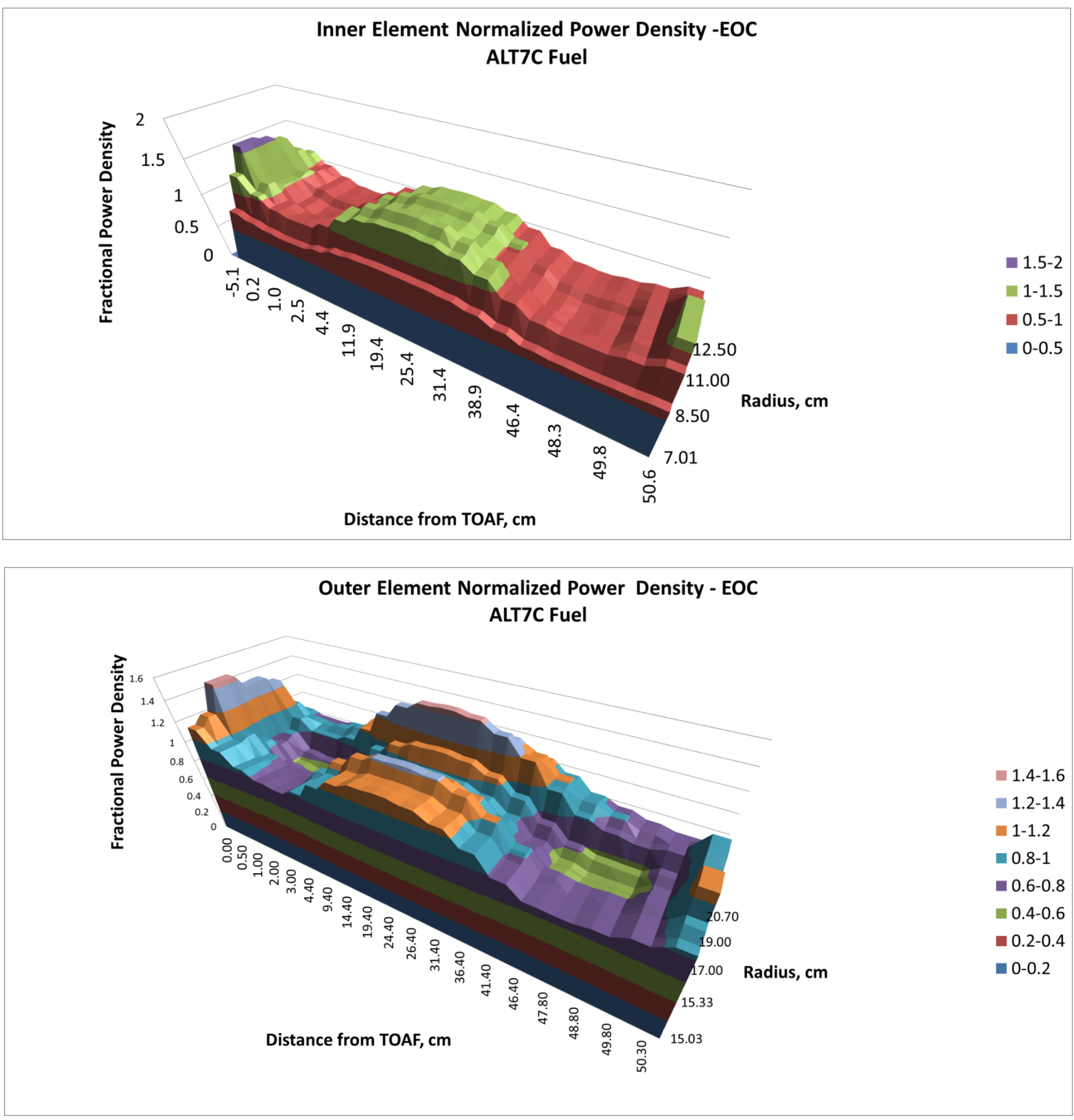

Fig. 12.5.4. LEU ALT7C fuel EOC inner and outer element relative power densities.

Axial temperature profiles for the ALT7C fuel EOC conditions are shown in Fig. 12.5.5 for both elements. The inner edge of the inner element has the highest EOC temperatures over most of the plate as shown in the top half of Fig. 12.5.5. For the outer element plate, the peak temperatures occur all along the outer edge as shown in the bottom half of Fig. 12.5.5. 


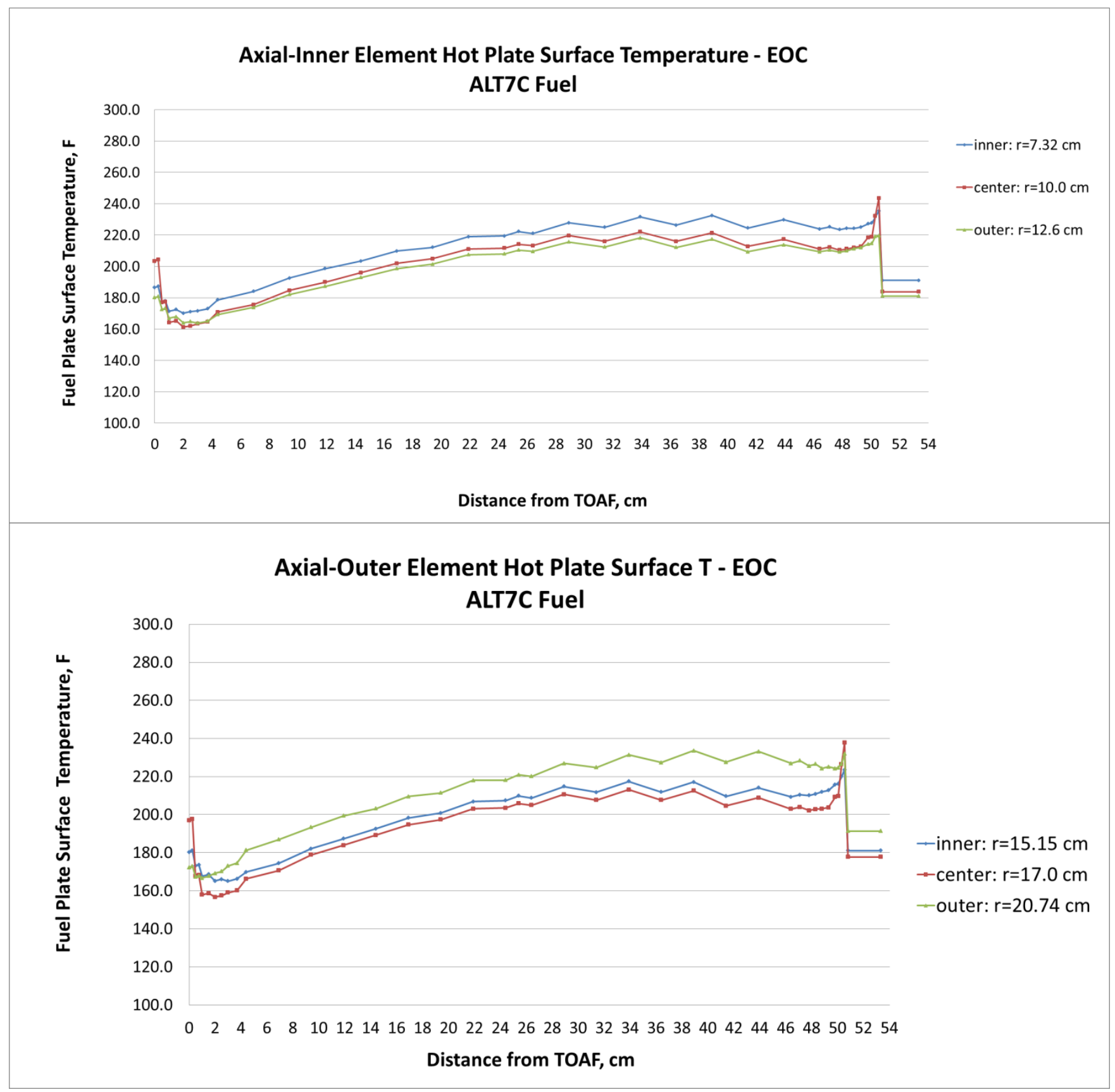

Fig. 12.5.5. LEU ALT7C fuel EOC inner and outer element hot plate surface temperature.

Axial heat flux profiles for the ALT7C fuel EOC conditions are shown in Fig. 12.5.6 for both elements. For the inner element plate, the center of the plate has the highest heat flux as shown in the top half of Fig. 12.5.6. For the outer element, the peak heat fluxes occur at the outer edge all along the plate as shown in the bottom half of Fig. 12.5.6. 

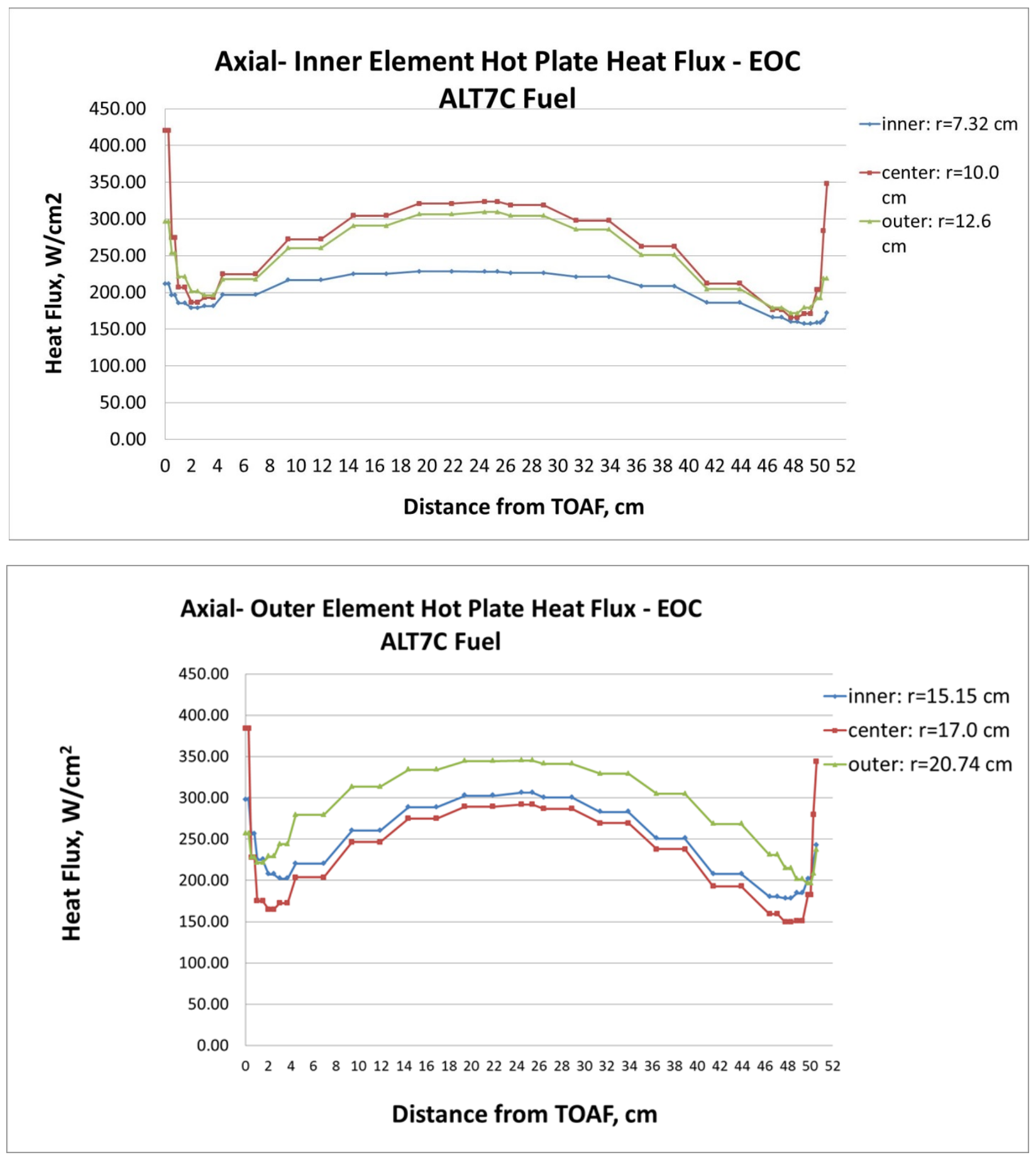

Fig. 12.5.6. LEU ALT7C fuel EOC inner and outer element hot plate heat flux.

A comparison between COMSOL and HSSHTC nominal results for peak surface temperatures and heat fluxes is provided in Table 12.5.1, for the ALT7C fuel. In general, there is good agreement between the two codes for the inner element peak surface temperature and heat flux. For the inner element, the HSSHTC peak surface temperature for BOC conditions varies by $\left(6{ }^{\circ} \mathrm{C}\right)$ from the COMSOL results. For the outer element, the HSSHTC consistently predicts a surface temperature within $3{ }^{\circ} \mathrm{C}$ of the COMSOL model. The HSSHTC consistently predicts a higher heat flux than COMSOL, except for the inner 
element, BOC conditions. For the IFE, BOC conditions, the HSSHTC heat flux is lower than COMSOL results (413 vs. $451 \mathrm{~W} / \mathrm{cm}^{2}$ ), which is consistent with the much lower peak surface temperature calculated by the HSSHTC.

Table 12.5. Comparison of COMSOL and HSSHTC peak clad surface temperatures and heat fluxes for the ALT7C fuel

\begin{tabular}{|c|c|c|c|c|c|c|c|c|}
\hline & \multicolumn{4}{|c|}{ BOC } & \multicolumn{4}{c|}{ EOC } \\
\hline \multirow{2}{*}{} & \multicolumn{2}{|c|}{$\begin{array}{c}\text { COMSOL } \\
\text { Results }\end{array}$} & $\begin{array}{c}\text { HSSHTC } \\
\text { Results }\end{array}$ & \multicolumn{2}{c|}{$\begin{array}{c}\text { COMSOL } \\
\text { Results }\end{array}$} & \multicolumn{2}{c|}{$\begin{array}{c}\text { HSSHTC } \\
\text { Results }\end{array}$} \\
\cline { 2 - 8 } & IFE & OFE & IFE & OFE & IFE & OFE & IFE & OFE \\
\hline $\begin{array}{c}\text { Peak clad surface temperature } \\
\left({ }^{\circ} \mathbf{C}\right)\end{array}$ & 121 & 116 & 117 & 113 & 116 & 112 & 116 & 115 \\
\hline $\begin{array}{c}\text { Peak clad surface heat flux } \\
\left(\mathbf{W} / \mathrm{cm}^{2}\right)\end{array}$ & 451 & 429 & 413 & 438 & 390 & 369 & 420 & 386 \\
\hline
\end{tabular}

In conclusion, all three variations of Alternate 7 (combining a permanent absorber in the lower unfueled region of all of the fuel plates, a burnable absorber in the inner element side plates, and a relocated and reshaped but still radially contoured fuel zone) would allow successful conversion of HFIR. 
This page intentionally blank 


\section{CONCLUSIONS AND RECOMMENDATIONS}

Several HFIR complex fuel design features were analyzed separately and then in combination. Specific conclusions about these features include:

- the axial contour at the bottom of the fuel zone in all fuel plates may be eliminated if replaced by a local permanent neutron absorber (e.g., Hf) that could be located just below the fuel zone in the unfueled region of the plate

- the burnable absorber in the fuel plates of the inner fuel element may be removed and relocated to both of the side plates of the inner fuel element

- a radial contour of the fuel zone in all fuel plates is still required

- the thermal peaks that limit performance of the fuel may be flattened by centering the fuel zone on the centerline of the depth (azimuthally) of the fuel plate and

- the thermal peaks may also be flattened by shaping the fuel zone symmetrically about this centerline.

The design that combines these features, termed "Alternate 7" in this evaluation, is recommended as the new preliminary HFIR LEU reference fuel design. Using the current analytical tools described in this report, it meets the reactor performance criteria of flux and cycle length and meets steady-state and transient thermal safety limits. It will be offered for review and feedback to other parts of the GTRI reactor conversion program.

Following feedback on the feasibility of manufacturing the new HFIR reference fuel design in a stable and repeatable manner, ORNL will further evaluate this design to:

- apply the latest, state-of-the-art analytical tools (e.g., MCNP with an explicit representation of the fuel plate, detailed 3D COMSOL multiphysics models) and documented as formal calculations and

- optimize some of the features (e.g., amount and location of the permanent neutron absorber versus new techniques for axial contouring, amount and location of the burnable neutron absorber, and the radial contour of the fuel zone) for reactor performance and practicality of manufacturing.

Following this further evaluation, the new HFIR LEU reference fuel design will be documented in a fuel specification and on drawings. Further refinement of the design will likely occur as fabrication, qualification, and analysis efforts continue throughout the program. 
This page intentionally blank 


\section{REFERENCES}

1. Irradiation Performance of U-Mo Alloy Based 'Monolithic' Plate-Type-Design Selection Update, INL/EXT-09-16807, Revision 1, July 2013

2. Low Enriched Uranium Fuel Design with Two-Dimensional Grading for the High Flux Isotope Reactor, ORNL/TM-2010/318, April 2011

3. X-5 Monte Carlo Team, MCNP-A General Monte Carlo N-Particle Transport Code, Version 5, LA-CP-03-0245, Los Alamos National Laboratory, April 2003.

4. W. Haeck, VESTA User's Manual - Version 2.0.0, Institut de Radioprotection et de Sûreté Nucléaire Report, DSU/SEC/T/2008-331 Indice A, France, 2009.

5. T.E. Cole, L.F. Parsley, and W. E. Thomas, Revisions of HFIR Fuel Element Steady State Heat Transfer Analysis Code, ORNL/CF-85/68.

6. F.P. Griffin, K. A. Smith, and J. R. Valentine, RELAP5 Consolidated Model of High Flux Isotope Reactor System, ORNL/RRD/INT-154, Rev. 0, Oak Ridge National Laboratory, April 2011.

7. Introduction to COMSOL Multiphysics, Part number: CM010004, Version 4.4, December 2013, http://www.comsol.com/shared/downloads/IntroductionToCOMSOLMultiphysics.pdf.

8. A. Bergeron, Review of the Oak Ridge National Laboratory (ORNL) Neutronics Calculations Regarding the Conversion of the High Flux Isotope Reactor (HFIR) to the Use of Low Enriched Uranium (LEU) Fuel, ANL/RERTR/TM-12/49, Argonne National Laboratory, July 2012.

9. Scale: A Comprehensive Modeling and Simulation Suite for Nuclear Safety Analysis and Design, ORNL/TM-2005/39, Version 6.1, June 2011. Available from Radiation Safety Information Computational Center at Oak Ridge National Laboratory as CCC-785.

10. R. T. Primm, III and N. Xoubi, Modeling of the High Flux Isotope Reactor Cycle 400, ORNL/TM-2004/251, Oak Ridge National Laboratory, August 2005.

11. D. Chandler, R. T. Primm, III, and G. I. Maldonado, Burnup and Spatially-Dependent Uranium Isotopic Calculations for the High Flux Isotope Reactor, Transaction American Nuclear Society, Vol. 103, 768 - 769, ANS 2010 Winter Meeting, Las Vegas, NV, November 2010.

12. RSICC Computer Code Collection CCC-371, ORIGEN 2.2. Available from RSICC, Oak Ridge National Laboratory (2002).

13. D. Chandler, R. T. Primm, III, and G. I. Maldonado, Validating MCNP for LEU Fuel Design via Power Distribution Comparisons, ORNL/TM-2008/126, Oak Ridge National Laboratory, November 2008.

14. G. Ilas and R. T. Primm, III, Methodology for Simulating the Irradiation of the Control Elements in HFIR, Transaction American Nuclear Society, Vol. 103, 396-398, Las Vegas, NV, November 2010.

15. C. O. Slater, R. T. Primm III, D. A. Pinkston, D. H. Cook, D. L. Selby, P. D. Ferguson, J. A. Bucholz, and E. L. Popov, Measured and Calculated Heating and Dose Rates for the HFIR HB4 Beam Tube and Cold Source, ORNL/TM-2009/012, Oak Ridge National Laboratory, March 2009.

16. D. E. Peplow, A Computational Model of the High Flux Isotope Reactor for the Calculation of Cold Source, Beam Tube, and Guide Hall Nuclear Parameters, ORNL/TM-2004/237, Oak Ridge National Laboratory, November 2004.

17. MATLAB, Release 2012a, The MathWorks, Inc., Natick, MA.

18. C. G. Velit, R. T. Primm, III, and J. C. Gehin, "Partial Safety Analysis for a Reduced Uranium Enrichment Core for the High Flux Isotope Reactor,” ORNL/TM-2007/226, Oak Ridge National Laboratory, April 2009.

19. High Flux Isotope Reactor Safety Analysis Report, ORNL/HFIR/SAR/2344, Rev 12, October 4, 2013.

20. J. R. Furl, RELAP5 Analysis to Support Resolution of Decay Heat Removal USQ Using Updated Fuel Hot Channel Data, RRD Calculation C-HFIR-2007-057, Rev. 1, Oak Ridge National Laboratory, June 25, 2008. 
21. G. Ilas and R. Shapiro, “Analysis of alternate designs for the HFIR LEU fuel core (burnable absorber relocation)”, ORNL/LTR-2012/453, Oak Ridge National Laboratory (November 2012).

22. “American National Standard for Decay Heat Power in Light Water Reactors,” ANSI/ANS-5.1005, American Nuclear Society (2005).

23. J. Peterson and G. Ilas, Calculation of Heating Values for the High Flux Isotope Reactor, Proceedings of PHYSOR 2012 - Advances in Reactor Physics - Linking Research, Industry, and Education, Knoxville, TN, April 15-20, 2012.

24. G. Ilas, "Relative Fission Flux in Unfueled Regions at the Bottom of the Fuel Elements," personal communication, Aug. 31, 2012.

25. R.D. Cheverton and T.M. Sims, "HFIR Core Nuclear Design,” ORNL-4621, July 1971.

26. R. B. Rothrock, "HFIR Safety Limits Calculations,” C-HFIR-2007-005, April 30, 2008. 